INEEL/EXT-2000-00994 MIT-ANP-PR-071

July 2000

\title{
Design of an Actinide Burning, Lead or Lead-Bismuth Cooled Reactor that Produces Low Cost Electricity
}

\section{Annual Project Status Report}

P. E. MacDonald (INEEL)

N. Todreas (MIT) 


\title{
Design of an Actinide Burning, Lead or Lead-Bismuth Cooled Reactor that Produces Low Cost Electricity
}

\author{
Annual Project Status Report \\ July 2000 \\ MIT-ANP-PR-071 \\ INEEL/EXT-2000-00994
}

MIT Principal Investigators

Jacopo Buongiorno -Reactor Design

Ron Ballinger -Material Studies

Ken Czerwinski -Coolant Technology

Michael Driscoll -Neutronics

Jeongyoun Lim-Materials

Pavel Hejzlar -Neutronics

Mujid Kazimi -Reactor Design

Dohyoung Kim -Reactor Design

Neil Todreas *-Reactor Design
INEEL Principal Investigators

Cliff Davis -Reactor Design

Steve Herring -Neutronics

Philip MacDonald* -Fuel Design

Eric Loewen -Materials Studies

Authur Shieh -Reactor Design

Galen Smolik -Materials Studies

Kevan Weaver -Neutronics

\section{*Project Leadership}




\section{TABLE OF CONTENTS}

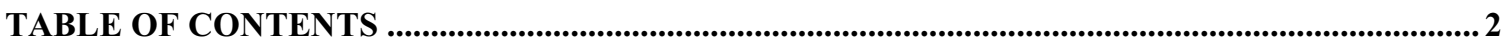

ACRONYMS

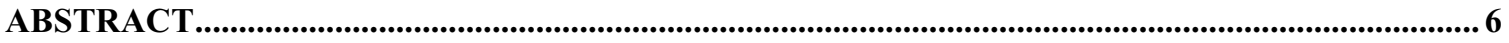

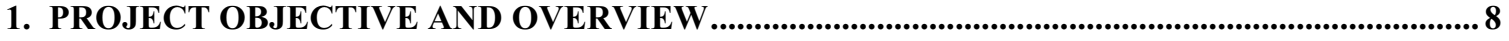

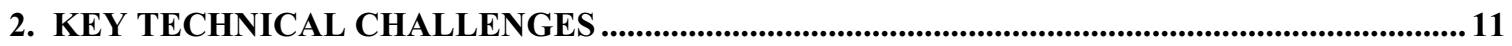

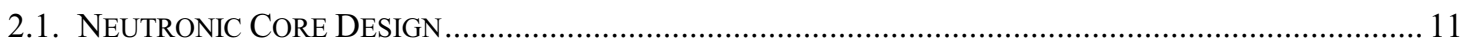

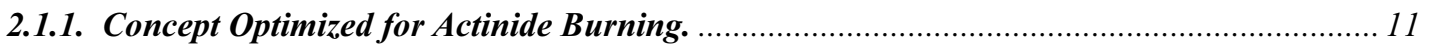

2.1.2. Concept Optimized for Economic Electricity Production. ………................................... 13

2.1.3. Concept optimized for both actinide burning and low cost electrical production. ................ 14

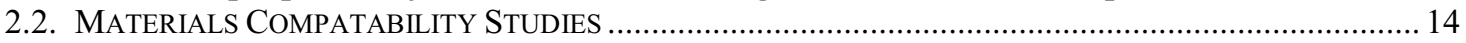

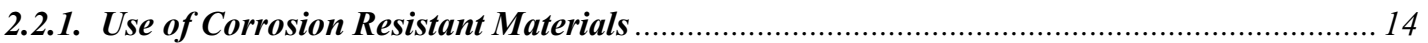

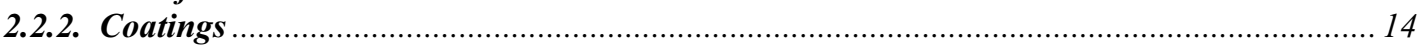

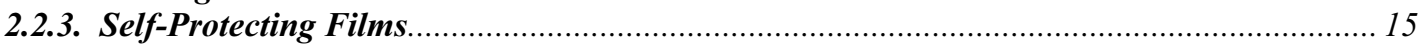

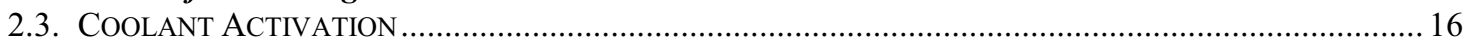

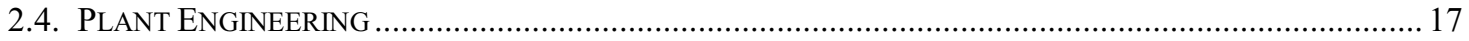

2.4.1. Direct Cycle and Direct Contact Heat Transfer ...................................................... 17

2.4.2. Direct Cycle - Aerosol Production Leading to Liquid Metal Embrittlement ........................ 17

2.4.3. Indirect Cycle - Power Conversion Cycle Optimization …............................................... 18

3. DESIGN LIMITS APPLICABLE TO ALL CONCEPT STUDIES...................................................20

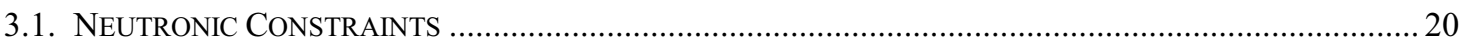

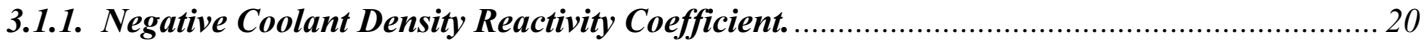

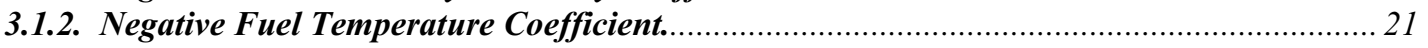

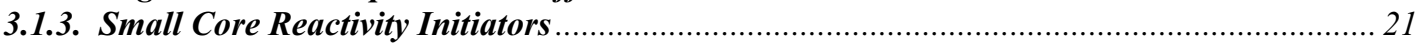

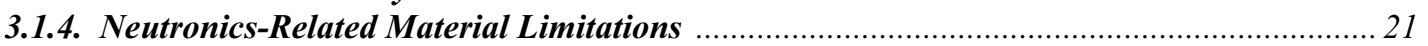

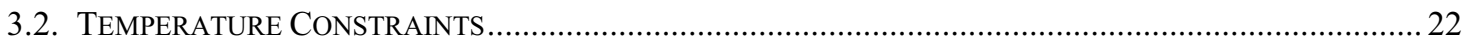

3.2.1. The Fuel.

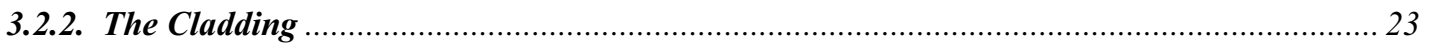

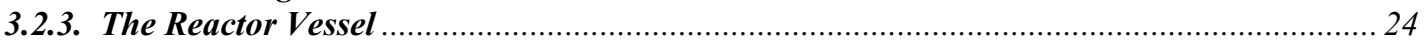

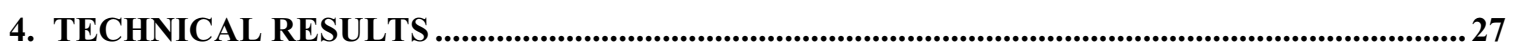

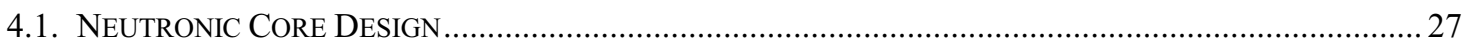

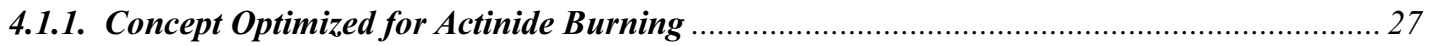

4.1.1.1. Neutron streaming assembly design .....................................................................................2

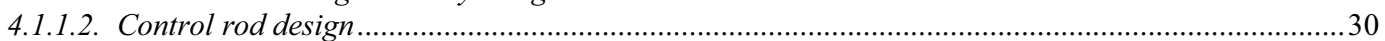

4.1.1.3. Enrichment Zoning, Batch Refueling Strategy and Power Distribution ..........................................32

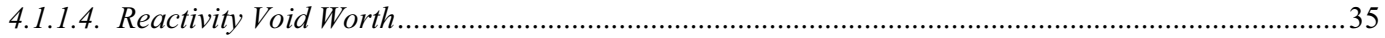

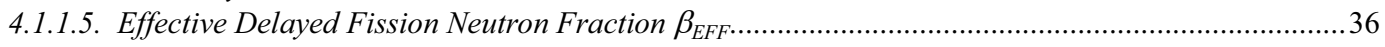

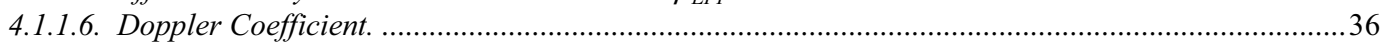

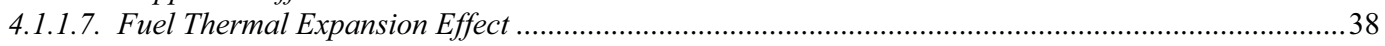

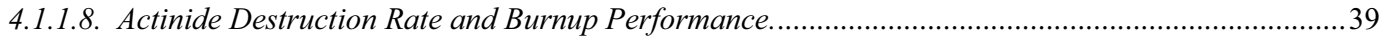

4.1.1.9. The option of fertile-free, long-life, minor actinide-burner with zero reactivity swing .....................41

4.1.1.10. Transmutation Capabilities of Long-Lived Fission Products ......................................................43

4.1.1.11. Generation of Polonium 210 in the coolant ....................................................................44

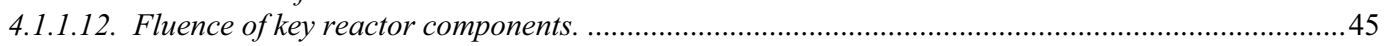

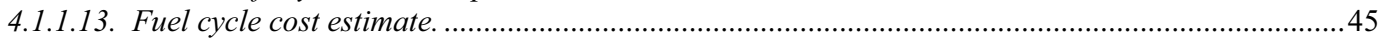


4.1.2. Concept Optimized for Economic Electricity Production ……....................................... 47

4.1.3. Design Approaches for both Actinide Burning and Low Cost Electrical Production........... 53

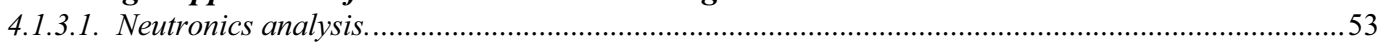

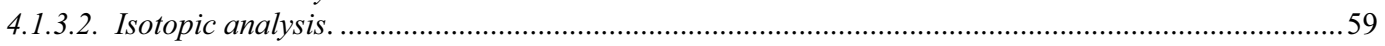

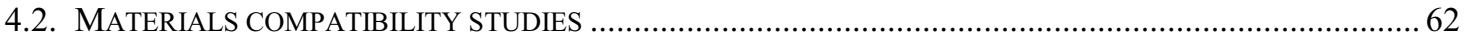

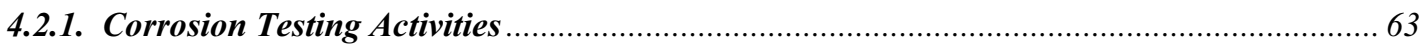

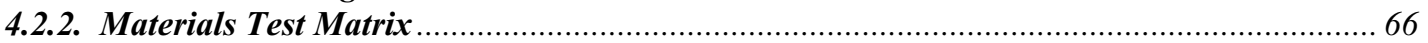

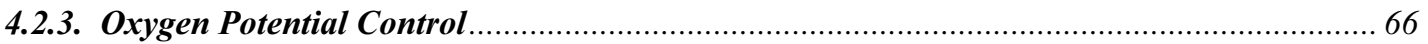

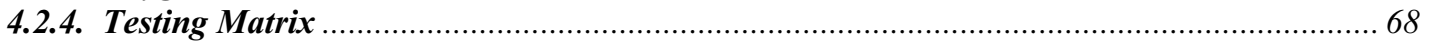

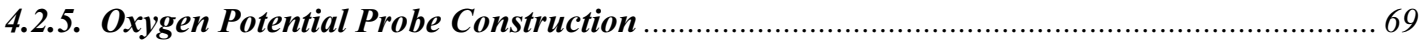

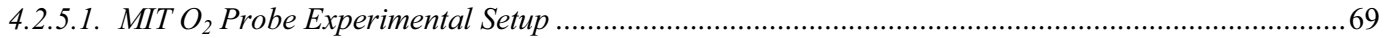

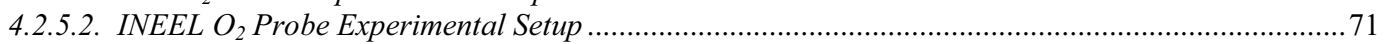

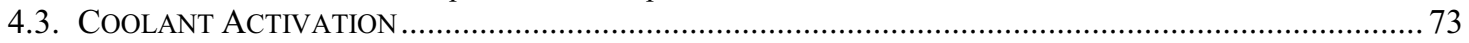

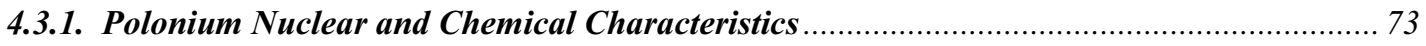

4.3.2. Theoretical Characterization of the Polonium Problem …….......................................... 74

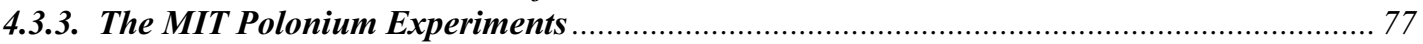

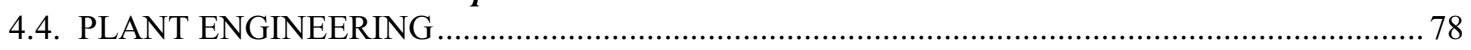

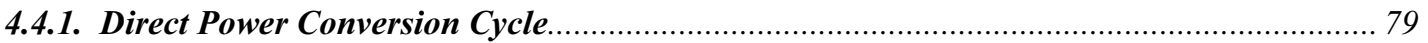

4.4.1.1. Direct Contact Heat Transfer Phenomena ………………………………………………….... 80

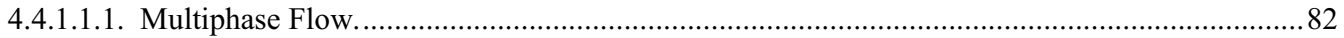

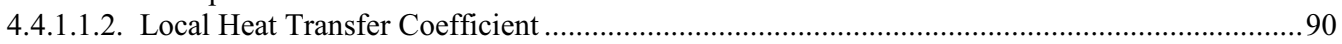

4.4.1.1.3. Validation of the Model................................................................................................. 93

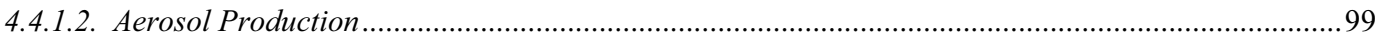

4.4.1.2.1. The Mechanisms of Lead-Bismuth Aerosols.......................................................................99

4.4.1.2.2. Lead-Bismuth Entrainment and Steam Separation ...................................................................99

4.4.1.2.3. Transport of the Lead-Bismuth Droplets in the Steam Lines........................................................... 105

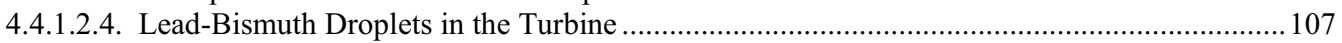

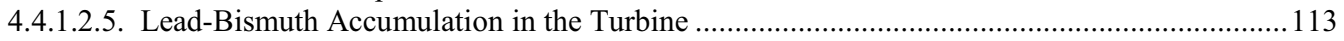

4.4.2. Indirect Steam Power Conversion Cycle - Steady State Power Determination ….............. 115

4.4.2.1. Primary Coolant Natural Circulation ................................................................................

4.4.2.2. Primary Coolant Forced Circulation ………………………………………………………..... 117

4.4.3. Plant Capital Cost Estimation Model........................................................................ 118

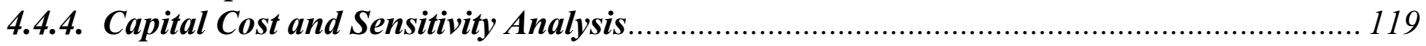

4.4.5. Indirect Power Conversion Cycle - Transient State Power Determination ...................... 123

4.4.6. Gas Lift Pump Evaluation for the Indirect Cycle Design .......................................... 133

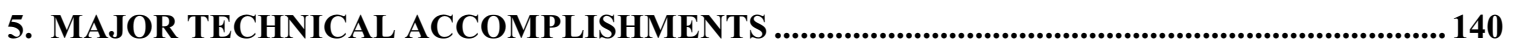

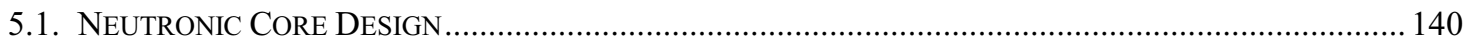

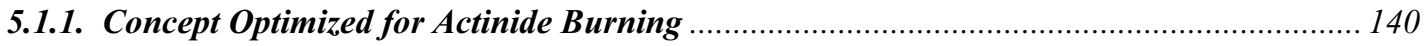

5.1.2. Concept Optimized for Economic Electricity Production ……....................................... 141

5.1.3. Approaches for both actinide burning and low cost electrical production ......................... 142

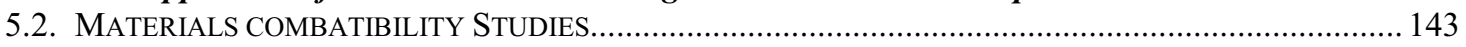

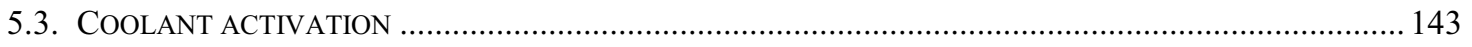

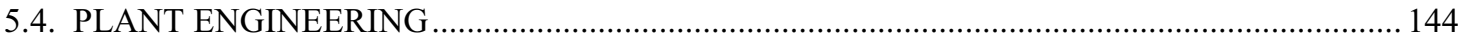

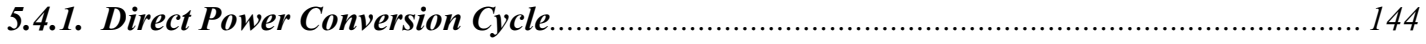

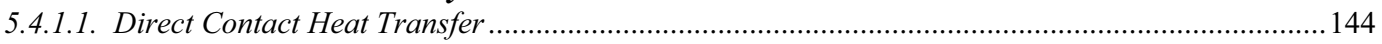

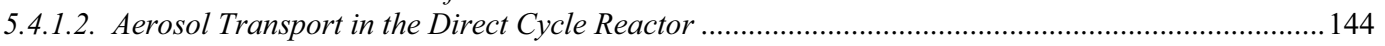

5.4.2. Indirect Steam Power Conversion Cycle-Steady State Power Determination ….................. 144

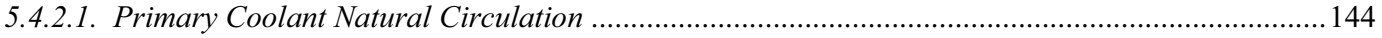

5.4.2.2. Primary Coolant Forced Circulation ………………………………………………………... 145

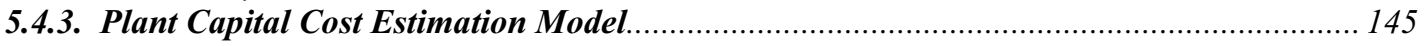

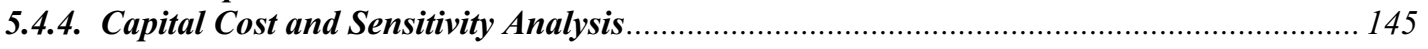

5.4.5. Indirect Power Conversion Cycle - Transient State Power Determination …................... 146

5.4.6. Gas Lift Pump Evaluation for Direct and Indirect Cycle Designs.................................. 146

6. MAJOR REMAINING TECHNICAL CHALLENGES AND FUTURE WORK ........................... 147 


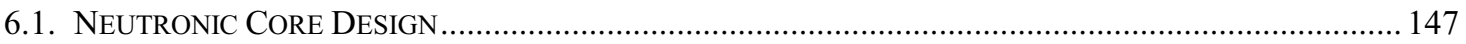

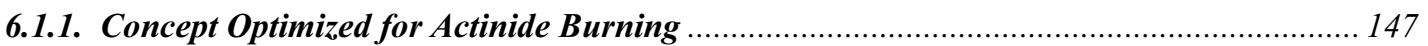

6.1.2. Concept Optimized for Economic Electricity Production ……................................... 147

6.1.3. Design Approaches for both Actinide Burning and Low Cost Electrical Production......... 148

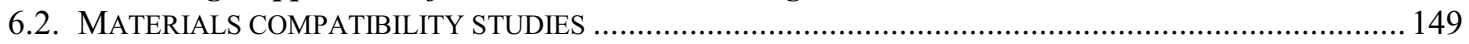

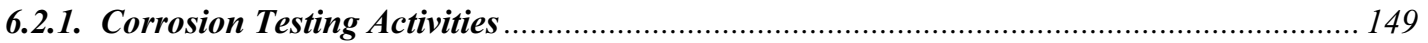

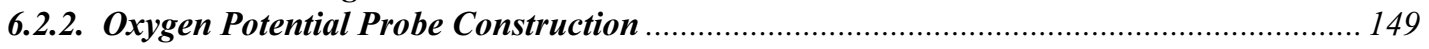

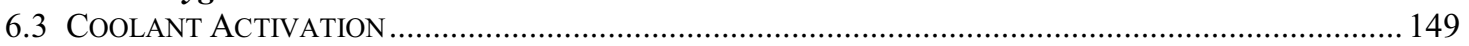

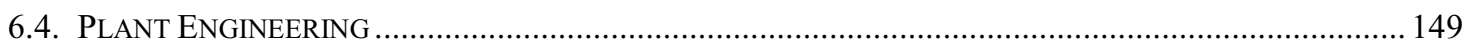

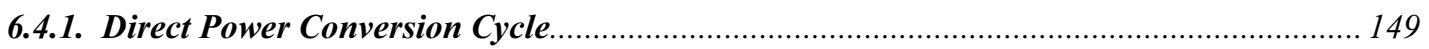

6.4.2. Indirect Steam Power Conversion Cycle - Steady State Power Determination .................. 150

6.4.2.1. Natural Circulation Primary Coolant ......................................................................................150

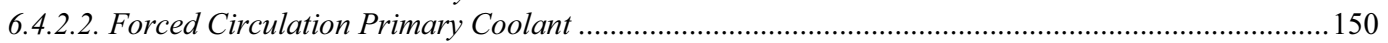

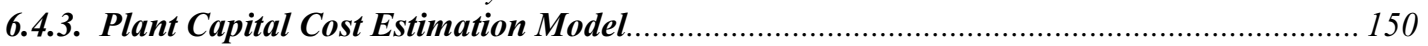

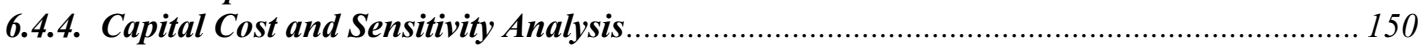

6.4.5. Indirect Power Conversion Cycle - Transient State Power Determination ....................... 151

6.4.6. Gas Lift Pump Evaluation for Direct and Indirect Cycle Designs................................... 151

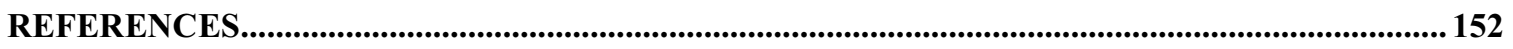

APPENDIX A - PROJECT WORK PLANS FOR JANUARY THROUGH OCTOBER 2000 .......... 163

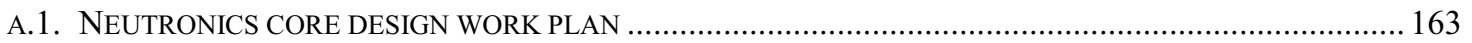

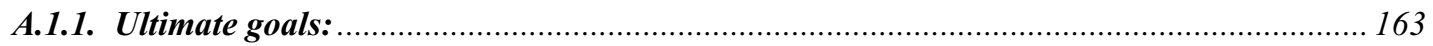

A.1.2. Details of the Burn and Breed Work Plan(MIT) ................................................... 163

A.1.3. Details of the Optimized Economical Design (INEEL + support from MIT as needed) .... 164

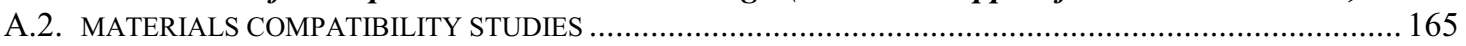

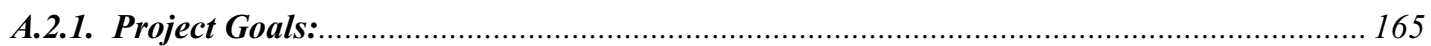

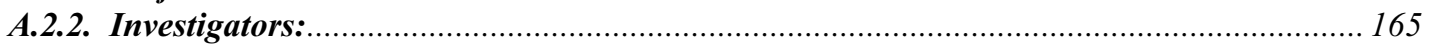

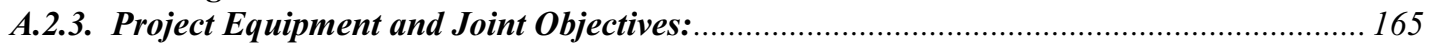

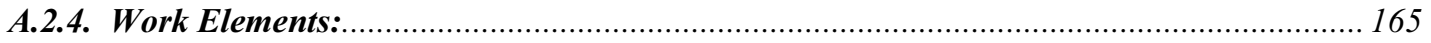

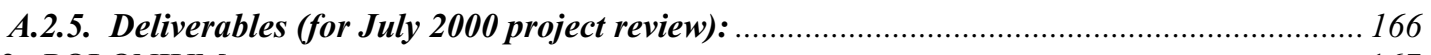

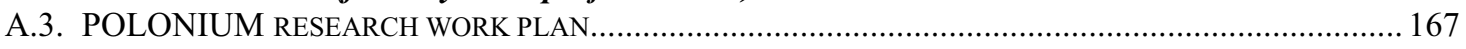

A.3.1. Objective:

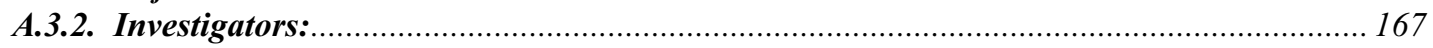

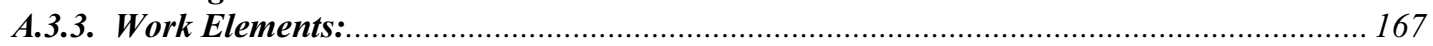

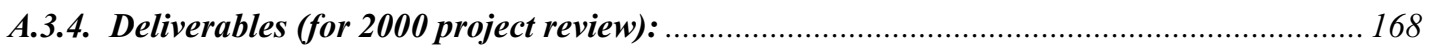

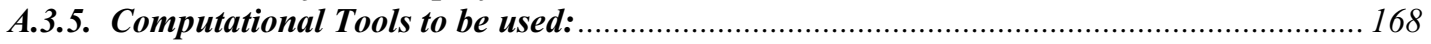

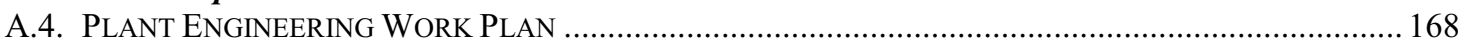

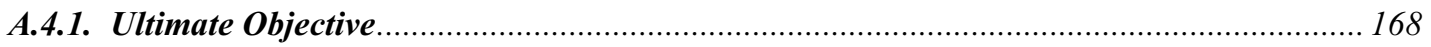

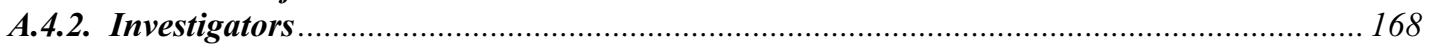

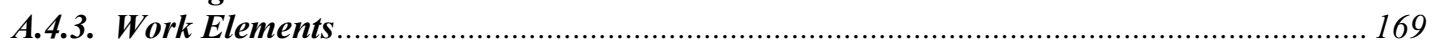

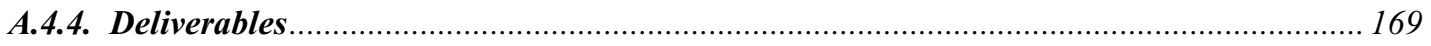

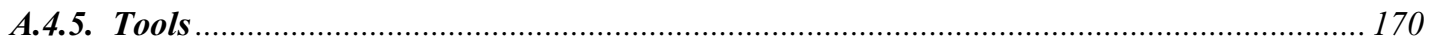

APPENDIX B LEAD-BISMUTH PROJECT PAPERS AND REPORTS................................................171

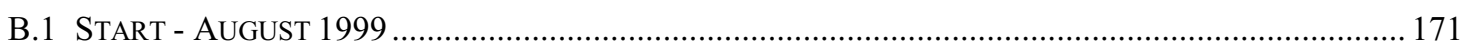

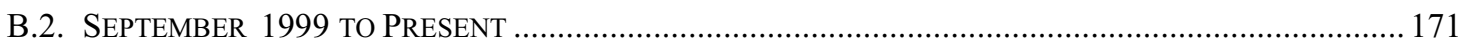




\section{Acronyms}

$\begin{array}{ll}\text { ABWR } & \text { Advanced Boiling Water Reactor } \\ \text { ALMR } & \text { Advanced Liquid Metal Reactor } \\ \text { ATHENA } & \text { Advanced Thermal-Hydraulic Energy Network Analyzer } \\ \text { ATW } & \text { Accelerator Transmutation of Waste } \\ \text { BOL } & \text { Beginning of Life } \\ \text { BWR } & \text { Boiling Water Reactor } \\ \text { CAPRA } & \text { Consommation Accrue de Plutonium dans les réacteurs a neutrons } \\ & \text { RApides (French research program for incineration of plutonium) } \\ \text { DOE } & \text { Department of Energy } \\ \text { EBR-I and II } & \text { Experimental Breeder Reactors I and II } \\ \text { ENDF } & \text { Evaluated Nuclear Data File/B-V or /B-VI (Version B-V or B-VI) } \\ \text { EFPY } & \text { Effective Full Power Years } \\ \text { EPA } & \text { Environmental Protection Agency } \\ \text { EPRI } & \text { Electric Power Research Institute } \\ \text { ETGAR-3 } & \text { Israeli test facility } \\ \text { FFTF } & \text { Fast Flux Test Facility } \\ \text { FPY } & \text { Full Power Years } \\ \text { HEPA } & \text { High Efficiency Particulate Air Filter } \\ \text { HM } & \text { Heavy Metal } \\ \text { IFR } & \text { Integral Fast Reactor } \\ \text { INEEL } & \text { Idaho National Engineering and Environmental Laboratory } \\ \text { LANL } & \text { Los Alamos National Laboratory } \\ \text { LMFBR } & \text { Liquid Metal Fast Breeder Reactor } \\ \text { LWR } & \text { Light Water Reactor } \\ \text { MA } & \text { Minor Actinides } \\ \text { MIT } & \text { Massachusetts Institute of Technology } \\ \text { MCNP } & \text { Monte Carlo N-Particle } \\ \text { MOCUP } & \text { MCNP-ORIGEN2 Coupled Utility Program } \\ \text { MOX } & \text { Mixed oxide fuel } \\ \text { NECDB } & \text { Nuclear Energy Cost Data Base } \\ \text { ORNL } & \text { Oak Ridge National Laboratory } \\ \text { PRISM } & \text { Power Reactor Innovative Small Module } \\ \text { PWR } & \text { Pressurized Water Reactor } \\ \text { RELAP5 } & \text { Reactor Excursion and Leak Analysis Program, Version 5 Research Consortium } \\ \text { RVACS } & \text { Reactor Vessel Auxiliary Cooling System } \\ \text { TRU } & \text { Transuranics } \\ \text { UTXS } & \text { University of Texas Cross-Sections } \\ \text { URC } & \text { Sniversity } \\ & \end{array}$




\begin{abstract}
The purpose of this Idaho National Engineering and Environmental Laboratory (INEEL) and Massachusetts Institute of Technology (MIT) University Research Consortium (URC) project is to investigate the suitability of lead or lead-bismuth cooled fast reactors for producing low-cost electricity as well as for actinide burning. The goal is to identify and analyze the key technical issues in core neutronics, materials, thermal-hydraulics, fuels, and economics associated with the development of this reactor concept. Work has been accomplished in four major areas of research: core neutronic design, material compatibility studies, plant engineering, and coolant activation.
\end{abstract}

In the area of core neutronic design, the reactivity vs. burnup and discharge isotopics of both non-fertile and fertile fuels were evaluated. An innovative core for pure actinide burning that uses streaming, fertile-free fuel assemblies was studied in depth. This particular core exhibits excellent reactivity performance upon coolant voiding, even for voids that occur in the core center, and has a transuranic (TRU) destruction rate that is comparable to the proposed accelerator transmutation of waste (ATW) facility. A fuel cycle cost analysis showed smaller cost than for ATW fuel, but considerably higher values than the $6 \mathrm{Mills} / \mathrm{kWh}$ characteristic of existing light-water-reactor (LWR) nuclear power plants. An option was studied that avoids the expense of fuel reprocessing by using a once-through fuel cycle and long life core to produce economic electricity. Metallic fuels driven by U-235, and using U-238 as the fertile material, were found to exhibit high conversion ratios and reactivity gain. They also possess a smaller ingestion hazard and result in less waste inventory, decay heat and radioactivity in the discharged fuel than the actinide-burner. In fact, this particular reactor will discharge 3 times less waste by mass than a typical Pressurized Water Reactor (PWR). On the other hand, they pose the worst proliferation threat since the bred-in plutonium has a high fraction of $\mathrm{Pu}-239(>90 \%)$. Also studied were metallic and nitride fertile fuels containing $13-20 \mathrm{wt} \%$ LWR plutonium plus minor actinides as the initial fissile inventory, with the remaining inventory being natural uranium or thorium. The goal was to maintain a reasonable overall TRU destruction rate while breeding in enough fissile material to extend the core lifetime to 15 to 20 effective-full-power-years. The thorium based fuels were found to have an actinide destruction rate that was approximately $70 \%$ that of the actinide-burner, and all of the fuels studied appear to have an optimum initial actinide loading that would allow for a reactivity swing of $<0.5 \%$ from the beginning to end-of-life. These studies suggest that a core can be designed to achieve a long life while maintaining safety and minimizing waste.

In the area of material compatibility studies, an experimental apparatus for the investigation of the flow-assisted dissolution and precipitation (corrosion) of potential fuel cladding and structural materials has been designed and built at the INEEL. The INEEL forced convection corrosion cell consists of a small heated vessel with a shroud and gas flow system. The gas flow rates, heat input, and shroud and vessel dimensions have been adjusted so that a controlled coolant flow rate, temperature, and oxygen potential are created within the down-comer located between the shroud and vessel wall. The corrosion cell is being used to test steel that is commercially available in the United States to temperatures above $650^{\circ} \mathrm{C}$. In addition, a spinner type corrosion tester has been designed and is being built at MIT as are probes to measure oxygen potential. 
Progress in plant engineering was made for two reactor concepts, one utilizing an indirect cycle with heat exchangers and the other utilizing a direct contact steam cycle. The evaluation of the indirect cycle designs has investigated the effects of various parameters to increase electric production at full power. A passive decay heat removal system based on the one used in General Electric's Power Reactor Innovative Small Module (PRISM) has also been developed, and the system response during a complete loss-of-feed-water transient has been analyzed. For the direct contact reactor, major issues related to the direct contact heat transfer rate and entrainment and carryover of liquid lead-bismuth to the turbine have been identified and analyzed. An economic analysis approach was also developed to determine the cost of electricity production in the leadbismuth reactor. The approach estimates the capital cost associated with the lead-bismuth reactor based on comparisons with PRISM. The approach will be formulated into a model and applied to develop specific cost estimates for the different reactor designs and thus aid in the selection of the most economic option.

In the area of lead-bismuth coolant activation, the radiological hazard was evaluated with particular emphasis on the direct contact reactor. In this system, the lack of a physical barrier between the primary and secondary coolant favors the release of the alpha-emitter Po-210 (a product of neutron activation of bismuth) and its transport throughout the plant. Modeling undertaken on the basis of the scarce information available in the literature confirmed the importance of this issue, as well as the need for experimental work to reduce the uncertainties on the basic characteristics of volatile polonium chemical forms. Experiments are currently being conducted at MIT to measure these basic characteristics. 


\section{Project Objective and Overview}

The purpose of this Idaho National Engineering and Environmental Laboratory (INEEL) and Massachusetts Institute of Technology (MIT) University Research Consortium (URC) project is to investigate the suitability of lead-bismuth cooled fast reactors for producing low-cost electricity as well as for actinide burning. The goal is to identify and analyze the key technical issues in core neutronics, materials, thermal-hydraulics, fuels, and economics associated with the development of this reactor concept.

While considerable design work has been done in the United States, Europe, and Japan on fast reactors, including actinide-burners, it has mostly been done for sodium cooled reactors. A leadbismuth cooled fast reactor was considered in the United States in the 1950s. However, it was abandoned in favor of sodium cooling for two reasons:

(1) lead bismuth coolant at the temperatures of interest can be very corrosive to structural materials; and

(2) the doubling time of sodium cooled fast reactors can be significantly shorter than that of leadbismuth cooled reactors as a result of the higher power density achievable in sodium cooled cores.

Whereas a short doubling time was considered an important performance characteristic in the 1950 's, it is of little significance today, as we do not foresee a depletion of low cost uranium resources in the near future, and we have a significant inventory of actinides which can be burned in a fast reactor. Regarding the material compatibility issue, the Russians adopted lead-bismuth for use in their most advanced nuclear submarines, the so-called "Alpha" class submarines which are the fastest in the world. The Russians have built and operated seven lead-bismuth reactors in submarines and two on-shore prototypes. More recently, they have studied the design of a variety of lead and lead-bismuth reactors for electric power generation, some of which can operate with one core loading for many years and do not require any fuel reprocessing.

Elsewhere, very long-lived core, lead-bismuth cooled, fast reactors have continued to be investigated in Japan, and in the United States at the University of California at Berkeley. A lead-bismuth cooled, accelerator-driven, sub-critical actinide-burner (labeled ATW) has been proposed by the Los Alamos National Laboratory (LANL) for burning the actinides and long-life fission products from spent light water reactor fuel. It is envisioned that the reactors investigated in this study could operate in concert with ATWs in a program to both burn the waste from the current generation of light water reactors and produce low-cost electricity. It should also be noted that there exists a synergy between the development of the ATW and a critical system: they share similar coolant and fuel technologies with the result that either system can greatly benefit from improvements achieved for the other.

Rationale for use of lead-alloy coolant. The choice of lead or lead-bismuth for the reactor coolant in a fast reactor offers enhanced safety and reliability. The advantages of lead-alloy over sodium as a coolant are related to the following basic material characteristics: chemical inertness with air and water; higher atomic number; low vapor pressure at operating temperatures; and high boiling temperature. These basic properties lead to the following advantages for lead-bismuth coolant: 
- Harder neutron spectrum and better reflection properties (with little moderation), which results in an improved neutron economy, especially when burning actinides, and makes it possible to get breeding even without blankets (neutron economy is vital to achieving the targeted long core lifetime while minimizing burnup reactivity loss and excessive control requirements).

- The high boiling temperature and high heat of vaporization of lead and lead-bismuth coolants (a boiling temperature of $1725{ }^{\circ} \mathrm{C}$ for lead-bismuth versus $892{ }^{\circ} \mathrm{C}$ for sodium), which eliminates boiling and related loss of cooling as a realistic accident scenario.

- Significantly lower reactivity associated with hypothetical voiding of the coolant. The positive reactivity effect of coolant voiding has long been a concern with sodium-cooled fast spectrum systems. We believe that lead-alloy cooled cores can be designed with a negative coolant void coefficient without resorting to impractical core design options that compromise system performance and economics (Hejzlar et al. 1999a and 1999b); therefore, events such as fuel rod failure and release of fission product gas and steam generator tube rupture will be of much less concern.

- Better shielding against gamma-rays and energetic neutrons.

- Lead-alloy coolant does not react energetically with air and water (eliminating the possibility of fires and the necessity of employing an intermediate heat transport loop, thereby reducing plant capital costs).

- Possibility of using relatively high outlet temperatures and high efficiency heat transfer cycles (with proper control of the coolant chemistry and choice of cladding and structural materials, it is likely that relatively high coolant temperatures can be obtained; in addition, there is potential for coupling of the reactor to other energy conversion and distribution systems of the future).

- Simpler containment structure due to the impossibility of fires and explosions.

- A volume change upon solidification that is small enough that structural components are not damaged.

In addition, liquid-metal cooled fast reactors in general have the following advantageous characteristics:

- Their excellent heat transfer capacity enables compact, high power-density cores. This attribute is essential to developing a relatively small (and economic) core.

- Their excellent capability for natural circulation, especially for lead-alloy cooled fast reactors, provides important safety advantages and offers significant potential for heat transport system simplification.

- They have excellent passive safety and autonomous operability characteristics attributable to the fast neutron energy spectrum, which enables:

(a) relatively high conversion ratio and weak fission product poisoning, thereby minimizing burnup reactivity loss and the associated need for active control and the potential for reactivity insertion accidents, and

(b) favorable neutronic and thermo-structural feedback characteristics allowing passive adjustment of the fission power generation to the system heat rejection.

Because lead or lead-bismuth has not been used as a reactor coolant outside of Russia, important technology issues (e.g., structural material corrosion, coolant chemistry control, filtration of impurities, coolant activation, etc.) must be addressed. There are also other disadvantages to the 
use of lead or lead-bismuth for cooling an actinide fast reactor in addition to the material compatibility problems. These include: high material cost; higher melting temperature $\left(125^{\circ} \mathrm{C}\right.$ for lead-bismuth versus $98^{\circ} \mathrm{C}$ for sodium); and the production of Po-210. But probably most important, the relative cost of the various design alternatives that have been proposed earlier must be evaluated.

Project organization. Given the status of the field, it was agreed that the focus of this investigation in the first years will be on the assessment of approaches to optimize core and plant arrangements in order to provide maximum safety and economic potential in this type of reactor. It is envisioned that one pool type plant design would be explored that could accommodate cores designed to achieve objectives at and between the following extremes:

(1) maximization of actinide consumption by utilizing a non-fertile metal fuel and

(2) minimization of electricity cost by utilizing fertile fuel in a long-lived core.

INEEL and MIT are carrying out this investigation in a cooperative, coordinated manner. Work plans for each of the four disciplinary-based areas that are being investigated (core neutronic design, material compatibility studies, coolant activation, and plant engineering) are in Appendix A. These work plans reflect the emphasis on work activity over the period January through July, 2000 necessitated by the administratively dictated shutdown of INEEL effort and the curtailment of the MIT effort in the fall period of 1999. In brief the distribution between INEEL and MIT lead responsibilities in these disciplinary areas is as follows:

(1) Neutronics - MIT examines core designs to achieve the two limiting objectives - maximum actinide consumption and minimization of electricity cost while INEEL examines a core designed to optimize both objectives simultaneously.

(2) Structural Materials-INEEL will perform circulation corrosion studies while MIT will perform static autoclave studies with spinning test sections. Further, INEEL's studies will focus on commercially available materials while MIT will focus on more advanced materials. Both INEEL and MIT are also developing the capability to fabricate oxygen potential measurement probes for both the materials and polonium investigations.

(3) Polonium - This activity is conducted solely by MIT and aimed at obtaining fundamental chemical data characterizing the release mechanisms of polonium from a lead-bismuth primary coolant.

(4) Plant Engineering-For the indirect power conversion cycles, the INEEL is assessing transient plant performance while MIT is assessing steady state plant performance. In both cases, the focus is on determining the maximum allowable plant power and associated plant capital cost for the following plant system options: primary coolant under natural versus forced-circulation; a steam versus helium secondary coolant system. MIT is also investigating the direct power conversion cycle.

The project has been active in disseminating its results through preparation of topical reports and technical papers in journals and technical conferences. These publications prior to August 1999 and from September 1999 to date are listed in Appendix B. 


\section{Key Technical Challenges}

\subsection{NEUTRONIC CORE DESIGN}

Striking a balance between actinide destruction, passive safety, proliferation resistance, and competitive economics is a difficult task. A number of different fuel types can be used depending on the scope and purpose of the reactor. These fuel types can be lumped into two general categories: fertile and non-fertile fuels. Each type has its own set of challenges, although some of the problems are common to both. Three design directions have been pursued -

- the first design emphasized maximum actinide destruction rate using non-fertile fuel,

- the second stressed economical aspects by using fertile fuel in a high conversion concept with once-through fuel cycle that does not require reprocessing, and

- the third focused on the attainment of a balance between the actinide destruction and economy using fertile fuel.

To effectively transmute plutonium and minor actinides from light water reactor (LWR) spent fuel, it is desirable to minimize the waste of neutrons in order to attain a large surplus available for transmutation. Metallic fuels based on a zirconium matrix provide large excess reactivity due to the low parasitic absorption cross-section of zirconium and due to the hard spectrum achievable because the fuel does not contain any moderating isotope. Nitride fuels or other fuel forms may also be suitable.

\subsubsection{Concept Optimized for Actinide Burning.}

To maximize the actinide transmutation capability of the system, breeding of new fissile material must be minimized hence making the presence of the fertile isotopes U-238 or Th-232 undesirable. The choice of fuel composition for maximum actinide transmutation is then restrained to the to-be-transmuted plutonium and minor actinides $(20-30 \% \mathrm{wt}$.) and to the zirconium matrix (70-80\% wt.), constituting the structural component of the fuel rods. It should be noted that the larger weight fraction of zirconium relative to the heavy metals makes this nonfertile fuel significantly different from the metallic fuel developed by the Argonne National Laboratory for the Integral Fast Reactor (IFR) project, providing the possibility to use dispersion type fuel with IFR type coated particles dispersed in a pure zirconium matrix.

Although the employment of metal, non-fertile fuel in the large core of actinide-burners achieves the highest excess reactivity, it raises three key issues:

1. a large positive coolant void reactivity coefficient,

2. small Doppler effect, and,

3. large rate of reactivity loss with burnup, i.e., large reactivity swing.

Coolant void coefficient. In comparison to oxide and nitride fuel types, the metal fuel has typically the most positive coolant void reactivity coefficient. The reasons for the positive coolant void coefficient can be found from the three major components - leakage effect, capture effect, and spectrum effect - affecting reactivity behavior during coolant voiding. When coolant voids, leakage is increased resulting in a reactivity reduction. On the other hand, the harder 
spectrum of the voided core results in reduced capture cross sections and a reduced capture rate. A harder spectrum also leads to reduced fission rates, however, the reduced capture rate in major fuel isotopes typically prevails over the decreasing trend of the fission rates. The net outcome is typically a reactivity increase due to decreasing capture-to-fission rates. In mixed-oxide cores, there are moderating isotopes in the fuel. During coolant voiding, when the main moderator, i.e. the coolant, is removed from the core these in-fuel moderators maintain some moderation, mitigating the spectrum hardening effect. The absence of these moderators in the metal fuel results in more pronounced spectrum hardening, and thus a more positive coolant void reactivity coefficient.

A number of lead-cooled or lead-bismuth cooled designs with negative coolant void worth have been proposed (Su'ud'and Sekimoto 1995, Greenspan et al. 1998, Orlov et al. 1994) but they could do so only under the important assumption that the coolant density change occurs uniformly throughout the entire core. A large shift in magnitude of coolant void reactivity to more positive values can be observed when voiding only the central part of the core and reflectors in comparison to voiding the whole core, including the reflectors (Orlov et al. 1994).

A legitimate question can be posed as to whether there is any practical possibility that a situation can arise that provides conditions for a voided region to exist in the central part of a leadbismuth-cooled core. The boiling temperature of lead-bismuth is $1725{ }^{\circ} \mathrm{C}$ versus $892{ }^{\circ} \mathrm{C}$ for sodium and lead-bismuth has a high heat of vaporization, hence it is generally considered to be practically impossible to create a major void in the core through vaporization of the lead-bismuth. Nevertheless, there are three hypothetical scenarios that could introduce voids into the core:

- carry-under of gas bubbles from the cover gas plenum,

- multiple failure of cladding in the mid- or lower-core regions and depressurization of the gas plenum above the fuel pins into the core, and

- ingress of steam from a rupture of a steam generator tubes (or helium from the heat exchanger in a Brayton cycle power unit) .

Typically, the designers of fast reactors rely on negative prompt Doppler and other feedback mechanisms to hold the core below prompt critical in case of coolant voiding. Because the Doppler effect is small in fertile free fuels and the effective delayed neutron fraction is relatively low because of the absence of U-238, the reliance on negative fuel temperature feedback is restricted. Therefore, one of the key challenges of the fertile-free core is to achieve a negative coolant void worth in local voiding scenarios. On the other hand, the large fraction of zirconium matrix makes the core more transparent to neutrons, helping to reduce coolant void worth.

Doppler Reactivity Coefficient. The amount of fertile isotopes in the non-fertile metallic fuel is very small (mostly Pu-240). Moreover, the hard spectrum leads to a decrease of the absorption rate in the resonance peaks. Both these factors result in a very small Doppler feedback and measures to attain a reasonably negative Doppler coefficient must be employed for non-fertile fuel. Reactivity changes from fuel thermal expansion are also prompt, hence if appreciable negative reactivity insertion from fuel thermal expansion is realized, the requirements on the magnitude of the negative Doppler coefficient may be reduced.

Reactivity Swing with Burnup. A major consequence of the absence of fertile isotopes is the faster net depletion of the fissionable material and hence a marked reduction of reactivity during a cycle. To ensure criticality at the end-of-life, the reactivity excess at the beginning must be large, 
making this design potentially vulnerable to accidents related to malfunction of the control rod mechanisms (e.g. rapid control rod ejection).

\subsubsection{Concept Optimized for Economic Electricity Production.}

To minimize the cost of electricity produced, it is desirable to have a reasonably large power output to reduce the cost per installed $\mathrm{kWe}$ and long refueling cycles so that the plant capacity factors are high and the fuel fabrication costs per unit energy are low. In addition, currently high reprocessing costs suggest that the once-through fuel cycle may be economically beneficial. Since very long refueling cycles with high burnup are also required to minimize the inventory of discharged fuel, use of fertile material is necessary. Fertile isotopes relieve to some extent the concerns with Doppler coefficient, although the hard spectrum of the lead-bismuth cooled core still makes the achievement of a sufficiently negative Doppler effect more challenging than in Na-cooled systems, especially for fuels with no moderating agents. The key challenges of the high conversion concept with large power rating are:

- attainment of negative coolant void worth,

- achievement of very long refueling cycle with a small (less than $\beta$ ) reactivity swing, and

- minimization of the spent fuel inventory, and its toxicity and assurance of proliferation resistance.

Coolant void worth. Because of its more negative Doppler effect and higher delayed neutron fraction (than in the actinide-burner design), a small local positive coolant void worth can be tolerated in the high conversion core. However, the core must be designed to assure that promptnegative fuel temperature feedback will render the overall response negative under all circumstances. It is more challenging to design a large core with fertile fuel to meet this requirement for two reasons:

1) because most of the fuel mass contains heavy metal rather than the neutron-transparent zirconium matrix of the actinide-burner core, the positive contribution of the spectral component to coolant void worth is higher, and

2) the option space to overcome positive contributors through increased leakage is limited because of the negative effect of leakage on conversion ratio, and thus on reactivity swing. In addition, strategies of enhanced leakage necessitate increased enrichment and fuel cycle cost.

Reactivity swing. To eliminate the hypothetical possibilities of going prompt critical, it is desirable to maintain reactivity excess less than $\beta_{\text {eff }}$ throughout the whole cycle. However, the excess reactivity must be sufficient to sustain criticality throughout the life of the reactor. This becomes a significant challenge for the long-life cores envisioned for this concept considering the fact that other safety parameters (in particular the coolant density coefficient) that negatively affect conversion ratio must be met as well.

Characteristics of discharged fuel. Since reprocessing is not considered for the once-through cycle, the inventory of spent fuel for the repository must be minimized, as well as its long term ingestion hazard and thermal decay power. Moreover, spent fuel should meet proliferation resistance criteria. Meeting all these objectives simultaneously is a challenging task. 


\subsubsection{Concept optimized for both actinide burning and low cost electrical production.}

This concept strives for an optimum between the previously discussed limiting design brackets. Thus, the challenges reviewed above pertain to this concept as well. There are two options associated with this particular design:

1) a once-through cycle where the initially loaded plutonium and minor actinides are reprocessed from LWR spent fuel (this being the only reprocessing step), and

2) a multi-reprocessing cycle that is similar to the pure actinide-burner design where actinides and long lived fission products are recycled back into the reactor at the end of the cycle.

The key challenge is to find a balance between the maximum actinide destruction rate, which prefers fertile-free fuel, and economics aspects that favor relatively long refueling cycles with some fertile material loaded. Fertile isotopes alleviate the challenge of the Doppler effect, as in the case of the high conversion concept. The coolant void worth and reactivity swing challenges discussed for that concept pertain also to this design, although the optimum fuel cycle length may be appreciably shorter extending somewhat the option space to improve coolant density coefficient through increased leakage.

\subsection{MATERIALS COMPATABILITY STUDIES}

While liquid metals, in particular lead-bismuth, are very attractive from a neutronics and thermal hydraulic point of view, there are a significant number of materials issues that, if not addressed, will negate the other advantages. The key materials issues are related to the fact that most metals have a finite solubility in lead or lead-bismuth. Moreover, the solubility will be a strong function of temperature. Thus, if the metal surfaces are not protected in some way, there will be a continuous removal of material from hot regions of the system and the deposition of material in the colder regions. The key technical challenge is to find a way to eliminate or at least mitigate this effect. Possible alternatives include:

- use of a material which has a very low solubility in lead-bismuth,

- use a coating of some kind,

- operate in an environment in which a self protecting film forms, or

- reduce the operating temperature such that the dissolution rate is acceptably low.

\subsubsection{Use of Corrosion Resistant Materials}

Steel is the preferred material for applications where the temperature is below $500^{\circ} \mathrm{C}$. The combination of a reasonably low dissolution rate and protective film formation (discussed below) yields acceptable performance. However, at higher temperatures steel becomes unacceptable and more exotic materials must be considered. However, these materials, which include molybdenum, niobium, and other refractory elements as well as ceramics, are either expensive, difficult to fabricate, or have a very limited database.

\subsubsection{Coatings}

Coatings that are insoluble in lead-bismuth are available. These include ceramics such as $\mathrm{ZrO}_{2}$ and graphite among others. The difficulty with this approach is that most coatings are brittle and, if breached, will result in localized dissolution of the material. Additionally, it will be very 
difficult to ensure that all exposed surfaces are coated. Thus, the use of coatings may seem like a workable idea but they are practically difficult to apply.

\subsubsection{Self-Protecting Films}

An alternative to the use of a metal with a zero or very low solubility in lead or lead-bismuth is to use a material which develops a protective surface film which precludes access of the lead or lead-bismuth to the underlying metal. The analogous material for aqueous service would be one that passivates. The protective film may be as thin as an adsorbed layer of oxygen or may be a considerably thicker bulk oxide.

Protective film formation requires that sufficient oxygen be present in the system to raise the potential above the equilibrium potential for the formation of the film. In essentially all cases, the film is an oxide. Figure 1 shows the free energy of formation for a number of oxides in comparison to that of $\mathrm{PbO}$. It is important that the free energy of formation for the film be below that of $\mathrm{PbO}$. If this is not the case, then the oxide will also form and "sludge" will build up in the system. It is also important that the film be stable with respect to reduction by lead or bismuth. With reference to Figure 1, iron appears to satisfy these criteria. However, at temperatures above $500^{\circ} \mathrm{C}$ the film is not stable. For higher temperatures another material must be found. While data is available for other materials, it is very old and inconsistent.

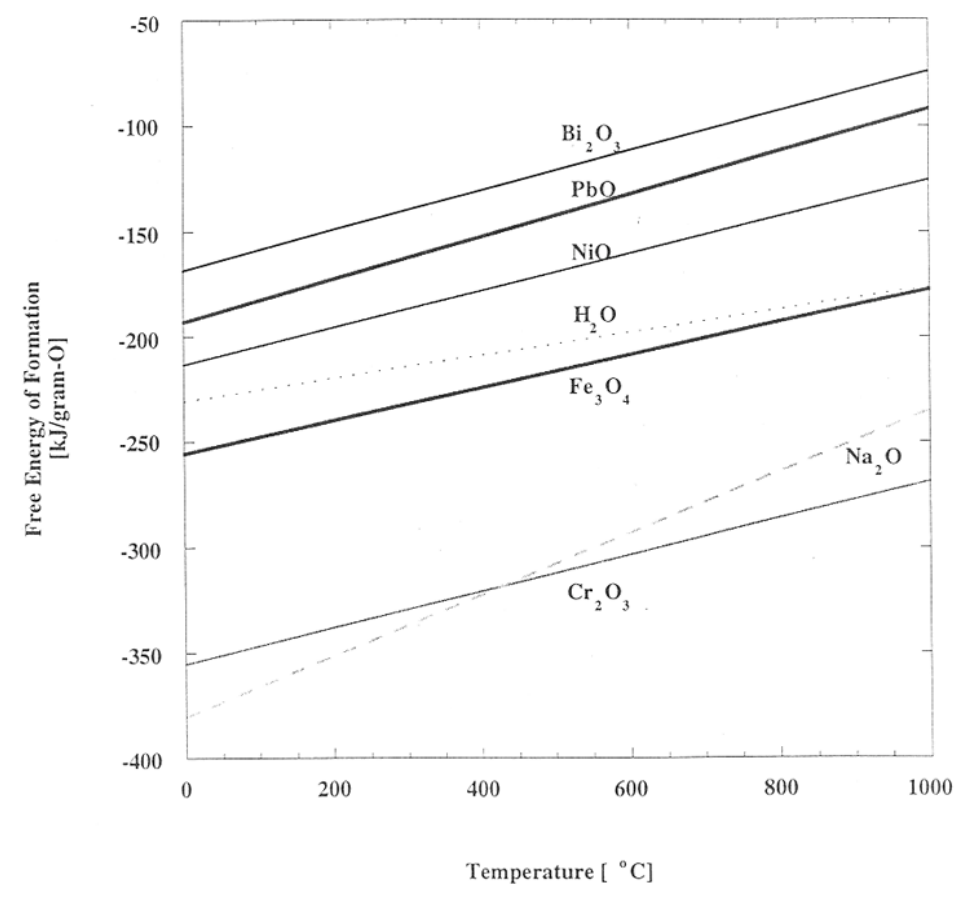

Figure 1. Free energy of formation for selected oxides in comparison with leadO.

Key Challenge. The key materials challenge for the use of lead-alloys as a coolant is to develop a system in which the structural material is insoluble in the coolant and/or to develop a material which forms a stable, self healing, protective film at potentials below that for the formation of $\mathrm{PbO}$. This will require that a more fundamental understanding of the film formation kinetics in lead-bismuth systems be developed. The purpose of this project is to make progress in the development of this understanding. 


\subsection{COOLANT ACTIVATION}

The use of molten lead-bismuth eutectic as a heavy liquid metal coolant for fast spectrum nuclear systems has been deemed preferable over pure lead (Spencer 2000, LANL 1999, Gromov et al. 1997 , Zaki and Sekimoto 1995$)$ due to its lower melting point $\left(125^{\circ} \mathrm{C}\right.$ vs. $\left.327^{\circ} \mathrm{C}\right)$, which greatly simplifies coolant handling as well as plant design and operation. However, lead-bismuth does display several disadvantages with respect to lead including coolant availability and cost (bismuth is a relatively rare and costly material), materials corrosion (at a given temperature the solubility of steel materials is larger in bismuth than in lead ${ }^{1}$ (Weeks 1971) and the radiological hazards associated with coolant activation. Polonium 210 (an extremely toxic alpha-emitter of approximately 140 days half-life) is formed from ${ }^{209} \mathrm{Bi}$ by neutron capture. In a single-phase lead-bismuth reactor the primary system is sealed and separated from the secondary system. As a result polonium is well retained in the lead-bismuth eutectic during normal operating conditions and can cause problems only if coolant leakage through the steam generator or the reactor vessel occurs. Also, some polonium migrates to the cover gas in the reactor plenum and can diffuse outside the primary system if the reactor pool is not perfectly tight. However, recent studies within the LANL ATW project ( $\mathrm{Li}$ et al. 1998) have shown that exposure of plant personnel to polonium can be maintained within tolerable limits, even in the case of a massive release of the cover gas or coolant into the reactor room. Nevertheless, due to its long half-life, ${ }^{210}$ Po may limit access to the surfaces on which it deposits, thus increasing maintenance costs and/or collective doses. Considerable experience in dealing with polonium related issues has been gained in the past 30 years in Russia where submarines were equipped with lead-bismuth cooled nuclear reactors (Zrodnikov et al. 1999). A polonium technology was developed that includes special polonium filters for air cleaning, polonium adsorbing adhesive films for decontamination of large surfaces, special respirators, and pressurized suits for maintenance of contaminated areas (Pankratov et al. 1992).

However, the case of a lead-bismuth/water direct-contact reactor presents a significantly more severe challenge. Under normal operating conditions, the primary system is not isolated and the radioactive polonium may be readily transported by steam throughout the secondary system (e.g. the steam lines, the turbine, and the condenser). Because leakage of some contaminated steam out of the turbine or other power cycle components is inevitable, a certain amount of polonium is likely to escape into the environment. It must be demonstrated that the polonium concentration in the leaking steam, and all other vented flows, is within the limits prescribed by the radiation protection regulations. As a result, the development of the lead-bismuth/water direct-contact reactor concept calls for a substantial investigation of the mechanisms of formation of radioactive polonium and its chemical compounds, a quantitative characterization of their release and transport throughout the plant, and identification of possible ways to mitigate the radiological concern associated with these phenomena. These questions are addressed in the work of this project.

\footnotetext{
${ }^{1}$ However, it should be noted that, due to the higher melting point of lead, a lead cooled reactor might have to operate at higher temperature which may offset the solubility difference.
} 


\subsection{PLANT ENGINEERING}

\subsubsection{Direct Cycle and Direct Contact Heat Transfer}

The lead-bismuth/water direct-contact reactor concept is based on direct contact vaporization of water in the reactor chimney to remove the core thermal power and generate steam for the power cycle. This heat transfer mode can be remarkably effective because the primary coolant (i.e. the hot lead-bismuth) and the secondary coolant (i.e. the water) are not separated by a solid barrier (e.g. a tube wall in a conventional steam generator), but are in intimate contact and share a larger interfacial area. The actual rate of heat transfer between the two fluids determines the chimney height required to fully vaporize the water as well as the density difference between the chimney and the down-comer. This, in turn, strongly affects the natural circulation flow in the whole reactor pool and ultimately the temperature distribution in the core. Therefore, it should be clear that the prediction and understanding of the direct heat transfer phenomena occurring in the reactor chimney upon injection of liquid water in the bulk of the hot lead-bismuth coolant is crucial to evaluate the feasibility and performance of the lead-bismuth/water direct-contact reactor system.

Direct contact heat transfer has been proposed and/or investigated in the past with regard to a variety of applications, ranging from geological heat extraction (Blair et al. 1976, Jacobs et al. 1977), to fuel-coolant-interaction in the analysis of disruptive accidents in nuclear reactors (Smith et al. 1982), to magnetic hydrodynamic systems for dc electricity generation (Branover 1989, Kaushik et al. 1995), to steam generators for sodium cooled reactors (Kinoshita et al. 2000, Grachev et al. 1999). However, most early experimental work focused on organic or refrigerant fluids (Blair et al. 1976, Smith et al. 1982) and/or a single droplet situation (Sideman and Gat 1966, Shimizu and Mori 1988). This enabled the investigator to neglect the interference of the dispersed phase particles and thus yielded a clean observation of the fundamental mechanisms involved. Nevertheless, if a significant power is to be removed from the lead-bismuth/water direct-contact reactor core, maintaining a reasonably short chimney and large flow rates of the dispersed phase (i.e. water) are required and interference between contiguous dispersed phase particles (i.e. droplets, bubbles) becomes important. A transition from bubbly to intermittent flow is likely to occur at high water flow rates, which may cause a marked reduction of the interfacial area and thus consequently the heat transfer rate.

Under certain operating conditions, the vaporization of water can be very rapid and violent thus leading to fragmentation of the droplet and to the formation of a pressure shock wave that can damage the channel and/or the surrounding. This phenomenon is known as steam explosion and must be prevented if a stable and controllable phase transition is to be obtained. However, steam explosion is thought to be a minor issue in our case primarily due to the high operating pressure of the lead-bismuth/water direct contact reactor.

\subsubsection{Direct Cycle - Aerosol Production Leading to Liquid Metal Embrittlement}

In the direct contact heat transfer reactor, the lead-bismuth primary coolant is mixed with liquid water above the core. Upon contact with the hot liquid metal, the water completely vaporizes and

a lead-bismuth/steam mixture rises to the top of the chimney where the steam is separated and 
sent to the turbine. A suitable steam separator ${ }^{2}$ is to be selected that satisfies the critical requirement of small residual lead-bismuth carry-over to the steam lines. Transport of leadbismuth aerosols through the steam-lines can result in a significant liquid lead-bismuth contamination of the turbine, which can induce embrittlement of the most stressed components, such as the moving blades and the rotor shaft. This phenomenon, known as liquid metal embrittlement, can lead to rapid and catastrophic failure of the turbine. Several solutions to the liquid metal embrittlement problem can be explored including: alternative blade materials, blade coatings, lead-bismuth removal by electrostatic precipitators, and oxidation of the lead-bismuth droplets $^{3}$. Also, the mechanical impact of liquid or solid heavy metal particles on the surface of the turbine blades raises an erosion concern and must be evaluated. Further, it is necessary to consider the effect of other sources of heavy metal aerosols such as evaporation of lead-bismuth and transport of polonium and polonium compounds to the components of the secondary system.

\subsubsection{Indirect Cycle - Power Conversion Cycle Optimization}

The key technical challenge in the evaluation of the indirect power conversion cycle is to optimize the performance of the plant in terms of both economics and safety. There is considerable latitude in the thermal-hydraulic design of the plant because only the design of the reactor core has been specified through the neutronic evaluation. The remainder of the primary coolant, secondary coolant, and decay heat removal systems need to be defined. Various plant configurations are being evaluated in terms of the secondary power conversion system, the motive force for primary coolant flow, and the decay heat removal system. The power conversion systems considered include steam generators using water as the secondary coolant and heat exchangers using helium as the secondary coolant. Both natural and forced circulation systems are being evaluated for the primary coolant. Furthermore, forced circulation of the primary coolant can be induced through centrifugal pumps as in current light water reactors or through gas lift pumps such as have been used in other systems with heavy metal coolants (El-Boher et al. 1988). A passive decay heat removal system is preferred to enhance its reliability and minimize its cost. The latitude in design allows considerable freedom, but also results in a significant challenge to rationally select optimal design parameters.

The rational selection of optimal design parameters requires that thermal-hydraulic limits be established against which the various plant configurations can be judged. Thermal-hydraulic limits related to fuel, cladding, and vessel temperature have been tentatively established as discussed in Section 3.2. Additional thermal-hydraulic data will be required to firmly establish these temperature limits.

The rational selection of optimal design parameters also requires the development of methods to determine the thermal-hydraulic response of the plant for a range of conditions, including steady, full-power operation, and during transients, such as caused by a loss of secondary heat sink. The application of these methods then allows various design options to be compared and to have a rational basis for selecting a preferred design option. Because the core power directly affects the economic performance of the plant, an important application of these methods is to determine a

\footnotetext{
${ }^{2}$ We will use the words "steam separator" to indicate a device that separates liquid lead-bismuth from steam.

${ }^{3}$ Oxides do not induce liquid metal embrittlement.
} 
limiting core power that ensures that temperature limits will be met for both steady, full-power operation and during transients.

The cost of electricity production is one of the key measures of the viability of a reactor cooled by lead-bismuth. Thus, an important challenge in the success of the project is to develop an economic model to estimate the cost of electricity production. Furthermore, the model needs to be applied for various plant configurations so that an optimal design can be selected.

A final technical challenge is to obtain an improved theoretical and experimental understanding of the thermal-hydraulics of systems with heavy metal coolants. For example, additional experimental data are required to confirm theoretical void fraction predictions associated with the use of gas lift pumps. 


\section{Design Limits Applicable to All Concept Studies}

The resolution of the key technical challenges of this project has been pursued by the activities described in Section 4. In these activities, the following neutronic and thermal constraints have been systematically applied to the different lead-bismuth cooled reactor designs examined.

Due to its basic physical characteristics, the use of a heavy liquid metal coolant offers potential for enhanced neutronic safety over traditional sodium cooled fast reactors. To investigate the trade-off between enhanced safety and design complication, relatively tight neutronic constraints (Section 3.1) have been selected (particularly on the void reactivity feedback). These constraints served as a stimulus to establish the safety limits of lead-bismuth cooled nuclear systems. However, in Year 3 of the present project these conservative constraints and the economic penalization they introduce will undergo a critical review. As a result, a different set of neutronic constraints might be selected to allow the design of a lead or lead-bismuth-cooled reactor for power production with optimum economics.

Large uncertainties exist on the thermal constraints (Section 3.2) because a database for the stainless steel tentatively selected for cladding and vessel purposes exists only in Russia and has not been made available to Western investigators. However, the experimental study of structural materials for lead and lead-bismuth applications is one of the objectives of this project and the definition of more reliable thermal constraints will be undertaken during Year 3.

\subsection{NEUTRONIC CONSTRAINTS}

\subsubsection{Negative Coolant Density Reactivity Coefficient.}

The approach typically undertaken in the liquid metal fast breeder reactor (LMFBR) design was to limit reactivity rise from coolant voiding to such values that Doppler and other feedback mechanisms hold the core below prompt critical for an extended period of time. This allows the core to be permanently shut down with minimal energy generation. The use of lead or leadbismuth coolant virtually excludes void generation due to boiling (the fuel and cladding would have to melt before coolant boiling could occur). However, the possibility of void ingress into the core exists from ruptured steam generator tubes or from escaped fission product gases accumulated in the fuel rod plenums. Considering these potential threats and the fact that the burner core has a small effective delayed neutron fraction, a constraint of negative coolant void worth, even in case of local non-homogenous voiding (termed also partial voiding) in the central core region, was introduced. Although this is a very strict constraint, a burner core with a local negative coolant reactivity coefficient as an inherent feature significantly eases concerns with potential void formation within the core from any scenario and eliminates the need to prove deterministically that these voids cannot lead to rapid reactivity insertion and potentially to core disruptive events.

A less strict constraint was adopted for the concepts optimized for electricity production, which use fertile fuels and exhibit a more negative Doppler effect and higher delayed neutron fraction than in the actinide-burner design. Therefore, a small, local, positive coolant-void worth can be tolerated in the high conversion core as long as the core is designed to assure that prompt 
negative fuel-temperature feedback will render the overall response negative under all circumstances. Thus a constraint of negative global void worth, i.e., reactivity reduction in case that whole core is voided while the coolant surrounding the core remains in the original state was adopted.

\subsubsection{Negative Fuel Temperature Coefficient.}

One of the key requirements for all reactor designs is a negative fuel temperature coefficient, which acts promptly to reduce reactivity upon temperature increase. Typically, the Doppler effect is the primary component of the fuel temperature coefficient, but in fast spectrum reactors where the number of neutrons in the epithermal resonance peaks is limited; the Doppler effect may be comparable to reactivity reduction from the fuel thermal expansion effect. In the design optimized for maximum actinide destruction, the lack of fertile material further reduces the magnitude of the Doppler effect, which may even acquire positive values. Because it is the net effect of the Doppler and thermal expansion phenomena that is responsible for the prompt reactivity response to fuel temperature changes, the key constraint of any reactor design is a sufficiently negative value of the fuel temperature coefficient under all reactor conditions. This constraint has been adopted for both the actinide-burner design and concepts optimized for economic electricity production.

\subsubsection{Small Core Reactivity Initiators}

Another principle strategy of the safe core design is to eliminate or minimize the potential of inadvertent reactivity insertion that could lead to prompt criticality and loss of core integrity. The actinide-burner design is very challenging in this aspect because, in the absence of effective burnable poisons for a hard spectrum core, control rods are necessary to compensate for a large reactivity excess at beginning-of-life. Consequently, there exists a possibility that an inadvertent rod withdrawal can introduce excessive reactivity. The constraint adopted to prevent the core from reaching the prompt critical state in such a scenario is to limit the control rod worth of the most reactive control rods to $0.5 \$$. In addition, the control rod system needs to be designed to bound reactivity changes caused by control rod drive-line expansion to less than $0.5 \$$.

In the concepts optimized for electricity production, the freedom to employ fertile fuel and thus significantly reduce the reactivity swing during the cycle through internal breeding allows one to adopt an even more stringent requirement that eliminates the hypothetical possibility of reaching the prompt critical state. The constraint adopted for these designs is to limit reactivity swing to values less than $\beta$.

\subsubsection{Neutronics-Related Material Limitations}

The exposure of reactor materials to neutron flux inflicts damage on the lattice structure and can significantly alter the properties of these materials, after substantial fluence is accumulated. Therefore, the structural materials are subject to fluence limits. For fast reactor cores, different kinds of stainless steel serve as the material of choice for the cladding and core support structures. The issues of application of stainless steels in reactors with lead-based coolants were discussed in Section 3.2. Because fluence data for the lead-compatible stainless steels, such as the Russian EP-823 material, are not available, the fluence limit for the low-swelling stainless steel cladding 
HT-9 developed for the United States fast reactor program was adopted as a constraint. The demonstrated fluence limit for this type of steel is $3.8-4.0 \times 10^{23} \mathrm{n} / \mathrm{cm}^{2}$ (Hill et al. 1999).

Gaseous fission products produce swelling of fuels, which at high burnups can lead to cladding damage from pellet-cladding interaction. Thus, each fuel form is limited by some maximum burnup. Ternary (UPuZr) metal alloy pins in HT-9 ferritic cladding have achieved $200 \mathrm{MWd} / \mathrm{kg}$ peak discharge burnup and are qualified and demonstrated for $150 \mathrm{MWd} / \mathrm{kg}$ peak discharge burnup and $100 \mathrm{MWd} / \mathrm{kg}$ average burnups (Hill et al. 1999). These values were adopted as constraints for fertile metallic fuels, where a major fraction $(90 \mathrm{wt} \%)$ consists of heavy metal. This constraint is relaxed for the actinide-burner design, where fertile material is absent and the major fraction of the fuel is the zirconium matrix ( $74 \% \mathrm{Zr}$ in comparison to $10 \% \mathrm{Zr}$ for the ternary metallic fuel). With such a large fraction of zirconium, it is expected that the fuel should be able to withstand these burnups with fission product loadings similar to conventional LWR fuel rods. However, research and experimental demonstration that the fuel can withstand these burnups will be required.

\subsection{TEMPERATURE CONSTRAINTS}

\subsubsection{The Fuel}

The fuel of the actinide-burning core presented in Section 4.1.1, is made of plutonium and minor actinides $(\mathrm{Pu}+\mathrm{MA})$ dispersed in a matrix of metallic zirconium. Due to the lack of experimental data for this fuel, a simplifying assumption is made that to a first approximation the thermophysical and thermodynamic properties of the minor actinides can be set equal to those of plutonium. This assumption should be rather accurate because of their similar chemical properties and because the minor actinides constitute only a small fraction of the fuel materials. Therefore an estimate of the melting point and crystalline phase transitions of the fuel can be gained from the phase diagram of the Pu-Zr binary alloy (see Figure 2). It can be seen that the alloy melting point (along with its crystalline stability) is an increasing function of the zirconium content.

There are two fuel batches of different zirconium content in the actinide-burning core $(71$ and $77 \% \mathrm{wt}$ ). In this range, the melting point of the $\mathrm{Pu}-\mathrm{Zr}$ alloy ranges from about 1600 to $1800^{\circ} \mathrm{C}$. This suggests that the fuel temperature limit be a function of the location in the core. To avoid complications, we shall conservatively assume that the maximum fuel temperature (occurring at the fuel pin centerline) is to be kept below $1400^{\circ} \mathrm{C}$, i.e. $200^{\circ} \mathrm{C}$ below the melting point of the $\mathrm{Zr} /(\mathrm{Pu}+\mathrm{MA})$ alloy in the fuel batch of minimum zirconium content. Although this choice is rather arbitrary, the thermal-hydraulic calculations presented in Section 4.4 demonstrate that the fuel temperature limit is much less constraining than the cladding and the vessel limits. Therefore an accurate definition of this limit is not strictly necessary. 


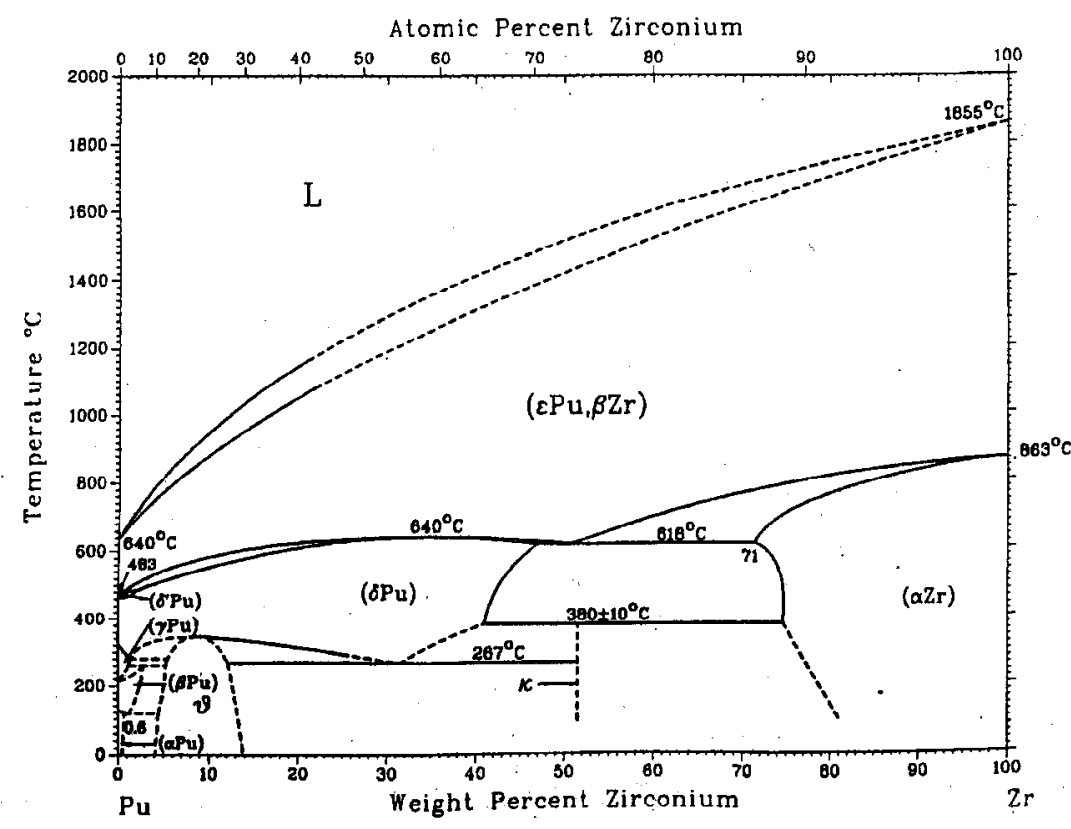

Figure 2. The phase diagram of Pu-Zr (from Hofman 1985).

\subsubsection{The Cladding}

Selection of a suitable cladding material for a lead-bismuth-cooled reactor is a serious technical challenge and an object of current studies within this project (see Section 4.2). Traditional austenitic stainless steels cannot be used due to the large solubility of nickel in bismuth, which would cause rapid selective leaching of that alloying element from the steel matrix and consequent loss of strength and integrity of the cladding. Also, given the hard neutron spectrum and the large burnup levels of typical lead-bismuth cooled systems, the cladding radiation damage requirements are high. The possibility of employing low nickel stainless steels and/or less traditional materials (i.e. W, Nb, Ta) is currently being explored in the United States (Weeks 1998, Li 1999, Loewen et al. 2000), in Israel (Tsirlin et al. 1999) and in Japan (Takahashi et al. 2000).

In the past, a martensitic/ferritic steel of low nickel content $(<1 \mathrm{wt} \%)$ has been extensively tested by the Russians within their lead-bismuth cooled reactor program and it was concluded that it is suitable for cladding purposes at temperatures up to $600-650^{\circ} \mathrm{C}$ (Adamov et al. 1997, Gromov et. al. 1994). In the Russian literature this steel is designated as EP-823 and its composition is reported in Table 1. Note that the chemistry of EP-823 is similar to that of the Western martensitic/ferritic steel HT-9. Because to date EP-823 is the only proven material for leadbismuth applications, we select it as the reference cladding material of the lead-cooled reactors examined in this study.

Table 1. Martensitic/ferritic steel composition (\%wt).

\begin{tabular}{|l|l|l|l|l|l|l|l|l|l|}
\hline & Cr & Ni & Mo & Si & V & Nb & W & C & Mn \\
\hline EP-823 & 12 & 0.8 & 0.9 & 1.3 & 0.4 & 0.4 & 0.8 & 0.2 & 0.6 \\
\hline HT-9 & 12 & 0.5 & 1.0 & 0.2 & 0.3 & 0.3 & 0.5 & 0.2 & 0.6 \\
\hline
\end{tabular}


The gap between the cladding and fuel requires bonding material to enhance thermal conductivity. The proven bonding material from the Argonne National Laboratory IFR program is sodium. However, to avoid the use of another material in the core, pure lead was selected as the bond between the fuel pellets and the stainless steel cladding. A research program will be required to confirm its compatibility with zirconium-based fuel and stainless steel cladding. Sodium bonding as in the Experimental Breeder Reactor II (EBR-II) and IFR is an alternative in case lead does not provide satisfactory performance. In any event, the amount of bonding agent is not large enough to significantly affect the core neutronic characteristics presented in the fuel section.

The maximum cladding temperature occurs at the cladding inner surface and, therefore, one would expect to observe the largest rate of corrosion there. However, the lead inventory between the cladding and the fuel is small and quickly becomes saturated with the products of steel dissolution (e.g. iron, chromium), which prevents further dissolution. On the other hand, the dissolution products are carried away at the cladding outer surface by the lead-bismuth coolant flow and further dissolution of the cladding can proceed. Thus, it is clear that the cladding temperature limit should actually be set on the cladding outer surface. In this study, the cladding limit is set equal to $650^{\circ} \mathrm{C}$ under normal operating conditions. Other investigators have adopted a more conservative limit at $600^{\circ} \mathrm{C}$ (Spencer et al. 2000). However, the cladding temperature is allowed to reach $750^{\circ} \mathrm{C}$ during transients and loss-of-heat-sink situations because the expected duration of these high temperature conditions is short. The choice of $750^{\circ} \mathrm{C}$ (i.e. $100^{\circ} \mathrm{C}$ above the steady-state limit) is somewhat arbitrary and a more accurate selection of this limit will be made in the future when corrosion data on the cladding materials becomes available.

\subsubsection{The Reactor Vessel}

For a given material, temperature and stresses are related because the maximum acceptable stress depends on the material strength, which generally decreases with temperature. This dependence is illustrated for the ferritic/martensitic stainless steel HT-9 in Figure 3. Note that due to thermal creep, the stress limit depends also on the operating time at high temperature. Using Figure 3, the temperature limit of the reactor vessel was established on the basis of a structural analysis by Buongiorno et al. (1999). Figures 4 and 5 illustrate this limit as a function of the vessel thickness, diameter $\left(D_{v}\right)$ and height ${ }^{4}\left(L_{v}\right)$. For example, for a reference $5 \mathrm{~cm}$ thickness, $6 \mathrm{~m}$ diameter, and $15 \mathrm{~m}$ height, the temperature limit is about $540^{\circ} \mathrm{C}$. Note that this limit is set on the membrane temperature (i.e. the temperature average across the vessel thickness). This coincides with the surface temperature under normal operating conditions (because there is no thermal gradient across the vessel), but differs from it in a loss-of-primary-heat-sink situation where the decay heat is discharged to the environment through the reactor vessel.

\footnotetext{
${ }^{4}$ The parameter $\mathrm{L}_{\mathrm{v}}$ is actually the length of the vessel cylindrical body at the ends of which two hemispherical heads are attached.
} 


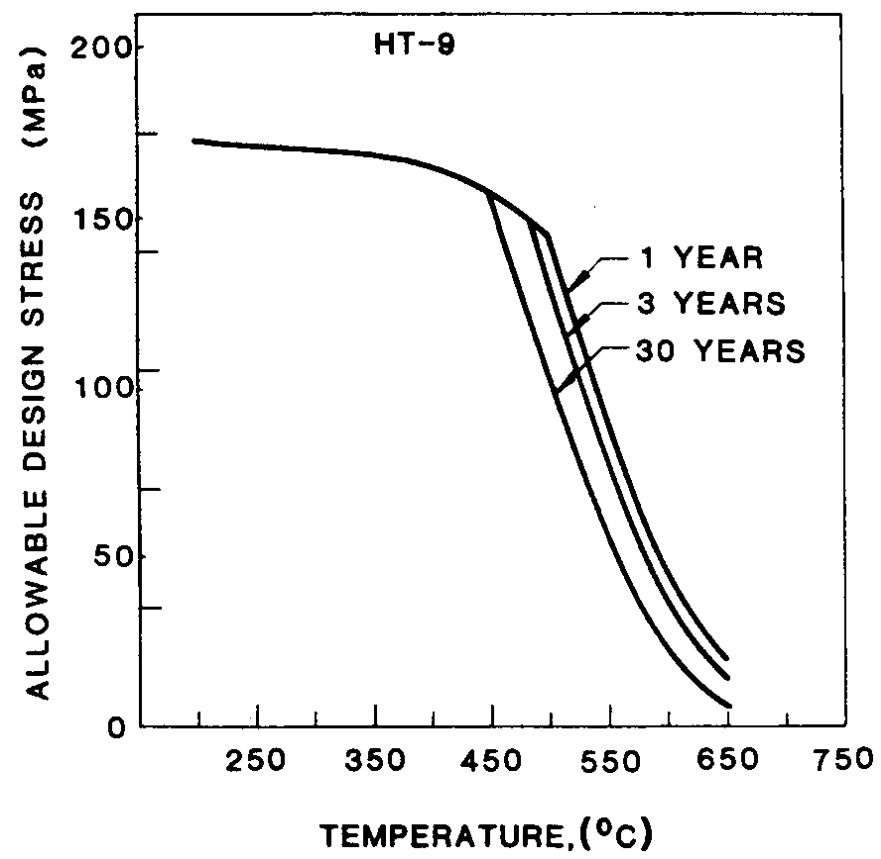

Figure 3. HT-9 allowable stress intensity (from Amodeo 1985).

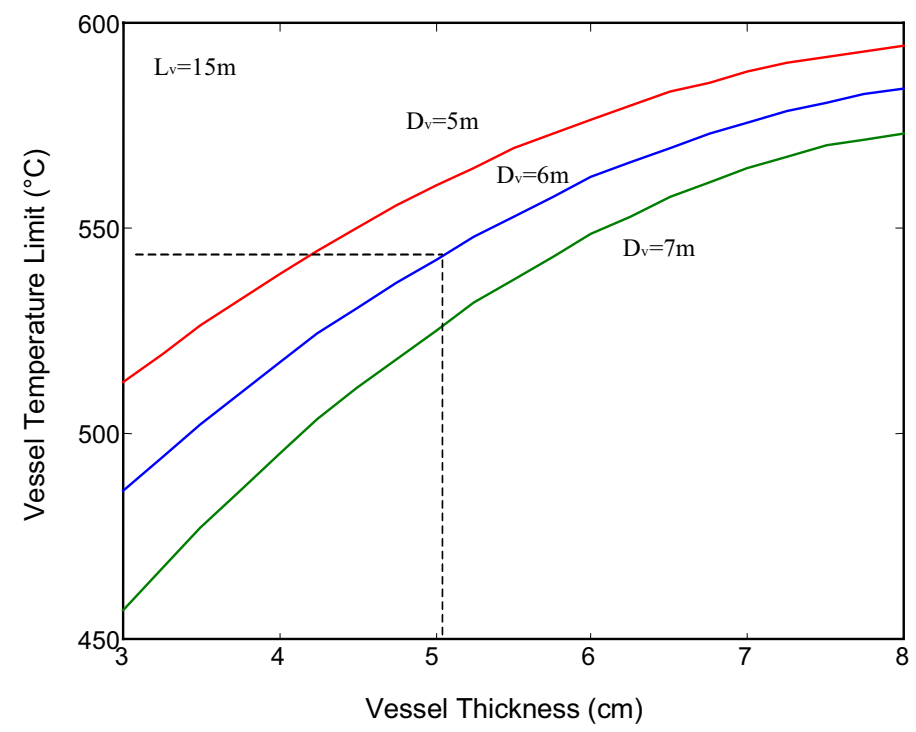

Figure 4. The diameter effect on the vessel temperature limit. 
Annual Project Status Report

July 2000

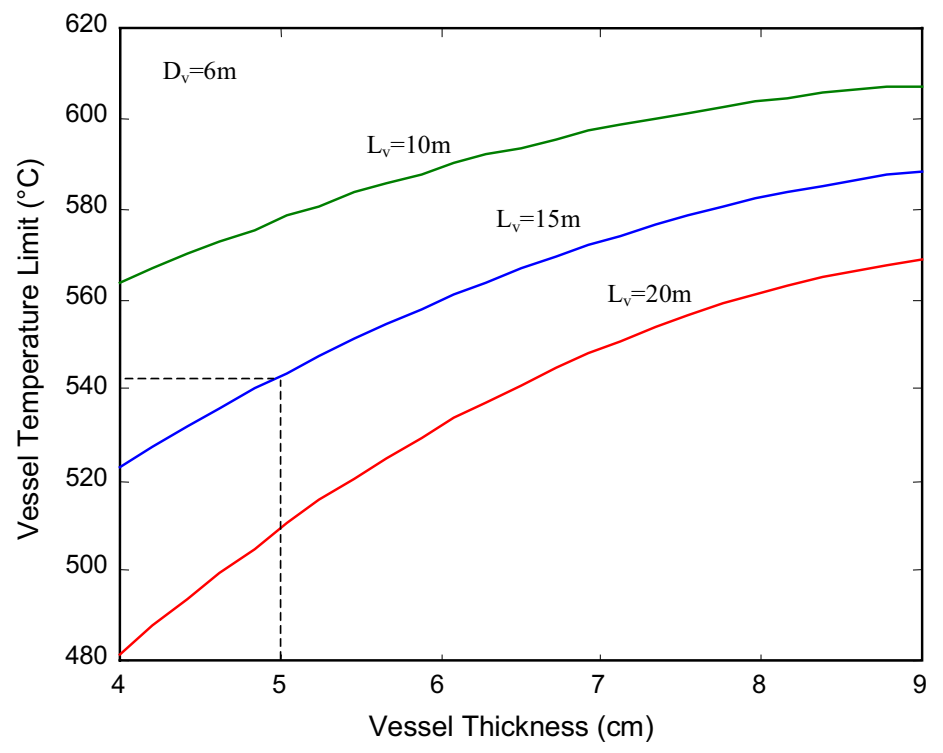

Figure 5. The height effect on the vessel temperature limit. 


\section{Technical Results}

\subsection{Neutronic Core Design}

Three alternatives have been explored as discussed in Chapter 1. The concept optimized for maximum actinide burning will be described in Section 4.1.1. Since the economic analysis showed that reprocessing is costly, an option that does not require reprocessing and would result in low cost electricity production was explored - see Section 4.1.2. Finally, the design approaches that strive for striking a balance between effective actinide burning and low cost electricity production will be presented in Section 4.1.3.

The results presented throughout this report were obtained from the Monte Carlo N-Particle Transport (MCNP) code (Briesmeister 1986), developed at LANL. The depletion studies used the MOCUP code (Moore et. al. 1995), which couples MCNP and the ORIGEN-2.1 code (Croff, 1980), developed at Oak Ridge National Laboratory (ORNL). MCNP determines neutron fluxes and reaction rates in generalized 3-D geometries and ORIGEN2 uses a matrix exponential method to determine the isotopic generation/depletion rates in the system. Sixty-two fission products accounting for $95 \%$ of the absorptions of all the fission products and 37 actinides were tracked in all MOCUP calculations.

\subsubsection{Concept Optimized for Actinide Burning}

One of the major thrusts of the design of the actinide-burner reactor was, in addition to maximizing actinide transmutation capabilities, the effort to overcome positive coolant void worth typical for fast reactors of large dimensions. The approach typically undertaken in liquid metal reactor sodium-cooled designs was to limit the reactivity rise from coolant voiding to such values that Doppler and other feedback mechanisms hold the core below prompt critical for an extended period of time. This allows the core to be permanently shut down with minimal energy generation (Bailey 1977). However, in the fertile-free core of the actinide-burner design (where the Doppler effect is small and the effective delayed neutron fraction is relatively low because of the absence of U238, which has large $\beta_{\text {eff }}$ ) the reliance on negative fuel temperature feed backs is restricted, hence it is important to strive for negative coolant void worth.

Considering the potential threats discussed in Section 2.1.1 we set up as one of the key objectives of this project to develop an actinide-burner core that exhibits negative coolant void worth even in case of local non-homogenous voiding (termed also partial voiding) in the central core region. Having a core with local negative coolant reactivity coefficient as an inherent feature significantly eases concerns with potential void formation within the core from any scenario and eliminates the need to prove deterministically that these voids cannot lead to rapid reactivity insertion and potentially to core disruptive events.

A number of approaches were undertaken to resolve positive coolant void worth problem, as discussed in Hejzlar et al. (1999). The resulting design that satisfies the above goal for the fertilefree metallic fuel with its important neutron physics characteristics is described in Section 4.1.1.1. 


\subsubsection{Neutron streaming assembly design}

The arrangement of the streaming fuel assembly is shown on Figure 6. The design of a streaming fuel assembly allows streaming of neutrons in both radial and axial directions directly from the center of the core. A number of streaming fuel assemblies and core configurations have been investigated. The arrangement in Figure 6 gives the best coolant void reactivity behavior and concurrently provides the possibility of control-rod drive cooling and low axial power

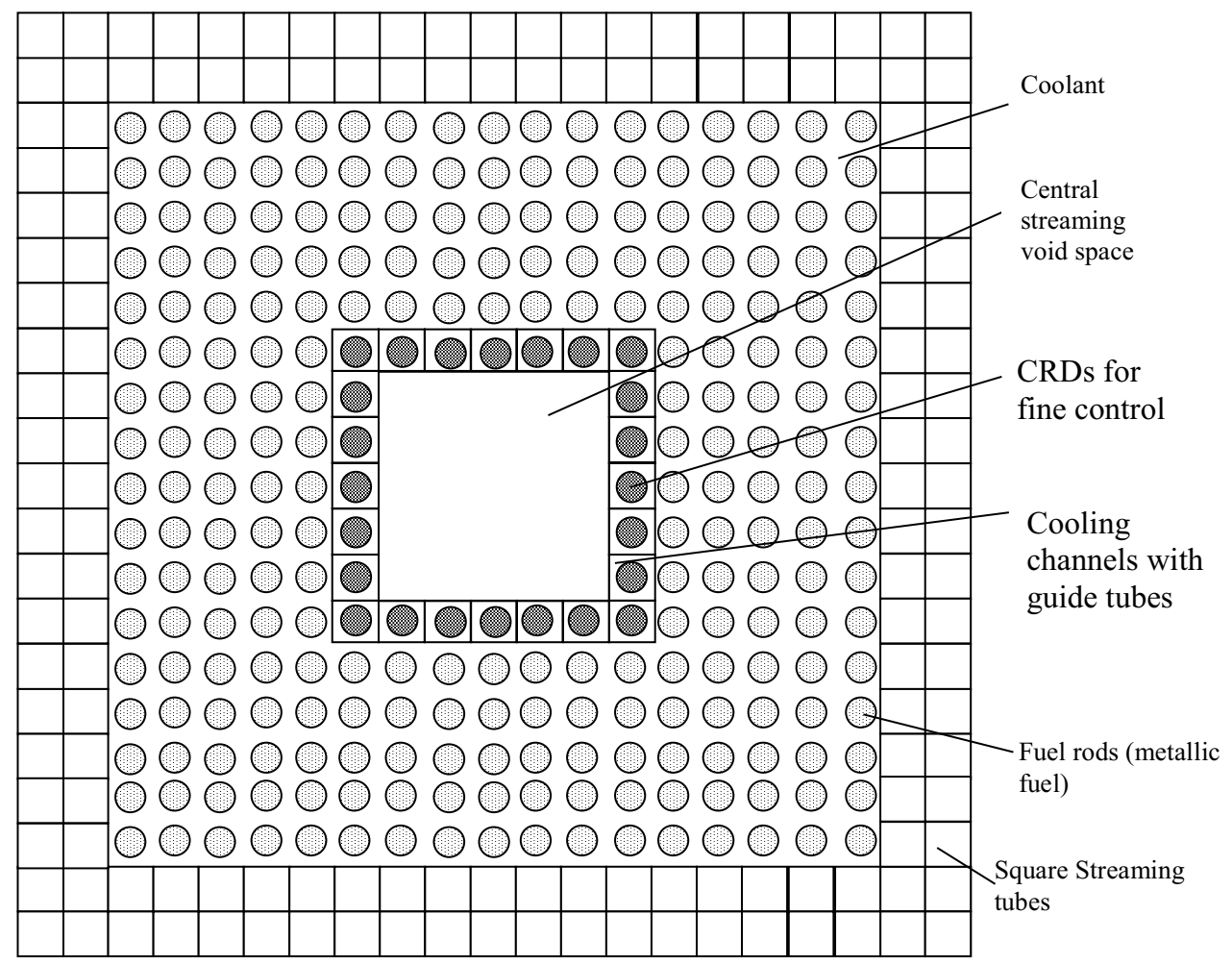

Figure 6. Streaming fuel assembly with cooled control-rod drives.

peaking. The assembly contains $21 \times 21$ positions with 240 fuel rods, 152 square streaming tubes arranged in two rows at the fuel assembly periphery, and $7 \times 7$ positions in the fuel assembly center. The streaming tubes are filled with gas and sealed. In addition to their neutron streaming function, they also provide structural support, making the elimination of tie rods possible. In case of failure of a streaming tube, the tube will be flooded with coolant leading to a very small reactivity increase. To achieve a significant reactivity change in such a scenario, a large number of these tubes would have to be flooded. Widespread void flooding is thus extremely unlikely. The thickness of the walls of the square tubes was taken the same as that of cladding, i.e., 0.63 $\mathrm{mm}$. The central region of each fuel assembly contains a $5 \times 5$ void space to enhance neutron streaming. The high leakage from the streaming fuel assemblies requires increased TRU inventory - about 1.3 times that of a void-free core design, which is not an economic penalty in the intended service, but would be for a conventional power-only fast breeder reactor. The main data employed in neutronic analysis are summarized in Table 2. 
Table 2. Design parameters of neutron transparent core with streaming fuel assemblies.

\begin{tabular}{|c|c|}
\hline Design parameter & Value \\
\hline Fuel pellet outside diameter & $8.64 \mathrm{~mm}$ \\
\hline Fuel composition & $23 \mathrm{wt} \%, 29 \mathrm{wt} \%{ }^{*}$ of $\mathrm{Pu}+$ actinides, $74 \mathrm{wt} \%$ of $\mathrm{Zr}$ \\
\hline Gap thickness (lead bond) & $0.2 \mathrm{~mm}$ \\
\hline Cladding thickness & $0.63 \mathrm{~mm}$ \\
\hline Pin outside diameter & $10.3 \mathrm{~mm}$ \\
\hline Pitch & $12.55 \mathrm{~mm}$ \\
\hline Pitch to diameter ratio & 1.2 \\
\hline Heated core length & $1.3 \mathrm{~m}$ \\
\hline Gas plenum height & $1.5 \mathrm{~m}^{* *}$ \\
\hline Number of fuel assemblies & 157 \\
\hline Number of positions in fuel assembly & $21 \times 21$ \\
\hline Number of fuel rods per fuel assembly & $240(17 \times 17$ array $)$ \\
\hline Number of control-rod drive fingers per fuel assembly & 24 \\
\hline Number of void positions in fuel assembly center & $5 \times 5$ \\
\hline Control rod material & $\mathrm{B}_{4} \mathrm{C}(90 \% \mathrm{~B} 10)$ \\
\hline Equivalent core diameter & $3.73 \mathrm{~m}$ \\
\hline Core barrel thickness & $2 \mathrm{~cm}$ \\
\hline Down-comer thickness & $0.7 \mathrm{~m}$ \\
\hline Thickness of the lead-bismuth layer in lower plenum & $1.5 \mathrm{~m}$ \\
\hline Thickness of the lead-bismuth chimney above core & $5 \mathrm{~m}$ \\
\hline Fuel density & $\mathrm{Pu}+\mathrm{Act}-\mathrm{Zr} ; 7.48 \mathrm{~g} / \mathrm{cm}^{3}$ (theoretical) \\
\hline Coolant & lead-bismuth \\
\hline Core-average coolant temperature and density & $480{ }^{\circ} \mathrm{C} ; 10.25 \mathrm{~g} / \mathrm{cm}^{3}$ \\
\hline Temperature of lead-bismuth coolant in the chimney & $600^{\circ} \mathrm{C}$ \\
\hline Temperature of lead-bismuth coolant in lower plenum & $180^{\circ} \mathrm{C}$ \\
\hline \multicolumn{2}{|c|}{$\begin{array}{l}{ }^{*} \text { In the initial core, the outer core region contains } 29 \mathrm{wt} \% \text { TRU-enriched fuel; the inner core region is } \\
\text { loaded with } 23 \mathrm{wt} \% \text { TRU-enriched fuel. } \\
{ }^{* *} \text { The plenum accommodates gaseous fission products. The size was selected relative to fuel pin height } \\
\text { based on IFR fuel experience. Detailed calculations of fission gas release were not performed for this } \\
\text { metallic fuel. }\end{array}$} \\
\hline
\end{tabular}

The control rods are made of $\mathrm{B}_{4} \mathrm{C}$ with $90 \% \mathrm{~B}-10$ enrichment and are utilized for both reactivity compensation and control. High neutron heating requires cooling of the control-rods with coolant. This can be effectively achieved by placing the control rods for reactivity compensation and control outside of the voided space, as indicated on Figure 6. The guide tubes direct the control-rod drive movement and protect the control-rod drives from jamming in case of fuel rod bowing against the control-rod drive channels. The control-rod drives have ample margin to shut down the reactor. In addition, the central void boxes can contain normally out-of-core backup safety rods used only for emergency shutdown: for example if operational control rods are denied entry by coolant freezing, oxide slag accumulation, or buoyancy forces. These scram rods do not require cooling during normal operation. During shutdown, radiative cooling will be sufficient.

The fuel is a metallic alloy of zirconium matrix, plutonium and minor actinides, arranged in a square pitch. Heavy metal (plutonium and minor actinides) enrichment was set to $20 \mathrm{wt} \%$ to 30 $\mathrm{wt} \%$ so that zirconium occupies $80 \mathrm{wt} \%$ to $70 \mathrm{wt} \%$ of the fuel cylinder. The isotopic composition of plutonium and minor actinides corresponds to that of pressurized water reactor (PWR) discharge fuel. The cladding and structural material was assumed to be made of special stainless steel, designated EP-823, developed by the Russians for their lead-bismuth-cooled reactors. 
Lead-bismuth-tin alloy (33wt $\%$ lead-33wt\%Sn-33wt\%bismuth) was selected as a bond between the fuel pellets and stainless steel cladding. This material was found to be compatible with Zircaloy-4 (Wright et al.1996), although for LWR conditions. Therefore, a research program will be required to confirm its compatibility with zirconium-based fuel and stainless steel cladding. Sodium bonding as in EBR-II and IFR is an alternative in case the lead-bismuth-tin alloy does not provide satisfactory performance. In any event, the amount of bonding agent is not large enough to significantly affect neutronics, which are the focus of the present study.

\subsubsection{Control rod design}

To minimize the axial power peaking, the control rod system employs both top- and bottom-entry rod insertion, as indicated on Figure 7. Half of the control rods are inserted from the top into the core and the other half are pulled into the core from the bottom. Control rod drives for both these sets of control rods can be mounted on top of the core or vessel or bottom, as in a boiling water reactor (BWR). Top mounting of bottom control rods is the preferred configuration because it provides significantly smaller reactivity changes from the expansion of the control-rod drive lines than bottom mounting.

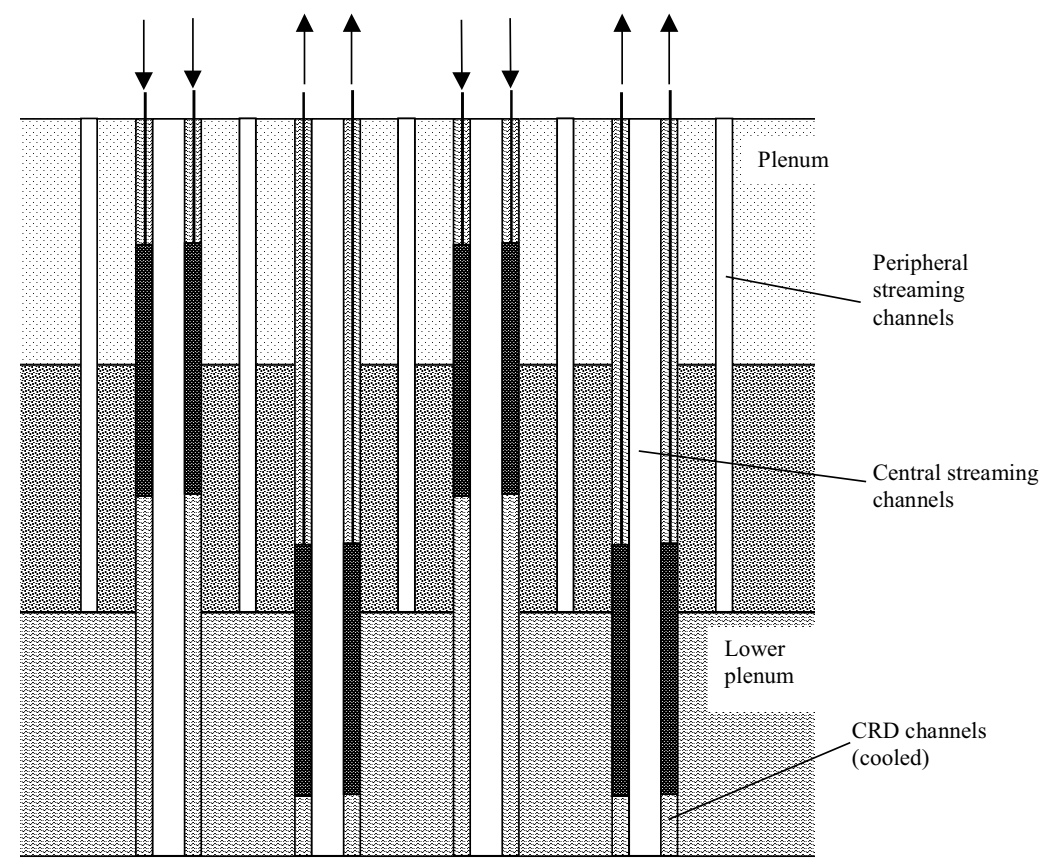

Figure 7. Schematic of the arrangement of double-entry control rods.

Bottom and top control-rods are arranged in a staggered "checker-board" layout. The bottomentry control-rods reside in the extended space between the core lower plate and core bottom. The bottom-entry control-rods are made of boron carbide, which has about four times lower specific density than lead-bismuth coolant, hence they are drawn into the core by the buoyancy forces. To attain passive insertion of top-entry control-rods by gravity, tungsten boride (WB), which has higher density than lead-bismuth, can be used for the control material. Another alternative is to use tungsten slugs above and below the control-rod active height to achieve gravity-driven insertion. Both alternatives were analyzed for coolant void coefficients and found to perform satisfactorily. The simple thermal hydraulic analysis showed that tungsten boride control-rods alone do not provide a sufficient gravity force against the upward buoyancy and flow 
forces to attain gravity insertion. This feature can be achieved by adding tungsten slugs below and above control-rod active height. However, tungsten has about a 3 times smaller linear coefficient of thermal expansion than stainless steel, which leads to an appreciable reactivity insertion from control-rod drive line expansion". In addition, the tungsten slugs below the control-rods parasitically absorb neutrons in the withdrawn control-rod position, which leads to lower reactivity and limited burnup. Therefore, boron carbide has been selected as the material for top-entry control-rod drives.

Because the excess reactivity at beginning-of-life that is compensated by the control rods is high, the design must ensure that the rod worth is less than $\beta$ and that ejection of more than one rod is prevented. Therefore, each of the 157 fuel assemblies has one control-rod with a separate drive. The worth of one control-rod with the highest reactivity compensation was calculated to be $0.5 \$$. Thus, ejection of one control-rod does not lead to prompt criticality. Moreover, to eliminate control rod ejection, dropout, or run-out events, a system of control-rod drives with two poison sections separated by a non-absorbing or void section with stops has been introduced as discussed in Hejzlar et al. (2000).

The proposed double-entry control rod system significantly flattens the axial power profile and increases the control rod worth (in comparison with top-entry only control-rod drives). This allows a substantial reduction of the B-10 enrichment and control-rod drive outer diameter, or a reduction of the number of control rods. Also, the reactivity sensitivity to control-rod position, which is very high in the top-entry alternative (due to location of the control-rod tip in a high-flux region) is reduced. Another advantage of this core design is better performance in the partial core-voiding scenario due to more effective leakage into the region below-the-core, which is equipped with control-rod drives that increase neutron losses in this region. Finally, this system allows one to achieve very small or even zero reactivity changes from control-rod drive line expansion, in spite of the large reactivity excess compensated by the control-rods at beginning-oflife. This is because of concurrent insertion and withdrawal of top- and bottom-entry controlrods, respectively, upon heating, thereby canceling out reactivity perturbations due to the expansion/contraction of only one control-rod group.

Typically, reactivity change per $1 \mathrm{~cm}$ of drive-line extension is calculated to indicate the system response to drive-line expansion. This scenario was simulated through inserting the top-entry control-rod drives into the core by $1 \mathrm{~cm}$ and simultaneous withdrawal of the bottom-entry control-rod drives by $1 \mathrm{~cm}$. The effective multiplication factor in this event was reduced from $1.00379 \pm 0.0005$ to $1.00277 \pm 0.0005$, i.e., a reactivity decrease by $0.4 \$$. The reason is a higher worth of the top-entry rods due to the gas plenum above the core, which allows more neutrons to stream into the top control-rod drives. However, the identical elongation of both the top- and bottom-entry drive-lines does not represent correctly the reactivity response to heat-up of drivelines because the drive-lines of the top-entry control-rods are shorter than the bottom-entry ones and will experience a larger stretch. If the drive-lines are made of stainless steel, the elongation of the top-entry control-rod drives for a temperature change of $+500{ }^{\circ} \mathrm{C}$ can be calculated to be $+3.32 \mathrm{~cm}$ and of the bottom-entry drive-lines $4.2 \mathrm{~cm}$. The reactivity change for such an adjustment of control-rod drive position was calculated to be $+0.4 \$$, i.e. an undesirable trend.

\footnotetext{
* Top-entry tungsten control-rod drive lines expand significantly less than the drive-lines of the bottomentry control-rods. Because the bottom-entry control-rod drives are withdrawn from the core upon driveline expansion, while top-entry control-rod drives are inserted into the core, the net effect is a reactivity increase.
} 
There are two design possibilities that minimize reactivity worth from control-rod drive-line expansion. The first involves the use of different drive-line material for the top-entry control-rod drives, i.e., with a larger linear temperature expansion coefficient. Because material compatibility requirements with lead-bismuth eutectic are strict, the search for such materials can be difficult. The second approach is to make the drive-line length of both the top-entry and bottom-entry control-rod drives the same. This can be done for example using a staircase reactor vessel head.

Ideally, reactivity worth from the control-rod drive-line expansion should exhibit small negative values or equal zero. MCNP calculations show that zero reactivity worth can be attained if the bottom-entry control-rod drive drive-lines expand by $3.7 \mathrm{~cm}$ and the top-entry ones by $3.3 \mathrm{~cm}$. This is ensured by the staircase vessel head configuration with a step height of $90 \mathrm{~cm}$. An alternative solution is to use a flat vessel head and make the top-entry drive-lines from metal with a 30\% larger linear temperature expansion coefficient than that of the bottom-entry drive-lines.

\subsubsection{Enrichment Zoning, Batch Refueling Strategy and Power Distribution}

The initial core employs two different levels of enrichment. Low-enriched fuel ( $23 \mathrm{wt} \%$ of TRU) is loaded in the core central region and fuel with higher TRU enrichment $(29 \%)$ on the core periphery. The goal is to attain an operating interval between refueling at the desired 1.5 years in a 2-batch cycle.

The layout of the core with two enrichment levels is shown in Figure 8. Figure 8 also illustrates

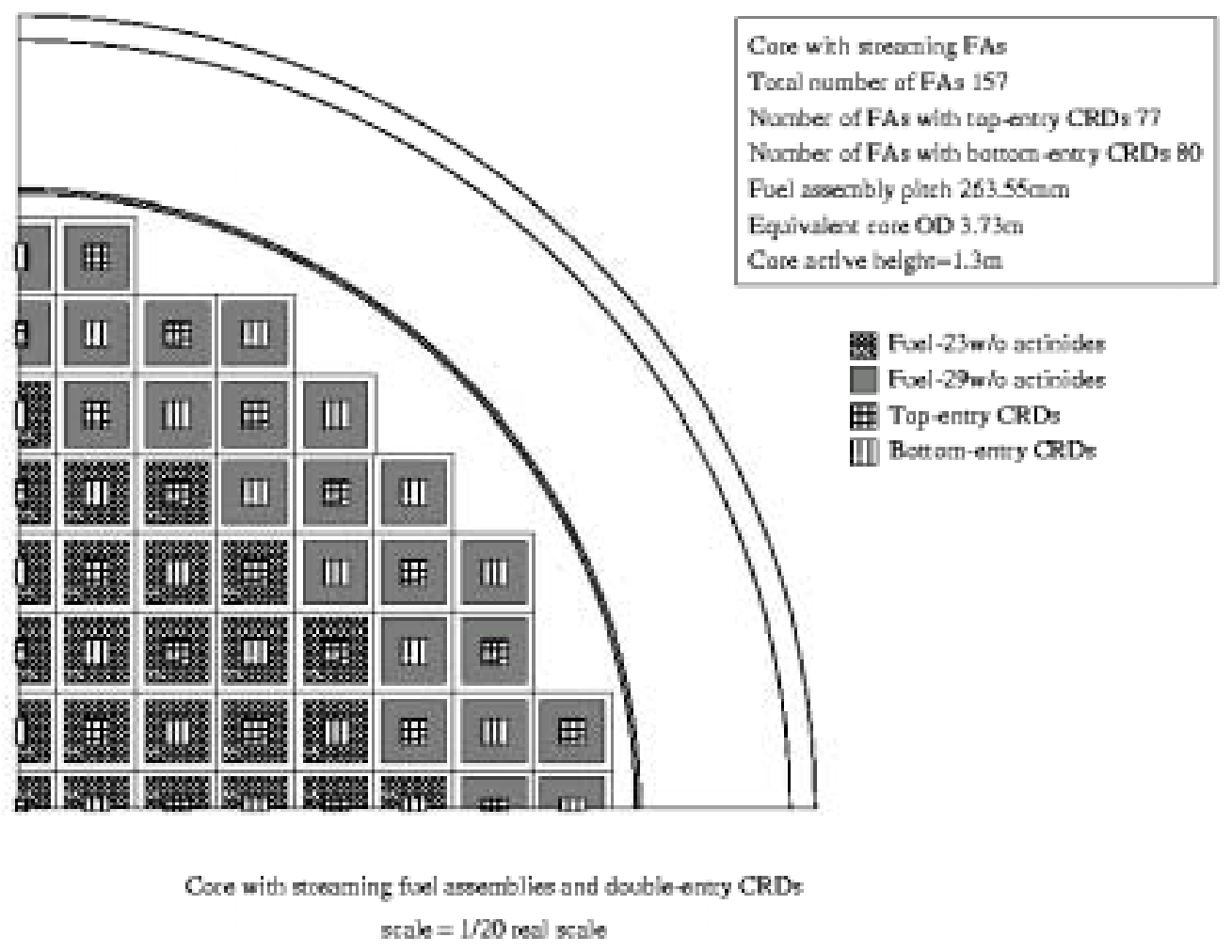

Figure 8. Core with streaming fuel assemblies and double entry control-rod drives. 
the staggered arrangement of the top-entry and bottom-entry control rods. The core contains 157 streaming assemblies. It has an equivalent core diameter of about $3.7 \mathrm{~m}-\mathrm{a}$ size, which is larger than that of a typical PWR core. The larger core dimensions result in lower volumetric power density $(126 \mathrm{~kW} / 1)$ in comparison with typical liquid metal reactor cores, but higher than in a PWR core due to significantly smaller core height.

Figure 9 shows the very small radial power peaking of the proposed core. Note the extremely flat neutron flux (averaged over all energies and all fuel pins within each assembly) profile across the core on Figure 10. This extremely flat neutron flux profile is a consequence of a large mean free path and very strong neutronic coupling. The large mean free path and tight coupling have crucial impacts on neutron physics. First, the instabilities in flux distribution, which can be a problem in large fast reactor cores (Shirakata et al. 1999), are eliminated and the proposed core concept can be scaled up without concerns about considerable changes of radial flux/power shapes in response to perturbations. Secondly, the space-dependency of neutron kinetics is significantly reduced and point kinetics analysis should provide accurate results. The proposed core should be highly stable against the above phenomena. Complex measures to mitigate both

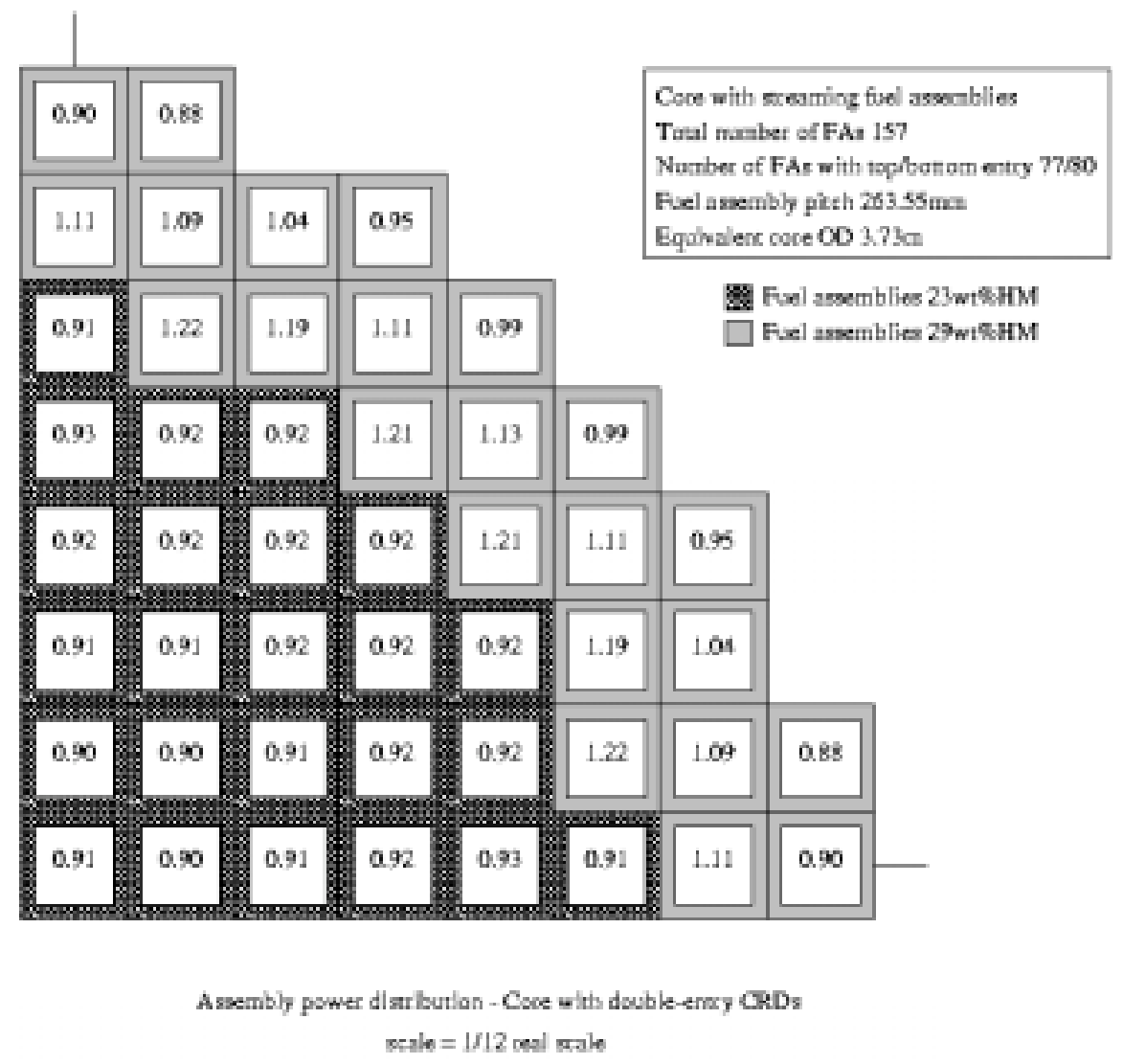

Figure 9. Assembly power distribution in the core with streaming fuel assemblies and double entry control-rod drives. 


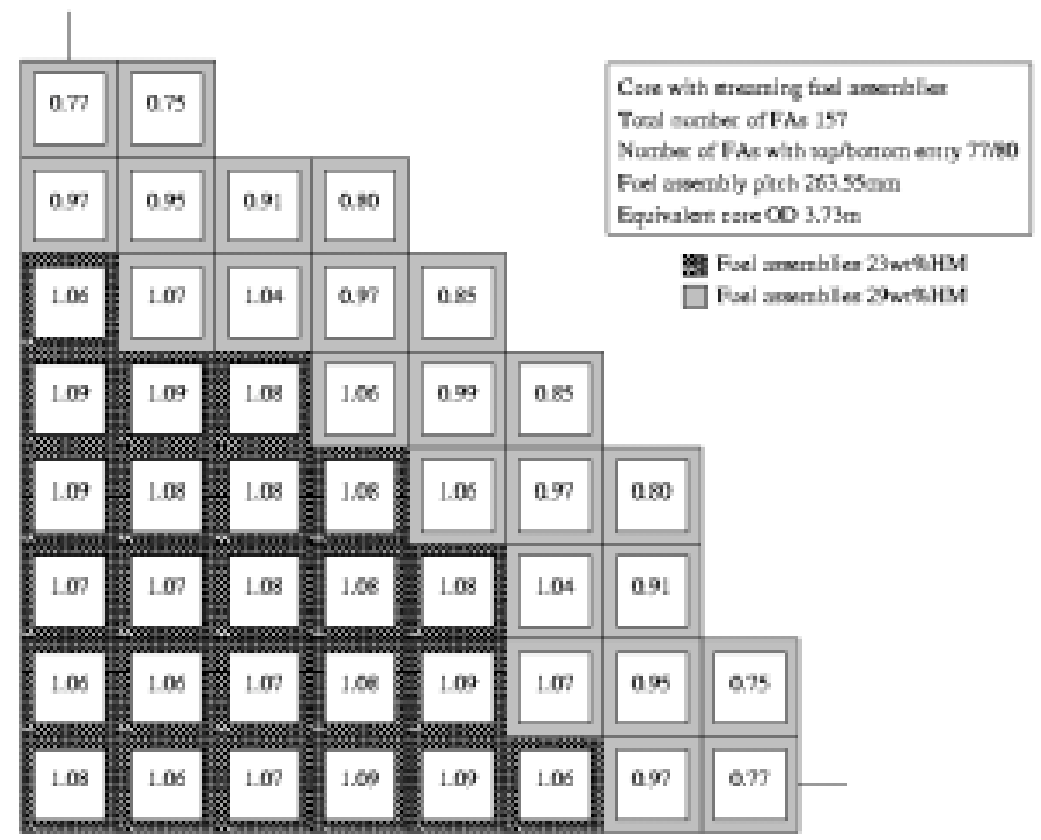

A renbly pover distibution - Care with dacble-entry ORD, stait $=1812$ ieal scale

Figure 10. Neutron flux profile in the core with streaming fuel assemblies and double entry control-rod drives.

the instability in flux distribution due to perturbation and the space dependency of kinetics will not need to be employed, simplifying the design. Eventually, of course, this will have to be confirmed by transient calculations. However, because of the large reactivity compensation by the control-rods, measures have to be taken to uniformly distribute the control-rods and thus avoid local hot spots.

The axial power profile also exhibits small peaking. Figure 11 plots the axial power distribution

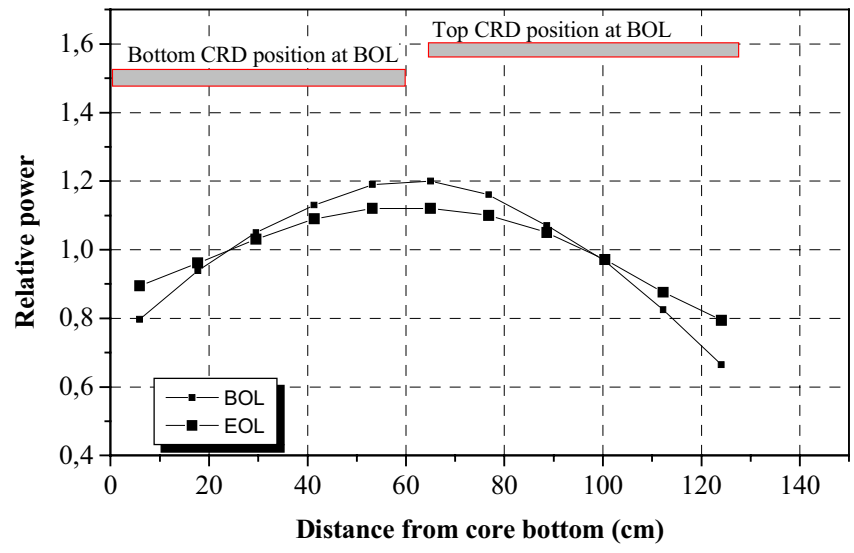

Figure 11. Axial power distribution. 
in the core outer region where axial peaking is slightly higher. The relatively flat (power peaking of 1.2) and symmetric power profile proves the effectiveness of the double-entry control rod system (compare with power peaking of 1.8 in the top-entry-only control-rod drive design).

The positions of the control rods at beginning-of-life that make the reactor critical are also indicated. Note that driving the rods all the way to their terminal positions gives a huge shutdown margin. Therefore, some of the control-rods could be mounted on diverse drives and used for fast scram. One technical solution is to equip selected control-rod drives with electro-hydraulic drive mechanisms, as in the ABWR, where hydraulic drive accomplishes scram and electromechanical nut and screw drive provides for fine control. Excellent experience with these drives has been obtained in Siemens and ABB-Atom's BWRs.

\subsubsection{Reactivity Void Worth}

Table 3 summarizes reactivity performance of the proposed design for the initial core. All disturbances lead to a reactivity decrease. Calculations were also performed for the end of the 1 st and 2 nd cycle and equilibrium composition (assumed to be the same as for ATW). The coolant density coefficient remains negative for all burnup states and the local coolant void worth exhibits either small negative values or is zero. Also note that the worth of the most reactive control-rod is below $1 \$$ - an important safety feature in case of inadvertent control-rod withdrawal.

Table 3. Reactivity performance of the core with streaming assemblies.

\begin{tabular}{|ll|}
\hline Description & $\mathbf{k}_{\text {eff }}$ \\
\hline Reference case $\left(\text { core-average coolant density }=10.25 \mathrm{~g} / \mathrm{cm}^{3}\right)^{1}$ & $1.0081 \pm 0.0006$ \\
Core-average coolant density $=8 \mathrm{~g} / \mathrm{cm}^{3}$ & $1.0020 \pm 0.0007$ \\
Core-average coolant density $=6 \mathrm{~g} / \mathrm{cm}^{3}$ & $0.9943 \pm 0.0007$ \\
Core-average coolant density $=0 \mathrm{~g} / \mathrm{cm}^{3}$ & $0.9246 \pm 0.0007$ \\
The most reactive fuel assembly is partially voided ${ }^{2}$ & $1.0068 \pm 0.0006$ \\
All compensation control-rod drives withdrawn & $1.2276 \pm 0.0007$ \\
Peripheral streaming tubes of the core central fuel assembly flooded & $1.0071 \pm 0.0007$ \\
Central void region of the core central fuel assembly flooded & $1.0067 \pm 0.0007$ \\
Average control-rod worth & $0.5 \$$ \\
Worth of the most reactive compensating control-rod & $0.7 \$$ \\
\hline${ }^{1}$ For all cases, bottom and top control-rod are inserted 60cm in the core, unless noted otherwise \\
${ }^{2}$ Partially voided central 50\% of the most reactive (central) fuel assembly \\
${ }^{3}$ Flooded with coolant to simulate massive failures of sealed streaming tubes
\end{tabular}

An extensive study has been undertaken to investigate the effect of void distribution throughout the core on coolant void worth (Hejzlar et al. 2000). The conclusions from this study can be summarized as follows:

1. The arrangement of streaming tubes is important in the achievement of negative coolant void worth in scenarios with partial core voiding.

2. Clustering of streaming tubes is beneficial as it allows better streaming and improves the spectrum driven component. A uniform distribution of small streaming tubes provides the worst coolant void worth behavior.

3. The size and location of the clustered streaming region also affects the coolant void coefficient. Streaming regions in the center of the fuel assemblies that are too large can even render the leakage component positive. 
4. The relative placement of control rods and streaming tubes appreciably affects reactivity prior to voiding. Location of control rods in the vicinity of fuel pins, far from the streaming tubes leads to lower reactivity, while placement of control rods in streaming regions further from fuel pins leads to a reactivity increase.

5. The best configuration appears to be a combination of a small central streaming region and peripheral streaming paths allowing streaming of neutrons out of the core upon partial voiding. The control rods should be located in such a manner that they are at least partially exposed to a streaming region to maximize the reactivity of the no voiding case and at the same time allow their cooling. The reference case, shown in Figure 6, satisfies all these desirable characteristics and exhibits the best performance.

\subsubsection{Effective Delayed Fission Neutron Fraction $\beta_{E F F}$}

The effective delayed neutron fraction was calculated using the MCNP option to turn off the effect of delayed neutrons on criticality. A benchmark case for an LWR was run to evaluate how close MCNP can calculate the delayed neutron fraction (Hejzlar et al. 2000). The results from the full-core model of the actinide-burner design at beginning-of-life are compared with the effective delayed neutron fraction of other fast reactors in Table 4.

Table 4. Comparison of $\beta_{\text {eff }}$ with various fast reactor designs.

\begin{tabular}{|l|l|l|l|}
\hline Reactor & Fuel & $\boldsymbol{\beta}_{\text {eff }}$ & Reference \\
\hline \hline Super Phenix (France) & $\mathrm{UO}_{2}-\mathrm{PuO}_{2}$ & 0.004 & Waltar and Reynolds (1981) \\
\hline CDFR (UK) & $\mathrm{UO}_{2}-\mathrm{PuO}_{2}$ & 0.003 & Waltar and Reynolds (1981) \\
\hline SNR-2 (Germany) & $\mathrm{UO}_{2}-\mathrm{PuO}_{2}$ & 0.004 & Waltar and Reynolds (1981) \\
\hline Conventional IFR core & $\mathrm{Metallic} \mathrm{U-Pu-Zr} \mathrm{fuel}$ & 0.0034 & Hill et. al., (1995) \\
\hline Pure plutonium burner core & $\begin{array}{l}\text { Metallic Pu-28Zr + Hf-26Zr } \\
\text { fuel }\end{array}$ & 0.002 & Hill et. al., (1995) \\
\hline Actinide burner (BOL) & Metallic TRU-74Zr & $\mathbf{0 . 0 0 2 5}$ & Hejzlar et al. (2000) \\
\hline
\end{tabular}

One can observe that the delayed neutron fraction of the lead-bismuth burner is smaller than the values of typical oxide-fueled fast reactors. This is a result of the very small heavy metal loading, since all the U-238, which is present in fast reactors and which has a large delayed neutron yield was removed. On the other hand, the value of 0.0025 is better than the value of about 0.002 , which Hill et al. (1995) obtained for a sodium-cooled pure plutonium burner design. Nevertheless, it is clear that in combination with a large reactivity swing, the actinide-burner design poses significant safety challenges by having a very small margin to prompt criticality. A simple estimate for the equilibrium core (Hejzlar et al. 2000) shows slightly higher $\beta_{\text {eff }}(0.0028)$ due to a larger contribution of the TRU with a higher delayed neutron yield than that of the most abundant fissile nuclide in the fresh core (Pu-239).

\subsubsection{Doppler Coefficient.}

The Doppler coefficient was calculated using the MCNP code with the temperature dependent cross section libraries imported from the University of Texas (UTXS) (Abdelrahman and Abdurrahman 1998). However, it is to be noted that the temperature-dependent libraries for Am241 and Cm-244 were not available in the UTXS set and their effect on Doppler coefficient is not included in the calculations presented in this section. Since these actinides involve less than $10 \%$ of total heavy metals, their contribution to the overall Doppler effect is small and the results are 
considered acceptable for this feasibility study. Future, more accurate calculations will have to include these nuclides.

The results of the calculations for the full core model with inserted control rods are presented in Table 5. Two cases were evaluated: the reference case and the case with additional hafnium resonance absorber ( $10 \mathrm{wt} \%$ of natural hafnium uniformly mixed with the fuel).

Table 5. Doppler coefficients for full core model.

\begin{tabular}{|l|l|l|}
\hline Case & $\mathbf{k}_{\text {eff }}$ & Doppler $(\mathbf{c} / \mathbf{K})^{*}$ \\
\hline Case 1- Reference fuel, control-rods $64 \mathrm{~cm}$ in the core, $\mathrm{T}=558 \mathrm{~K}$ & $0.98366 \pm 0.0003$ & \\
\hline Case 1 - Reference fuel, control-rods 64cm in the core, T=1154K & $0.98308 \pm 0.0003$ & \\
\hline Case 1 - Doppler coefficient & & $\mathbf{- 0 . 0 4 0 \pm 0 . 0 2}$ \\
\hline Case 2 - Fuel with Hf, T=558K, control-rods 59cm in the core & $0.99319 \pm 0.0003$ & \\
\hline Case 2 - Fuel with Hf, T=1154K, control-rods 59cm in the core & $0.99399 \pm 0.0003$ & \\
\hline Case 2 - Doppler coefficient & & $\mathbf{0 . 0 5 4 \pm 0 . 0 2}$ \\
\hline
\end{tabular}

Assumes $\beta_{\text {eff }}=0.0025$, as calculated in the previous section; the Doppler coefficient is the linearized average value between temperatures 558 and $1154 \mathrm{~K}$.

A surprising finding is that introducing hafnium into the zirconium matrix makes the Doppler coefficient positive. These results show that use of hafnium or other substitute absorbers is not warranted for this hard-spectrum core design. Since there are no nuclides with resolved resonance peaks above $10^{4} \mathrm{eV}$, most of the captures occur in the low energy tail. To maintain this tail, some moderating material must be present in the core and a zirconium matrix with a large volume fraction of zirconium, which is the third lightest nuclide in the core (after B and C in control-rod drives), appears to be an important scatterer. It has been shown (Hejzlar et al. 2000) that the case with Hf exhibits an appreciable reduction of the number of neutrons in the lowenergy tail, in particular, in the energy range between $1 \mathrm{eV}$ to $100 \mathrm{eV}$, where important resonance peaks of a number of nuclides lie (specifically, the most important resonance peak at $\mathrm{E}=1 \mathrm{eV}$ for $\mathrm{Pu}-240$ ). Because $\mathrm{Hf}$ does not have such a large resonance peak as $\mathrm{Pu}-240$, resonances in $\mathrm{Hf}$ are not sufficient to compensate for the reduced capture rates in the Pu-240 and other heavy metal nuclides due to spectrum depression in the low energy tail. Therefore, replacing zirconium with heavier absorbers is not an efficient method to increase the magnitude of the Doppler feedback. These results are similar to the conclusions of Novikova et al., (1998) who, based on the proposal of CAPRA's researchers (Rouault et al. 1996), conclude that reactors with a scatterer to soften the neutron spectrum can burn recycled plutonium with a high fraction of $\mathrm{Pu}-240$ while having a negative Doppler effect. They used a $\mathrm{MgO}$ matrix and a number of selected $\mathrm{ZrH}_{2}$ pins for spectrum softening in the lead-bismuth-cooled core.

The above values were obtained for the fresh core. The assessment of Doppler effect at the end of a $2^{\text {nd }}$ cycle was made using the MCNP full core model with the available temperature dependent libraries (U234,U235, U238, Pu238 through Pu242, and Am243). The libraries for the remaining TRU were taken at $300^{\circ} \mathrm{K}$, thus the broadening of their resonance peaks and changes in fission and capture rates were not accounted for. The result of this simple estimate yielded about the same Doppler coefficient as for the fresh core, i.e., $-0.040 \pm 0.024 \phi / K$. Note that the effect of fission products is not included in this result. Fission products should lead to a more negative Doppler coefficient because fission products replace heavy metal in the core improving scattering properties of the fuel and increasing resonance absorption. The analysis of the equilibrium core was not performed, however, the qualitative judgement based on the equilibrium composition of ATW fuel, indicates that its Doppler effect should be higher than that of the fresh 
core because the fractional amount of Pu-239 and most other odd-odd nuclides is less and the percentages of the even nuclides, in particular Pu-240 are higher. Changes of the Doppler coefficient with burnup will have to be calculated in the future after accurate data for all the TRU are available and MCNP libraries prepared.

Because the temperature dependence of the Doppler coefficient in a hard spectrum reactor is different from that of the oxide-fueled reactors, a more consistent comparison is the reactivity change between 558 and $1154^{\circ} \mathrm{K}$. The change of reactivity over this temperature increase in a sodium cooled fast reactor (Superphenix) is calculated to be -0.0062 . The reactivity reduction between the same temperatures for the lead-bismuth burner can be calculated directly from Table 5 as -0.0006 , which is ten times less than the values typical for fast oxide-fueled, sodium-cooled reactors.

Although significantly smaller, the Doppler coefficient of the proposed fuel remains negative. This plausible result is rather surprising because one would expect a positive Doppler effect in the absence of a strong resonance absorber and in the very hard spectrum of this core. The Doppler coefficient is very sensitive to the neutron spectrum and in sodium-cooled, oxide-fueled reactors, spectrum hardening from loss of coolant leads typically to a reduction of the magnitude of the Doppler effect by $50 \%$. Thus, in addition to the absence of a strong neutron absorber, the actinide-burner core with lead-bismuth coolant and metallic fuel has a hard spectrum in the flooded state, which leads to a significant reduction of the Doppler coefficient. The other important reason for a decreased Doppler effect is the low heavy metal loading, both due to the high fraction of zirconium in the matrix and a high void fraction in the core. On the other hand some nuclides exhibit a different behavior in this hard spectrum than in sodium-cooled reactors. Specifically, Pu-239 typically contributes positively to the Doppler effect in sodium-cooled reactors, but has a negative contribution in the lead-bismuth core due to a negligible change of the fission cross section, but a distinguishable increase of capture cross section. This results in a reduction of the fission-to-capture rate in this most important fissile species. This effect, together with the negative contribution from the $\mathrm{Pu}-240$, is responsible for the negative Doppler coefficient in spite of the absence of U-238.

Regarding the small magnitude of the Doppler effect, it is to be noted that other operating reactors also exhibited similar values. For U-235-fueled reactors using metal fuels, the Doppler effect is very small (less than $0.1 \mathrm{pcm} / \mathrm{K}$ ) and may be even positive (Hetrick 1993). The experimental breeder reactors EBR-I and EBR-II fall in this category. In the slightly softer spectrum of the Enrico Fermi Reactor (also fueled by metal fuel and U235), the Doppler coefficient was calculated to be $-0.2 \mathrm{pcm} / \mathrm{K}$ (Nicholson, 1960). All these values have about the same magnitude as the actinide-burner fuel, even though the fuel of the above reactors had a large wt $\%$ of U238. Also Hill et al., (1995) reported the value of the Doppler coefficient for a traditional breeder with metallic fuel $\sim-0.05 \phi / \mathrm{K}$, which is comparable to the value calculated for the reference fuel of the actinide-burner. Therefore, the Doppler coefficient of $-0.04 \notin / \mathrm{K}$ in combination with the negative prompt fuel thermal expansion coefficient (see next Section) and negative coolant void worth is deemed to be acceptable.

\subsubsection{Fuel Thermal Expansion Effect}

A full core model with double-entry control-rod drives was used to calculate the thermal expansion effect. All dimensions and concentrations throughout the core were kept fixed, except for the fuel, which was assumed to elongate its height into the upper gas plenum and increase its 
diameter. A fuel density change leads to changes in the number densities. To eliminate the effects of fuel temperature variation on other reactivity-related aspects, such as the Doppler coefficient and scattering fuel properties, the fuel temperature was held constant in all calculations. Thus, the analysis yields only the effect of thermal expansion of the fuel.

A large temperature change of $600^{\circ} \mathrm{C}$ (from $20^{\circ} \mathrm{C}$ to $620^{\circ} \mathrm{C}$ ) was taken to maximize the thermal expansion effect so that the computed reactivity change is larger than the statistical uncertainty of the MCNP results. The average coefficient of thermal expansion in the range $20-620^{\circ} \mathrm{C}$ was used for the calculations. For some isotopes, where the coefficient of thermal expansion dependence on temperature was not available, values at room temperature were taken. This assumption yields smaller dimensional changes, i.e., conservative results, since thermal expansion and density changes increase with higher temperature.

The results (see Table 6) show that the fuel thermal expansion effect is negative and that its magnitude is comparable to the Doppler coefficient. However, even in combination with the Doppler coefficient, the total value of the prompt negative fuel temperature feedback is still less than the typical values of the Doppler coefficient for LMFBRs with oxide fuels. An increase of thermal expansion can be attained through addition of an alloy with high thermal expansion coefficient. Such alloys have been investigated by Japanese researchers as a thermal expansion controlled material for the enhancement of inherent safety in metallic fast breeder reactor cores (Tokiwai et al. 1999).

Table 6. Fuel thermal expansion coefficient.

\begin{tabular}{|l|l|l|}
\hline Case & $\mathbf{k}_{\text {eff }}$ & $\begin{array}{l}\text { Thermal exp. coef. } \\
(\mathbf{d} / \mathbf{K})^{*}\end{array}$ \\
\hline Cold fuel $\left(\right.$ at $\left.\mathrm{T}=20^{\circ} \mathrm{C}, \mathrm{R}_{\mathrm{f}}=0.432 \mathrm{~cm}, \mathrm{H}_{\mathrm{f}}=130 \mathrm{~cm}\right)$ & $0.99891 \pm 0.00028$ & \\
\hline Hot fuel (at $\left.\mathrm{T}=600^{\circ} \mathrm{C}, \mathrm{R}_{\mathrm{f}}=0.43429 \mathrm{~cm}, \mathrm{H}_{\mathrm{f}}=130.689 \mathrm{~cm}\right)$ & $0.99827 \pm 0.00028$ & \\
\hline Thermal expansion coefficient & & $-0.043 \pm 0.02$ \\
\hline
\end{tabular}

*Assumes $\beta_{\text {eff }}=0.0025$, as calculated in the previous section; the thermal expansion coefficient is the linearized value between $20^{\circ} \mathrm{C}$ and $620^{\circ} \mathrm{C}$.

\subsubsection{Actinide Destruction Rate and Burnup Performance.}

Changes in fuel composition during burnup were modeled using MOCUP (Moore et al. 1995) with a detailed $1 / 8$ th core MCNP model. Burnup calculations with a detailed $1 / 8$ th core model using the MOCUP coupling program are computationally very expensive*. Therefore, only two cycles were run to determine if the refueling interval of 1.5 years can be achieved and to evaluate the actinide destruction rate. Because the neutron flux across the core is almost flat, only two core regions were modeled by MOCUP assuming that each entire region is exposed to a constant region-average neutron flux. Sixty-two fission products accounting for $95 \%$ of the absorptions of all the fission products and 37 actinides were tracked in each region. This is the maximum number of nuclides with variable cross sections that ORIGEN-2.1 allows to be dynamically replaced in its libraries. Also, the number of cells in the MCNP model is close to the maximum limit of 99,999 .

The effective multiplication factor is shown in Figure 12. The initial cycle is for the fresh core; after 610 full power days, refueling was performed by replacing the fuel in the central region by

\footnotetext{
* One MOCUP step takes about 20hours on a DEC workstation with a 500MHz processor.
} 
once burned fuel from the outer region and loading fresh fuel with $29 \mathrm{wt} \%$ TRU enrichment into the outer region. It can be seen that the objective of the length of refueling interval of at least $1.5 y e a r s$ is achieved. The reactor can be operated for about 1.6 years at full power before half of the core is refueled. This is well above a 6-month batch length that is considered as a minimum requirement for a commercial reactor (Wakabayashi et al. 1998). Another alternative is to reduce the reactivity swing and shorten the batch length, which is always possible with this design. Other studies on fast reactor burners have proposed cores with more batches with a shorter cycle length. Since the 1.5-year batch length is feasible, it is considered preferable over shorter batches from an economic viewpoint.

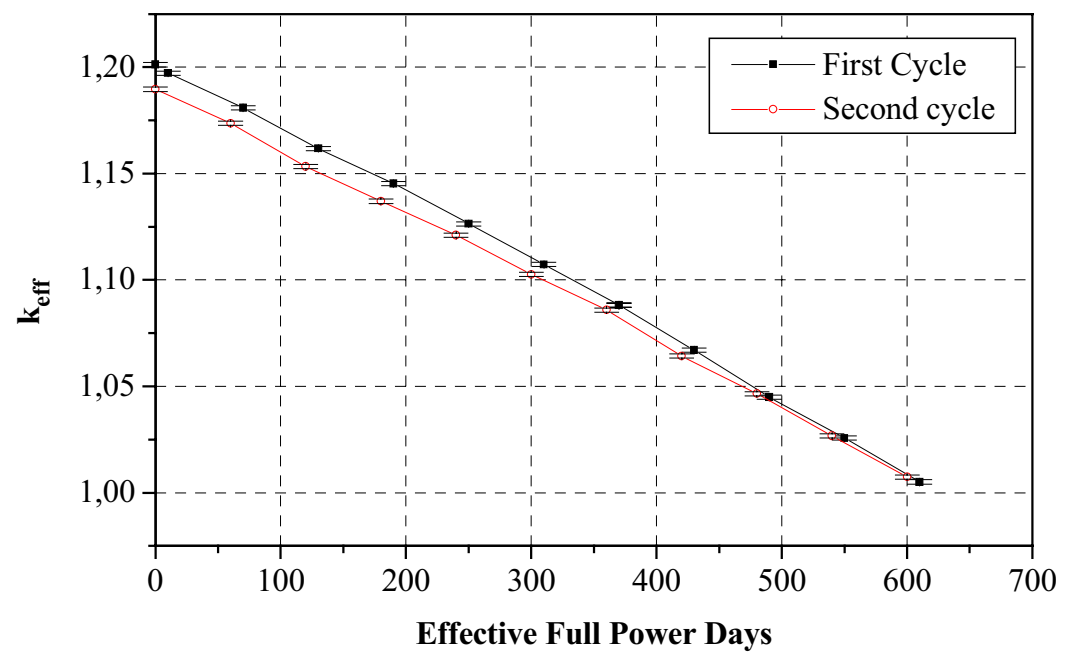

Figure 12. Changes of $k_{\text {eff }}$ with burnup for the initial and second cycle.

Possibilities to reduce the reactivity swing through the employment of burnable poisons, such as B-10, rhenium , and other absorbers, were also investigated, but without success due to low cross sections of these nuclides in the very hard spectrum of this reactor. However, it has been shown through calculations that Np-237 and Am-241 can effectively act as burnable poison to attain even a nearly flat reactivity versus burnup curve for high minor actinide loadings - see next section.

The discharge burnup for the initial cycle is approximately 370,000 MWd/tHM. Ternary (UPuZr) metal alloy pins in HT-9 ferritic cladding have achieved $200 \mathrm{MWd} / \mathrm{kg}$ peak discharge burnup and are qualified and demonstrated for $150 \mathrm{MWd} / \mathrm{kg}$ peak discharge burnup (Hill et al. 1999). Because the fuel contains a large fraction of zirconium ( $74 \% \mathrm{Zr}$ in comparison to $10 \% \mathrm{Zr}$ for the ternary metallic fuel), it is expected that it should be able to withstand these burnups while having pin fission product loadings similar to conventional LWR fuel. However, research and experimental demonstration that the fuel can withstand these burnups will be required. The same issue holds for the proposed ATW fuel, hence the experiments can be performed within the framework of this program.

The consumption rate of actinides per effective fuel power year (EFPY) is plotted in Figure 13. The net destruction rate is $660 \mathrm{~kg} / \mathrm{FPY}$. For a capacity factor of 0.75 , which is a reasonable estimate for the capacity factor of a fast reactor, the destruction rate per year is $495 \mathrm{~kg} / \mathrm{year}$. Hill 
et al. (1995) studied a sodium cooled fast reactor as an actinide-burner using metallic fuel and achieved a destruction rate of $231 \mathrm{~kg}$ TRU/year per $840 \mathrm{MWt}$ at the same capacity factor. Scaling to $1800 \mathrm{MWt}$ yields $495 \mathrm{~kg} /$ year. The dedicated fast cores for actinide transmutation in a pure minor actinide recycling mode investigated by French researchers (Tommasi and Massara 1999) can destroy (approximately) a maximum amount of $42 \mathrm{~kg} / \mathrm{TWh}$ (thermal) of minor actinides. The proposed burner with streaming assemblies destroys almost exactly this amount, i.e.,

$660 \mathrm{~kg} / \mathrm{FPY} / 8760 \mathrm{~h} / \mathrm{FPY} *\left(10^{6} \mathrm{MWth} / \mathrm{TWth}\right) / 1800 \mathrm{MWth}=41.9 \mathrm{~kg} / \mathrm{TWh}($ thermal $)$

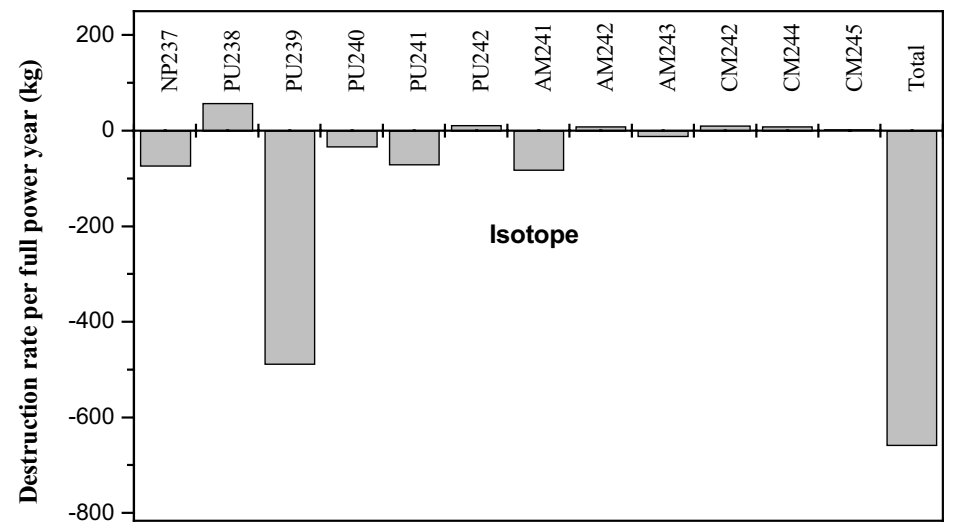

Figure 13. Consumption rate of TRUs per full power year.

Hence in terms of TRU consumption rate both sodium-cooled and lead-bismuth-cooled actinideburner reactors seem to be comparable.

The ATW designers claim to be able to destroy $650 \mathrm{~kg} /$ year per $2000 \mathrm{MWt}$ in a ATW, or 585 $\mathrm{kg} /$ year per $1800 \mathrm{MWt}$. Accounting for the ATW availability of $75 \%$ (Venneri 1998) the ATW destruction is $780 \mathrm{~kg} / \mathrm{FPy}$. Thus, the destruction rate per FPY is $18 \%$ higher for the ATW than for the proposed fast burner. However, based on the availability data for current accelerators, as discussed in Piaszczyk (1998) and Eriksson and Piaszczyk (1998) and considering the fact that the overall capacity factor of the coupled accelerator-reactor system is the product of the capacity factors of these two subsystems, one can expect that the ATW destruction rate per year would be penalized by a lower capacity factor. But even without this penalization, the proposed actinideburner is a competitive alternative to accelerator-driven systems in terms of actinide destruction rate.

\subsubsection{The option of fertile-free, long-life, minor actinide-burner with zero reactivity swing.}

The option of burning an increased content of minor actinides in the streaming core design was also investigated. The most abundant minor actinide isotopes are Np-237 and Am-241. Both isotopes have very attractive properties that can significantly reduce the reactivity swing or even make it approximately zero. When Np-237 captures neutrons, it is transmuted to Np-238 and Np- 
239, which decays to Pu-239 with a half-life of 2.355days. Am-241 is transmuted upon neutron capture to Am-242 or Am-242m, which can also be fissioned. -It is the magnitude of the fission and capture cross sections of Np-237 and Am-241 and subsequently of Pu-239 and Am-242m in the hard-spectrum lead-bismuth cooled reactor that makes these two minor actinides attractive (see Table 7).

Table 7. One-group effective cross sections of key minor actinides and their progenitors in the lead-bismuth-cooled reactor.

\begin{tabular}{|l|l|l|}
\hline Isotope & $\boldsymbol{\sigma}_{\mathbf{c}}$ (barn) & $\boldsymbol{\sigma}_{\mathbf{f}}$ (barn) \\
\hline $\mathrm{Np}-237$ & 1.132 & 0.345 \\
\hline $\mathrm{Pu}-239$ & 0.357 & 1.689 \\
\hline $\mathrm{Am}-241$ & 1.384 & 0.269 \\
\hline $\mathrm{Am}-242 \mathrm{~m}$ & 0.267 & 3.348 \\
\hline
\end{tabular}

Both Np-237 and Am-241 have a relatively high capture cross section and low fission cross section. Thus they both behave to some extent as burnable absorbers since their number density decreases upon capture, leading to reduced neutron loss in these nuclides with burnup. Moreover, $\mathrm{Pu}-239$ and Am-242m, which eventually replace them, have significantly higher fission cross sections than their predecessors. Additionally, Am-242m $\alpha$ decays to Np-238, which $\beta$ - decays to $\mathrm{Pu}-239$, which also has a significantly higher fission cross section than the original isotope of Am-241. Therefore, if sufficient weight fraction of minor actinides is present in the fuel, the reactivity swing will be appreciably reduced.

This is shown on Figure 14, depicting the results of a burnup study in a unit cell with axial

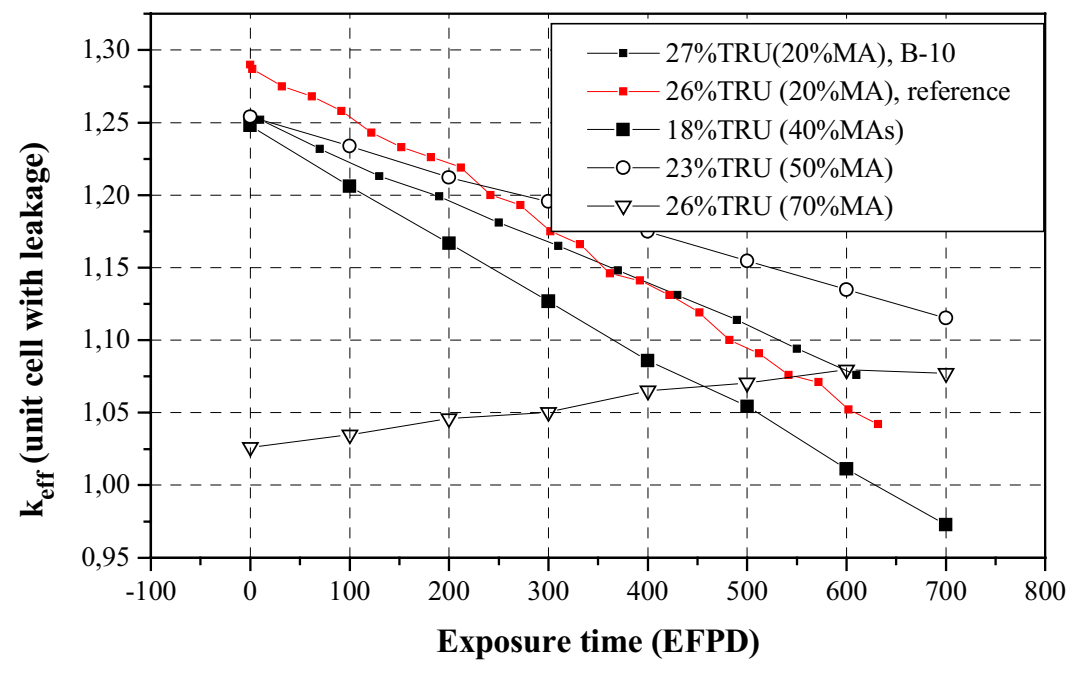

Figure 14. Unit cell burnup for various initial fuel compositions.

leakage accounted for. The composition of the plutonium and minor actinide vector was kept fixed equal to that of the LWR spent fuel and the weight fraction of minor actinides (in TRU) and total TRU weight fraction was varied. Curve "26\%TRU (20\%MA)" depicts the reference case. The top curve with B-10 shows the effect of adding boron as burnable poison. If the fraction of 
minor actinides in TRU is doubled to $40 \%$ (curve "18\%TRU,40\%MA"), the slope of the curve is not affected. However, a further increase of the minor actinide fraction to $50 \%$ leads to a significant reduction of the burnup curve slope, yielding better results than boron. Increasing minor actinide content to $70 \%$ (note that the percent fraction of TRUs was adjusted to give k-inf at beginning-of-life about 1) causes a reversal of the reactivity trend.

The net destruction rate of actinides for the case with $70 \mathrm{wt} \%$ minor actinide content was calculated to be $660 \mathrm{~kg} / \mathrm{FPY}$, which is comparable to the reference case. However, the composition of the discharged fuel is very different, with a high-content of $\mathrm{Pu}-238$ (composition of the plutonium vector after 800 EFPD was $\mathrm{Pu}-238 / \mathrm{Pu}-239 / \mathrm{Pu}-240 / \mathrm{Pu}-241 / \mathrm{Pu}-242=39.20$, $25.19,21.46,4.91,9.23 \mathrm{wt} \%)$. Such a vector is highly proliferation resistant, and the large amount of highly radioactive $\mathrm{Pu}-238$ makes reprocessing and fabrication difficult. The currently favorable limit on $\mathrm{Pu}-238$ content is typically taken to be $5 \mathrm{wt} \%$. The $39.2 \mathrm{wt} \%$ (179kg per $1 \mathrm{MT}$ ) of $\mathrm{Pu}-238$ is far above this limit and would yield decay heat of $0.1 \mathrm{MWth}$ and radioactivity of $3 \times 10^{6} \mathrm{Ci}$ (per $1 \mathrm{MT}$ one year after extraction from the reactor).

Another challenge is more positive coolant density coefficient in the fuels rich with minor actinides. Calculations performed for $70 \%$ minor actinide fuel in a streaming core showed positive coolant void worth. However, decreasing the minor actinide content to $60 \%$ allowed for an appreciable reduction of the critical mass of TRU (" $33 \%$ and $37 \%$ TRU in the inner and outer core regions, respectively) making the core more transparent to neutrons. Therefore, the feasibility to achieve a negative coolant void worth was confirmed. However, a high minor actinide content would deplete the minor actinides from the spent LWR fuel inventory and produce intensively radioactive discharged fuel with a very high content of $\mathrm{Pu}-238$. Therefore, further exploration of this route was not pursued in detail, but it is kept open as one of the possible avenues to explore further.

\subsubsection{Transmutation Capabilities of Long-Lived Fission Products}

The possibilities to transmute long-lived fission products in the proposed actinide-burner reactor were investigated for Tc-99 - the isotope with the second largest annual discharged amount and very long half-life. Two strategies of Tc-99 incineration were investigated. In the first one, the moderated assemblies with Tc-99 targets were loaded on the core periphery, the second approach employed mixing the Tc-99 with the TRU in the core. In both strategies, it was confirmed that the number of technetium transmutations per fission of TRU nucleus well exceeded the number of Tc nuclides co-produced with TRU fission.

A number of arrangements of technetium pins within moderated peripheral fuel assemblies were investigated (Hejzlar et al. 2000). The best performance was found for the case of staggered arrangement of moderating rods $\left(\mathrm{ZrH}_{2}\right)$ and target rods, however, the transmutation efficiency of $2.2 \%$ ( $39 \mathrm{~kg}$ of Tc-99 per EFPY per initial inventory of $1740 \mathrm{~kg}$ ) is relatively low. The main reason is a significant reduction of neutron flux in the peripheral moderated assemblies due to self shielding, which is more influential on the overall performance than an increase of the effective absorption cross section through moderation. In an effort to enhance the neutron flux, moderated assemblies were distributed throughout the core. However, this strategy was not found to be efficient because the self-shielding effects were prevalent in the large fuel assemblies used in the streaming core. Therefore, the widespread belief that moderation techniques are beneficial for transmutation was not confirmed for this design. Moreover, neutrons at lower energies that return from the moderated assemblies back to the core are more intensively captured in the fuel, 
increasing curium accumulation in adjacent fuel assemblies. There are basically two competing trends that work against each other making it difficult to achieve two goals at the same time. A thermalized spectrum increases parasitic captures in structural materials, and more importantly increases the capture to fission ratio in the TRU nuclides, worsening the TRU burning capability. On the other hand, it increases the capture cross section of Tc-99. However, because this latter increase is outweighed by the self-shielding effects, the strategy of using moderating assemblies was not found to offer any appreciable advantage in the critical fast burner.

The strategy of uniformly mixing Tc-99 directly with fuel at the expense of the zirconium matrix gave slightly better transmutation efficiency $(2.6 \%$ of the initial inventory per EFPY) than the schemes with moderated assemblies, primarily due to a higher exposure flux across the core. A French study on incineration of long lived fission products shows that about $90 \mathrm{~kg} / \mathrm{year}$ of Tc-99 from 3.53 tonnes of loaded Tc-99 can be transmuted in sodium-cooled fast reactors (Golfier et al. 1999), which gives a comparable burnup efficiency of $2.5 \%$. However, the same study indicates that about $1644 \mathrm{~kg}$ of Tc-99 could be loaded into a PWR, mixing the fuel with $1 \%$ of Tc-99 at the expense of over-enrichment of the fuel (4.4\% against 3.5\% U-235), from which $187.2 \mathrm{~kg} /$ year can be incinerated. Clearly, this incineration efficiency of $11.4 \% / y$ ear is appreciably higher than in the case of fast spectrum burners. Therefore, the question arises, whether the incineration of Tc99 in fast reactors is warranted in view of no tangible gain in the Tc-99 incineration efficiency in these systems when PWR technology is fully developed and available for use with some minor development.

On the other hand, the ATW designers report appreciably higher Tc-99 incineration efficiency. Based on the results of changes in equilibrium ATW fuel composition during a 100-day cycle, the amount of transmuted Tc-99 per FPY can be estimated to be approximately $81 \mathrm{~kg}$ out of $172 \mathrm{~kg}$ of the charged Tc-99 inventory. (incineration efficiency of 46\%). The details of the ATW assembly design with Tc-99 targets was not known to the present authors; most likely moderated assemblies with Tc-99 targets are placed in the region of high neutron flux. Since ATW has excess neutrons from spallation reactions and most likely higher flux levels, if the targets with Tc-99 are properly placed to make use of these high flux levels in combination with good neutron moderation, significantly higher Tc-99 incineration rates can be achieved. More efficient transmutation of Tc-99 is an advantage of ATW, which could not be matched by the proposed fast burner.

\subsubsection{Generation of Polonium 210 in the coolant}

One disadvantage of the lead-bismuth eutectic is generation of radioactive Po-210 (half-life of 138.4 days) as a result of $(n, \gamma)$ reaction of Bi-209. Handling of $\alpha$-active polonium has been successfully resolved within the framework of a Russian program. Polonium issues are even more important for the direct-cycle lead-bismuth concept investigated (Buongiorno et al. 1999) because $\mathrm{Po}-210$ rapidly forms a chemically stable compound with lead ( $\mathrm{PbPo})$, which evaporates into steam and could proceed to the turbine. Therefore, a reasonably accurate knowledge of the Po-210 content in the coolant is necessary. This has been done using MCNP for neutron flux mapping in various regions of the reactor vessel and ORIGEN-2.1 to obtain Po-210 mass and activity in each region as a function of operating time. The results for vessel-average activity per $\mathrm{kg}$ of coolant inventory are plotted in Figure 15. The trend of the curve indicates that the equilibrium should not be much beyond $60 \mathrm{Ci} / \mathrm{kg}$. This corresponds to Russian estimates, which claim radioactivity levels of about $70 \mathrm{Ci} / \mathrm{kg}$. 


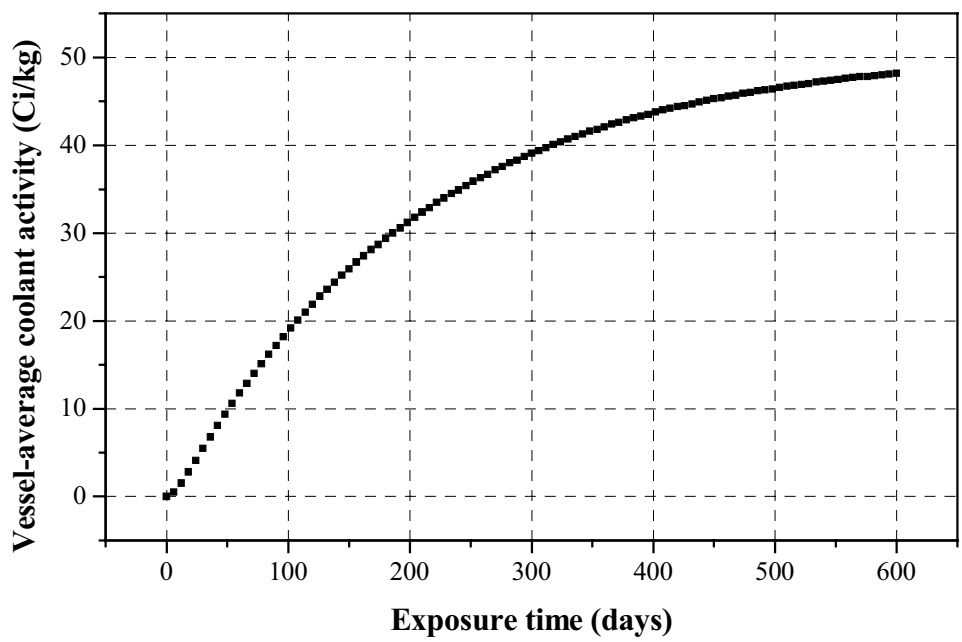

Figure 15. Average Po-210 coolant activity in the fast actinide-burner.

\subsubsection{Fluence of key reactor components.}

The hard neutron spectrum and high neutron leakage from the neutron transparent core raises the concern of material issues at high neutron flux, especially of the reactor vessel. To evaluate the feasibility of the design, the neutron flux on the reactor vessel on the core belt-line and on the cladding was calculated using MCNP flux edits. The results are summarized in Table 8.

Table 8. Neutron flux at selected reactor components at core power of 1800MWth.

\begin{tabular}{|l|l|l|}
\hline Component & $\phi\left(\mathbf{n} / \mathbf{c m}^{2} \mathbf{- s}\right)$ & Fluence $\left(\mathbf{n} / \mathbf{c m}^{2}\right)$ \\
\hline Cladding & $2.61 \times 10^{15}(\mathrm{E}>0.1 \mathrm{MeV})$ & After 3.2 years $2.7 \times 10^{23}$ \\
\hline Vessel wall (down-comer thickness $=50 \mathrm{~cm})$ & $6.65 \times 10^{11^{*}}(\mathrm{E}>1 \mathrm{MeV})$ & After 30 years $2.1 \times 10^{19}$ \\
\hline Vessel wall (down-comer thickness $=70 \mathrm{~cm})$ & $2.00 \times 10^{11^{*}}(\mathrm{E}>1 \mathrm{MeV})$ & After 30 years $6.3 \times 10^{18}$ \\
\hline Vessel wall (down-comer thickness $=100 \mathrm{~cm})$ & $1.80 \times 10^{10^{* *}}(\mathrm{E}>1 \mathrm{MeV})$ & After 30 years $5.7 \times 10^{17}$ \\
\hline
\end{tabular}

The fluxes were edited on the vessel wall at the level of the active core (averaged over core height)

Fluence on the vessel wall is a strong function of the thickness of the down-comer gap. Fluence on the vessel does not pose a problem since the thickness of the down-comer can be adjusted to attain desirably low fluence levels. PWR vessels are typically exposed to fluences of $2 \times 10^{19}$ $(\mathrm{E}>1 \mathrm{MeV}) \mathrm{n} / \mathrm{cm}^{2}$. Also, fluence on cladding after an exposure of 3.2 years (residence time of the fuel assemblies in the core) falls well within the current experience of liquid metal reactors. The fluence limit for the low-swelling cladding HT-9 steel alloy developed for the United States fast reactor program is $3.8-4.0 \times 10^{23} \mathrm{n} / \mathrm{cm}^{2}(\mathrm{E}>0.1 \mathrm{MeV})($ Hill et al. 1999) which is well above the fluence on cladding calculated in Table 8.

\subsubsection{Fuel cycle cost estimate.}

One of the most significant aspects in designing a new technology system is its economic prospect in comparison with existing technologies. The fuel cycle cost is an important factor in the cost of electricity generated by a nuclear power plant. Therefore, an evaluation of the fuel 
cycle costs for the proposed actinide-burner reactor was made using three models: 1) ORNL model (Delene and Hudson 1993), 2) fast breeder reactor model (Waltar and Reynolds 1981) and 3) Simple model (Handwerk et al. 1998). The description of the models and the assumptions used in the calculations are given in Kim et al. (2000), here only the main assumptions and the results will be presented.

The mass balance for one fuel facility, which can serve 10 typical actinide-burner reactors (considered as a reference case) is shown in Figure 16. This fuel facility will process about 554.4 MT/year of uranium from LWR spent fuel. A total of 5.74 MT/year of TRU will be extracted in the LWR spent fuel reprocessing plant for the 10 actinide-burner reactors.

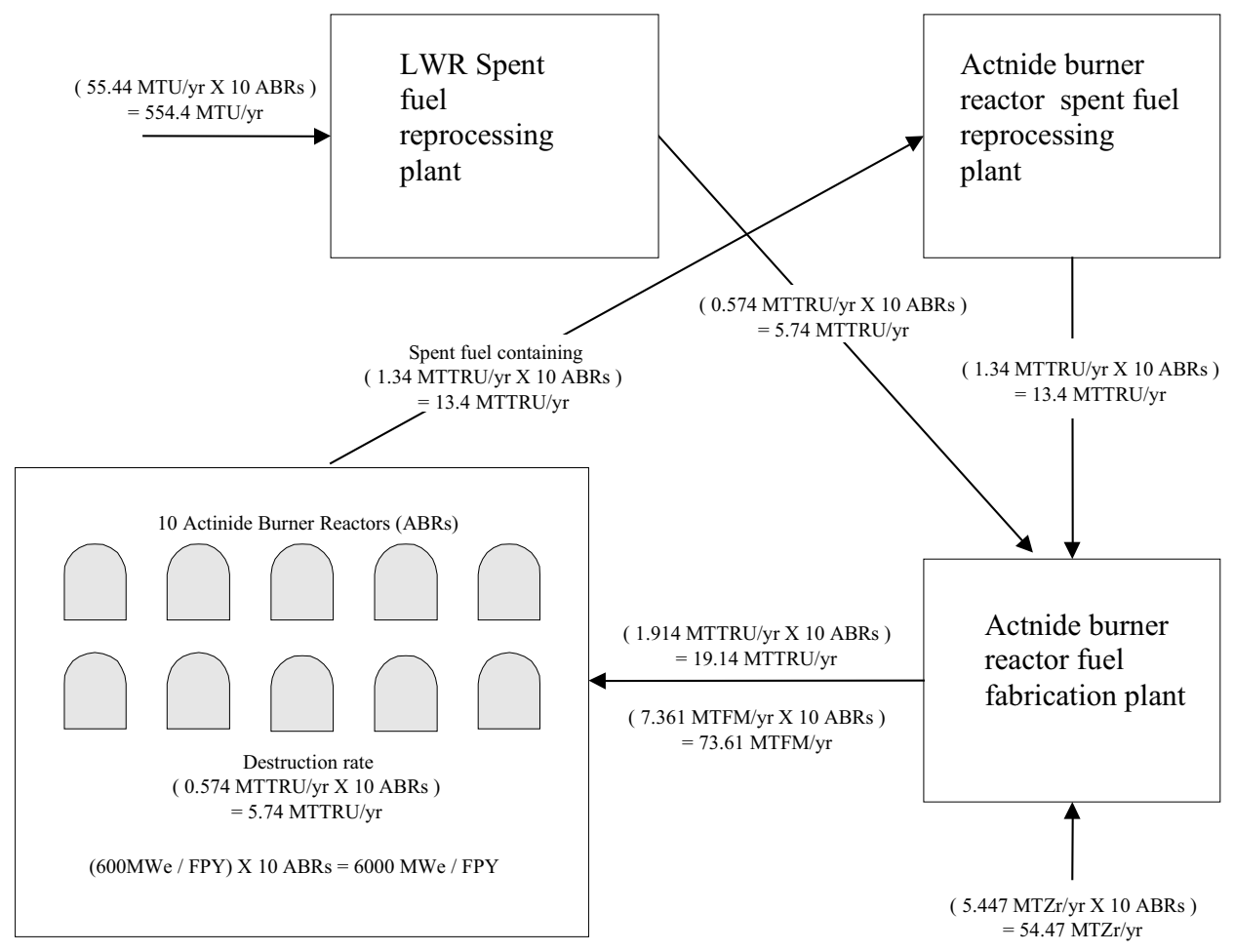

Figure 16. Front-end of Fuel Cycle for One Fuel Processing Facility.

The spent fuel from the actnide burner reactors will contain 13.4 MT of transuranics mixed with zirconium and fission products. These transuranics are extracted in the actinide-burner reactor spent fuel reprocessing plant and sent to the actnide-burner reactor fuel-fabrication plant. The fuel fabrication plant will blend the 5.74 MT TRU/year of plutonium plus minor actinides (TRU) from the LWR spent fuel reprocessing plant and 13.4 MT TRU/year from the actinide-burner reactor reprocessing plant with zirconium, (54.47 MT Zr/year) to create one year's worth of fuel for 10 actnide burner reactors. This annually needed quantity of fuel contains 19.14 MT of TRU or 73.61 MT of fuel metal (TRU plus zirconium). The burning of 5.74 MT TRU/year in 10 actnide burner reactors generates $18,000 \mathrm{MWth} / \mathrm{FPY}$ which corresponds to $6000 \mathrm{MWe} / \mathrm{FPY}$ (system thermodynamic efficiency $=33.3 \%$ ). The capacity factor was assumed to be $80 \%$. The study assumed on-site fuel cycle facilities so that the financial parameters for utility ownership can be used. These financial parameters for utility ownership were taken from the DOE's Nuclear Energy Cost Data Base (Delene and Hudson 1993). 
The fuel cost calculated by the above models is plotted as a function of the number of actnide burner reactors served by one facility on Figure 17. The fuel cost in the actinide-burner reactor is found to be less than that of ATW fuel, but considerably higher than the 6 mills $/ \mathrm{kW}-\mathrm{hr}$ characteristic of existing LWR nuclear power plants. Unless there can be reductions in other cost factors (for example, reactor capital cost or operations costs) or in the fuel cycle itself, it will be hard to justify deployment of this actnide-burner reactor from a purely economic point of view. This study suggests one possible way to reduce the fuel cycle cost, which is by enlarging the production capacity of the fuel facility. For example, if scaled up to handle 800MTU/year of LWR fuel, as in the existing French and UK facilities, which would serve 14 actnide burner reactors, and the other needed processes also had the capacity for serving 14 actnide burner reactors, the fuel cycle cost could be cut from 12 mills/kW-hr to about 10 mills/kW-hr.

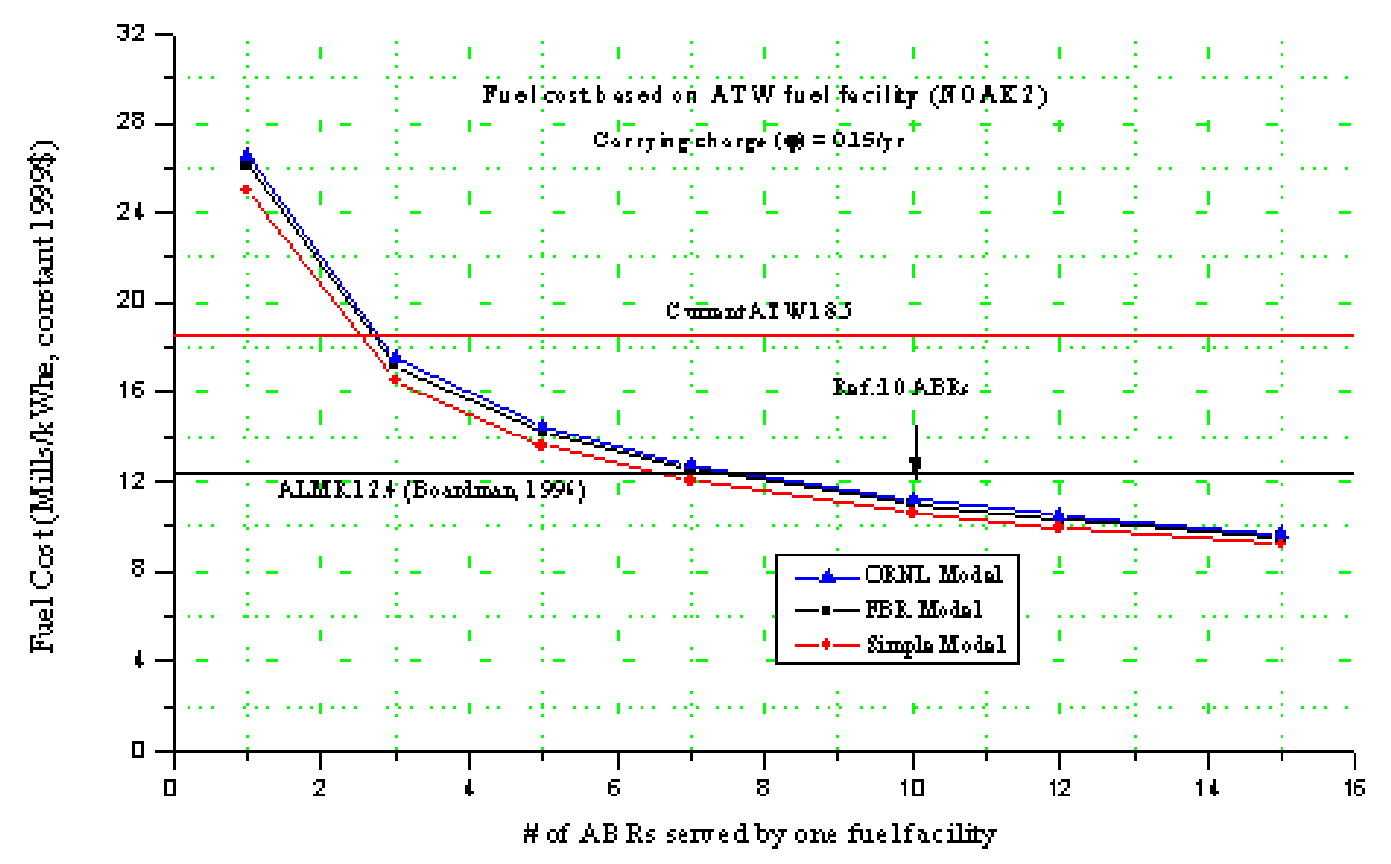

Figure 17. Fuel costs for the actinide-burner reactor given by the three models applied in this study.

\subsubsection{Concept Optimized for Economic Electricity Production}

In the previous section, the feasibility of a lead-cooled burner that can be competitive in terms of actinide destruction rate with ATW while maintaining good safety characteristics has been confirmed. It has been also shown that the drawback of both the critical burner and ATW is a high fuel cycle cost. Thus, the next efforts were directed at the study of a lead-bismuth-cooled concept that does not require expensive reprocessing and can produce electricity at low cost. The objective is to develop a conceptual design of a high conversion reactor of appreciable power output that 
- operates in a once through cycle,

- needs no reprocessing,

- has very long refueling period (up to 15 years)

- discharges minimum amount of waste,

- is proliferation resistant, and

- achieves excellent safety characteristics with emphasis on inherent and passive safety.

Similar work has been performed elsewhere (Su'ud and Sekimoto 1995, Greenspan et al. 1998), but only for very small cores, since it was difficult to attain a negative coolant void coefficient for larger cores. This project will investigate the possibility of designing a large core with these characteristics while maintaining a negative coolant density coefficient.

First a systematic scoping study was performed on an infinite unit cell to explore the maximum theoretical potential for internal conversion achievable for each fuel type and other characteristics of interest to the above goals. The MOCUP code tracking 62 fission products and 37 actinides was used for the analyses. Fuels considered in the study are listed in Table 9. Uranium dioxide was taken as a reference fuel against which the alternative fuel types are compared. The mononitride (UN) and mono-carbide (UC) fuels are also proven nonmetallic fuel types, although to a much less extent than $\mathrm{UO}_{2}$. In the metallic fuel category, the proven IFR fuel UZr was selected for study. All these fuels are U-235-enriched. The initial enrichment was found by iterative MCNP runs to achieve an approximately critical state in the modeled unit cell. In each fuel category, alternative fuel mixtures were considered using weapons-grade plutonium as the starting fissile material instead of U-235. To explore the possible benefits of thorium as a fertile material, variants with Th were also explored. Thorium based fuels employed depleted U-238 to denature bred-in U-233, except for PuThZr fuel, where the U-238 was not employed to assess the potential of pure thorium fuel.

Table 9. Fuel types considered in the long-life core study.

\begin{tabular}{|c|c|c|}
\hline Fuel type & Composition & k-inf at BOL \\
\hline \multicolumn{3}{|l|}{ Oxides } \\
\hline $\mathrm{UO}_{2}$ (reference) & $11.1 \mathrm{wt} \%$ enrichment $\mathrm{U}-235^{*}$ & $1.000 \pm 0.001$ \\
\hline \multicolumn{3}{|l|}{ Nitrides } \\
\hline UN & enrichment $=10.2 \mathrm{wt} \%$ enrichment $\mathrm{U}-235$ & $1.001 \pm 0.001$ \\
\hline UPuN & $\begin{array}{l}\text { In } \mathrm{HM}=9 \mathrm{wt} \% \mathrm{Pu}^{*}, 91 \mathrm{wt} \% \mathrm{U} \text { with } 0.2 \mathrm{wt} \% \mathrm{U}-235 \\
\mathrm{Pu} \text { vector } 238 / 239 / 240 / 241 / 242=2 / 58 / 26 / 10 / 4 \mathrm{wt} \%\end{array}$ & $1.001 \pm 0.001$ \\
\hline UThN & In $\mathrm{HM}=30 \mathrm{wt} \% \mathrm{Th}-232,70 \mathrm{wt} \% \mathrm{U}$ with $16.6 \mathrm{wt} \% \mathrm{U}-235$ enrichment $^{*}$ & $1.003 \pm 0.001$ \\
\hline \multicolumn{3}{|l|}{ Carbides } \\
\hline UC & enrichment $=9.8 \mathrm{wt} \% \mathrm{U} 235$ & $1.006 \pm 0.002$ \\
\hline $\mathrm{UPuC}$ & $\begin{array}{l}\text { In } \mathrm{HM}=9.7 \mathrm{wt} \% \mathrm{Pu}, 90.3 \mathrm{wt} \% \mathrm{U} \text { with } 0.2 \mathrm{wt} \% \mathrm{U}-235 \\
\mathrm{Pu} \text { vector } 238 / 239 / 240 / 241 / 242=2 / 58 / 26 / 10 / 4 \mathrm{wt} \%\end{array}$ & $1.002 \pm 0.001$ \\
\hline UThC & In $\mathrm{HM}=30 \mathrm{wt} \% \mathrm{Th} 232,70 \mathrm{wt} \% \mathrm{U}$ with $16.0 \mathrm{wt} \% \mathrm{U}-235$ & $1.000 \pm 0.001$ \\
\hline \multicolumn{3}{|l|}{ Metallic } \\
\hline $\mathrm{UZr}$ & $60 \mathrm{wt} \% \mathrm{U}$ with enrichment $=8.7 \mathrm{wt} \% \mathrm{U} 235,10 \mathrm{wt} \% \mathrm{Zr}$, & $1.004 \pm 0.001$ \\
\hline UPuZr & $\begin{array}{l}10 \mathrm{wt} \% \mathrm{Zr}, 7.2 \mathrm{wt} \% \mathrm{Pu}^{*}, 82.8 \mathrm{wt} \% \mathrm{U} \text { with } 0.2 \mathrm{wt} \% \mathrm{U}-235 \\
\text { Pu vector } 238 / 239 / 240 / 241 / 242=2 / 58 / 26 / 10 / 4 \mathrm{wt} \%\end{array}$ & $1.007 \pm 0.001$ \\
\hline UThZr & $60 \mathrm{wt} \% \mathrm{U}$ with enrichment $=15 \mathrm{wt} \% \mathrm{U} 235,30 \% \mathrm{Th}, 10 \mathrm{wt} \% \mathrm{Zr}$ & $1.006 \pm 0.001$ \\
\hline PuThZr & $\begin{array}{l}\text { 10wt } \% \mathrm{Zr}, 10.2 \mathrm{wt}^{\circ} \% \mathrm{Pu}^{*}, 79.8 \mathrm{wt} \% \mathrm{Th}-232 \\
\text { Pu vector 238/239/240/241/242=2/58/26/10/4wt\% }\end{array}$ & $1.007 \pm 0.001$ \\
\hline
\end{tabular}

${ }^{*}$ The enrichment or plutonium weight fraction was adjusted to attain a critical unit cell in an infinite lattice. i.e., $\mathrm{k}_{\mathrm{inf}} \sim 1$ 
Table 10 shows the density and reactor-physics characteristics of interest for each fuel type. The densities were either taken from tables of properties (where available) or calculated as 95\% theoretical densities using the weight fractions of nuclides present in a given fuel. The initial conversion ratios were calculated from the conventional definition, i.e., the ratio of neutron capture in U-238 and in Th-232 to the neutron absorption rate in U-233, U-235, Pu-239, and Pu241.

Table 10. Characteristics of individual fuel types.

\begin{tabular}{|c|c|c|c|c|c|c|c|c|}
\hline Fuel type & $\begin{array}{l}\text { Density } \\
\left(\mathrm{g} / \mathrm{cm}^{3}\right)\end{array}$ & ICR $^{*}$ & $\begin{array}{l}\text { B }_{\mathrm{d}} \\
(\mathrm{MWd} / \\
\mathrm{kgHM})\end{array}$ & $\begin{array}{l}\sigma_{\mathrm{f}}(\mathrm{b}) \\
\text { fissile }^{* *}\end{array}$ & $\begin{array}{l}\sigma_{\mathrm{c}}(\mathbf{b}) \\
\text { fissile }^{* * *}\end{array}$ & $\begin{array}{l}\sigma_{\mathbf{c}}(\mathbf{b}) \\
\text { fertile }^{+}\end{array}$ & $\begin{array}{l}\text { Equil. } \\
\mathbf{N}_{\text {fissile }} / \\
\mathbf{N}_{\text {fertile }}\end{array}$ & $\begin{array}{l}\text { EOL } \\
\frac{N_{23}+N_{25}}{N_{U}}\end{array}$ \\
\hline \multicolumn{9}{|l|}{ Oxides } \\
\hline $\mathrm{UO}_{2}$ (reference) & 10.42 & 0.967 & 116 & 1.835 & 0.536 & 0.289 & 0.122 & \\
\hline \multicolumn{9}{|l|}{ Nitrides } \\
\hline UN & 13.61 & 0.988 & 87 & 1.697 & 0.459 & 0.246 & 0.114 & \\
\hline UPuN & 13.65 & 1.572 & 87 & 1.768 & 0.445 & 0.264 & 0.119 & \\
\hline UThN & 11.98 & 0.914 & 99 & $\begin{array}{l}2.472 / \\
1.710\end{array}$ & $\begin{array}{l}0.230 / \\
0.368\end{array}$ & \begin{tabular}{|l|}
$0.278 /$ \\
0.244
\end{tabular} & $\begin{array}{l}0.103 / \\
0.117\end{array}$ & 0.110 \\
\hline \multicolumn{9}{|l|}{ Carbides } \\
\hline $\mathrm{UC}$ & 12.95 & 1.067 & 91 & 1.718 & 0.475 & 0.258 & 0.118 & \\
\hline $\mathrm{UPuC}$ & 12.98 & 1.692 & 91 & 1.754 & 0.451 & 0.276 & 0.125 & \\
\hline UThC & 11.45 & 0.976 & 103 & $\begin{array}{l}2.502 / \\
1.705\end{array}$ & $\begin{array}{l}0.480 / \\
0.384\end{array}$ & $\begin{array}{l}0.291 / \\
0.257\end{array}$ & $\begin{array}{l}0.098 / \\
0.123\end{array}$ & 0.106 \\
\hline \multicolumn{9}{|l|}{ Metallic } \\
\hline $\mathrm{UZr}$ & 15.2 & 1.114 & 82 & 1.495 & 0.364 & 0.200 & 0.108 & \\
\hline UPuZr & 15.2 & 1.849 & 82 & 1.636 & 0.282 & 0.214 & 0.112 & \\
\hline UThZr & 13.1 & 1.015 & 95 & $\begin{array}{l}2.263 / \\
1.624\end{array}$ & $\begin{array}{l}0.200 / \\
0.253\end{array}$ & $\begin{array}{l}0.230 / \\
0.199\end{array}$ & $\begin{array}{l}0.09 / \\
0.106\end{array}$ & 0.103 \\
\hline PuThZr & 10.7 & 1.519 & 116 & $\begin{array}{l}2.311 / \\
1.634\end{array}$ & $\begin{array}{l}0.210 / \\
0.281\end{array}$ & 0.242 & 0.096 & 0.914 \\
\hline
\end{tabular}

* Internal conversion ratio at beginning-of-life is defined as $\frac{\phi\left(\Sigma_{c}^{28}+\Sigma_{c}^{02}+\Sigma_{c}^{40}\right)}{\phi\left(\Sigma_{a}^{25}+\Sigma_{a}^{49}+\Sigma_{c}^{41}\right)}$

${ }^{* *} \mathrm{U}-235$ for systems without $\mathrm{Pu}, \mathrm{Pu}-239$ for systems with plutonium and U-233/Pu-239 for systems with Th

${ }^{+}$U-238 for UPu systems and Th-232/U-238 for UTh systems

The discharge burnup after 15 years of fuel residence time is shown in the 4th column. It is defined per initial heavy metal mass and was calculated from the average pin linear heat rate of $100 \mathrm{MWd} / \mathrm{kg}$ - the average maximum burnup demonstrated for IFR metallic fuel. The same linear power was used for all fuel types, although it is to be noted that not all the fuels under investigation will necessarily withstand high burnups because of mechanical and pellet-cladding interaction constraints. For the fixed burnup limit, lower discharge burnup (for constant exposure time) indicates a possibility to increase power rating, hence fuels with low discharge burnups are 
preferable*. In this aspect, metallic IFR-type fuels provide the best performance, while $\mathrm{UO}_{2}$ fuels acquire the highest burnup.

Columns 5 and 6 show one-group effective cross sections of major fissile isotopes (U-235 for all U systems, Pu-239 for systems with plutonium and U-233 and Pu-239 for systems containing Th) for fission and capture, respectively. Column 7 lists capture cross sections for fertile isotopes (U238 for UPu systems and Th-232 and U-238 for UTh fuels). U-233 exhibits the largest fission and the smallest capture cross section. U-235 has the largest fission cross section in the $\mathrm{UO}_{2}$ fuel form and the smallest one in the metallic fuel form. This is consistent with the trend that the harder the spectrum, the smaller the cross-section. A similar trend can be observed for capture cross sections, but the decrease of capture cross-section with spectrum hardening is more pronounced than the changes of fission cross-section. Thus the fission to capture cross-section ratio increases when moving to metallic fuel resulting in higher reactivity for fixed enrichment or lower enrichment requirement for fixed reactivity.

The one-group effective capture cross section of major fertile isotopes (U-238 for UPu fuels and Th-232 and U-238 for UTh systems) is shown in column 7. The cross section is the largest for $\mathrm{UO}_{2}$ (the softest spectrum), and is decreasing through carbide, nitride and finally metallic fuels, which exhibit the smallest values. Notwithstanding this fact, the initial conversion ratio is the largest for metallic fuels due to their favorable fission to capture cross-section ratio.

The next column shows the equilibrium fissile to fertile number densitration. This characteristic was obtained by equating production to destruction. Note that U-233 exhibits smaller fissile over fertile nuclide ratio than U-235 or Pu-239. Therefore, there is significantly less U-233 bred in thorium fuels than $\mathrm{Pu}-239$ in fuels with U-238 fertile material. In addition, U-233 has a lower $\eta$ value than $\mathrm{Pu}-239$. Thus, the thorium-uranium systems have less promising potential for internal breeding and achievement of long core life. In addition, the proliferation resistance criterion requires that the ratio of U-233+U-235 nuclides to total number of uranium nuclides is less than $12 \%$. Therefore, Th-232 must be loaded together with U-238 to denature U-233, which strictly limits the benefits of Th. The last column, which shows the above ratio for individual thorium fuels at the end-of-life (after 15 EFPYs of exposure), indicates that for the initial Th weight fraction of $30 \mathrm{wt} \%$, the proliferation limit of the discharged fuel is satisfied. However, the margin is relatively small and further increase of thorium fraction in the fuel is very limited, especially in case of nitride fuels where this limit is almost reached at $30 \mathrm{wt} \%$ of thorium. If thorium only is used as fertile material, very clean U-233 is present in discharged fuel, as the last line of Table 10 indicates.

The development of $\mathrm{k}_{\mathrm{inf}}$ as a function of burnup is shown in Figure 18. The lead-bismuth coolant provides a hard spectrum, which results in a significant contribution of fissions of even nuclides and thus an increase of fuel quality resulting in a reactivity rise with exposure time for all fuels ${ }^{* *}$ considered. Clearly, metallic fuels provide the best breeding potential. They are followed by carbide fuels, nitride fuels, and finally the oxides. Within one fuel category, plutonium fuels exhibit the largest reactivity increase, U-235 driven fuels are the next and the fuels containing Th

\footnotetext{
${ }^{*}$ In the future, the differences in the burnup limit due to pellet-cladding interactions and other constraints for individual fuel types must be considered.

** This increase is valid for an infinite unit cell, but does not necessarily mean that the same trend will be observed for a real system where a fraction of neutrons is consumed in parasitic absorptions and leakage out of the core. Therefore, less neutrons are available for breeding, which will result in reactivity reduction with burnup for low-ICR fuels.
} 
show the smallest reactivity rise. Note that larger reactivity increases are desirable since higher reactivity excess provides more option space to counteract the coolant void worth challenge through enhanced leakage while maintaining still enough neutrons for breeding.

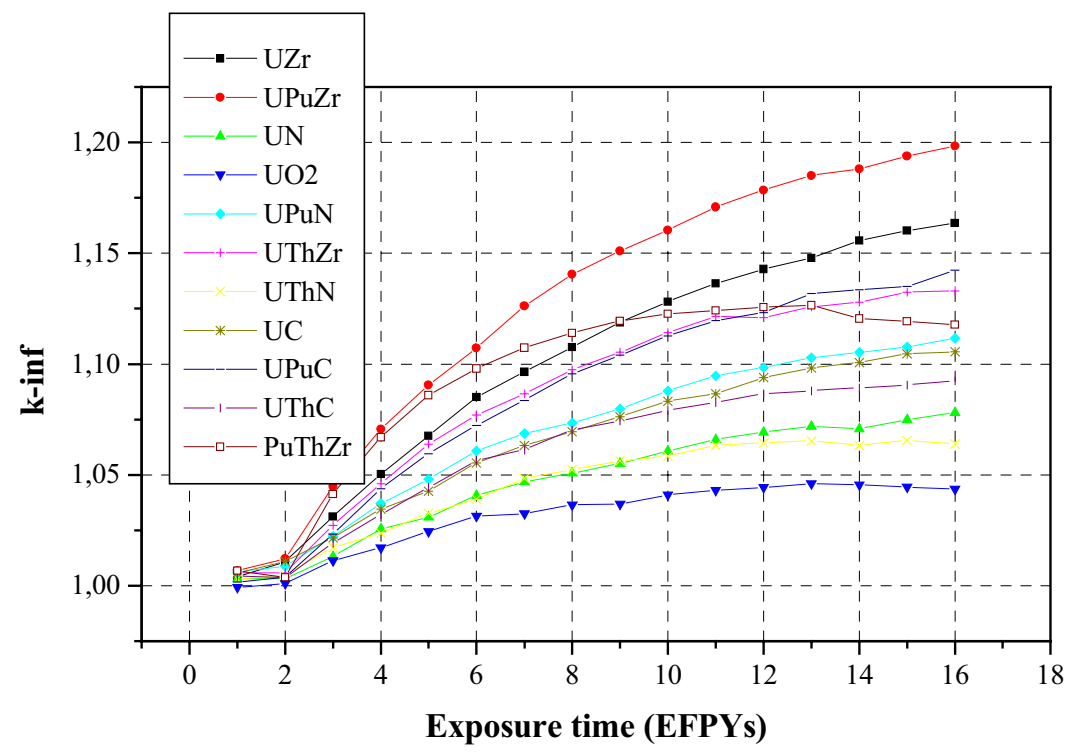

Figure 18. Development of $k_{\text {inf }}$ in a unit cell of an infinite lattice for various fuel types.

Other calculated characteristics involved the amount of heavy metal going to a permanent repository, its radioactivity, thermal power and radioactive ingestion hazard. The calculations assumed that the reactor was operated at full power for 15 EFPYs, the discharged fuel went through 50 years of cooling (10 years in the pools at the nuclear power plant and 40 years in dry storage) before being deposited in the permanent repository. The results are presented in Table 11.

Table 11. Total mass, activity, thermal power and radioactive ingestion hazard per 1 MT of fuel after 15 EFPY of operation and 50 years cooling after discharge from reactor.

\begin{tabular}{|l|l|l|l|l|l|}
\hline Fuel & $\begin{array}{l}\text { Actinide mass } \\
(\mathbf{k g})\end{array}$ & $\begin{array}{l}\text { TRU } \\
(\mathbf{k g})\end{array}$ & $\begin{array}{l}\text { Activity } \\
(\mathbf{C i})\end{array}$ & $\begin{array}{l}\text { Thermal power } \\
(\mathbf{W})\end{array}$ & $\begin{array}{l}\text { Ingestion hazard } \\
\text { in } \mathbf{~ m}^{\mathbf{3}} \mathbf{\text { of water }}\end{array}$ \\
\hline $\mathrm{UN}$ & 879 & 77.71 & $1.14 \mathrm{E}+04$ & $2.86 \mathrm{E}+02$ & $1.85 \mathrm{E}+09$ \\
\hline UC & 887 & 81.13 & $1.21 \mathrm{E}+04$ & $3.01 \mathrm{E}+02$ & $1.95 \mathrm{E}+09$ \\
\hline UZr & 840 & 66.84 & $8.28 \mathrm{E}+03$ & $2.16 \mathrm{E}+02$ & $1.40 \mathrm{E}+09$ \\
\hline UThN & 872 & 80.89 & $1.34 \mathrm{E}+04$ & $3.66 \mathrm{E}+02$ & $2.00 \mathrm{E}+09$ \\
\hline UThC & 876 & 86.51 & $1.50 \mathrm{E}+04$ & $4.04 \mathrm{E}+02$ & $2.24 \mathrm{E}+09$ \\
\hline UThZr & 833 & 70.23 & $1.12 \mathrm{E}+04$ & $3.15 \mathrm{E}+02$ & $1.64 \mathrm{E}+09$ \\
\hline UPuN & 875 & 121.36 & $8.91 \mathrm{E}+04$ & $1.70 \mathrm{E}+03$ & $1.15 \mathrm{E}+10$ \\
\hline UPuC & 883 & 124.28 & $8.88 \mathrm{E}+04$ & $1.70 \mathrm{E}+03$ & $1.15 \mathrm{E}+10$ \\
\hline UPuZr & 837 & 98.85 & $6.28 \mathrm{E}+04$ & $1.23 \mathrm{E}+03$ & $8.32 \mathrm{E}+09$ \\
\hline $\mathrm{UO}_{2}$ & 793 & 82.06 & $2.24 \mathrm{E}+04$ & $5.17 \mathrm{E}+02$ & $3.36 \mathrm{E}+09$ \\
\hline PuThZr & 810 & 113.04 & $8.84 \mathrm{E}+04$ & $1.86 \mathrm{E}+03$ & $1.10 \mathrm{E}+10$ \\
\hline
\end{tabular}

All TRUs except for naturally occurring actinides (all actinides minus Th-232, U-238 and U-235) 
The mass of discharged actinides sent to the permanent repository is roughly comparable for individual fuels. However, the amount of TRU, excluding the naturally occurring isotopes, per 1 MT of fuel to be disposed is appreciably higher for plutonium driven fuels. Metallic fuels have the most favorable heavy metal inventory per 1 MT of fuel to be disposed. Comparison of the discharged actinide mass inventory with a typical $\mathrm{UO}_{2}$-fueled PWR showed that the high conversion concept with UZr fuel would discharge approximately 3 times less actinides per year per MWhr than a typical PWR. (Assuming a PWR power output of $1142 \mathrm{MWe}$, plant efficiency of $33.5 \%$, fuel inventory of 101 tones of $\mathrm{UO}_{2}$, burnup of $33 \mathrm{GWd} / \mathrm{t}$, and 3 cycles with the replacement of $1 / 3$ rd of the core inventory once a year.) Increasing the burnup of metallic fuel to $200 \mathrm{MWd} / \mathrm{kg}$ can further significantly reduce the amount of waste.

UZr fuel exhibits the smallest radioactivity and ingestion hazard. The carbide fuels tend to have a larger hazard than the nitride fuels but less than oxide fuel. All fuel types containing plutonium in the initial loading have by almost an order of magnitude higher toxicity than other fuel forms. In the thorium-based fuels, the activity of polonium, radon, radium and other isotopes from the thorium decay chain provide a significant contribution of the overall fuel activity, which degrades the benefits of thorium fuels. Similar trends can be observed for thermal power. The decay heat is by far the smallest for UZr fuel and significantly larger than any other fuel types (by an order of magnitude) in plutonium fuels. High decay heat levels in plutonium fuels are the consequence of a high content of Pu-238 and Am-241, which are strong alpha emitters with a half life of 87.7 and 432.7 years, respectively.

To meet proliferation resistance criteria appears to be the key challenge of the lead-bismuth cooled long life reactor. Table 12 compares plutonium vectors and the spontaneous neutron generation rate of plutonium in the discharged fuel with weapons-grade and PWR plutonium. The uranium -fueled systems, including those with U-238 denatured Th-232 show a very high content of Pu-239. The reason for this phenomenon lies in the high U-238 capture to fission of $\mathrm{Pu}-239$ ratio (compare 0.12 for the high conversion concept versus 0.0085 for a PWR). The best fuel from the proliferation viewpoint, if one considers only the plutonium threat is the PuThZr fuel, which has a very high $\mathrm{Pu}-240$ and $\mathrm{Pu}-238$ fraction, comparable to that of a PWR. However, the almost pure $\mathrm{U}-233$ in this fuel poses a significant proliferation threat.

Table 12. Plutonium vector for discharged fuel and spontaneous neutron production.

\begin{tabular}{|c|c|c|c|c|c|c|}
\hline & $\begin{array}{l}\text { Weapons } \\
\text { grade }\end{array}$ & $\mathbf{U N}$ & $\mathbf{U C}$ & $\mathbf{U Z r}$ & UThN & UThC \\
\hline \multicolumn{7}{|c|}{ Pu composition (wt\%) } \\
\hline $\mathrm{Pu}-238$ & 0.012 & 0.28 & 0.27 & 0.21 & 0.45 & 0.48 \\
\hline Pu-239 & 93.80 & 91.23 & 91.06 & 93.06 & 90.88 & 90.20 \\
\hline $\mathrm{Pu}-240$ & 5.80 & 8.43 & 8.60 & 6.70 & 8.61 & 9.25 \\
\hline Pu-241 & 0.35 & 0.04 & 0.04 & 0.03 & 0.04 & 0.04 \\
\hline $\mathrm{Pu}-243$ & 0.022 & 0.02 & 0.02 & 0.01 & 0.02 & 0.03 \\
\hline Total $\mathrm{Pu}(\mathrm{kg})$ & - & 64.71 & 68.23 & 57.05 & 43.86 & 47.78 \\
\hline \multicolumn{7}{|c|}{ Spontaneous neutron production (n/kg-s) } \\
\hline & $5.35 E+04$ & $1.02 \mathrm{E}+05$ & $1.01 \mathrm{E}+05$ & $8.81 \mathrm{E}+04$ & $1.29 \mathrm{E}+05$ & $1.35 \mathrm{E}+05$ \\
\hline
\end{tabular}


Table 12. Plutonium vector for discharged fuel and spontaneous neutron production (continued).

\begin{tabular}{|c|c|c|c|c|c|c|c|}
\hline & UThZr & UPuN & UPuC & UPuZr & $\mathbf{U O}_{2}$ & PuThZr & PWR* \\
\hline \multicolumn{8}{|c|}{$\mathrm{Pu}$ composition $(\mathrm{wt} \%)$} \\
\hline $\mathrm{Pu}-238$ & 0.38 & 0.92 & 0.89 & 0.22 & 0.51 & 2.22 & 2.40 \\
\hline $\mathrm{Pu}-239$ & 92.46 & 70.49 & 71.13 & 74.68 & 86.72 & 36.68 & 54.20 \\
\hline $\mathrm{Pu}-240$ & 7.12 & 24.84 & 24.36 & 21.73 & 12.62 & 50.72 & 22.30 \\
\hline $\mathrm{Pu}-241$ & 0.03 & 0.29 & 0.28 & 0.24 & 0.08 & 0.63 & 14.90 \\
\hline $\mathrm{Pu}-243$ & 0.02 & 3.46 & 3.34 & 3.13 & 0.07 & 9.75 & 6.20 \\
\hline Total Pu(kg) & 36.89 & 115.82 & 118.79 & 94.80 & 79.82 & 42.83 & - \\
\hline \multicolumn{8}{|c|}{ Spontaneous neutron production (n/kg-s) } \\
\hline & $1.15 \mathrm{E}+05$ & $2.24 \mathrm{E}+05$ & $2.19 \mathrm{E}+05$ & $2.00 \mathrm{E}+05$ & $1.44 \mathrm{E}+05$ & $4.66 \mathrm{E}+05$ & $3.72 \mathrm{E}+05$ \\
\hline
\end{tabular}

$\mathrm{UO}_{2}$ fuel, burnup 45MWD/kg, taken from Herring and MacDonald (1999).

The consequences of fuel choices in a hard spectrum lead-bismuth cooled reactor are summarized in Table 13. Fuels driven by U-235 with U-238 fertile material exhibit high conversion ratios and reactivity gain and have the smallest ingestion hazard, waste inventory, decay heat, and radioactivity of discharged fuel. On the other hand, they pose the worst proliferation threat since the bred-in plutonium has a high content of Pu-239. Among those candidates, metallic UZr fuel has the best reactivity and waste indicators, but the worst proliferation aspect with a plutonium vector close to that of weapon grade plutonium. Generally, it can be stated that with respect to curie and TRU discharge inventory and ingestion hazard, chemical fuel forms can be ranked from metallic fuels (lowest) to nitrides, carbides and oxides with highest values. The difference between the nitride and carbide fuels is small. The fuels that have plutonium as the fissile material exhibit a significantly higher ingestion hazard and curie inventory. Fuels with Th-232 as the fertile material produce less plutonium, nevertheless, their fuel toxicity is slightly higher than that of the U-238 fuels.

\subsubsection{Design Approaches for both Actinide Burning and Low Cost Electrical Production}

\subsubsection{Neutronics analysis.}

Analysis Tools. The current work uses the MOCUP (Moore et al. 1995) code to analyze the reactivity characteristics and isotopic concentrations of unit fuel pins/cells. For this particular problem, 38 actinides and 50 fission products are being tracked through the MCNP portion of the analysis, which accounts for $>95 \%$ of the parasitic adsorptions in the fuel. The cross section sets used for the MCNP calculations are based on the ENDF/B-V and ENDF/B-VI data tables, including temperature dependent sets that were produced from these tables.

Fuel Parameters. Because one of the goals of this reactor is to burn actinides rather than using enriched fuel, the composition of the fuel must be carefully chosen so as to limit or reduce the production of actinides, yet the reactor must still be capable of long refueling cycles. This particular requirement would seem to favor thorium over uranium as a fertile material, especially if minimization of minor actinide and fissile plutonium production in the reactor is considered the more important factor. However, the production of U-233 from thorium must also be considered as a proliferation concern, which would necessitate the addition of some uranium to the fuel (preferably in the form of depleted uranium). 
Table 13. Consequences of hard spectrum lead-bismuth fuel choices.

\begin{tabular}{|c|c|c|c|}
\hline FISSILE & FERTILE & PRO & $\mathrm{CON}$ \\
\hline \multirow[t]{3}{*}{$\begin{array}{l}\text { U-235@ } \leq 20 \\
\text { w/o } \\
\text { enrichment }\end{array}$} & U-238 & $\begin{array}{l}\text { - Fresh core fuel is not weapons usable } \\
\text { - Lowest radioactivity, decay heat and } \\
\text { radioactive ingestion hazard of spent } \\
\text { fuel } \\
\text { - The smallest mass of spent fuel } \\
\text { - Very high conversion ratio }\end{array}$ & - Produces weapons grade plutonium \\
\hline & Th-232 & $\begin{array}{l}\text { - U-233 is denatured by U-238 } \\
\text { - Less plutonium production } \\
\text { - Spent fuel toxicity only slightly higher }\end{array}$ & $\begin{array}{l}\text { - Limited to } \leq 30 \text { w/o Th because of } \\
\text { enrichment limit on U-235 } \\
\text { - Lowest conversion ratio } \\
\text { - Highest initial enrichment } \\
\text { - Lowest heavy metal loading }\end{array}$ \\
\hline & None & $\begin{array}{l}\text { Option Not Feasible Due to } \\
\text { U-235 Enrichment Limit }\end{array}$ & \\
\hline \multirow[t]{3}{*}{$\begin{array}{l}\text { Pu: LWR } \\
\text { Spent Fuel or } \\
\text { Weapons } \\
\text { Surplus; With } \\
\text { or Without } \\
\text { Minor } \\
\text { Actinides }\end{array}$} & U-238 & $\begin{array}{l}\text { - Highest conversion ratio } \\
\text { - Smallest initial fissile enrichment }\end{array}$ & $\begin{array}{l}\text { - Fresh core is an inventory of weapons- } \\
\text { usable plutonium } \\
\text { - So is spent fuel } \\
\text { - High neutron flux, hence high dpa due to } \\
\text { low fissile loading } \\
\text { - High radioactivity, decay heat and } \\
\text { radioactive ingestion hazard of spent fuel }\end{array}$ \\
\hline & Th-232 & $\begin{array}{l}\text { - High plutonium destruction rate } \\
\text { - Appreciable U-232 production }\end{array}$ & $\begin{array}{l}\text { - Produces weapons grade U-233 } \\
\text { - Highest neutron flux and dpa } \\
\text { - High radioactivity, decay heat and } \\
\text { radioactive ingestion hazard of spent fuel }\end{array}$ \\
\hline & $\begin{array}{ll}\text { None } & (\mathrm{Pu} \\
\text { and/or } & \mathrm{MA} \\
\text { Burner }) & \end{array}$ & $\begin{array}{l}\text { - High plutonium/MA destruction rate } \\
\text { - Spent fuel not weapons usable }\end{array}$ & $\begin{array}{l}\text { - Large cycle } \Delta \mathrm{k} \text {, small } \beta \text { and Doppler } \\
\Delta \mathrm{k} \text { - especially if MA-only }\end{array}$ \\
\hline \multicolumn{4}{|c|}{ Ranking of performance characteristics } \\
\hline \multicolumn{2}{|c|}{ Characteristic } & Rank with chemical fuel form & Rank with fissile/fertile isotope \\
\hline \multicolumn{2}{|c|}{$\begin{array}{l}\text { Conversion ratio } \\
\text { Reactivity gain } \\
\text { Discharged TRU inventory } \\
\text { Curie Inventory } \\
\text { Thermal decay power } \\
\text { Ingestion hazard } \\
\text { Discharged } \mathrm{Pu} \text { inventory } \\
\% \mathrm{Pu}-239 \text { in } \mathrm{Pu}\end{array}$} & $\begin{array}{l}\text { Metal }(\mathrm{Zr})>\text { Carbide }>\text { Nitride }>\text { Oxide } \\
\text { Metal }(\mathrm{Zr})>\text { Carbide }>\text { Nitride }>\text { Oxide } \\
\text { Oxide }>\text { Carbide }>\text { Nitride }>\text { Metal }(\mathrm{Zr}) \\
\text { Oxide }>\text { Carbide }>\text { Nitride }>\text { Metal }(\mathrm{Zr}) \\
\text { Oxide }>\text { Carbide }>\text { Nitride }>\text { Metal }(\mathrm{Zr}) \\
\text { Oxide }>\text { Carbide }>\text { Nitride }>\text { Metal }(\mathrm{Zr}) \\
\text { Oxide }>\text { Carbide }>\text { Nitride }>\text { Metal }(\mathrm{Zr}) \\
\text { Metal }(\mathrm{Zr})>\text { Nitride } \approx \text { Carbide }>\text { Oxide }\end{array}$ & $\begin{array}{l}\mathrm{Pu}>>\mathrm{U}-235 ; \mathrm{U}-238>\mathrm{Th}-232 \\
\mathrm{Pu}>>\mathrm{U}-235 ; \mathrm{U}-238>>\mathrm{Th}-232 \\
\mathrm{Pu}>>\mathrm{U}-235 ; \mathrm{Th}-232>\mathrm{U}-238 \\
\mathrm{Pu}>>\mathrm{U}-235 ; \mathrm{Th}-232>\mathrm{U}-238 \\
\mathrm{Pu}>>\mathrm{U}-235 ; \mathrm{Th}-232>\mathrm{U}-238 \\
\mathrm{Pu}>>\mathrm{U}-235 ; \mathrm{Th}-232>\mathrm{U}-238 \\
\mathrm{Pu}>>\mathrm{U}-235 ; \mathrm{U}-238>>\mathrm{Th}-232 \\
\mathrm{U}-235>\mathrm{Pu} ; \mathrm{U}-238>>\text { Th-232 }\end{array}$ \\
\hline
\end{tabular}

The fuels studied were metallic and nitride, with the fertile material consisting of naturally occurring uranium and thorium. The different fuel types studied had a constant pitch to diameter ratio of 1.6 using a square pitch, a core power of $830 \mathrm{MW}(\mathrm{th})$, and an initial plutonium plus minor actinide $(\mathrm{Pu}+\mathrm{MA})$ loading that varied from 13 to $20 \mathrm{wt} \%$. Table 14 gives a summary of the fuel compositions. 
Table 14. Beginning-of-life fuel composition.

\begin{tabular}{|c|c|c|c|c|c|c|}
\hline & $\mathrm{U}-\mathrm{Zr}$ & $\mathrm{U}-\mathrm{Zr}$ & $\mathbf{U}-\mathbf{N}$ & $\mathbf{U}-\mathbf{N}$ & Th-Zr & Th-N \\
\hline U or Th (wt\%) & $70 \%$ & $76.9 \%$ & $74.5 \%$ & $79.2 \%$ & $70 \%$ & $74.4 \%$ \\
\hline $\mathrm{Zr}$ or $\mathrm{N}(\mathrm{wt} \%)$ & $10 \%$ & $10.0 \%$ & $5.5 \%$ & $5.5 \%$ & $10 \%$ & $5.6 \%$ \\
\hline $\mathrm{Pu}(\mathrm{wt} \%)$ & $16 \%$ & $10.5 \%$ & $16.0 \%$ & $12.2 \%$ & $16 \%$ & $16.0 \%$ \\
\hline MA (wt\%) & $4 \%$ & $2.6 \%$ & $4.0 \%$ & $3.1 \%$ & $4 \%$ & $4.0 \%$ \\
\hline \multicolumn{7}{|c|}{ BOL Pu Isotopic Fractions } \\
\hline $\begin{array}{c}\text { Pu-238 } \\
2 \%\end{array}$ & \multicolumn{2}{|c|}{$\begin{array}{c}\text { Pu-239 } \\
58 \%\end{array}$} & $\begin{array}{c}\text { Pu-240 } \\
26 \%\end{array}$ & Pu-241 & & Pu-242 \\
\hline \multicolumn{7}{|c|}{ BOL MA Isotopic Fractions } \\
\hline $\begin{array}{c}\text { Np-237 } \\
43 \%\end{array}$ & \multicolumn{2}{|c|}{$\begin{array}{c}\text { Am-241 } \\
45 \%\end{array}$} & \multicolumn{2}{|c|}{ Am-243 } & $\mathrm{Cm}-244$ & \\
\hline
\end{tabular}

The large pitch to diameter ratio results in a small thermal-hydraulic resistance in the core, and is an important consideration for total natural convective cooling. Future work will optimize the pitch to diameter ratio to account for forced flow, while allowing enough natural circulation in the core during a loss-of-flow accident to permit sufficient heat transfer to guarantee cladding integrity.

The next consideration in using these different fuel types is the reactor power level and power density. This issue becomes important for long-lived cores because the power density and amount of fissile material that will be needed to sustain a critical reactor will have to be adjusted or optimized based on the fluence limits for the cladding and structures (or possibly burnup limits for some fuels). The fissile components used for the current analysis are $\mathrm{Pu}-239$ and $\mathrm{Pu}-241$, and were kept at a constant ratio for the initial plutonium and minor actinide loading. Although choosing a constant weight ratio means that the atom densities, and therefore the total mass of the fissile plutonium will be different for each case, the results of the calculations can be used to extrapolate to an optimal fuel composition.

The current analysis has been limited to cylindrical pins placed in assemblies, with an average power density of $150 \mathrm{MW} / \mathrm{m}^{3}$. The calculations were performed using these pins in a unit cell with axial leakage and reflecting radial boundaries (Weaver et al. 2000a and 2000b). The parameters of the pin can be seen in Table 15 .

Table 15. Parameters of the cylindrical fuel pins.

\begin{tabular}{|l|l}
\hline \multicolumn{1}{|c|}{ Design Parameter } & \multicolumn{1}{|c}{ Value } \\
\hline Fuel OD & $0.864 \mathrm{~cm}$ \\
\hline Gap Thickness & $0.02 \mathrm{~cm}$ \\
\hline $\begin{array}{l}\text { Gap Material } \\
\text { (metallic fuel only) }\end{array}$ & $\begin{array}{l}33 \mathrm{wt} \% \mathrm{~Pb}-33 \mathrm{wt} \% \\
\mathrm{Sn}-33 \mathrm{wt} \% \mathrm{Bi}\end{array}$ \\
\hline Cladding Thickness & $0.063 \mathrm{~cm}$ \\
\hline Cladding OD & $1.03 \mathrm{~cm}$ \\
\hline P/D & 1.6 \\
\hline Active Fuel Height & $120 \mathrm{~cm}$ \\
\hline $\begin{array}{l}\text { Gas Plenum Height } \\
\text { (metallic fuel only) }\end{array}$ & $90 \mathrm{~cm}$ \\
\hline $\begin{array}{l}\text { Average Coolant } \\
\text { Density }\end{array}$ & $10.25 \mathrm{~g} / \mathrm{cm}^{3}$ \\
\hline
\end{tabular}


The metallic fuel has three interesting properties that are important to this type of fuel:

- the gas plenum above the fuel,

- axial expansion, and

- the materials used in the gap between the fuel and cladding.

$\bullet$

The gas plenum is used to store the fission gases as they diffuse from the metallic fuel. This plenum will be reduced somewhat from the value assumed in this analysis if a dispersion fuel is used, but currently there is insufficient information to choose an appropriate value. The gap material is used to enhance the overall thermal conductivity of the fuel rod. However, use of a dispersion fuel would probably eliminate the need for gap materials. It is important to note that other fuel geometries may show better neutronic or thermal-hydraulic properties, but will be studied in future work.

Void Reactivity Coefficient. While total and partial voiding of the core due to coolant overheating is nearly impossible because of the high boiling temperature of lead and leadbismuth, local voiding is considered to be a possibility. For example, a steam bubble might pass through the core due to a steam tube rupture, or a fission gas bubble might be released into the core due to fuel rod failure. Table $\mathbf{1 6}$ shows the reactivity results of voiding the center half of the fuel. Note that all of the fuels studied have a positive coefficient.

Table 16. Calculated local void reactivities at beginning-of-life for $20 \mathrm{wt} \%$ added TRU cases.

\begin{tabular}{|c|c|}
\hline & $\begin{array}{c}\text { Void } \\
\text { Reactivity } \\
(\% \Delta \mathbf{k} / \mathbf{k})\end{array}$ \\
\hline Metallic Fuel \\
\hline U-Zr & $1.49 \%$ \\
\hline Th-Zr & $1.17 \%$ \\
\hline Nitride Fuel \\
\hline U-N & $1.86 \%$ \\
\hline Th-N & $1.70 \%$ \\
\hline
\end{tabular}

The worth of the reactivity is dependent on the delayed neutron fraction $(\beta)$, which itself is dependent on the content of the fuel. MCNP was used to calculate the delayed neutron fraction and reactivity worth of the void, and they were found to be from $\$ 4$ to over $\$ 5$. This is a significant insertion of reactivity that would cause cladding failure due to overheating from a super-prompt-critical excursion, and requires modification of the core or assemblies. In section 4.1.1, a passive "streaming" assembly for a non-fertile fueled core was introduced that allows for neutron leakage in the axial and radial directions. The design compensates for the reactivity increase, and creates a negative coefficient due to local or total voiding of non-fertile assemblies. Recent work has shown that the streaming assembly design will not produce a negative local coefficient for uranium fueled cores, but will significantly reduce the positive coefficient. When combined with the negative Doppler coefficient, a combined negative coefficient will result.

Doppler Reactivity Coefficient. Current work done at MIT (see Section 4.1.1) has shown that, although small, the Doppler coefficient is negative for most fuel types. 
Reactivity Swing with Burnup. The burnup time steps taken in MOCUP for all cases were oneyear steps with no outages. Previous work has shown that a one-year time step is sufficient to obtain accurate results. The results of the metallic ( $\mathrm{Zr}$ based) fuels are summarized in Figure 19.

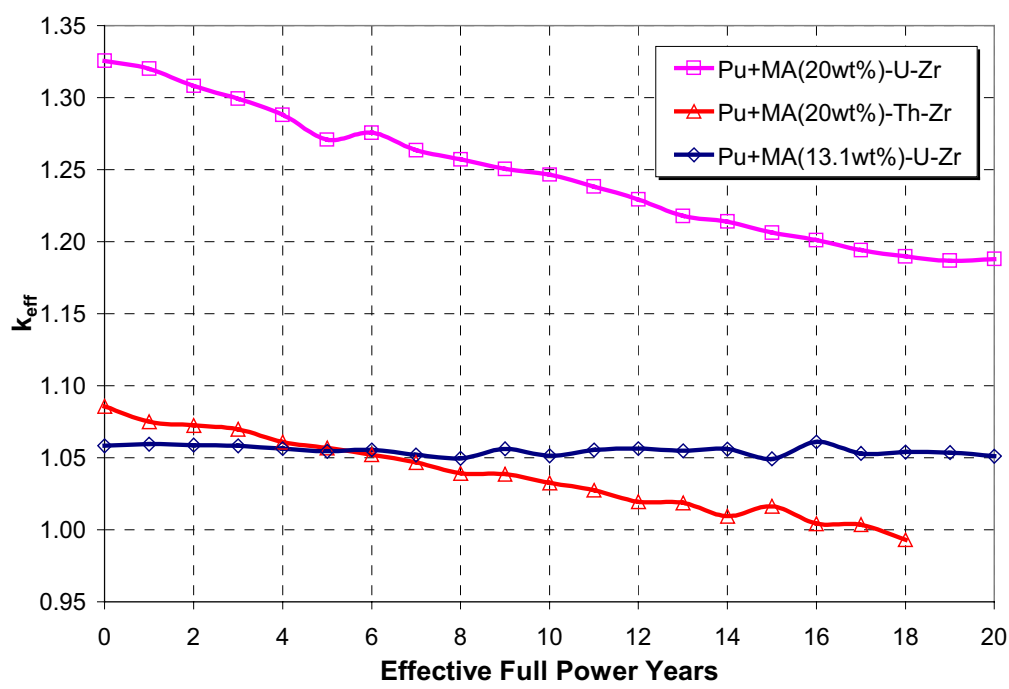

Figure 19. Reactivity comparison for metallic fuels.

The $\mathrm{Pu}+\mathrm{MA}(20 \mathrm{wt} \%) \mathrm{UZr}$ fuel has the highest reactivity at beginning-of-life, and has the potential for the longest life ( $\sim 50$ years). However, the excess reactivity at beginning-of-life is high, making it vulnerable to control rod ejection accidents, and a fuel/core life greater than 20 years may not be physically possible due to material neutron fluence and corrosion constraints. A more realistic comparison is made by lowering the initial plutonium and minor actinide weight percent, thus decreasing the beginning-of-life excess reactivity and shortening the life. This is shown with the initial $\mathrm{Pu}+\mathrm{MA}$ loading of $13.1 \mathrm{wt} \%$ for the PuUZr fuel. Of particular interest is the apparent zero slope of the reactivity curve for this loading; essentially no reactivity is lost during burnup through a 20-year period. Because lead/lead-bismuth cooled cores can be designed to attain an in-core breeding ratio of approximately one, the consumed fissile material is quickly replaced by new fissile material making breeding without fuel shuffling or blankets possible, as has been shown.

The $\mathrm{Pu}+\mathrm{MA}(20 \mathrm{wt} \%)$ ThZr fuel also has a low excess reactivity at beginning-of-life and a relatively long lifetime ( 18 years), but does not enjoy the apparent zero slope of its $\mathrm{UZr}$ counterpart. However, the advantages of using a thorium-based fuel are the small amount of actinides produced during burnup, and the small reactivity swing as compared to the $\mathrm{Pu}+\mathrm{MA}(20 \mathrm{wt} \%) \mathrm{UZr}$ fuel.

The excess reactivity and reactivity swing in the $\mathrm{Pu}+\mathrm{MA}(20 \mathrm{wt} \%) \mathrm{UN}$ fuel appear to be smaller than in the $\mathrm{Pu}+\mathrm{MA}(20 \mathrm{wt} \%) \mathrm{UZr}$ fuel, but the same problem exists. The $\mathrm{Pu}+\mathrm{MA}(20 \mathrm{wt} \%) \mathrm{UN}$ fuel still has a high beginning-of-life excess reactivity. As with the metallic fuel, a more realistic comparison is made by lowering the initial plutonium and minor actinide weight percent, as can be seen with the $\mathrm{Pu}+\mathrm{MA}(15.3 \mathrm{wt} \%) \mathrm{UN}$ fuel in Figure 20. The Pu+MA(15.3wt\%) UN is similar to the lower "enriched" metallic fuel; it has an apparent slope of zero for the reactivity swing through a 20 -year period. 


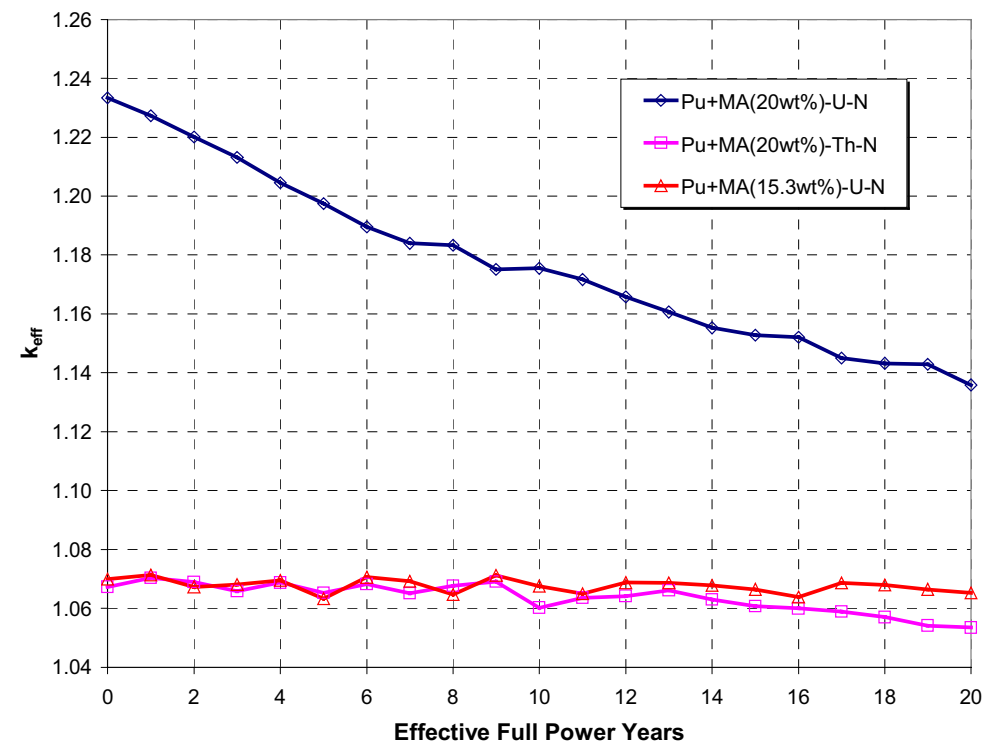

Figure 20. Reactivity comparison of nitride fuels.

The $\mathrm{Pu}+\mathrm{MA}(20 \mathrm{wt} \%) \mathrm{ThN}$ fuel, on the other hand, performs better than its metallic counterpart. It has a slightly smaller excess reactivity at beginning-of-life, and has a very small reactivity swing; k-effective remains almost constant for 20 years. A comparison of all the low reactivity swing cases can be seen in Figure 21.

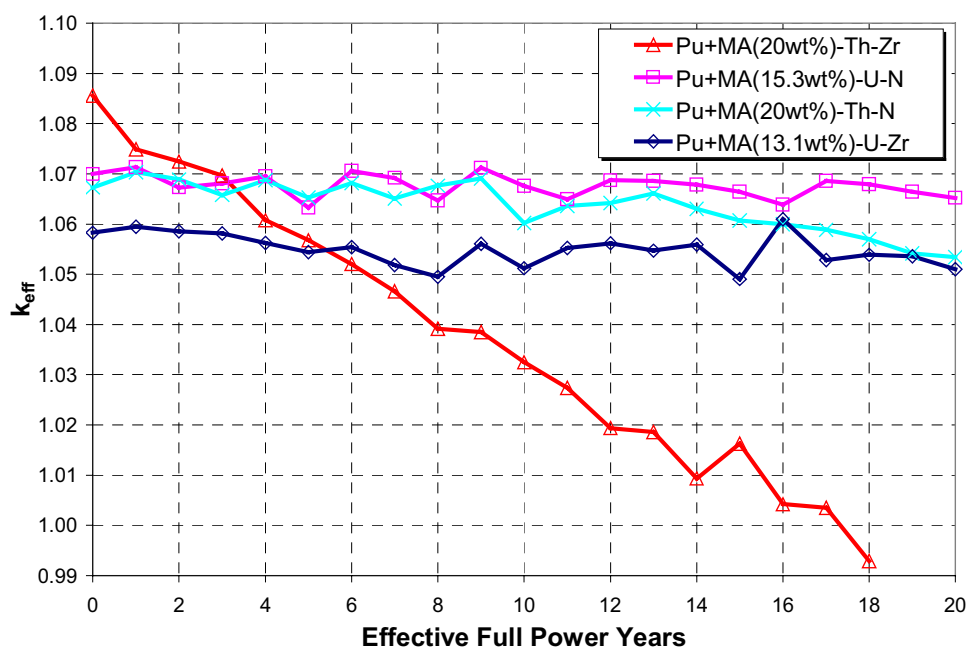

Figure 21. Comparison of small reactivity swing cases.

It appears from the data in Figure 21 that three of the cases may have long lifetimes ( $>20$ years), and could even have a lower excess reactivity at beginning-of-life if the $\mathrm{Pu}+\mathrm{MA}$ addition is decreased further. The implication is that a long core life could be achieved at an initial keffective of less than 1.01 , or a maximum reactivity insertion of $<1 \% \Delta \mathrm{k} / \mathrm{k}$. Thus the safety margin of this reactor for an inadvertent reactivity insertion (worst case scenario) would be very 
large, and autonomous operation is a valid possibility, given that the other reactivity feedback coefficients are satisfactory.

\subsubsection{Isotopic analysis.}

Actinide Destruction and Generation Rates. As stated previously, the actinide transmutation rate is dependent on whether fertile or non-fertile fuel is used, and whether the fertile material is uranium or thorium. Because one of the goals of this critical system is to burn actinides, it is desirable that the plutonium and minor actinide generation rate be less than the depletion rate (i.e., more is consumed than generated). The highest destruction rate of the initially loaded plutonium and minor actinides is achieved with non-fertile fuel. Figure 22 shows the average burnup rates of the six fertile fuel cases that are discussed in this section.

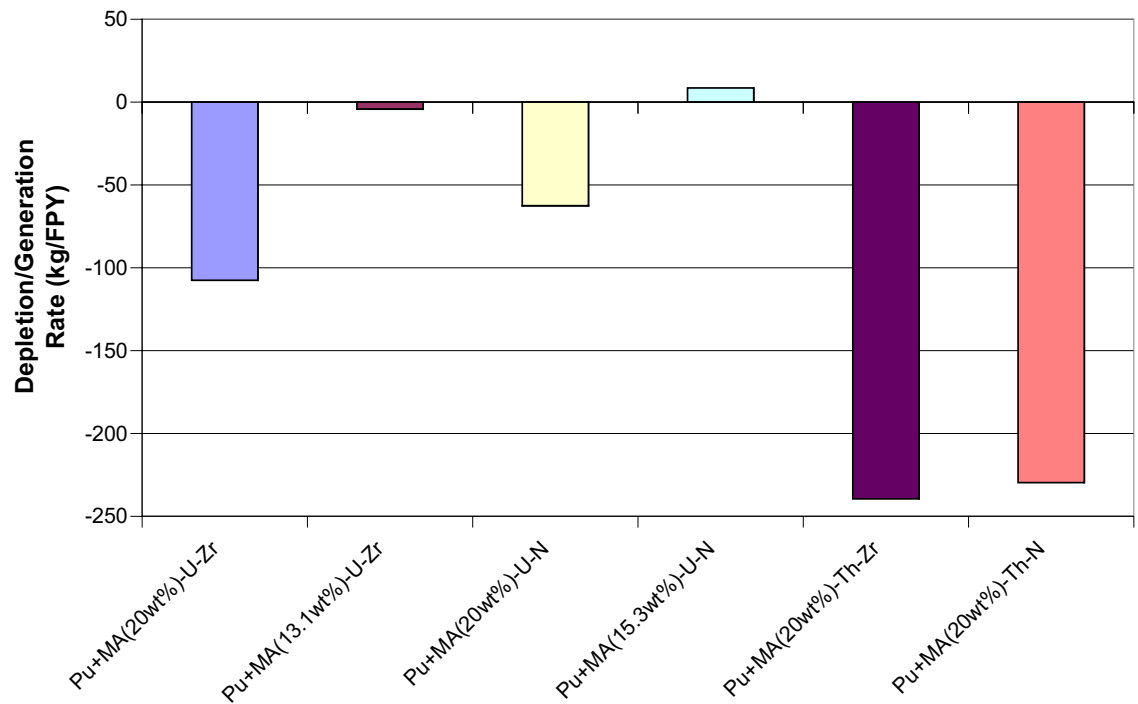

Figure 22. Average $\mathrm{Pu}+\mathrm{MA}$ burnup rates.

The depletion/generation rates of the initially loaded plutonium and minor actinides for the uranium fueled cores ranged from a small addition of $8 \mathrm{~kg} / \mathrm{FPY}$, to a depletion of $108 \mathrm{~kg} / \mathrm{FPY}$; where as the thorium fueled cores had a significantly larger overall net depletion rate of 230 to $239 \mathrm{~kg} / \mathrm{FPY}$. It is interesting to note that the overall net destruction rates for the thorium-based fuels are more than two times higher than the uranium fuel with the highest destruction rate.

Figures 23 and 24 show the specific isotopic generation/depletion rates for plutonium and some minor actinides in the uranium and thorium based fuels, respectively. 


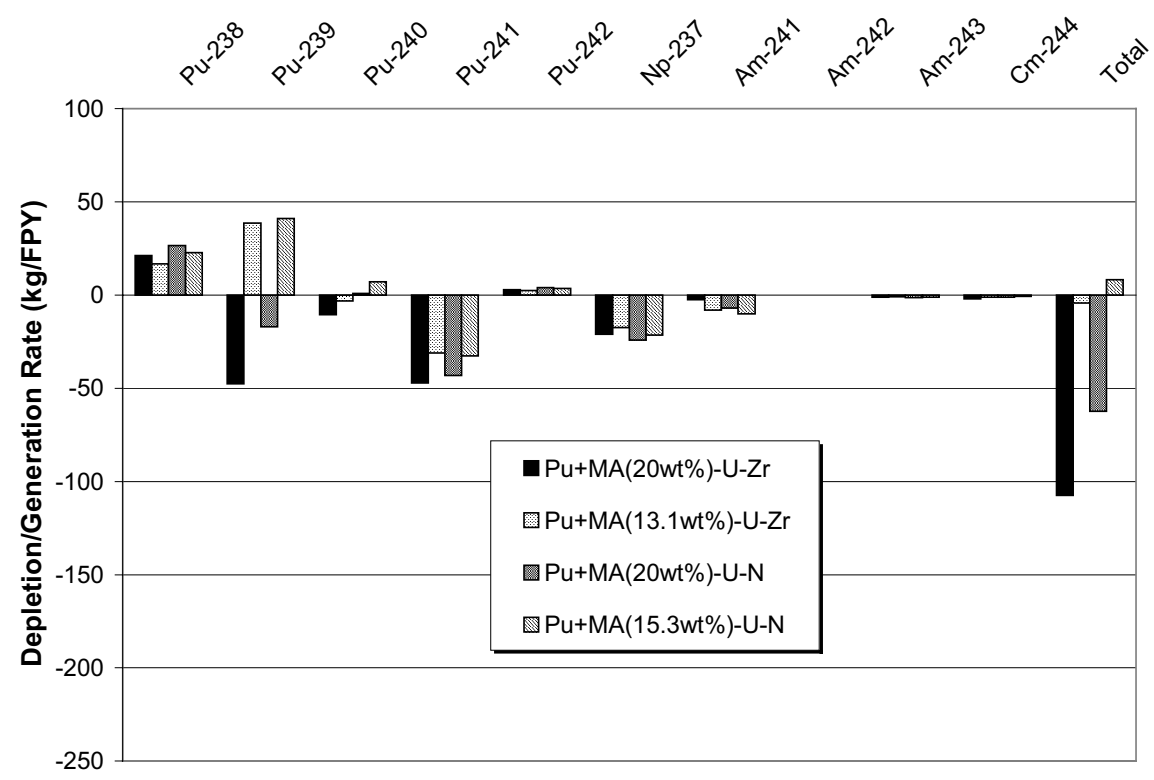

Figure 23. Average specific isotopic depletion/generation rates for uranium based fuels.

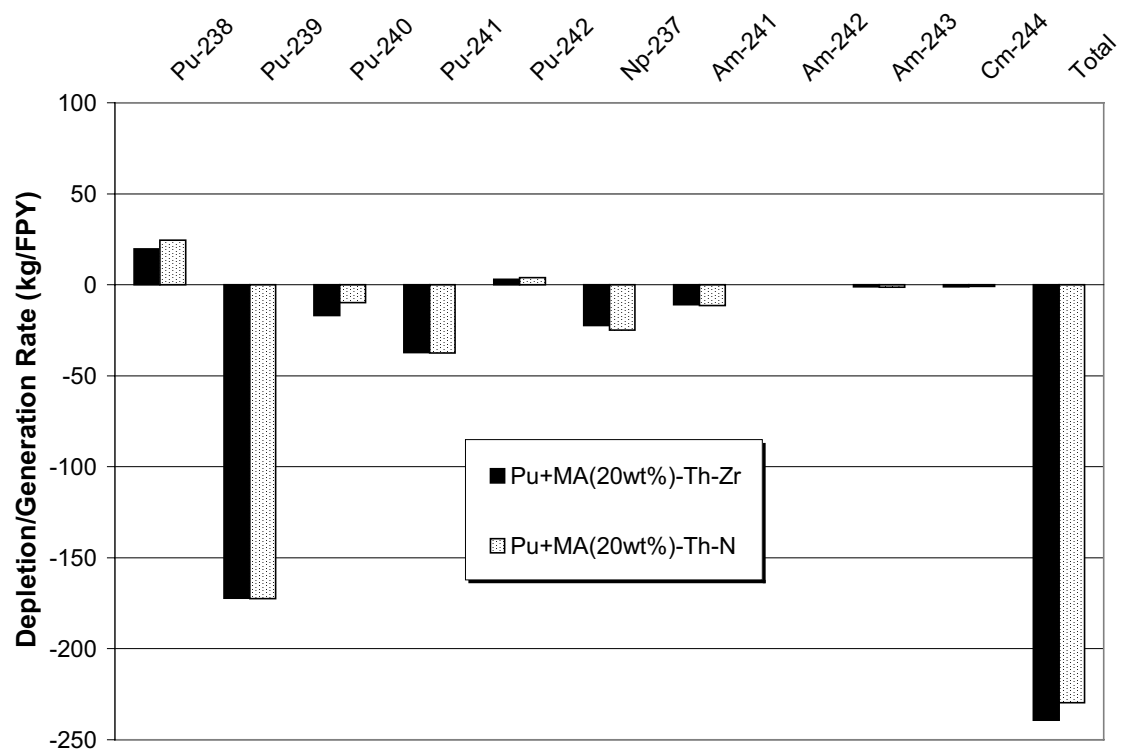

Figure 24. Average specific isotopic depletion/generation rates for thorium based fuels.

There are two important points to note here:

- The Pu-238 and -242 content increases in all cases. The effects of these two isotopes on the proliferation resistance of the fuel will be discussed later.

- The Pu-239 is depleted significantly in the thorium-based fuels, and in fact is the largest contributor to the total $\mathrm{Pu}+\mathrm{MA}$ depletion rate. However, the $\mathrm{Pu}-239$ concentration increases in two of the uranium cases; specifically those cases that are more attractive for their reactivity versus burnup curve. 
The reason for the higher Pu-239 content (and, therefore, lower destruction rate) for the uranium cases is the conversion of $\mathrm{U}-238$, with the $\mathrm{Pu}+\mathrm{MA}(15.3 \mathrm{wt} \%) \mathrm{UN}$ fuel having the highest net increase. This is due to the softer spectrum in the nitride fuels, resulting in more captures than in the metallic fuels.

Figure 25 shows the rate of production of U-233 in the thorium-based fuels, which also is a proliferation concern. Notice the faster increase of the U-233 in the nitride fuel as compared to the metallic fuel. This can be attributed to the larger thorium capture cross section in the softer spectrum of the nitride fuel, and the greater overall amount of thorium in the fuel, where the density of thorium is higher in the nitride fuel thus accounting for more U-233 being produced. As was mentioned earlier, it will be necessary to add other uranium isotopes (preferably depleted uranium) to prevent the U-233 from exceeding $12 \mathrm{wt} \%$ of the total uranium (Forsberg et al. 1999) to satisfy proliferation concerns.

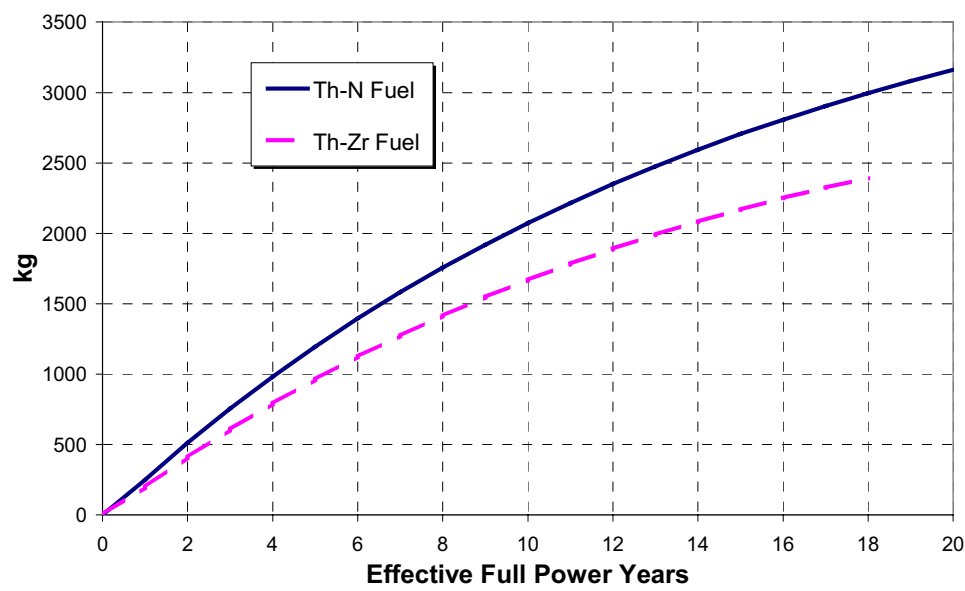

Figure 25. Production of U-233 in thorium based fuels.

Actinide Discharge. The beginning-of-life actinide loadings, and end-of-life plutonium and weapons usable material discharge for each fuel type can be seen in Table 17.

Table 17. Heavy metal loading and discharge ${ }^{5}$.

\begin{tabular}{|l|c|c|c|c|c|c|c|}
\hline Fuel & $\begin{array}{c}\text { Initial } \\
\text { Pu+MA } \\
\text { (wt\%) }\end{array}$ & $\begin{array}{c}\text { Initial } \\
\text { Pu+MA } \\
\text { (tonnes) }\end{array}$ & $\begin{array}{c}\text { Total } \\
\text { Initial HM } \\
\text { Loading } \\
\text { (tonnes) }\end{array}$ & EFPY & $\begin{array}{c}\text { Pu } \\
\text { Discharge } \\
\text { at EOL } \\
\text { (tonnes) }\end{array}$ & $\begin{array}{c}\text { Pu+MA } \\
\text { Discharge } \\
\text { at EOL } \\
\text { (tonnes) }\end{array}$ & $\begin{array}{c}\text { Pu } \\
\text { Consumption } \\
\text { Rate } \\
\text { (kg/FPY) }\end{array}$ \\
\hline $\mathrm{U}-\mathrm{Zr}$ & $20 \%$ & 16.8 & 75.5 & $>20$ & 11.9 & 14.6 & 80 \\
\hline $\mathrm{U}-\mathrm{Zr}$ & $13.1 \%$ & 11.0 & 75.3 & $>20$ & 9.2 & 10.9 & -23 \\
\hline $\mathrm{U}-\mathrm{N}$ & $20 \%$ & 16.0 & 76.8 & $>20$ & 12.3 & 14.8 & 29 \\
\hline $\mathrm{U}-\mathrm{N}$ & $15.3 \%$ & 12.3 & 76.8 & $>20$ & 10.7 & 12.4 & -43 \\
\hline $\mathrm{Th}-\mathrm{Zr}$ & $20 \%$ & 11.9 & 53.7 & 18 & 5.9 & 7.6 & 203 \\
\hline $\mathrm{Th}-\mathrm{N}$ & $20 \%$ & 13.7 & 65.3 & $>20$ & 7.1 & 9.1 & 194 \\
\hline
\end{tabular}

\footnotetext{
${ }^{5}$ The assumption is made that the initial fertile loading of natural uranium or thorium does not count in calculating the actinide discharge, or can be subtracted in the final tally since it is not weapons usable material.
} 
The weapons usable material discharge $(\mathrm{Pu}+\mathrm{MA})$ is 11 to 15 tonnes for the uranium based fuels after $20 \mathrm{FPY}$, and only 8 to 9 tonnes for the thorium based fuels after 18 to $20 \mathrm{FPY}$. This equates to a discharge rate of 550 to $750 \mathrm{~kg} /$ year for a uranium core, and about $450 \mathrm{~kg} /$ year for a thorium core. Because of the very long lifetimes of the fuel, fuel shuffling or reprocessing would be unnecessary. It is envisioned that the entire core would be discharged at end-of-life, and replaced by a fresh core.

The plutonium is depleted in all of the $20 \mathrm{wt} \%(\mathrm{Pu}+\mathrm{MA})$ cases, with the uranium fuels burning $29-80 \mathrm{~kg} /$ year, and the fertile thorium fuels burning 194-203 kg/year. In the $13.1 \mathrm{wt} \%(\mathrm{Pu}+\mathrm{MA})$ $\mathrm{U}-\mathrm{Zr}$ and $15.3 \mathrm{wt} \%(\mathrm{Pu}+\mathrm{MA}) \mathrm{U}-\mathrm{N}$ cases, the plutonium content increases by 23 and $43 \mathrm{~kg} /$ year, respectively. In the case of total plutonium discharged at end-of-life, the uranium fuels discharge 9 to 12 metric tons, with the thorium fuels discharging 6 to 7 metric tons.

Spent Fuel Isotopics. The isotopic fractions in the spent fuel are highly dependent on the fuel type, as can be seen in Table 18.

Table 18. Plutonium isotopics in the spent fuel for once through cycle.

\begin{tabular}{|c|c|c|c|c|c|c|c|}
\hline \multirow{2}{*}{ Fuel } & \multirow{2}{*}{$\begin{array}{c}\text { Initial } \\
\text { Pu+M } \\
\text { (wt\%) }\end{array}$} & \multirow{2}{*}{ EFPY } & \multicolumn{5}{|c|}{ Spent Fuel Pu Isotopic Fractions } \\
\cline { 4 - 8 } & & Pu-238 & Pu-239 & Pu-240 & Pu-241 & Pu-242 \\
\hline U-Zr & $20 \%$ & $>20$ & $5.9 \%$ & $57.8 \%$ & $27.8 \%$ & $3.5 \%$ & $5.1 \%$ \\
\hline U-Zr & $13.1 \%$ & $>20$ & $5.5 \%$ & $63.3 \%$ & $24.1 \%$ & $2.8 \%$ & $4.4 \%$ \\
\hline U-N & $20 \%$ & $>20$ & $6.4 \%$ & $57.8 \%$ & $27.4 \%$ & $3.5 \%$ & $4.9 \%$ \\
\hline U-N & $15.3 \%$ & $>20$ & $6.1 \%$ & $61.0 \%$ & $25.3 \%$ & $3.1 \%$ & $4.4 \%$ \\
\hline Th-Zr & $20 \%$ & 18 & $9.2 \%$ & $41.3 \%$ & $37.1 \%$ & $5.0 \%$ & $7.4 \%$ \\
\hline Th-N & $20 \%$ & $>20$ & $10.0 \%$ & $40.4 \%$ & $37.3 \%$ & $4.9 \%$ & $7.3 \%$ \\
\hline
\end{tabular}

Of special interest is the change in the fractions of both $\mathrm{Pu}-238$ and $\mathrm{Pu}-239$, where the $\mathrm{Pu}-238$ fraction increases in all cases. The Pu-239 content only changes slightly in the uranium cases and, in fact, increases slightly in two of the cases, but is significantly less in the thorium fuels. The thorium-based fuels contain the highest fractions of $\mathrm{Pu}-238$, at $9.2 \mathrm{wt} \%$ and $10 \mathrm{wt} \%$ for the metallic and nitride fuels respectively. Pu-238 concentrations of 8 to $10 \%$ provide a heat load which is high enough to melt the high explosives used in nuclear weapons unless the weapon is actively cooled, or constructed in parts (Herring and MacDonald 1999). This would be a difficult technical challenge for states without nuclear-weapons experience, or for sub-national groups.

The $\mathrm{Pu}-240$ and 242 fractions are also high in the thorium fuels. $\mathrm{Pu}-238,240$, and 242 produce copious amounts of spontaneous neutrons, significantly reducing the yield of any weapon built from these materials to a small fraction of the theoretical yield.

\subsection{MATERIALS COMPATIBILITY STUDIES}

The program is consists of two major tasks:

- the development of an understanding of the corrosion behavior of fuel cladding and core structural materials in lead-bismuth, and, 
- the development of a sensor that can be used to measure the oxygen potential of the system.

The corrosion behavior of these materials is being investigated via a rotating electrode experimental setup at MIT and a dynamic corrosion cell at INEEL. The oxygen sensor, while not essential for the initial experiments, is important for the measurement of the oxygen concentration in lead-bismuth. Knowledge of the oxygen concentration in the lead-bismuth is critical to the understanding of the relationship between oxygen potential and film formation kinetics.

\subsubsection{Corrosion Testing Activities}

During this reporting period, the collaborative experimental facilities at MIT and INEEL became operational. The initial designs were reviewed by all the participants at the FY-99 annual review meeting and the final designs were discussed at the FY-00 mid-year meeting in April. An overview of both faculties is provided below.

The "Spin" Tester has been designed and constructed at MIT and will be fully operational by $8 / 1 / 2000$, after initial melting experiments are completed. The MIT experimental apparatus is shown in Figure 26.

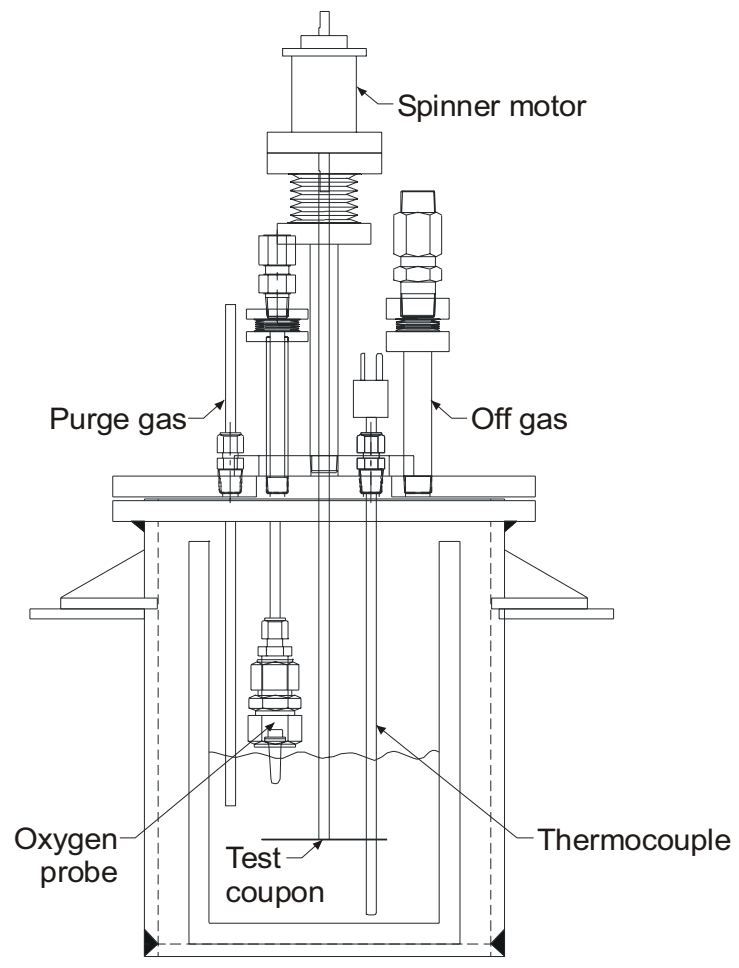

Figure 26. Schematic of the MIT Rotating Electrode "Spinner" Test Setup.

The experimental apparatus consists of a rotating electrode system that is heated using a crucible furnace. The furnace is capable of operating temperatures of up to $1200^{\circ} \mathrm{C}$. The retort, which is the containment for the system, is a stainless steel bucket designed to act as a pressure boundary as well as to distribute the weight of molten metal and crucible to the outer support. 
Material for the inner crucible contacting the molten lead-bismuth is made of magnesia stabilized zirconia. Earlier thermodynamic property research, such as free energy of oxide formation for various materials in contact with liquid lead or bismuth has used $\mathrm{ZrO}_{2}$ based ceramic vessels. No attack from those liquid metals has been reported. The spinning unit is composed of a motor, in which the feed-through is connected to the specimen. A bellows arrangement is used to pull the specimen out from the molten lead through the hole in the top flange when the experiment is completed. The speed of rotating is adjustable up to a maximum of $2000 \mathrm{rpm}$. The design basis for the maximum rotation speed is $8 \mathrm{~m} / \mathrm{s}$ on the edge of a specimen of 3 -in. diameter. The specimen is electrically insulated from the rotating shaft with small yttria-stabilized zirconia washers. The cover flange located on the top of the bucket has one large and six small penetrations which are for: specimen insertion, cover gas inlet and outlet lines, the oxygen meter assembly, a reference material for the oxygen sensor, and a thermocouple and gas bubbler, respectively.

The test temperature will range from $400^{\circ} \mathrm{C}$ to $800^{\circ} \mathrm{C}$. For each temperature, specimens will be tested at rotational speeds ranging from 10 to $500 \mathrm{rpm}$. The expected data will be corrosion rate as function of temperature and rotational speed of each sample under known oxygen concentrations. These data will be used to develop fundamental corrosion kinetics data as well as film formation data.

A dynamic corrosion apparatus for the investigation of flow-assisted dissolution and precipitation (corrosion) of potential fuel cladding and structural materials to be used in liquid lead-alloy cooled reactors has also been deployed at the INEEL (Loewen et al. 2000). During this reporting period, the cell was designed, subjected to a hazard review, constructed, permitted, approved by the safety review board, and became fully operational (June 1, 2000). The INEEL forced convection corrosion cell consists of a small heated vessel with a shroud and gas flow system. The gas flow rates, heat input, and shroud and vessel dimensions have been adjusted so that a controlled coolant flow rate, temperature, and oxygen potential are created within the downcomer located between the shroud and vessel wall. The ATHENA computer code was used to optimize the design dimensions so as to get the highest possible molten lead flow rates for a given gas injection rate (Loewen et al. 2000).

A diagram of the experimental apparatus showing the molten lead flow directions is provided in Figure 27. Figure 28 provides a picture of the major subsystems described below. The corrosion cell contains a small vessel, with an inner diameter of approximately $10.2-\mathrm{cm}$, that is separated into three regions by a shroud. The three regions include a riser that is located inside the shroud, a down-comer that is located between the shroud and the vessel wall, and an upper plenum region located above the top of the shroud. The experiment will contain a pool of a molten lead-alloy with a level above the top of the shroud. An inert gas will be injected into the riser near its bottom. The inert gas will flow up through the riser, reducing the hydrostatic head in the riser. The difference in hydrostatic head between the riser and down-comer will then cause liquid lead to flow up through the riser, then down the down-comer, and back to the riser through a gap located at the bottom of the shroud. The inert gas will separate in the upper plenum and be removed through the top of the vessel. Varying the flow through the down-comer will allow us to evaluate the effects of flow on erosion. The cell gas injection system has the capability to inject both oxidative $\left(\mathrm{CO}_{2}\right.$ and $\left.\mathrm{O}_{2}\right)$ and reducing gases $\left(\mathrm{H}_{2}\right)$. This will allow us to control the oxidative potential in the cell as was previously shown in Figure 1. The reductive and oxidative gas will make up a small part of the gas injected into the bottom of the riser. Adjusting the gas flow will control the fluid velocity in the down-comer. The oxidation potential will be corrected as needed. 


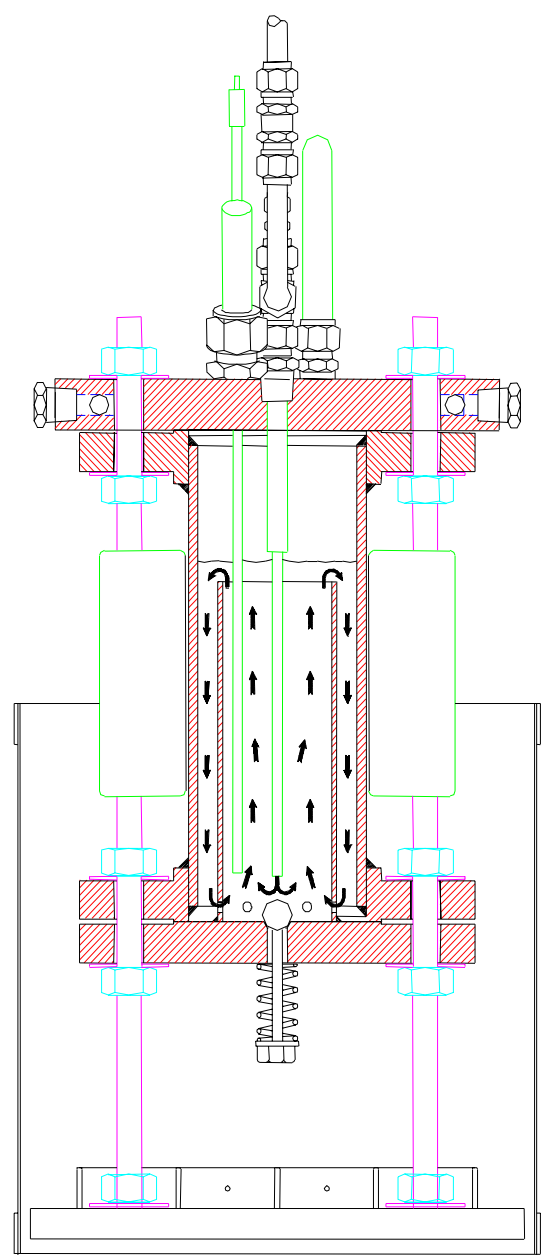

Figure 27. Schematic diagram of the INEEL experimental apparatus.

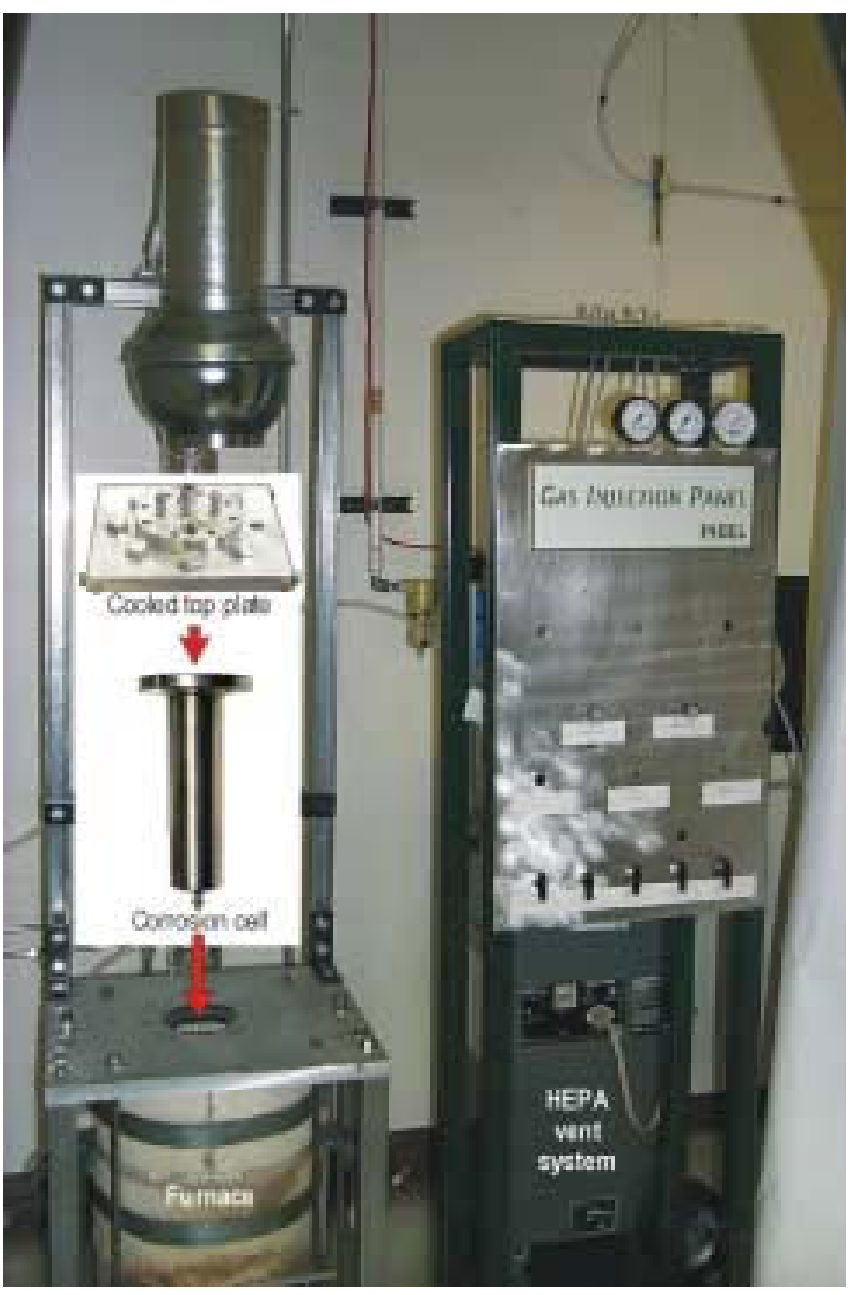

Figure 28. INEEL Corrosion Systems

Each of the experimental sub-systems are described in a little more detail below:

1) Gas Injection System. Two pressure-regulated manifolds deliver an inert gas (Ar, He, or $\left.\mathrm{N}_{2}\right)$ into the corrosion vessel. The gas injection will occur above and below the liquid metal. The anticipated gas flow rate is about 30 standard liters per minute. Oxygen can be added to the inert gas injected below the surface of the molten lead-alloy to control the oxygen potential of the system. The $\mathrm{O}_{2}$ source is provided by a standard gas cylinder with $\mathrm{O}_{2}$ added into an inert gas carrier $\left(\mathrm{He}, \mathrm{Ar}, \mathrm{N}_{2}\right)$. A reducing agent $\left(\mathrm{H}_{2}\right)$ can be injected into the corrosion cell headspace to remove metal oxides and control $\mathrm{O}_{2}$ levels in the corrosion cell.

2) Corrosion Cell. This cell is constructed from standard pipe with welded-on flanges. The cell contains several gas-tight fittings on top to allow gas injection, off-gas removal, and temperature and $\mathrm{O}_{2}$ measurement. The pipe, which is the test sample and initially contains a solidified leadalloy, is located in a small (18-cm diameter) electric furnace. The electric furnace, utilizing standard heating equipment, heats the pipe and, in turn, melts the lead-alloy sealed within. Heating is controlled by K-type thermocouples. Cooling coils can be soldered to the exterior of the upper pipe wall to increase the thermal gradient between the hot and cold regions in the cell. 
The corrosion cell drains into a sealed stainless steel can at negative pressure at the completion of an experiment.

3) Gas Handling System. This system takes the off-gas from the corrosion cell, cools it, filters it and captures dust before discharging it into the suction of a HEPA filter.

4) Specialized Ventilation. The experimental unit makes use of a portable HEPA system. The unit is powered by $110 \mathrm{VAC}$, is on wheels, with variable flow rate. Venting of the corrosion cell is through cooled media to ensure that no lead vapor escapes to the environment.

\subsubsection{Materials Test Matrix}

The objective of the corrosion-testing program is to identify the corrosion resistance of candidate structural materials featuring either low solubility in liquid lead or that forms a protective film. From the results of early research conducted on corrosion in liquid lead, materials known to be resistant to corrosion by molten lead have been chosen. These materials include molybdenum, tantalum, and tungsten. These elements have been studied in the past. However, these studies are incomplete (Manly 1954, Manly 1956, Asher et al. 1977, Wilkinson et al. 1955, Weeks 1971, Sheir et al. 1993, Li 1999).

Molybdenum showed good resistance to attack by liquid lead in $40-\mathrm{hr}$ static test at $1000^{\circ} \mathrm{C}$ and 500-hr thermal convection loop test (flow rate: $1 \mathrm{fpm}$ ) with $\mathrm{T}_{\max }=800^{\circ} \mathrm{C}$ and $\mathrm{T}_{\min }=400^{\circ} \mathrm{C}$ carried out at the ORNL in 1950s (Manly 1954 and 1956). Asher et al. (1977) reported the same kind of results from dynamic loop tests. However, in static tests at $1000^{\circ} \mathrm{C}$ done at Argonne National Laboratory, molybdenum showed somewhat higher solubility $(\sim 0.48 \mathrm{~g}$ per $100 \mathrm{~g}$ of lead) than expected, which was due to some sort of oxidation confirmed via the scale on the surface (Wilkinson et al. 1955).

Tantalum was also reported to be highly resistant to liquid lead at temperatures up to $1000^{\circ} \mathrm{C}$ (Manly 1954, Asher et al. 1977, Weeks 1971), and the rate of attack was less than $0.025 \mathrm{~mm} /$ year (Sheir et al. 1993). It exhibits no detrimental effects when stress rupture tests are conducted in molten lead at $815^{\circ} \mathrm{C}$ (Sheir et al. 1993). Early research on tungsten also suggests good resistance to liquid lead (Weeks 1971, Sheir et al. 1993).

While MIT is focusing on small exotic metals coupons, INEEL studies are using fabricated pipes (4-in and 3-in outer diameter) from metals that are more commonly used in nuclear power plants. The metals that are being investigated are two stainless steels (316 and 410), carbon steel and zirconium. Standard pipe sizes of 3 and 4" diameter have been used to construct the corrosion cell. Type 316 stainless steel has been found to be the least resistive to lead-corrosion attack (Manly 1956). Therefore, we are using this material for a baseline and tie point between the MIT and INEEL data.

\subsubsection{Oxygen Potential Control}

The control of oxygen is of great importance in both experimental facilities to investigate the corrosion of material and the oxide film characteristics. At MIT the oxygen potential of lead will be controlled using mixture of $\mathrm{H}_{2} / \mathrm{H}_{2} \mathrm{O}$. Using the free energy of oxide formation for each metal oxide, the pressure ratio of $\mathrm{H}_{2} \mathrm{O}$ and $\mathrm{H}_{2}$ can be calculated using the following equation: 
$\frac{\mathrm{P}_{\mathrm{H}_{2} \mathrm{O}}}{\mathrm{P}_{\mathrm{H}_{2}}}=\mathrm{P}_{\mathrm{O}_{2}}^{1 / 2} \exp \left(-\frac{\Delta \mathrm{F}_{\mathrm{H}_{2} \mathrm{O}}^{0}}{\mathrm{RT}}\right)=\exp \left(-\frac{\Delta \mathrm{F}_{\mathrm{H}_{2} \mathrm{O}}^{0}-1 / \mathrm{y} \Delta \mathrm{F}_{\mathrm{M}_{\mathrm{x}} \mathrm{O}_{\mathrm{y}}}^{0}}{\mathrm{RT}}\right)$

Then, $\log \frac{\mathrm{P}_{\mathrm{H}_{2} \mathrm{O}}}{\mathrm{P}_{\mathrm{H}_{2}}}$ values have the form of "A+B/T" and these constants are as shown in Table 19.

Table 19. The pressure ratio of $\mathrm{H}_{2} \mathrm{O}$ and $\mathrm{H}_{2}$ for various metal oxide systems.

\begin{tabular}{|l|l|l|l|l|l|l|l|l|}
\hline $\log \frac{\mathrm{P}_{\mathrm{H}_{2} \mathrm{O}}}{\mathrm{P}_{\mathrm{H}_{2}}}$ & $\mathbf{B i}_{\mathbf{2}} \mathbf{O}_{\mathbf{3}}$ & $\mathbf{P b O}$ & $\mathbf{N i O}$ & $\mathbf{F e}_{\mathbf{3}} \mathbf{O}_{\mathbf{4}}$ & $\mathbf{C r}_{\mathbf{2}} \mathbf{O}_{\mathbf{3}}$ & $\mathbf{M o O}$ & $\mathbf{W} \mathbf{O}_{\mathbf{2}}$ & $\mathbf{T a}_{\mathbf{2}} \mathbf{O}_{\mathbf{5}}$ \\
\hline $\mathrm{A}$ & 2.06 & 2.43 & 1.75 & 1.25 & 1.69 & 1.54 & 1.61 & 1.41 \\
\hline $\mathrm{B}$ & 2692 & 1301 & 420.4 & -1646 & -6981 & -2255 & -2222 & -8302 \\
\hline
\end{tabular}

Free energy values used in this calculation were obtained from Li (1999a). Figure 29 shows the range of $\log \frac{\mathrm{P}_{\mathrm{H}_{2} \mathrm{O}}}{\mathrm{P}_{\mathrm{H}_{2}}}$ vs. temperature for various metal oxide systems.

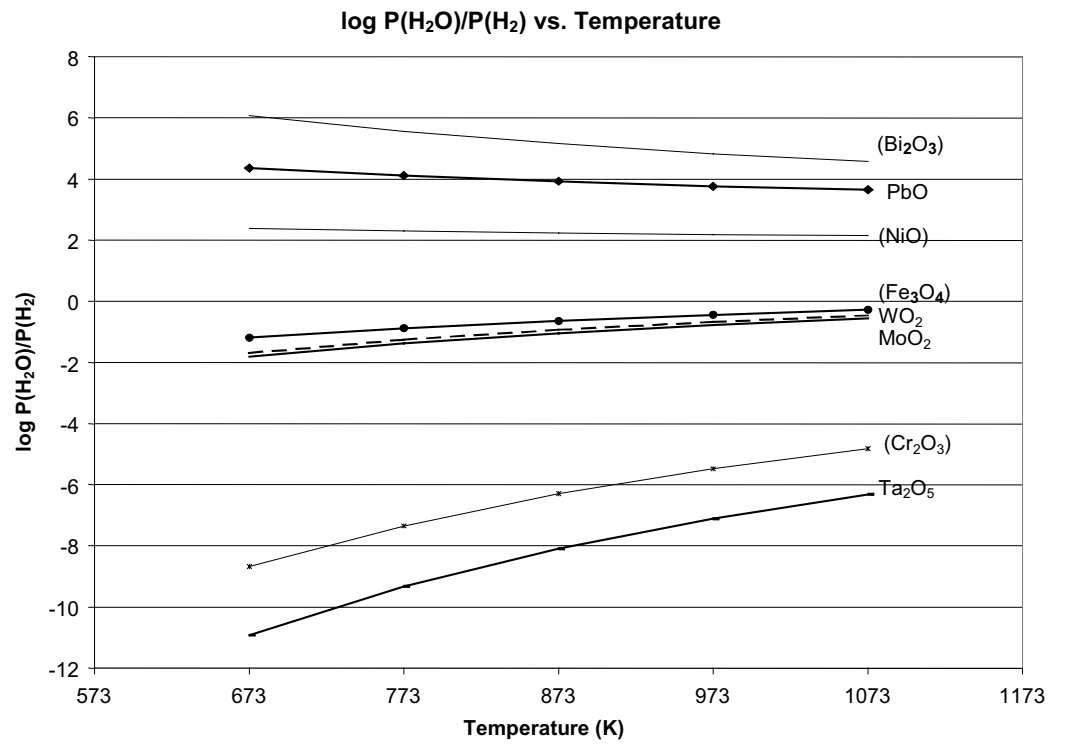

Figure 29. $\log \frac{\mathrm{P}_{\mathrm{H}_{2} \mathrm{O}}}{\mathrm{P}_{\mathrm{H}_{2}}}$ vs. temperature for various metal oxides.

The inlet and exhausted gas are monitored using a gas analyser system which will include a moisture analyser, oxygen analyser, and an oxygen sensor operated in the gas phase.

INEEL is investigating oxygen control using $\mathrm{O}_{2}, \mathrm{H}_{2}$, and $\mathrm{CH}_{4}$. The detailed thermodynamic discussion presented above for $\mathrm{H}_{2} \mathrm{O}$ system will be omitted for the $\mathrm{H}_{2} / \mathrm{O}_{2}$ system. The only 
difference is that solid carbon will be used as means to keep the $\mathrm{O}_{2}$ potential between the iron and lead oxidation lines.

\subsubsection{Testing Matrix}

An integrated INEEL and MIT test matrix was developed at the FY-00 mid-year review meeting. INEEL will perform 100 hour tests on two stainless steels (316 and 410), low carbon steel, and zirconium. Corrosion data will be obtained as a function of temperature and oxygen potential for each material. Scanning electron microscope analysis of selected test specimens will be performed at the Idaho Research Center Metallurgical Laboratory. The testing will be performed from 450 and $650^{\circ} \mathrm{C}$ with pure lead as the corrosion medium. In addition, the INEEL will develop an oxidation/reduction control system to provide a protective layer for the structural materials. In conjunction, MIT will perform spinner tests using molybdenum, tungsten, tantalum, and 316 stainless steel. These materials have a very low solubility in lead and lead-bismuth (except for the 316 stainless steel). The MIT experiments will range from 400 to $800^{\circ} \mathrm{C}$ at RPM's ranging from 10 to 500, for similar durations. The tie point between the experiments will be the 316 stainless steel operated in both experimental facilities so that a comparison of the results can be made. Additionally, MIT has provided INEEL small coupons of Mo, W, and Ta to place inside the large INEEL dynamic corrosion cell.

The MIT and INEEL test matrixes are provided in Tables 20 and 21, respectively.

Table 20. MIT Material Test Matrix.

\begin{tabular}{|l|l|l|l|l|l|l|l|l|l|l|l|}
\hline \multirow{2}{*}{ Material } & \multicolumn{4}{|c|}{ Temperature $\left({ }^{\circ}\right.$ C) } & \multicolumn{4}{|c|}{ Rotating speed (RPM) } \\
\cline { 2 - 11 } & 400 & 500 & 600 & 700 & 800 & 10 & 50 & 100 & 300 & 500 \\
\hline Molybdenum & $\mathrm{X}$ & $\mathrm{X}$ & $\mathrm{X}$ & $\mathrm{X}$ & $\mathrm{X}$ & $\mathrm{X}$ & $\mathrm{X}$ & $\mathrm{X}$ & $\mathrm{X}$ & $\mathrm{X}$ \\
\hline Tungsten & $\mathrm{X}$ & $\mathrm{X}$ & $\mathrm{X}$ & $\mathrm{X}$ & $\mathrm{X}$ & $\mathrm{X}$ & $\mathrm{X}$ & $\mathrm{X}$ & $\mathrm{X}$ & $\mathrm{X}$ \\
\hline Tantalum & $\mathrm{X}$ & $\mathrm{X}$ & $\mathrm{X}$ & $\mathrm{X}$ & $\mathrm{X}$ & $\mathrm{X}$ & $\mathrm{X}$ & $\mathrm{X}$ & $\mathrm{X}$ & $\mathrm{X}$ \\
\hline Stainless Steel 316 & & & $\mathrm{X}$ & & & & $\mathrm{X}$ & & $\mathrm{X}$ & \\
\hline
\end{tabular}

Table 21. INEEL Test Matrix.

\begin{tabular}{|l|c|c}
\hline Metal & Temperature $\left({ }^{\mathbf{}} \mathbf{C}\right)$ & Time (hours) \\
\hline $\mathrm{Fe}$ & 450 & 6 \\
\hline $\mathrm{Fe}$ & $550-650$ & 24 \\
\hline 316 Stainless steel & 650 & 24 \\
\hline $\mathrm{Fe}$ & 550 & 100 \\
\hline $\mathrm{Fe}$ & 650 & 100 \\
\hline 316 Stainless steel & 550 & 100 \\
\hline 316 Stainless steel & 650 & 100 \\
\hline 410 Stainless steel & 550 & 100 \\
\hline 316 Stainless steel & 650 & 100 \\
\hline 410 Stainless steel & 550 & 100 \\
\hline 410 Stainless steel & 650 & 100 \\
\hline $\mathrm{Zr} \mathrm{w} / 2 \% \mathrm{Nb}$ & 550 & 100 \\
\hline $\mathrm{Zr} \mathrm{w} / 2 \% \mathrm{Nb}$ & 650 & 100 \\
\hline
\end{tabular}




\subsubsection{Oxygen Potential Probe Construction}

The importance of oxygen in the corrosion control of structural materials by liquid metals has introduced the necessity of developing oxygen-monitoring system applicable to highly corrosive liquid metal environment. Oxygen sensors for liquid sodium coolant were investigated by numerous research groups, such as Westinghouse, Interatom, the Central Institute for Nuclear Research (ZfK), General Electric, and Harwell (Hobdell and Smith 1982), from the early 1960s to the 1980s. For the liquid Pb-17Li system, research was also conducted in the framework of European Fusion Technology Program (De Schutter et al. 1991). Both MIT and INEEL are fabricating and calibrating $\mathrm{O}_{2}$ probes as a means of collaboration and cross checking of results. When our data is consistent, we will compare our results to the Russian probe data that LANL has (Li 1999b). (LANL has purchased $\mathrm{O}_{2}$ probes from Russia.)

The objective of this study lies in the deployment of an oxygen probe applicable to the molten lead-alloy environment. With this aim, an electrochemical oxygen potential probe equipped with a solid electrolyte and appropriate reference electrodes is being developed. As of this date, the oxygen probe is in the initial stages of testing. The probe exhibits the correct temperature dependence but suffers from a constant offset in potential. We are in the process of determining the source of the offset.

With a reference electrode having invariant oxygen activity, the difference in oxygen activities between both sides of the solid electrolyte $\left(\mathrm{a}_{1}\right.$ and $\left.\mathrm{a}_{2}\right)$ can be measured as electromotive force (EMF) following the Nernst law:

$\mathrm{EMF}=\frac{\mathrm{RT}}{\mathrm{nF}} \ln \frac{\mathrm{a}_{1}}{\mathrm{a}_{2}}$

where $\mathrm{R}$ is the universal gas constant, $\mathrm{T}$ the absolute temperature in ${ }^{\circ} \mathrm{K}, \mathrm{n}$ the number of participating electrons for the electrode reaction per atom of species, and $\mathrm{F}$ is the Faraday constant (Hobdell and Smith 1982).

The main concerns in choosing the oxygen-ion-conducting solid electrolyte are its compatibility with the liquid lead alloy, ionic conductivity, and commercial availability. Yttria-stabilized zirconia was selected as an electrolyte based on these considerations. A platinum/air reference electrode was incorporated for the preliminary test of the sensor in both a gas and liquid lead environment. This choice was made based on its well-known convenience, stability (Subbarao 1980), reproducibility, and mechanical integrity in terms of vibration (Hobdell and Smith 1982). Also liquid metal/metal oxide references such as $\mathrm{In} / \mathrm{In}_{2} \mathrm{O}_{3}$ or $\mathrm{Bi} / \mathrm{Bi}_{2} \mathrm{O}_{3}$ are considered as future systems for measuring low oxygen concentrations in the melt. In this report, only the experimental results obtained using the Pt/air reference electrode system are to be discussed.

\subsubsection{1. $\mathrm{MIT} \mathrm{O}_{2}$ Probe Experimental Setup}

Prior to use, a one-end closed yttria-stabilized zirconia tube (10.5 wt $\% \mathrm{Y}_{2} \mathrm{O}_{3}$, Vesuvius McDanel) of 0.375 in. diameter was washed with ethanol and allowed to dry at room temperature. Then, the inside of tube was coated with porous platinum paste (A3788A, Engelhard) and a platinum mesh connected to platinum wire insulated with alumina tube was inserted into the tube. After drying at room temperature for $10 \mathrm{hrs}$, the assembly was heated at $1100^{\circ} \mathrm{C}$ for $1 \mathrm{hr}$ in an air atmosphere. 
Then the yttria-stabilized zirconia tube was sealed to another larger diameter tube with $\mathrm{ZrO}_{2}$ based ceramic adhesive (Ultratemp 516, Aremco Product, Inc.). The sealing process involves applying the adhesive, drying for $4 \mathrm{hrs}$ at room temperature, heating for $1 \mathrm{~h}$ at $366^{\circ} \mathrm{K}$, and then heating for $1 \mathrm{~h}$ at $477^{\circ} \mathrm{K}$. All processes were done under argon gas environment (5.0 grade, Airco). Table 22 shows the composition of the argon gas. The experimental apparatus is shown in Figure 30. An alumina crucible containing $1 \mathrm{~kg}$ of lead is placed inside of a retort that acts as a pressure boundary in the furnace. A water-cooled stainless steel plate, which seals the retort, has five openings for the argon gas entry, argon gas exit, a thermocouple, a conducting wire immersed in lead, and the sensor assembly. The oxygen pressure in the exit gas is monitored with an oxygen sensor (Platinum series, Delta-F Cooperation). This sensor was used to verify that the device when operating at high temperatures did not have any leaks other than the permeation of oxygen through the solid electrolyte. The platinum wire, which is inserted to the yttria-stabilized zirconia tube, is connected to the switching control unit. The other terminal of the unit is connected to the conducting wire (molybdenum) immersed in molten lead. The experiment begins by melting lead under an inert atmosphere of argon gas (flow rate: 2 cubic feet per hour).

Table 22. Composition of Argon (AIRCO, Grade 5.0).

\begin{tabular}{|l|l|l|l|l|}
\hline Total Impurity & $\mathbf{N}_{\mathbf{2}}$ & $\mathbf{O}_{\mathbf{2}}$ & $\mathbf{H}_{\mathbf{2}} \mathbf{O}$ & Hydrocarbon \\
\hline$<10 \mathrm{ppm}$ & $<4 \mathrm{ppm}$ & $<1 \mathrm{ppm}$ & $<1 \mathrm{ppm}$ & $<1 \mathrm{ppm}$ \\
\hline
\end{tabular}

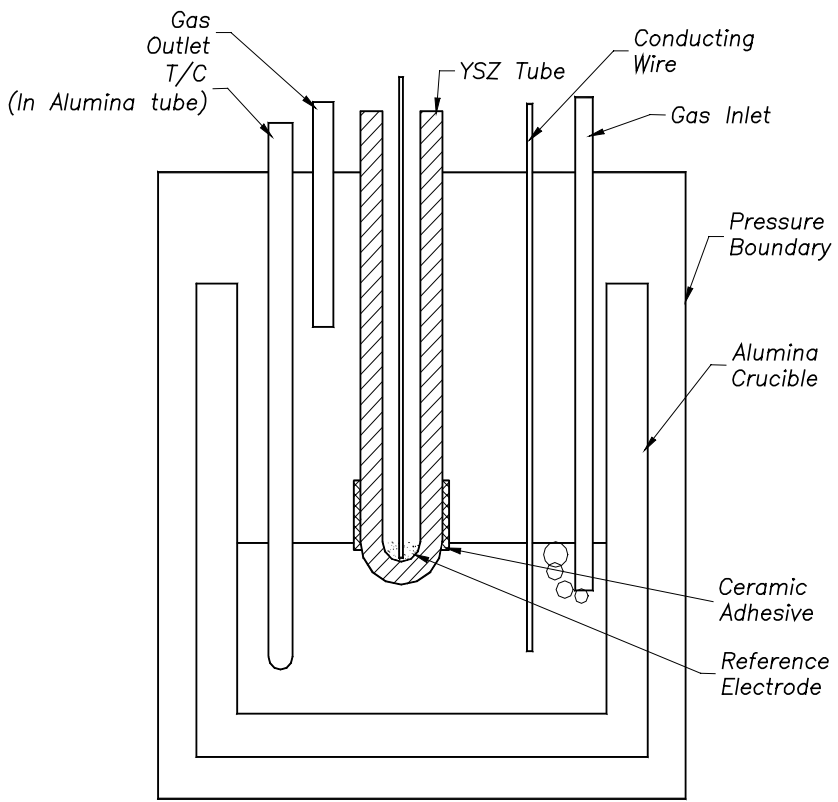

Figure 30. Schematic diagram of the MIT oxygen probe testing facility (furnace is not shown).

Preliminary results obtained from the molten lead experiment purged by argon gas are shown in Figure 31. The upper line shows the calculated potential, assuming that oxygen in the molten lead is in equilibrium with the lead oxide. The experimental value shows a large offset from the calculated one. This behavior is under investigation. 


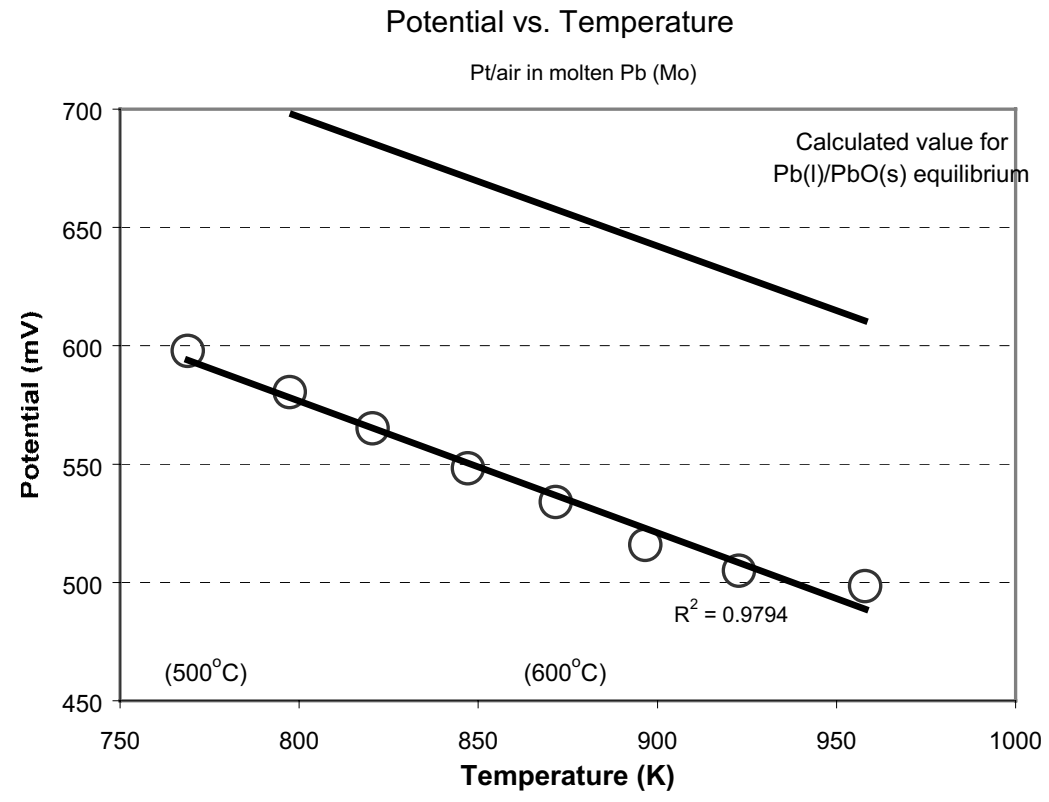

Figure 31. EMF versus temperature values obtained from molten lead experiment using yttria-stabilized zirconia solid electrolyte and $\mathrm{Pt} /$ air reference electrode in an argon atmosphere.

\subsubsection{INEEL $\mathrm{O}_{2}$ Probe Experimental Setup}

The INEEL oxygen probe has been constructed using an yttria-stabilized zirconia ceramic tube. The conditions providing the operating principal of the probe are shown in Figure 32.

\section{Enlarged Cross-sectional Representation of the Zirconia Substrate}

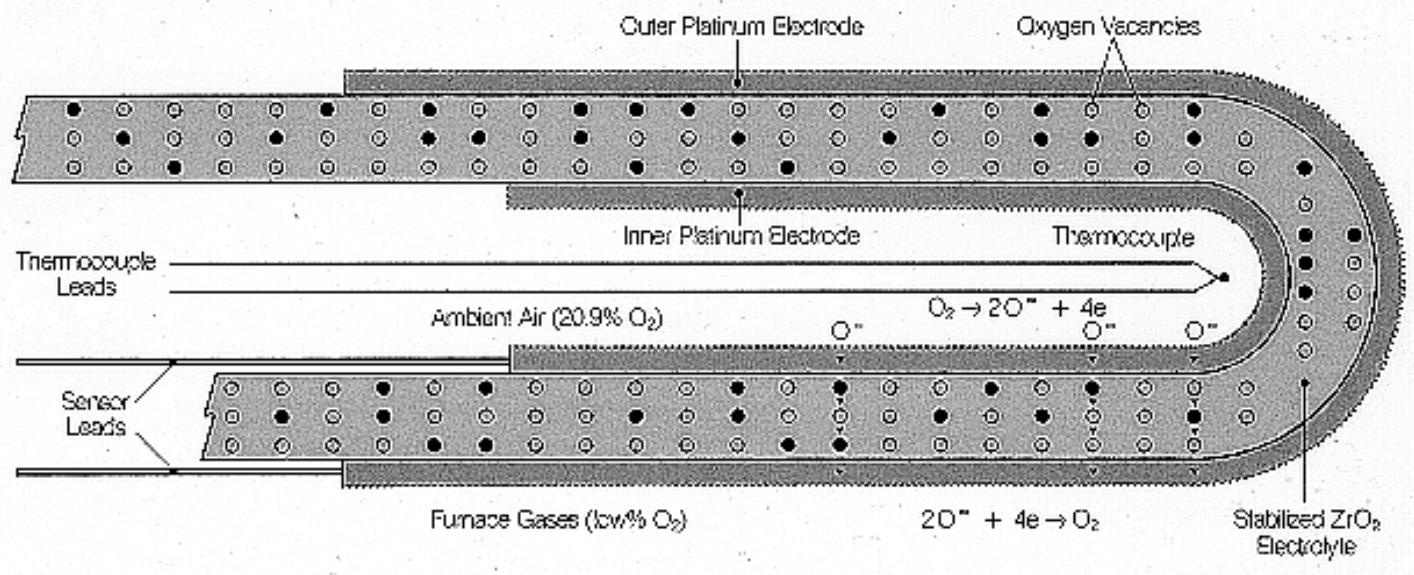

Figure 32. Schematic showing the basis for oxygen activity measurement with zirconia probe. 
Differences in oxygen activity across the wall of the ceramic tube cause a variance in oxygen vacancy concentrations at the two surfaces. The differences in oxygen vacancy concentrations produce an emf across the wall of the tube. The emf is related by the Nernst equation as follows:

$\mathrm{E}(\mathrm{emf})=0.0215 \times \mathrm{T} \times \ln$ (inside $\mathrm{O}_{2}$ activity/ outside $\mathrm{O}_{2}$ activity)

The inner and outer surfaces of the zirconia tube are prepared with a platinum surface. A thermocouple with Pt and Pt-Rh leads can be used to measure temperature and provide one of the leads for emf measurements. The illustration in Figure 32 shows the reference on the inside of the closed-end tube as the oxygen in ambient air. The environment on the outside is the one for which the oxygen activity is being measured.

We have assembled a yttria-stabilized zirconia probe within a larger 2.3-in. diameter closed-end alumina tube. The drawing in Figure 33 shows the enclosure. A water-cooled flange is used to provide the feed-through for the various penetrations. A reference gas of known oxygen content can be filled into the space between the alumina tube and the zirconia probe. The oxygen activity on the inside of the zirconia probe is that of ambient air.

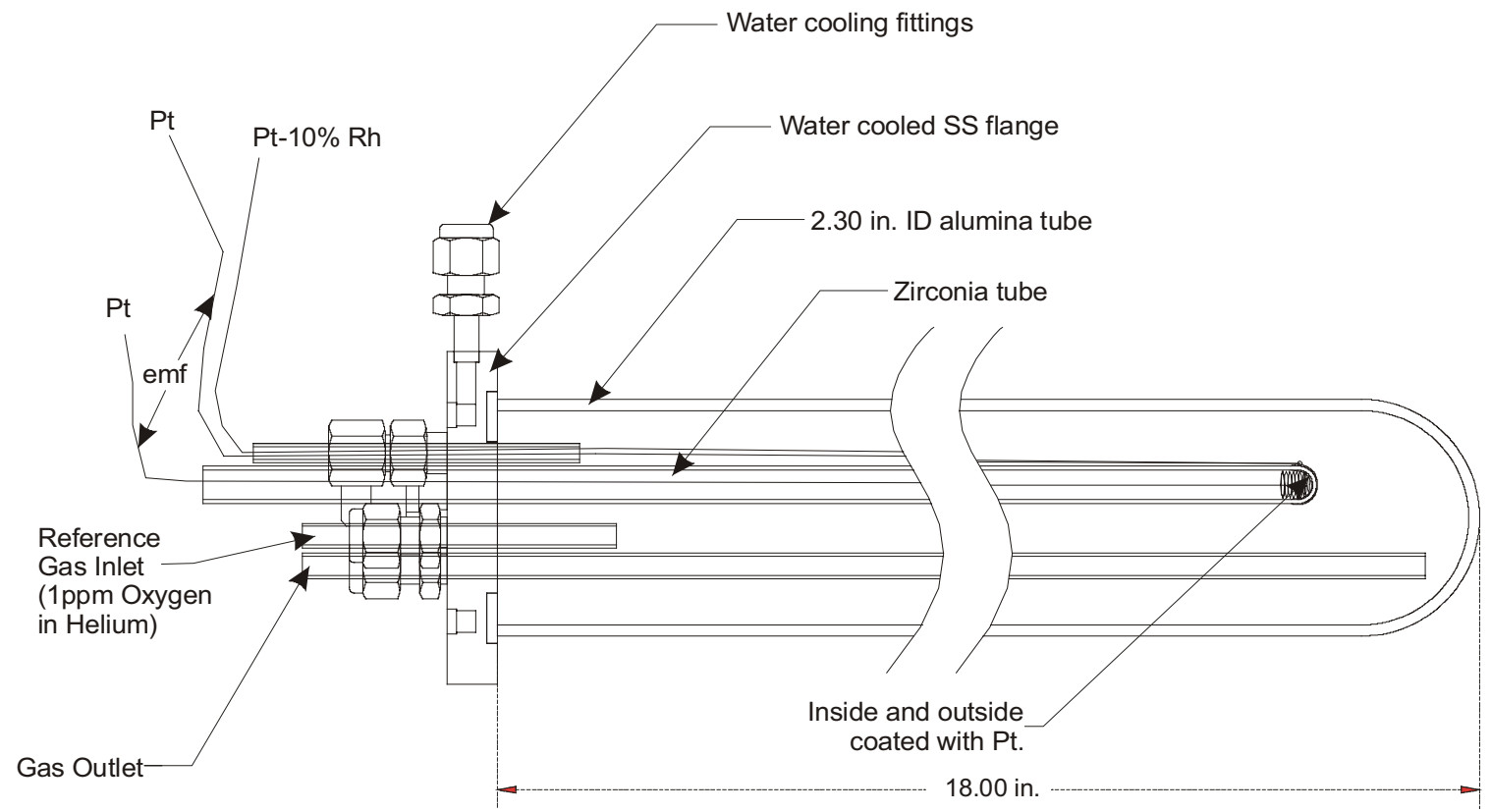

OXYGEN PROBE

Figure 33. INEEL zirconia probe contained within a closed-end alumina tube with a water-cooled flange. 


\subsection{COOLANT ACTIVATION}

\subsubsection{Polonium Nuclear and Chemical Characteristics}

Polonium has no stable isotopes. However, ${ }^{210} \mathrm{Po},{ }^{214} \mathrm{Po}$ and ${ }^{218} \mathrm{Po}$ do naturally occur in the decay chain of ${ }^{238} \mathrm{U}$ (General Electric 1996). The isotope of interest in our case, ${ }^{210} \mathrm{Po}$, has a relatively long half-life and emits alpha particles of $5.3 \mathrm{MeV}$ with $100 \%$ yield $^{6}$. It is produced in the leadbismuth coolant by neutron activation of ${ }^{209} \mathrm{Bi}^{7}$ according to the following reaction chain:

$$
{ }^{209} \mathrm{Bi}+\mathrm{n} \rightarrow{ }^{210} \mathrm{Bi} \underset{\mathrm{t}_{1 / 2}=5 \text { days }}{\stackrel{\beta^{-}}{\rightarrow}}{ }^{210} \mathrm{Po} \underset{\mathrm{t}_{1 / 2}=138 \text { days }}{\stackrel{\alpha}{\rightarrow}}{ }^{206} \mathrm{~Pb}
$$

To characterize its radiotoxicity, we shall make use of the concept of "derived air concentration". Because ${ }^{210} \mathrm{Po}$ is an emitter of energetic alpha particles, its derived air concentration is very stringent, $10 \mathrm{~Bq} / \mathrm{m}^{3}$ or $3 \times 10^{-10} \mu \mathrm{Ci} / \mathrm{cm}^{3}$ as reported by the Environmental Protection Agency (EPA 1988), which may raise a potential radiological problem.

When created by neutron activation in the lead-bismuth coolant, polonium rapidly forms a stable compound with lead, known as lead-polonide (Li et al. 1998, Yefimov et at. 1998). As a result, only up to $0.2 \%$ of the polonium present in lead-bismuth is in the unbound elementary form (Po) ( $\mathrm{Li}$ et al. 1998). Upon contact of lead-polonide with water, a very volatile hydride $\left(\mathrm{H}_{2} \mathrm{Po}\right)$ is formed (Yefimov et al. 1998, Gromov et al. 1996, Schipakhin et al. 1992) according to the reaction:

$$
\mathrm{PbPo}_{(\mathrm{s})}+\mathrm{H}_{2} \mathrm{O}_{(\mathrm{g})} \leftrightarrow \mathrm{H}_{2} \mathrm{Po}_{(\mathrm{g})}+\mathrm{PbO}_{(\mathrm{s})}
$$

Additional parallel mechanisms of Po release into steam are direct evaporation of lead-polonide and simple Po (Feuerstein et al. 1992, Gromov et al. 1996, Schipakhin et al. 1992).

Continuous on-line polonium extraction from the lead-bismuth coolant is essential to inhibit the formation of the volatile $\mathrm{H}_{2} \mathrm{Po}$, to decrease lead-polonide evaporation, and hence to ultimately minimize the polonium transport out of the reactor-pool. Even small rates of polonium extraction can result in considerable reduction of polonium concentration in lead-bismuth, as will be shown later (see Figure 35 below). However, it should be emphasized that, despite the construction of submarine lead-bismuth reactors in the former Soviet Union, there is no industrially established and proven polonium extraction technology to date. The development of such technology is not among the objectives of this study, but it is clear that a thorough research effort on this subject is necessary should the development of commercial lead-bismuth nuclear systems (especially of the direct contact heat transfer type) be more decisively pursued in the future.

Here the alkaline extraction method is adopted which is based on the following reaction (Orlov 1998):

$\mathrm{PbPo}+4 \mathrm{NaOH} \leftrightarrow \mathrm{Na}_{2} \mathrm{Po}+\mathrm{Na}_{2} \mathrm{PbO}_{2}+2 \mathrm{H}_{2} \mathrm{O}$

\footnotetext{
${ }^{6}$ And is therefore known as a pure $\alpha$-emitter.

${ }^{7}$ The isotopic abundance of ${ }^{209} \mathrm{Bi}$ is $100 \%$ (i.e. ${ }^{209} \mathrm{Bi}$ is the only natural isotope of bismuth).
} 
The minimum required contact time of lead-bismuth with the sodium melt is thought to be 2 minutes, which in principle makes alkaline extraction suitable for on-line utilization. After 2 minutes contact, the removal efficiency of this system is known to be approximately $90 \%$ (Yefimov et al. 1998).

\subsubsection{Theoretical Characterization of the Polonium Problem}

In this section simple calculations based on available data on polonium chemistry will be used to provide a first estimate of the magnitude of the polonium challenge in the lead-bismuth/water direct contact reactor. Two fundamental assumptions are made:

1) The polonium volatility is modeled assuming that the partial pressure of polonium hydride is three orders of magnitude larger than that of elementary polonium and lead-polonide. This assumption is entirely arbitrary because no reliable data are available on the chemistry of the hydride. However, within the framework of this project an experiment is being conducted at MIT to study the chemistry of the polonium hydride and obtain the polonium hydride partial pressure as a function of temperature, lead-oxide and lead polonide activities.

2) It is conservatively assumed that the steam leaving the reactor pool is saturated with the polonium species, therefore ignoring the kinetics of the reactions involved in polonium release.

A polonium balance over the control volume represented by the total lead-bismuth inventory in the reactor pool yields:

$\frac{\mathrm{dN}_{\mathrm{Po}}}{\mathrm{dt}}=\Gamma_{\text {prod }}-\Gamma_{\text {decay }}-\Gamma_{\text {extr }}-\Gamma_{\text {rel }}$

where $\mathrm{N}_{\mathrm{Po}}$ is the total number of ${ }^{210}$ Po nuclei in the lead-bismuth coolant and $\Gamma_{\text {prod }}, \Gamma_{\text {decay }}, \Gamma_{\text {extr }}$ and $\Gamma_{\text {rel }}$ are the $(n, \gamma)$ production, the decay, the extraction and release terms. Figure 34 pictorially illustrates the polonium balance.

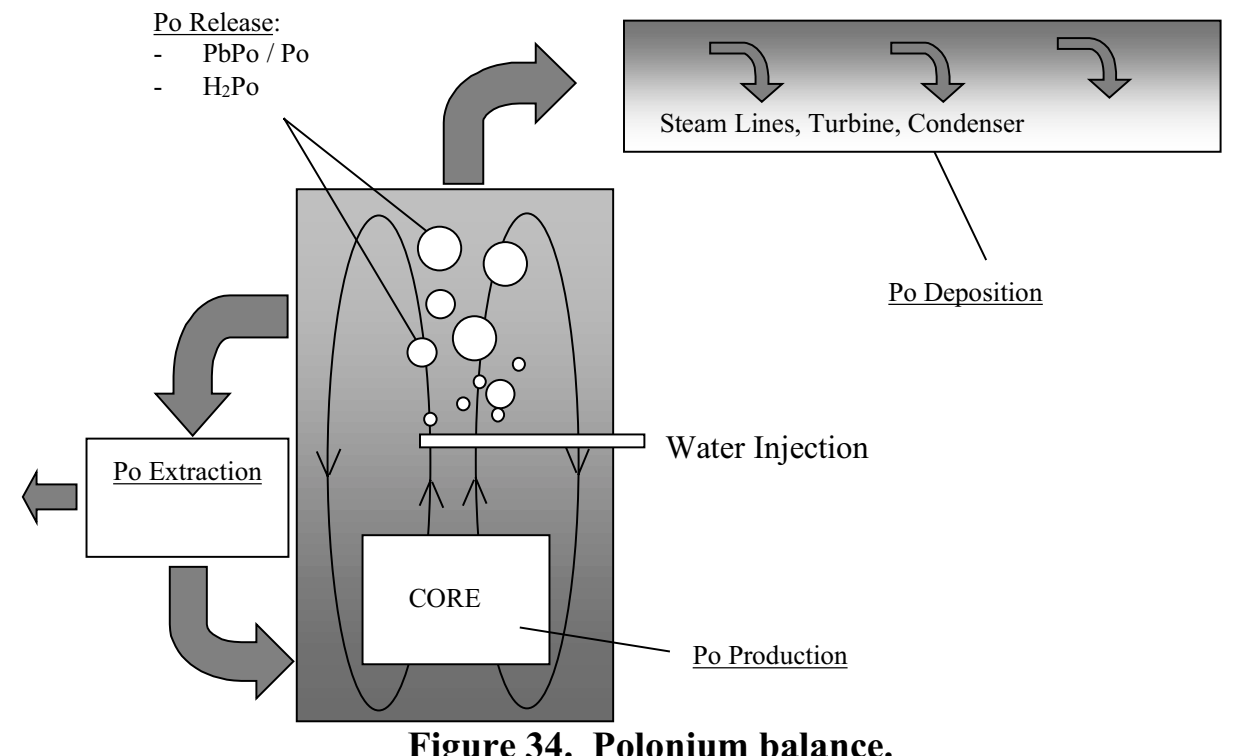


Expressions were obtained for the production, decay, extraction and release terms based on first principles. Equation 4 was integrated to give the results illustrated in Figure 35, where $T$ is the temperature that drives the release of polonium, $\mathrm{f}$ is the lead-bismuth mass flow rate fraction sent to the on-line extraction polonium system, $\mathrm{C}_{\mathrm{Po}, \mathrm{cool}}$ is the polonium specific activity in the leadbismuth coolant $(\mathrm{Ci} / \mathrm{kg})$, and $C_{P o, s t}^{*}$ is the polonium concentration of steam at atmospheric pressure. Note that the steam leaking out of the secondary system expands to atmospheric pressure and therefore $C_{P o, s t}^{*}$ is the correct parameter to use. Figure 35 was obtained under the assumption that the reactor pool is a cylinder of 5 and $10 \mathrm{~m}$ diameter and height, respectively, $75 \%$ filled with liquid lead-bismuth. The core power (which determines the rate of polonium production) is assumed to be $1800 \mathrm{MWth}$, the steam flow is $1000 \mathrm{~kg} / \mathrm{s}$ and the operating pressure is $7.0 \mathrm{MPa}$.

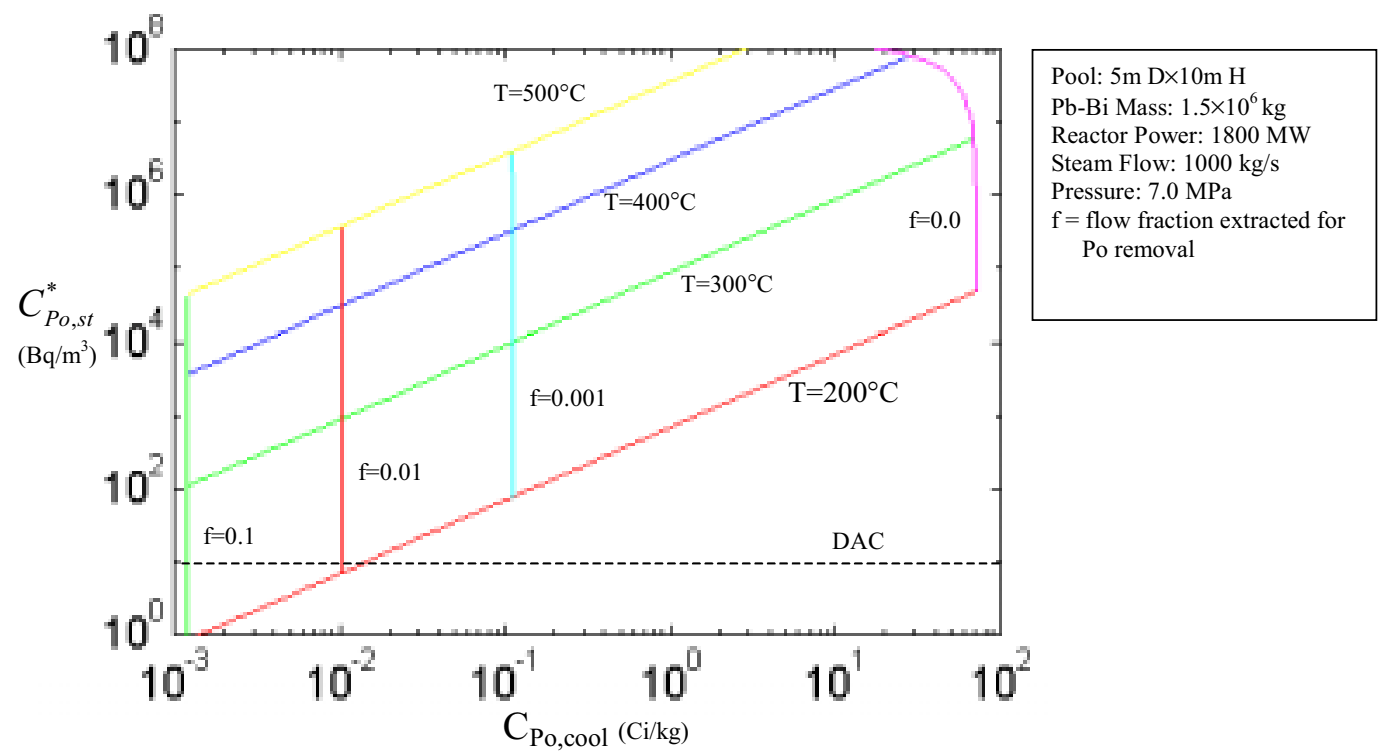

Figure 35. Polonium transport in the lead-bismuth/water direct contact reactor.

As anticipated, the effect of the polonium extraction system rate on the polonium concentration in lead-bismuth is remarkable: increasing $\mathrm{f}$ from 0.0 (no polonium extraction system) to 0.001 decreases the polonium content of the lead-bismuth coolant by almost three orders of magnitude (for a given temperature). Because the extraction term is much larger than the decay and release terms even at modest values of $\mathrm{f}$, the polonium concentration in the coolant $\mathrm{C}_{\mathrm{Po} \text {,cool }}$ is practically independent of temperature for a given $\mathrm{f}$, as illustrated in Figure 35. However, when $\mathrm{f}=0.0$ (i.e. no extraction), polonium release to steam becomes a relevant mechanism of polonium removal and a dependence of $\mathrm{C}_{\mathrm{Po}, \text { cool }}$ on temperature is observed (especially at high temperatures).

However, it can be seen that for practically all temperatures and extraction rates, the magnitude of polonium contamination of the leaking steam is above the allowed limits (expressed as the ${ }^{210} \mathrm{Po}$ derived air concentration). This might not constitute a severe concern because modern BWR turbines are equipped with a dedicated gland steam sealing system that virtually eliminates steam leakage (Sawyer 1999, Todd 2000). This system consists of an evaporator that delivers clean steam to the turbine shaft and major valves. The steam is forced to flow through a labyrinth 
packing gland outward to the turbine building atmosphere hence providing a seal to the radioactive steam.

The polonium contamination of the surfaces of the main secondary system components (i.e. the steam lines, the turbine and the condenser) was also estimated under the assumption that all the polonium activity released from the reactor deposits in the secondary system. Unprotected maintenance can be carried out for an $\alpha$-activity up to $0.9 \mu \mathrm{Ci} / \mathrm{m}^{2}$. Above this threshold, access to the surface requires decontamination and/or the use of radiation protection equipment such as sealed suits and respirators. Assuming a total steam line, turbine, and condenser surface area of about 630,230 and $74300 \mathrm{~m}^{2}$, respectively, the surface activity is 8,23 and $0.07 \mathrm{Ci} / \mathrm{m}^{2}$, respectively, which is unacceptably above the free-access limit. These numbers were calculated for $\mathrm{f}=0.01$ and $\mathrm{T}=300^{\circ} \mathrm{C}$.

This suggests that, if a significant deposition of polonium does in fact take place on the components of the lead-bismuth/water direct-contact reactor secondary system, their maintenance costs may be high since extensive surface decontamination and/or the use of special radiation protection equipment will be required.

On the other hand, if all polonium remains in the water (i.e. no steam leakage, no deposition), the specific activity of the feed-water is $6 \mathrm{mCi} / \mathrm{kg}$, assuming that the total water inventory of the secondary system amounts to about 200,000 gallons, i.e. $\sim 760 \mathrm{~m}^{3}$ (Sawyer 1999). Note that the annual limit of intake by ingestion for ${ }^{210} \mathrm{Po}$ is $3 \mu \mathrm{Ci}$ (EPA 1988).

This theoretical evaluation has shown that the problem of polonium release and transport in the lead-bismuth/water direct-contact reactor is a very serious, potentially a show-stopping issue. The radiation levels in the steam, in the feed-water, and on the surface of the main secondary system components exceed the EPA limits for inhalation, ingestion and unrestricted maintenance, respectively, under any practically feasible polonium extraction rate in the reactor pool and over the whole range of temperatures considered. However, the uncertainties affecting this analysis are very significant. They are as follows:

a) We modeled polonium volatility assuming that the rate of formation and release of polonium hydride is three orders of magnitude larger than that of elementary polonium and leadpolonide. This assumption is entirely arbitrary because no reliable data are available on the chemistry of the hydride.

b) We have conservatively assumed that the steam leaving the reactor pool is saturated with the polonium species, therefore ignoring the kinetics of the reactions involved in polonium release.

c) We have not considered the effect of a polonium extraction system in the secondary circuit. This could be a full-load system located upstream of the turbine or a smaller system that is part of the chemistry and volume control system. In either case, the amount of polonium circulating in the secondary system could be easily decreased by orders of magnitude.

To reduce uncertainties a) and b) and acquire a more realistic evaluation of the polonium issue, an experimental campaign on polonium release rates is being conducted at MIT. A detailed description of the experiment apparatus, objectives and results is presented in the following sections. 


\subsubsection{The MIT Polonium Experiments}

Given the importance of the polonium issue in determining the viability of the lead-bismuth/water direct-contact reactor concept, it was decided to undertake an experimental campaign to generate data on:

1) The equilibrium concentration of polonium hydride in steam in the 300 to $500^{\circ} \mathrm{C}$ temperature range as a function of polonium concentration and oxygen partial pressure in the lead-bismuth melt ${ }^{8}$.

2) The kinetics of polonium hydride formation and release in steam.

To this purpose, a high temperature reaction cell has been constructed at MIT to accommodate a liquid lead-bismuth bath and radioactive polonium. The radioactive polonium was produced by irradiation of $99.99 \%$ bismuth samples in the MIT research reactor. The cell consists of two distinct autoclaves connected by a separation valve. Steam is injected in the first autoclave (which hosts the molten lead-bismuth and polonium) and then collected in the second autoclave where it is condensed and drained. The alpha-activity of the condensed steam is then measured in a liquid scintillator. The experimental procedure is very similar if one wants to isolate the leadpolonide contribution to polonium release. In this case the steam is replaced by an inert gas (e.g. argon), which is collected in the second autoclave and vented to a polonium trap. The activity of the trapping solution is then counted in the liquid scintillator. A schematic of the cell is illustrated in Figure 36 and a photo of the actual apparatus is shown in Figure 37.

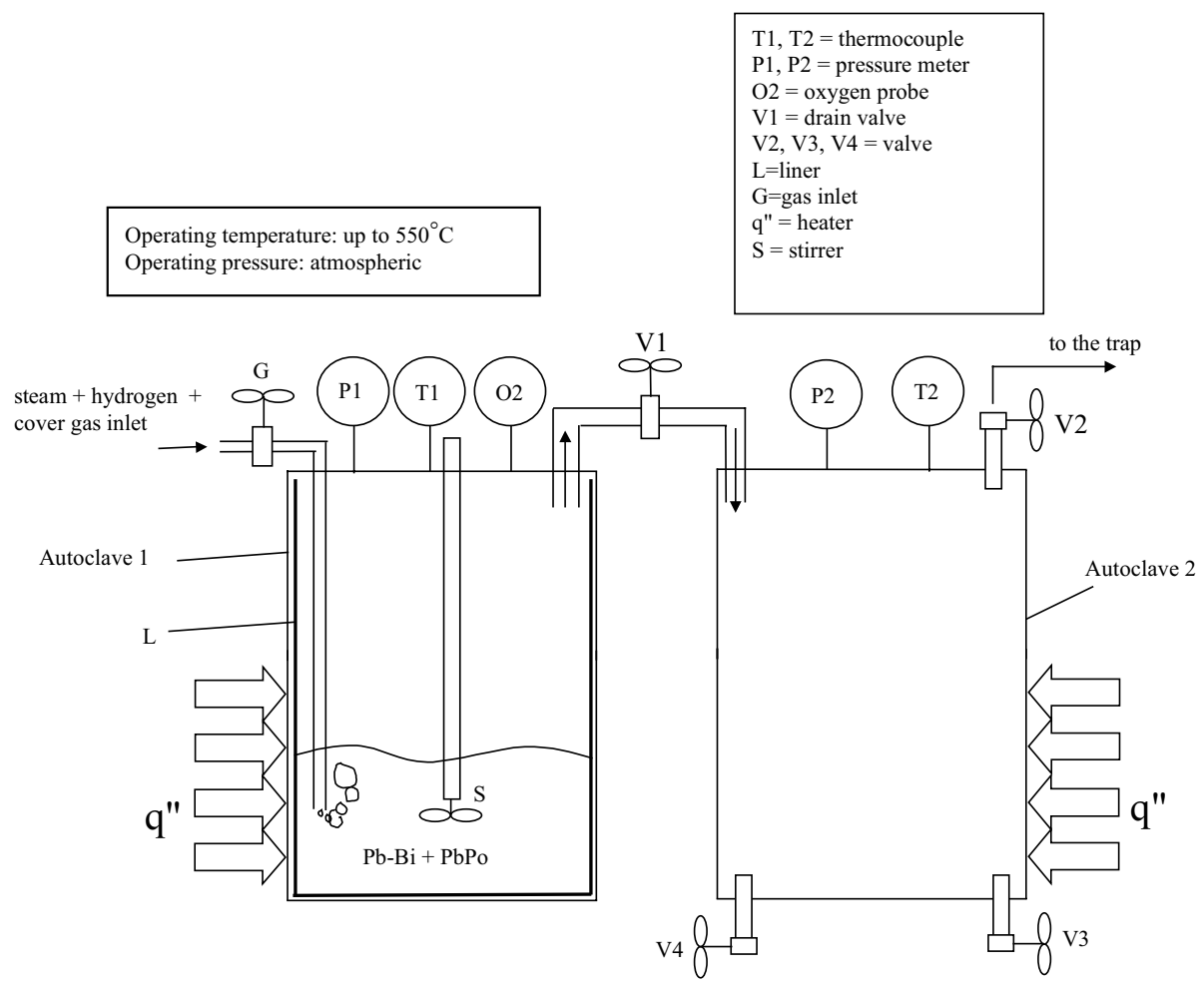

Figure 36. Schematic of the MIT polonium experimental apparatus

\footnotetext{
${ }^{8}$ From Equation 4 it can be seen that the presence of lead-oxide in the lead-bismuth melt inhibits the generation of the polonium hydride. This makes the oxygen activity (which controls the lead-oxide concentration in the melt) a variable of primary importance in the experiments.
} 


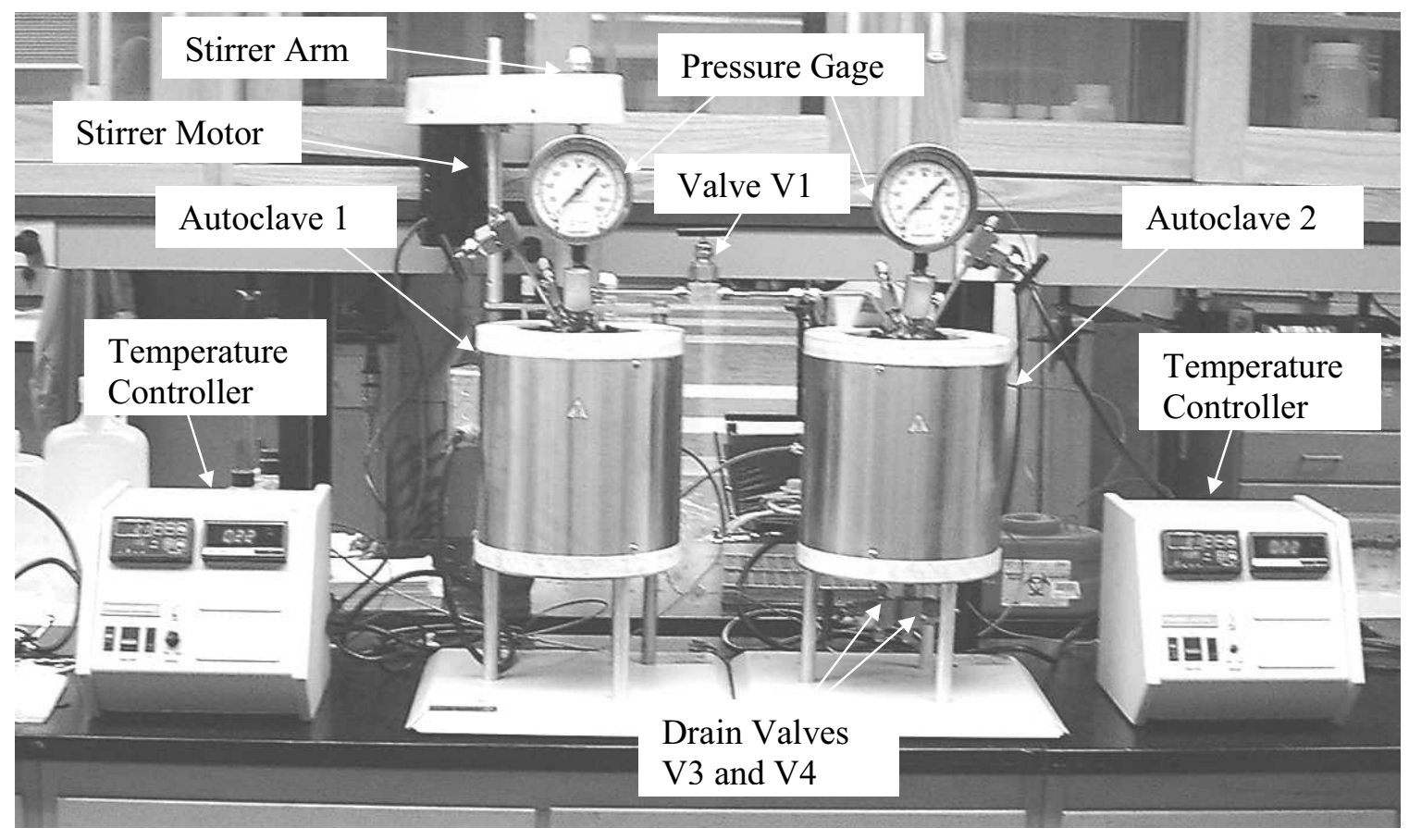

Figure 37. MIT polonium experimental apparatus

It is expected that a significant database on the release of polonium species from a lead-bismuth melt will be generated by means of this equipment by the end of the summer 2000 .

\subsection{PLANT ENGINEERING}

Progress in plant engineering has been made defining two different types of reactor concepts, one utilizing a direct steam power conversion cycle and the other utilizing an indirect cycle

In the direct cycle design, water is injected above the core and steam is produced through direct contact with the lead-bismuth. The steam is then passed through a turbine to produce electricity. This design has been extensively studied this year. In the indirect cycle designs, heat exchangers are used to cool the lead-bismuth and to heat a secondary coolant, either water or helium. In one option, the secondary coolant is water that is heated to steam using a Rankine cycle. In the other option, the secondary coolant is helium that is heated using a Brayton cycle. Both natural circulation and forced circulation options will be considered to drive the lead-bismuth in the indirect cycle designs. This year the primary natural circulation, secondary steam indirect cycle has been studied.

The evaluation of the reactor with the direct contact cycle has investigated the heat transfer process between the lead-bismuth and water and aerosol production and transport. Several void fraction correlations were also evaluated for investigating the natural circulation potential of the reactor. 
The evaluation of the indirect cycle designs has concentrated on two major areas. First, the optimization of the indirect steam cycle design with natural circulation of the primary coolant at steady, full-power operation has been performed. Sensitivity studies to investigate the effects of various parameters, such as the pitch-to-diameter ratio of the core fuel rods and heat exchanger tubes, chimney height, and heat exchanger lattice (triangular versus rectangular), on the fullpower, steady-state peak cladding temperature have been performed. The results of the sensitivity calculations were also compared to the cladding temperature design limits presented in Section 3 to determine the benefit of potential design changes. The maximum core power that could be obtained, while meeting the cladding temperature limit described in Section 3 for steady-state operation, was also determined for a variety of design options. Second, a passive decay heat removal system was designed based on the Reactor Vessel Auxiliary Cooling System (RVACS) of the Power Reactor Innovative Small Module (PRISM) (General Electric, 1986). A complete loss-of-feed-water transient was analyzed. The maximum initial core power was determined so that the peak cladding temperature during the loss-of-feed-water event was less than the transient limit presented in Section 3. Potential design enhancements to the RVACS were also evaluated.

The ATHENA (Carlson et al., 1986) computer code was assessed for the calculation of void fraction in mixtures of lead-bismuth and gas during co-current, vertical up-flow. The assessment was performed to aid in the evaluation of gas lift pumps in the indirect cycle designs.

Finally, an economic analysis approach to determine the cost of electricity production in the leadbismuth reactor was developed. The approach estimates the capital cost associated with the leadbismuth reactor based on comparisons with PRISM. Although PRISM uses sodium, rather than lead-bismuth, as the primary coolant and has an intermediate heat transport loop, the design is similar enough to allow reasonable cost estimates for the current designs. The approach will be formulated into a model and will be applied to develop specific cost estimates for the different reactor designs and thus aid in the selection of the most economic option.

The various pieces of the plant engineering work are described in more detail below. The evaluation of the direct contact power conversion cycle is presented in Section 4.4.1. The evaluation of the indirect cycle at steady, full-power operation is presented in Section 4.4.2. The approach used to estimate the capital cost of the plant is described in Section 4.4.3. Section 4.4.4 provides a preliminary estimate of the capital cost for a plant configuration using natural circulation of the primary coolant and an indirect steam cycle. An evaluation of the indirect cycle during a loss-of-feed-water transient is described in Section 4.4.5. Section 4.4.6 presents an assessment of the ATHENA code for use in the evaluation of gas lift pumps.

\subsubsection{Direct Power Conversion Cycle}

The evaluation of the reactor with the direct power conversion cycle has investigated the heat transfer process between the lead-bismuth and the water and aerosol production and transport. Section 4.4.1.1 describes the investigation of the heat transfer between the lead-bismuth and the water. Section 4.4.1.2 describes the investigation of the aerosol production and transport. 


\subsubsection{Direct Contact Heat Transfer Phenomena}

Some preliminary insight into the direct contact heat transfer phenomena can be gained by considering the evolution of a single liquid water droplet (i.e. the dispersed fluid) in a hot stagnant liquid metal (i.e. the continuum fluid). A schematic of the regions and phenomena involved is illustrated in Figure 38, where for sake of generality it is assumed that the temperature of the droplet is initially below the saturation point at the system operating pressure. Let us focus on the stable phase transition sequence first.

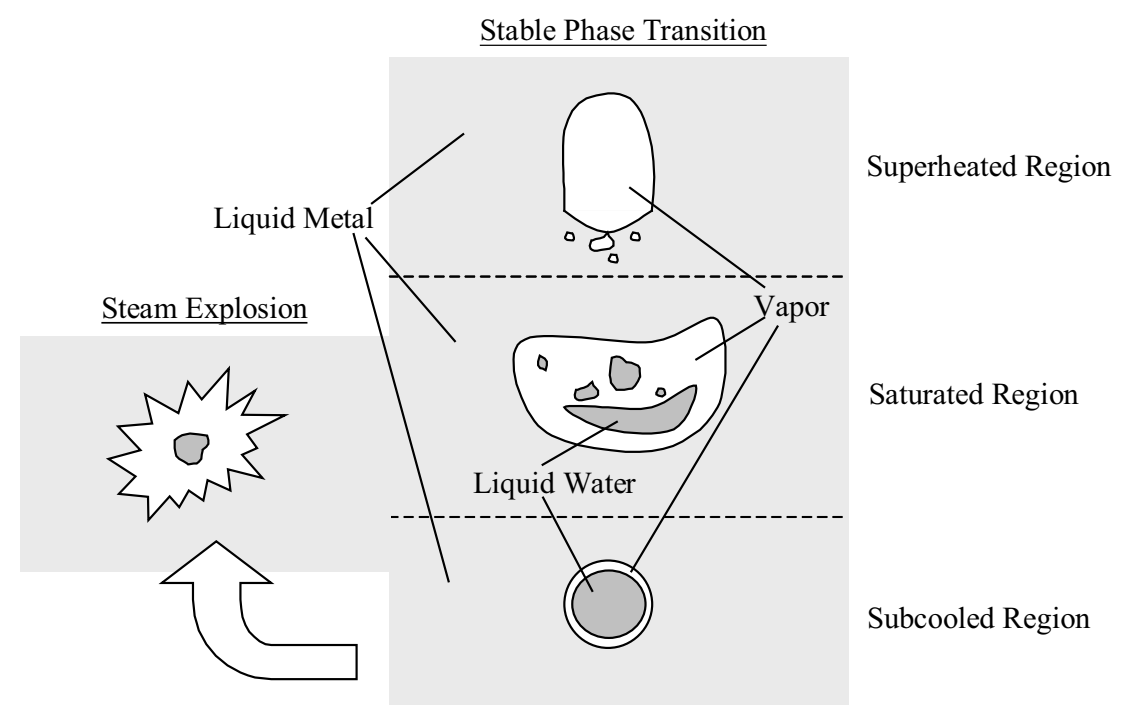

Figure 38. Direct contact vaporization of a single droplet.

In the sub-cooled region, the water droplet remains mostly liquid and its temperature increases as the heat is supplied at the interface with the liquid metal. Depending on the bulk temperatures and the thermo-physical properties of both fluids, the temperature at the interface can quickly raise to the point where heterogeneous nucleation takes place and a stable vapor film is generated that blankets the sub-cooled liquid within the droplet. If this occurs, the system exhibits three phases in the sub-cooled region: the liquid metal, the vapor, and the liquid water. If this does not occur, only two phases are present: the liquid metal and the liquid water.

When the saturation temperature is achieved, a massive vaporization of the liquid water begins, the droplet/bubble rapidly expands and its shape may become rather irregular. Note that by definition, three phases are present in the saturated region: the liquid metal, the vapor and the liquid water. The liquid water nucleus within the vapor bubble eventually dries out and only two phases are left: the liquid metal and the vapor bubbles, whose shape can greatly vary (e.g. spherical, ellipsoidal, cap-shaped, bullet-shaped) depending on the fluids, the droplet initial mass, the system geometry and operating conditions.

In the chimney of the lead-bismuth/water direct contact reactor, several particles (i.e. droplets or bubbles) of the dispersed fluid are present in the bulk of the continuum fluid. A schematic of this situation can be seen in Figure 39. Again we will refer to lead-bismuth and water as the continuum and dispersed fluid, respectively. Because the interfacial area is generally not known a priori, it is convenient to describe the direct contact heat transfer between the two phases as a volumetric phenomenon. This leads to the introduction of the so-called volumetric heat transfer 
coefficient (vhtc), which represents the rate of heat exchanged by the two fluids per unit volume of the flow and per unit temperature difference. Its SI units are $\mathrm{W} / \mathrm{m}^{3} \cdot \mathrm{K}$.

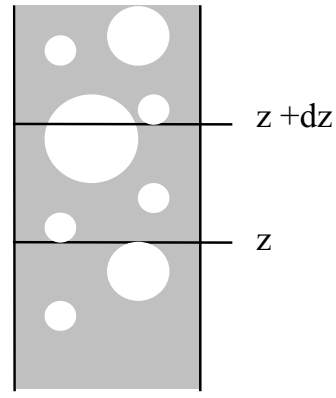

Figure 39. A multi-particle direct-contact channel.

Knowledge of the vhtc is key to calculating the thermal performance of a direct contact heat exchanger (e.g. the chimney of the lead-bismuth/water direct contact reactor). To illustrate this point, let us write the steady-state energy conservation equations for the system of Figure 39, where it is assumed that the dispersed (colder) fluid, the water, is at saturation and is experiencing a change of phase:

$$
\begin{aligned}
& -\dot{m}_{p} c_{p} d T_{p}=h_{v} A\left(T_{p}-T_{w}\right) d z \\
& \dot{m}_{w} h_{f g} d x_{w}=h_{v} A\left(T_{p}-T_{w}\right) d z
\end{aligned}
$$

where $\dot{m}$ is the mass flow rate, $\mathrm{T}$ is the temperature ${ }^{9}, \mathrm{x}_{\mathrm{w}}$ is the steam quality ${ }^{10}, \mathrm{~h}_{\mathrm{v}}$ is the volumetric heat transfer coefficient, and $A$ is the channel flow area. The subscripts $p$ and $w$ refer to the continuum and dispersed fluid, respectively. $c_{p}$ and $h_{f g}$ are the lead-bismuth specific heat and the water vaporization enthalpy, respectively. Note that in Equations 7 and $8, \mathrm{~h}_{\mathrm{v}}$ is actually a vhtc averaged over the flow area $\mathrm{A}$.

If the value of $h_{v}$ is known, the integration of Equations 7 and 8 enables establishing the relationship between the inlet conditions of the fluids, their mass flow rates, the channel flow area and the length required to achieve target outlet conditions. For example, if the mass flow rates and the inlet conditions are known, Equations 7 and 8 can be used to predict the chimney length required to achieve complete water vaporization.

Therefore, it can be stated that the problem of direct contact heat transfer is to find the value of the vhtc for the fluids and thermal-hydraulic conditions of interest. Ideally, it would be desirable to make use of correlations of proven accuracy for such conditions in a way similar to what is done for the surface heat transfer coefficient in the analysis of traditional thermal systems where the fluids are separated by a conductive wall, e.g. one uses the Dittus-Boelter correlation for single-phase internal forced convection or the Chen correlation for saturated boiling. Unfortunately, a wide database for direct contact heat transfer does not exist and reliable correlations are not available particularly for liquid metal/water systems at high-pressure and temperature, i.e. the lead-bismuth/water direct-contact reactor situation.

\footnotetext{
${ }^{9}$ Note that in this case $T_{\mathrm{w}}$ is the saturation temperature of water, known if the system pressure is given.

${ }^{10}$ Defined as the flow rate of vapor over the total water flow rate (liquid + vapor).
} 
An alternative approach builds on the following definition of the vhtc:

$h_{v}=h a_{i}$

where $\mathrm{h}$ is the local surface heat transfer $\left(\mathrm{W} / \mathrm{m}^{2} \cdot \mathrm{K}\right)$ and $\mathrm{a}_{\mathrm{i}}$ is the interfacial area concentration $\left(\mathrm{m}^{2} / \mathrm{m}^{3}\right)$, i.e. the interface area between the fluids per unit volume of the flow. The problem of finding the vhtc is then broken into the separated problems of finding the local surface heat transfer coefficient and the interfacial area concentration where $a_{i}$ describes the internal geometric structure of the flow and the available area to transfer energy from one phase to another. Its value depends mainly on the droplet/bubble size, shape and number and therefore depends ultimately on the flow regime. The value of $\mathrm{h}$ also depends on the internal geometry of the flow, as well as on the relatively velocity of the phases and on the thermodynamic conditions of the fluids (e.g. saturated vs. superheated water).

In the following sections the value of $h$ and $a_{i}$ will be estimated on the basis of mechanistic models of the hydraulic and thermal phenomena occurring in the lead-bismuth/water directcontact reactor chimney. The predictions so generated will be benchmarked with experimental data where possible.

\subsection{Multiphase Flow.}

The ultimate goal of this section is to evaluate the interfacial area concentration in the leadbismuth/water direct-contact reactor chimney, which generally depends on the flow regime and on the void fraction. Therefore, the first two parts of this section deal with (i) the characterization of the transitions between different flow regimes and (ii) with the identification of a reliable predictive tool to estimate the void fraction in lead-bismuth/water multi-phase flow.

Flow Transitions. At the bottom of the reactor chimney, the sub-cooled liquid water is injected in the lead-bismuth in the form of fine droplets. For any water flow rates of practical interest, the mean distance between these droplets is sufficiently large so that the droplet interaction (e.g. droplet coalescence) can be neglected. Although a thin vapor film will rapidly develop around the droplet as a result of homogeneous nucleation induced by the high lead-bismuth temperature, the size of the droplets does not change significantly because the droplet bulk remains liquid. Under these circumstances, the mixture displays an ideal bubbly flow pattern, with small spherical bubbles steadily rising at a more or less fixed distance.

When the temperature of the liquid nucleus reaches saturation, a vigorous vaporization is initiated. The droplet/bubble size begins to increase as does the flow void fraction. The flow regime remains bubbly until the mean distance between contiguous bubbles is so small that the rate of coalescence becomes significant and bubbly flow gradually disappears. At this stage, there is considerable bubble entrainment in each other's wake and larger bubbles are formed that move at a higher velocity than in bubbly flow. The flow becomes agitated and unsteady. Smaller bubbles are also formed by break-up of the larger bubbles due to collision with turbulent eddies and/or by shear off at the bubble periphery. These two competing effects (bubble coalescence and break-up) result in an intermittent flow, where roughly two groups of bubbles are present: (i) large bubbles whose shape markedly deviates from spherical and (ii) small spherical/ellipsoidal bubbles (Fu et al. 2000) flowing in the wake of the large bubbles. If the large bubbles have a bullet elongated shape and occupy the whole channel flow area, the intermittent flow is called 
"slug flow". If the channel diameter is large (greater than $\mathrm{D}_{\text {cap }}$ defined in Equation 14), the bullet-shaped bubbles are not stable and slug flow does not occur. Instead the bubbles have a cap hemispherical shape of diameter significantly smaller than the channel diameter and the intermittent flow is called "cap flow". The transition to intermittent flow results in a larger average velocity of the bubbles and generally in a marked reduction of the interfacial area between water and lead-bismuth due to the presence of the large bubbles whose surface to volume ratio is small.

If the volumetric flow rate of the dispersed phase further increases, the large bubbles begin to agglomerate and create a central water streaming and channeling region. In this region, elongated irregular filaments of dispersed fluid are present (this is the so-called "churn flow") until the transition to an actual annular flow takes place. At that point, most of the liquid metal is displaced to the channel wall and a continuum steam/liquid water core flows in the middle of the channel.

Note that the chimney is partitioned into 157 square channels each corresponding to a fuel assembly. Partitioning prevents bubble radial drifting, hence yielding uniform mixture quality and heat transfer throughout the reactor chimney. The hydraulic diameter ${ }^{11}$ of the chimney channels is approximately $26 \mathrm{~cm}$. Because Equation 14 predicts a maximum bubble diameter of about $6 \mathrm{~cm}$, it is anticipated that the intermittent flow of interest for the lead-bismuth/water directcontact reactor application is cap flow.

Taitel's generalized theory of flow transitions (Taitel et al. 1980) was used to generate a flow map for the lead-bismuth/water direct-contact reactor chimney. A fundamental assumption was made that there is no velocity slip between the steam and the liquid water, i.e. the two water phases rise with the same velocity ${ }^{12}$. This is well justified by visual observations of the direct contact vaporization process of water in hot liquid metal, which show that the water rises as twophase bubbles where a liquid nucleus is always surrounded by a vapor film (Nishi et al. 1998). This assumption greatly simplifies the analysis because it allows treating the water effectively as one phase only characterized by a single velocity and a single density, $\rho_{\mathrm{w}}$. This assumption also enables making use of the traditional two-phase flow correlations for bubble rise velocity and void fraction, avoiding the complications of a third independently moving phase.

Figure 40 shows the flow map for the conditions of interest. The two variables selected to describe the flow are the lead-bismuth superficial velocity $\mathrm{j}_{\mathrm{p}}$ and the water superficial velocity $\mathrm{j}_{\mathrm{w}}$. The flow regime boundaries depend on the thermo-physical properties of the fluids (e.g. the water density) and thus on the steam quality $\mathrm{x}_{\mathrm{w}}$. Therefore, in principle a set of curves for different values of the water density should be drawn for each transition in Figure 40. However, to simplify the map, only the boundaries for $\mathrm{x}_{\mathrm{w}}=1$ (i.e. dry steam) were drawn.

\footnotetext{
${ }^{11}$ Note that in a square channel the hydraulic diameter $(4 *$ flow area/wetted perimeter) is equal to the square side.

${ }^{12}$ On the other hand, velocity slip between the two-phase water bubbles and the liquid metal is considered.
} 


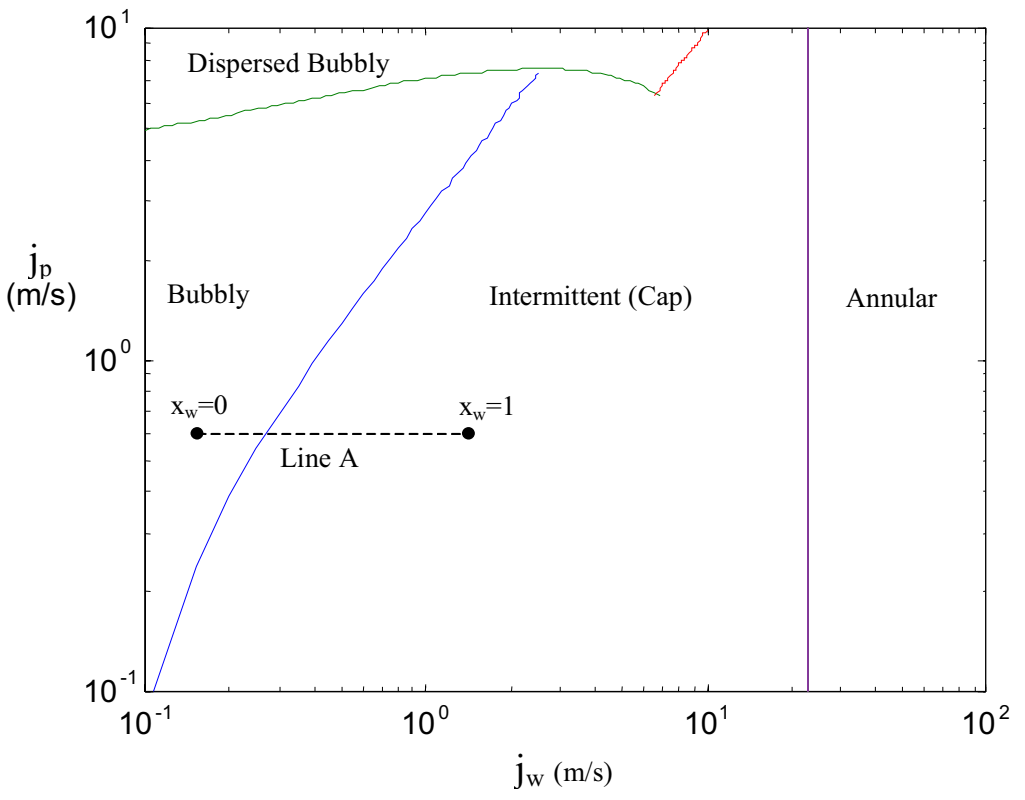

Figure 40. The lead-bismuth/water direct-contact reactor chimney flow map $(P=7.0 \mathrm{MPa}$,

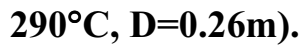

However, Line A in Figure $\mathbf{4 0}$ also shows the flow regime evolution within the chimney channel as the water progressively vaporizes and its superficial velocity (which is inversely proportional to density) increases. Line A is drawn for the reference conditions $\dot{m}_{p}=380 \mathrm{~kg} / \mathrm{s}$ and $\dot{m}_{w}=3 \mathrm{~kg} / \mathrm{s}$. It can be seen that upon vaporization a transition from bubbly to intermittent flow occurs, more specifically a transition to cap flow. Figure $\mathbf{4 0}$ shows that the lead-bismuth/water direct-contact reactor reference conditions are well within the bubbly/intermittent region and far from the annular and finely dispersed bubbly flow regions.

Void Fraction Correlation. Because most of the chimney operates in intermittent flow (as shown in Figure 43), the knowledge of the void fraction for intermittent flow is key to predict (i) the natural circulation flow in the primary circuit, (ii) the interfacial area concentration and thus the heat transfer rate in most part of the chimney. Most models and correlations for the prediction of the void fraction in two-phase flow were developed for steam/water and air/water systems. The considerably different thermo-physical properties (e.g. density and surface tension) of liquid metal/steam mixtures makes the application of these water based correlations to the leadbismuth/water direct-contact reactor chimney open to question.

In the quest for a predictive tool suitable to the lead-bismuth/water direct-contact reactor conditions, several void fraction correlations for intermittent flow were considered in this study. Mostly they are based on the drift-flux model. In this type of correlation the void fraction is expressed as:

$$
\alpha=\frac{\beta}{C_{0}+u_{w j} / j}
$$


$\beta$ and $\mathrm{j}$ are the volumetric flow ratio and the total superficial velocity, respectively. Each of the correlations selected provides an expression for the coefficients $\mathrm{C}_{0}$ and $\mathrm{u}_{\mathrm{wj}}$, which can be found in the reported references.

The correlations considered are:

- Zuber-Findlay slug flow (1965). This model assumes that the diameter of the bullet-shaped bubbles in slug flow is equal to the channel diameter. However, as already mentioned, the existence of big bullet-shaped bubbles in large diameter channels is questionable as shown by the visual observations in (Kataoka and Ishii 1987) and (Kawanishi et al. 1990).

- Zuber-Findlay churn flow (1965). This model assumes that at high vapor superficial velocity large bubbles are unstable because they are broken by turbulent eddies. The maximum diameter of the resulting smaller bubbles is determined by the surface tension.

- EPRI (Chexal et al. 1992). This correlation was benchmarked against a wide range of steam/water and water/air data (Chexal et al. 1991 and 1992). The authors claim it can be applied to all flow regimes, at any pressure, mass flux and channel diameter. However, at very low void fraction (i.e. $<0.1$, typical of bubbly flow) it yields a global slip ratio smaller than one. This might result from a prevalence of sub-cooled water boiling data in the low void fraction region of the correlation database.

- Ishii-Kataoka-Rouhani. It was initially developed by Ishii-Kataoka (Kataoka and Ishii 1987) for pool systems only. When adapted by Rouhani to flow systems (Rouhani 1992), the expression for the Ishii-Kataoka vapor drift velocity $u_{\mathrm{wj}}$ was retained, but a new expression for the distribution parameter $\mathrm{C}_{0}$ was developed by Rouhani (1969). In this model, particular attention is given to the effect of the channel diameter on the size, shape and velocity of the rising bubbles. Experiments with large diameter channels (Kataoka and Ishii 1987, Kawanishi et al. 1990) indicate that there is a maximum stable size of the bubbles, independent of the channel diameter. Moreover, due to the turbulence of the two-phase flow, these bubbles display significant deviation from the ideal bullet shape of a slug bubble. Also they appear to rise at higher velocity than predicted by the theory for bullet-shaped bubbles (Zuber and Findlay 1965).

- Kawanishi (1990). This correlation is meant for steam/water systems only and its dependence on the pressure is dimensional. For application to our lead-bismuth/steam twophase flow, we inserted in the correlation the value of the pressure that makes the steam/water density ratio equal to lead-bismuth/water direct-contact reactor density ratio.

- Corradini-Casas (1992). This correlation was developed for low-pressure, heavy liquid metal/steam pool conditions, typical of core-melt accident analysis in nuclear reactors (e.g. corium/concrete interactions). Because it is based on relatively shallow pool experimental data, an effect of the pool height was observed on the radial distribution of voids. As the bubbles move upward, they tend to drift to the pool center thus increasing the distribution coefficient $\mathrm{C}_{0}$. However, in adiabatic steady-state long channels $(\mathrm{L} / \mathrm{D}>10)$, the flow is expected to be fully developed and little dependence on the channel length (or on the mode of vapor injection) should be observed. Therefore, to make the correlation suitable to two-phase flow in long channels, the value of the distribution parameter was arbitrarily assumed independent of the pool height and equal to the maximum value in Corradini's experiment. 
- Dix (1971). This correlation was mainly developed for LWR applications. It assumes there is no local slip between the two phases, but it allows for a radial distribution of void and velocity. Effectively, it is a drift-flux correlation where $u_{\mathrm{wj}}$ is set equal to zero. The Dix model does not display a dependence on the channel diameter and the mass flux.

- Homogeneous Equilibrium Model (Todreas and Kazimi 1990). Effectively, the homogeneous equilibrium model void fraction can be obtained from a drift-flux correlation where $\mathrm{u}_{\mathrm{wj}}$ and $\mathrm{C}_{0}$ are set equal to zero and one, respectively. The homogeneous equilibrium model does not display a dependence on the channel diameter and the mass flux.

- Finally, the El-Boher/Lesin correlation (El-Boher et al. 1988), which is not based on the driftflux model, was considered. It is based on data collected at the lead-bismuth/steam facility ETGAR-3 of the Ben Gurion University in Israel. Buongiorno (2000) shows that most of the ETGAR-3 experimental data lie in the intermittent region with a significant 'tail' in the bubbly flow region. However, the temperature and pressure at which the ETGAR-3 experiments were conducted are very different from those of the lead-bismuth/water directcontact reactor chimney. Also, the El-Boher/Lesin correlation is a purely empirical correlation. It is not based on a hydrodynamic model (e.g. drift-flux or homogeneous equilibrium model) and its coefficients do not change with the flow regime.

A summary of the essential characteristics of all the correlations considered in this study is reported in Table 23.

Table 23. The correlations for intermittent flow regime.

\begin{tabular}{|c|c|c|c|c|c|}
\hline Correlation & \multirow{2}{*}{ Type } & \multicolumn{4}{|c|}{ Database } \\
\cline { 3 - 6 } & Drift-flux & $\begin{array}{c}\text { Steam/water } \\
\text { air/water }\end{array}$ & Intermittent (slug) & $0.1-18.0$ & $0.05-0.6$ \\
\hline Zuber-Findlay (slug) & Drift-flux & $\begin{array}{c}\text { Steam/water } \\
\text { air/water }\end{array}$ & Intermittent (churn) & $0.1-18.0$ & $0.05-0.6$ \\
\hline Zuber-Findlay (churn) & Drift-flux & $\begin{array}{c}\text { Steam/water } \\
\text { Air/water }\end{array}$ & All flow regimes & $0.1-18.0$ & $0.005-0.5$ \\
\hline EPRI & Drift-flux & $\begin{array}{c}\text { Steam/water } \\
\text { air/water }\end{array}$ & Bubbly, Intermittent & $0.1-18.0$ & $0.01-0.6$ \\
\hline Ishii-Kataoka-Rouhani & Drift-flux & Steam/water & Bubbly, Intermittent & $0.5-1.5$ & $0.02-0.1$ \\
\hline Kawanishi et al. & Drift-flux & $\begin{array}{c}\text { Nitrogen/heavy } \\
\text { metal }\end{array}$ & $\begin{array}{c}\text { Bubbly, Intermittent } \\
\text { (churn) }\end{array}$ & 0.1 & 0.15 \\
\hline Corradini-Casas & No local slip & Steam/water & All flow regimes & $1.0-7.0$ & N/A \\
\hline Dix & No global slip & N/A & N/A & N/A & N/A \\
\hline $\begin{array}{c}\text { Homogeneous } \\
\text { Equilibrium Model }\end{array}$ & Empirical & Steam/heavy metal & Bubbly, Intermittent & 0.35 & 0.2 \\
\hline El-Boher/Lesin & & & & & 0.2 \\
\hline
\end{tabular}

In vertical two-phase flow the phase relative velocity is a strong function of the density of the two phases. Table 24 reports the value of the density ratio for several different systems relevant to this study. It should be noted that, based on the density ratio, the lead-bismuth/water directcontact reactor two-phase flow is substantially different from ETGAR-3 or a traditional BWR and is more hydro-dynamically similar to a low-pressure water/air system. It is, therefore, expected that, when applied to the lead-bismuth/water direct-contact reactor conditions, the El-Boher/Lesin 
correlation (valid for the high $\rho_{p} / \rho_{w}$ ETGAR-3 conditions) will systematically over-predict the relative velocity and under-predict the void fraction. On the other hand, the correlations of proven accuracy for BWR thermal-hydraulic conditions are expected to under-predict the relative velocity and over-predict the void fraction.

Table 24. Hydrodynamic relevant parameters of two-phase systems.

\begin{tabular}{|c|c|c|c|c|}
\hline & ETGAR-3 & Air/Water & $\begin{array}{c}\text { Lead-Bismuth/Water } \\
\text { Direct-Contact } \\
\text { Reactor }^{13}\end{array}$ & BWR \\
\hline $\mathrm{P}(\mathrm{MPa})$ & 0.35 & 0.35 & 7.0 & 7.0 \\
\hline$\rho_{p} / \rho_{w}$ & $\sim 6,000$ & $\sim 250$ & $\sim 250$ & $\sim 20$ \\
\hline $\mathrm{D}(\mathrm{m})$ & 0.2 & N/A & $\sim 0.2$ & $\sim 0.02$ \\
\hline
\end{tabular}

The application of any of the above void fraction correlations to the lead-bismuth/water directcontact reactor chimney conditions represents an extrapolation beyond their database. Therefore, a methodology was developed which enables evaluating the acceptability of a void fraction correlation when it is desirable to use it beyond the range of its experimental database. The methodology is as follows.

The correlation of interest is to be tested against six postulated criteria. The goal is to establish the "domain of physically acceptable applicability", i.e. the region of the flow map where the correlation can be meaningfully utilized. It should be emphasized that this domain does not define a region where the correlation is accurate, but only one where the correlation does not produce results in contradiction with the known characteristics of two-phase vertical up-flow.

To establish the "domain of physically acceptable applicability", the correlation is tested against six criteria that fit the conditions under investigation:

1) $\mathrm{S} \geq 1$. Because the density of the vapor phase is smaller than the density of the liquid phase, the global slip ratio must be greater than unity in adiabatic fully developed steady-state vertical up-flow. Clearly, this criterion does not necessarily hold for heated channels where sub-cooled boiling occurs (e.g. in the sub-cooled region of the steam/water channels of a BWR): in this case the bubbles are created at the heated wall and remain relatively close to it (where the velocity is low). As a result, the global slip can be smaller than unity.

2) $\lim _{G \rightarrow \infty} S=1$ (in dispersed bubbly flow). At high mass flux, only small diameter bubbles exist (because bigger bubbles are broken and dispersed by turbulent eddies), the effect of gravity is small and the local slip ratio must approach unity. Moreover, at high mass flux the radial velocity profile is flat. Therefore, the global slip ratio must also approach unity.

3) $\left(\frac{\partial \alpha}{\partial x}\right)_{G}>0$. For a given mass flux, an increase of the flow quality must cause an increase of the void fraction.

\footnotetext{
${ }^{13}$ The density ratio reported here is calculated assuming $\mathrm{x}_{\mathrm{w}}=1$.
} 
4) $\left(\frac{\partial \alpha}{\partial G}\right)_{x}>0$. For a given flow quality, an increase of the mass flux flattens the radial velocity profile in the channel, reduces the global slip ratio hence causing an increase of the void fraction. Again it should be noted that this criterion does not necessarily hold for adiabatic flows (e.g. sub-cooled boiling) where the bubbles may be concentrated in the region of low velocity near the wall.

5) $\frac{x}{\alpha}\left(\frac{\partial \alpha}{\partial x}\right)_{G}>\frac{G}{\alpha}\left(\frac{\partial \alpha}{\partial G}\right)_{x}$. This criterion postulates that the void fraction must primarily depend on the quality and only to a smaller extent on the mass flux. In other words, it is postulated that the effect described in (3) must be dominant over the effect described in (4).

6) $\frac{\partial(\beta / \alpha)}{\partial(1 / j)}=u_{w j}>0$. The drift velocity of the vapor phase $u_{\mathrm{wj}}$ (i.e. the terminal velocity of a vapor bubble in the stagnant liquid) must be positive.

It should be noted that the above criteria are postulated for adiabatic fully developed steady-state two-phase up-flow only (i.e. the dispersed phase is not concentrated at the channel wall), which is applicable to the lead-bismuth/water direct-contact reactor chimney situation.

A description of the application of this methodology to the correlations of Table 24 is reported by Buongiorno (2000), where also the "domain of physically acceptable applicability" of the ElBoher/Lesin correlation is illustrated. On the basis of this methodology and of their respective underlying models, the correlations were screened and compared. The following recommendations were made:

- Given the significant discrepancies observed between the correlations, an experimental assessment of the void fraction under typical lead-bismuth/water direct-contact reactor conditions is strongly recommended.

- For interim calculations, the El-Boher/Lesin correlation should be used when a conservatively low prediction of the void fraction at the lead-bismuth/water direct-contact reactor conditions is required, but never outside its domain of applicability because it becomes physically unacceptable.

- The Ishii-Kataoka-Rouhani correlation should be used when a more realistic assessment is required. The Ishii-Kataoka-Rouhani correlation was chosen over the Zuber-Findlay and EPRI correlations due to its emphasis on the channel diameter effect (i.e. the impossibility of establishing slug flow in a large diameter channel), its relative simplicity (as opposed to the complexity of the EPRI correlation) and its good agreement with experiments at low mass flux. Moreover, the Ishii-Kataoka-Rouhani correlation was chosen over the Kawanishi correlation because the pressure dependence of the former is non-dimensional.

Interfacial Area Concentration. Several methods have been proposed in the past to assess the interfacial area concentration $a_{i}$ in two-phase flow. This parameter is of key importance in any hydraulic models that rely on a separate set of conservation equations for each phase. In these models, estimates of the transfer terms between the phases must be provided to close the problem. Because mass, momentum and energy transfer takes place at the phase interface, all these terms strongly depend on the value of $a_{i}$. The most general method to evaluate $a_{i}$ treats this parameter as a property of the flow. A transport equation for $a_{i}$ is written, which enables predicting the 
internal geometric structure of the two-phase flow as a function of space and time (Kocamustafaogullari and Ishii 1995). The solution of this equation requires the provision of constitutive relations, i.e. source and sink terms for $a_{i}$ due to bubble coalescence and break-up. The source and sink terms of the transport equation are, to date, well characterized mostly for bubbly flow, where they would be less needed given the relatively simple flow geometry. The development of the source and sink terms for intermittent flow, which is more relevant to our application, is the object of current investigation (Fu et al. 1999 and 2000) and few data are available. Therefore, in this study we do not follow the transport equation approach, but the expressions for the interfacial area concentration are derived on the basis of simple considerations based on the assumed flow regime geometry. These expressions can be then be used in Equation 9 to calculate the vhtc.

Bubbly Flow. The following assumptions are made for bubbly flow:

- The initial diameter of the injected liquid water droplets is known

- The droplets are injected uniformly across the channel

- The droplets and the bubbles (resulting from droplet vaporization) are spherical ${ }^{14}$

- Bubble coalescence and break-up can be ignored.

The void fraction is calculated from the drift-flux model (see Equation 10) with $\mathrm{C}_{0}=1$ and the dispersed phase drift velocity $u_{w j}$ given by Zuber and Findlay (1965). Due to the fourth assumption above, the bubble diameter $D_{b}$ at any value of the water density $\rho_{w}$ can be obtained by a simple mass balance of the dispersed phase as:

$$
D_{b}=D_{b 0}\left(\frac{\rho_{w 0}}{\rho_{w}}\right)^{1 / 3}
$$

where $\mathrm{D}_{\mathrm{b} 0}$ and $\rho_{\mathrm{w} 0}$ are the initial droplet diameter (known by the first assumption above) and density, respectively. Then the number of bubbles per unit volume, $\mathrm{n}_{\mathrm{b}}$, can be found as:

$$
n_{b}=\frac{\alpha}{\frac{\pi}{6} D_{b}^{3}}
$$

Finally, the interfacial area concentration $a_{\mathrm{i}}$ in bubbly flow is:

$$
a_{i}=\pi D_{b}^{2} n_{b}=\frac{6 \alpha}{D_{b}}
$$

Intermittent Flow. The intermittent flow of interest to our application is cap flow characterized by large cap bubbles with smaller bubbles flowing in their wake (see Figure 41). The following assumptions are made:

a) The shape of the cap bubbles is hemispherical and their diameter is given by the maximum stable diameter (Kataoka and Ishii 1987):

$$
D_{\text {cap }}=30 \sqrt{\frac{\sigma}{g\left(\rho_{p}-\rho_{w}\right)}}
$$

\footnotetext{
${ }^{14}$ This is a conservative assumption because for a given volume a spherical bubble has a minimum interfacial area.
} 
b) The shape of the small bubbles is spherical and their diameter is equal to 1.5 times the Laplace length as indicated in (Fu et al. 2000). Then:

$$
D_{\text {small }}=1.5 \sqrt{\frac{\sigma}{g\left(\rho_{p}-\rho_{w}\right)}}
$$

c) The cap and small bubbles share the same drift velocity (and thus the same absolute velocity).

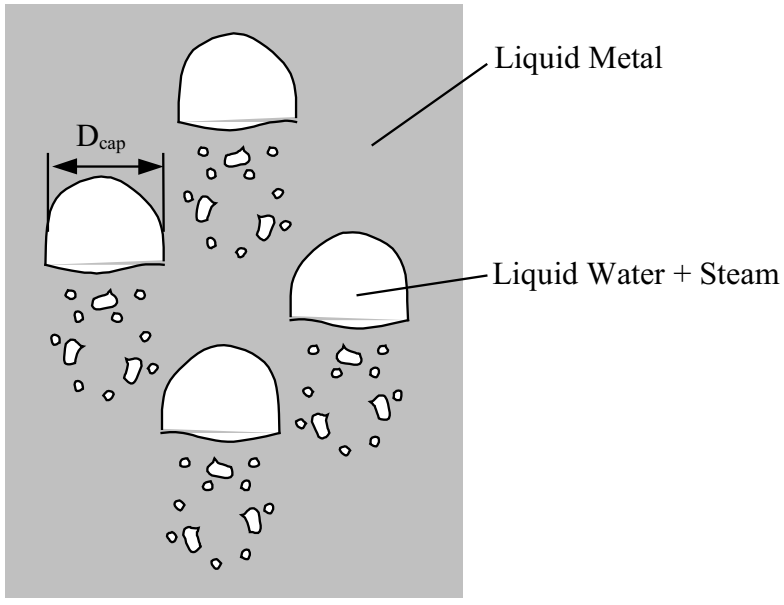

Figure 41. The cap flow regime

The void fraction in the cap flow regime is calculated by means of the Ishii-Kataoka-Rouhani correlation. We will indicate by $f_{c}$ the fraction of $\alpha$ due to the cap bubbles. With this definition, $f_{c} \alpha$ represents the volume of the cap bubbles per unit volume of the flow. Obviously, $\left(1-f_{c}\right) \alpha$ is the volume of the small bubbles per unit volume of the flow. Then, the interfacial area concentration in cap flow can be calculated as:

$$
a_{i}=f_{c} \alpha \frac{9}{D_{\text {cap }}}+\left(1-f_{c}\right) \alpha \frac{6}{D_{\text {small }}}
$$

where $9 / D_{\text {cap }}$ and $6 / D_{\text {small }}$ are the interfacial area per unit volume of the cap and small bubbles, respectively, derived from elementary geometry. Similar equations are proposed by Ishii (1987). Based on the data in reference (Fu et al. 2000) it is assumed that the value of $f_{c}$ is equal to 0.75 when the transition from bubbly to cap flow is completed.

\subsection{Local Heat Transfer Coefficient}

To calculate the vhtc it is also necessary to evaluate the rate of heat transfer at the interface of the dispersed and the continuum phase, which is described by the local surface heat transfer coefficient. To do so, we divide the lead-bismuth/water direct-contact reactor chimney in three heat transfer regions according to the thermodynamic state of the dispersed phase: the sub-cooled, saturation, and the superheat regions (see Figure 38).

The Sub-cooled Region. To calculate the heat transfer coefficient in the sub-cooled region, it is important to first evaluate whether a vapor film is formed that separates the droplet liquid bulk from the hot lead-bismuth. This is done by comparing the temperature at the lead-bismuth/water interface upon contact with the temperature of homogeneous nucleation of water. Calculations 
show that at lead-bismuth/water direct-contact reactor conditions $(7.0 \mathrm{MPa})$, a vapor film will form if $\mathrm{T}_{i}$ exceeds approximately $330^{\circ} \mathrm{C}$, which occurs for most practical lead-bismuth/water direct-contact reactor situations.

The surface heat transfer coefficient in the sub-cooled region, $\mathrm{h}_{\text {sub }}$, was calculated as the sum of two thermal resistances in series: (i) the heat transfer coefficient from the bulk of liquid metal to the interface and (ii) the heat transfer coefficient of the vapor film. That is:

$$
\frac{1}{h_{\text {sub }}}=\frac{1}{h_{p}}+\frac{1}{h_{\text {film }}}
$$

Note that in Equation 17 the internal thermal resistance of the liquid water is neglected, which is equivalent to assume effective mixing in the droplet in accordance with the results reported by Smith et al. (1982). To calculate $h_{p}$ the liquid metal correlation recommended by Kim (2000) was

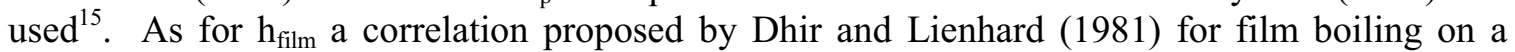
sphere was used. It was also found that at typical lead-bismuth/water direct-contact reactor conditions is $\mathrm{h}_{\text {film }}<<\mathrm{h}_{\mathrm{p}}$. This is expected due to the small thermal conductivity of steam with respect to the lead-bismuth liquid metal.

Steam Explosion. An issue associated with the evolution of the liquid droplets in the sub-cooled region is that of steam explosion. Under certain conditions (typically low operating pressure and high sub-cooling) the vapor film (blanketing the liquid droplet) is not stable and a violent expansion of the droplet can occur, which causes a shock wave that can damage the channel. There seems to be general agreement that steam explosion can occur only if:

a) the interface temperature $T_{i}$ is above the temperature of homogeneous nucleation of the dispersed phase (Henry et al. 1974, Reid 1983, Furuya et al. 1996),

b) $T_{i}$ is below the critical temperature of the dispersed phase (Henry and Fauske 1975, Furuya et al. 1996),

c) the operating pressure is below a threshold value (Henry 1978, Branover 1992, Furuya et al. 1996, Kinoshita et al. 2000).

Several fluid pairs have been found to satisfactorily obey these conditions, ranging from liquified natural gas/water to refrigerant/water, from refrigerant/oil to water/lead-bismuth. Condition (a) expresses the fact that no bubble nucleation can occur if the liquid at the interface is not sufficiently superheated. On the other hand, if homogenous nucleation occurs, a vapor film forms at the interface. This film may be unstable resulting in oscillations of the interface, which eventually lead to the film collapse and to consequent violent vaporization (Matsumura and Nariai 1996). If the interface temperature is above the critical temperature of the dispersed phase, the film is relatively thick and does not collapse (Henry and Fauske 1975). Finally, if the system pressure is large, the vapor embryos generated at the interface by homogenous nucleation cannot grow rapidly. This is due to the large density of vapor at high-pressure. Consequently, the generated vapor can be easily accommodated by a moderate volume increase of the vapor embryos and the phase change is not explosive. The value of the pressure above which no steam explosion occurs was found to be $\sim 0.2 \mathrm{MPa}$ for R-22/water and R-22/oil (Henry and McUmber 1977), $0.5 \mathrm{MPa}$ for water/molten $\mathrm{NaCl}$ (Henry 1978), 0.5MPa for water/lead-bismuth (Furuya et al. 1996) and $\sim 0.2 \mathrm{MPa}$ for butane/ethylene (Branover 1992).

\footnotetext{
${ }^{15}$ A similar correlation was proposed by Nishi (1998).
} 
At typical lead-bismuth/water direct-contact reactor conditions, the interface temperature in the sub-cooled region is well above the homogeneous nucleation temperature as well as the critical temperature. Therefore, condition (a) for steam explosion is met, but condition (b) is not. Moreover, because the lead-bismuth/water direct-contact reactor operating pressure is well above the threshold value for water/lead-bismuth, condition (c) is not met either. Therefore, it can be concluded that the lead-bismuth/water direct-contact reactor features ample safety margin to steam explosion under normal operating conditions. However, scenarios can be envisioned where an accidental depressurization of the reactor pool takes place. In this case, the possibility of steam explosion depends on the magnitude of the depressurization and on the lead-bismuth temperature during the transients. Accident analysis is beyond the scope of this study, but a more thorough investigation of this issue will have to be undertaken, should the development of the lead-bismuth/water direct-contact reactor concept be considered in the future.

Saturated Region. It was noticed that the liquid water does not wet the lead-bismuth surface after the droplet reaches saturation, i.e. the liquid water is always segregated from the leadbismuth by a vapor blanket (see Figure 38). Therefore, the same equations of the sub-cooled region can be used to calculate the local heat transfer coefficient of the saturated region, $\mathrm{h}_{\text {sat }}$, that will be given again by the sum of two thermal resistances in series: liquid metal heat convection and film boiling. Also, note that in the saturated region there is no temperature gradient within the liquid water and thus its internal thermal resistance can be rigorously neglected. However, depending on the flow regime ${ }^{16}$, the geometry in the saturated region may change, hence requiring some modifications. In intermittent flow there are two groups of bubbles of different size and geometry, and thus two different values of the local heat transfer coefficient, which ought to be properly averaged prior to their use in Equation 9. Based on the conservation of energy, it was shown that the local heat transfer coefficient in the saturated region can be found as the weighted sum of the local heat transfer coefficient of the small and cap bubbles, with the interfacial area concentrations as the weights.

Superheated Region. The heat transfer coefficient in the superheated region is the sum of the liquid metal thermal resistance and the thermal resistance within the bubble in series. Because all the liquid water has dried out, heat transfer in the bubble occurs mostly by conduction. The solution of the heat conduction equation in spherical geometry provides the local heat transfer coefficient, equal to $\mathrm{k}_{\mathrm{g}} / \mathrm{D}_{\mathrm{b}}$. Again, in intermittent cap flow, it is necessary to average the value of the local heat transfer over the two bubble groups, which is done by using the interfacial area concentration as the weights.

The expressions developed in the previous sections are combined to predict the thermal and hydraulic evolution of the flow along the channel. It is assumed that all the inlet conditions are known. These are the water and lead-bismuth mass flow rates and temperatures and the water droplet diameter. The water outlet conditions are also given by setting the degree of steam superheat (i.e. the water outlet temperature) that is to be achieved. Note that this fixes the power exchanged in the channel and enables immediately calculation of the lead-bismuth outlet temperature by means of a simple energy balance. The channel flow geometry (flow area, equivalent diameter) is given, except for the channel length, which is an output of the calculation.

\footnotetext{
${ }^{16}$ which is always bubbly in the subcooled region
} 
Special care is given to avoid sharp discontinuities of the flow parameters (e.g. void fraction, interfacial area concentration), that are not physical at the transition from bubbly to intermittent flow. The equations providing the dependent variables for bubbly and intermittent flow are interpolated so that at void fraction 0.05 the flow is mostly bubbly while at void fraction 0.3 the flow is mostly intermittent. The interpolation is not linear, but exponential to yield continuous curves with continuous derivatives. However, a step-like discontinuity of $h$ is allowed at the transition from the saturated to the superheated region due to the sudden disappearance of evaporative heat transfer.

\subsection{Validation of the Model}

In this section the model to estimate the vhtc is applied to several different conditions to ensure that all the expected trends are properly generated. In the rest of this discussion we will always assume that the fluids are water and liquid lead-bismuth (designated by the subscripts $\mathrm{w}$ and $\mathrm{p}$, respectively), flowing in a square channel of side $0.26 \mathrm{~m}$. The operating pressure is $7.0 \mathrm{MPa}$. The water inlet temperature is always $250^{\circ} \mathrm{C}$ (i.e. the water sub-cooling at the channel inlet is about $136^{\circ} \mathrm{C}$ ). The lead-bismuth inlet temperature, the lead-bismuth mass flow rate, the mixture quality $\mathrm{x}$, and the inlet droplet diameter are specified in each figure as is the degree of steam superheat to be achieved.

Figure 42 illustrates a typical variation of the lead-bismuth and water temperatures in the channel. The temperature at the lead-bismuth/water interface is also drawn. Note that the interface temperature at any location in the channel is very close to the lead-bismuth bulk

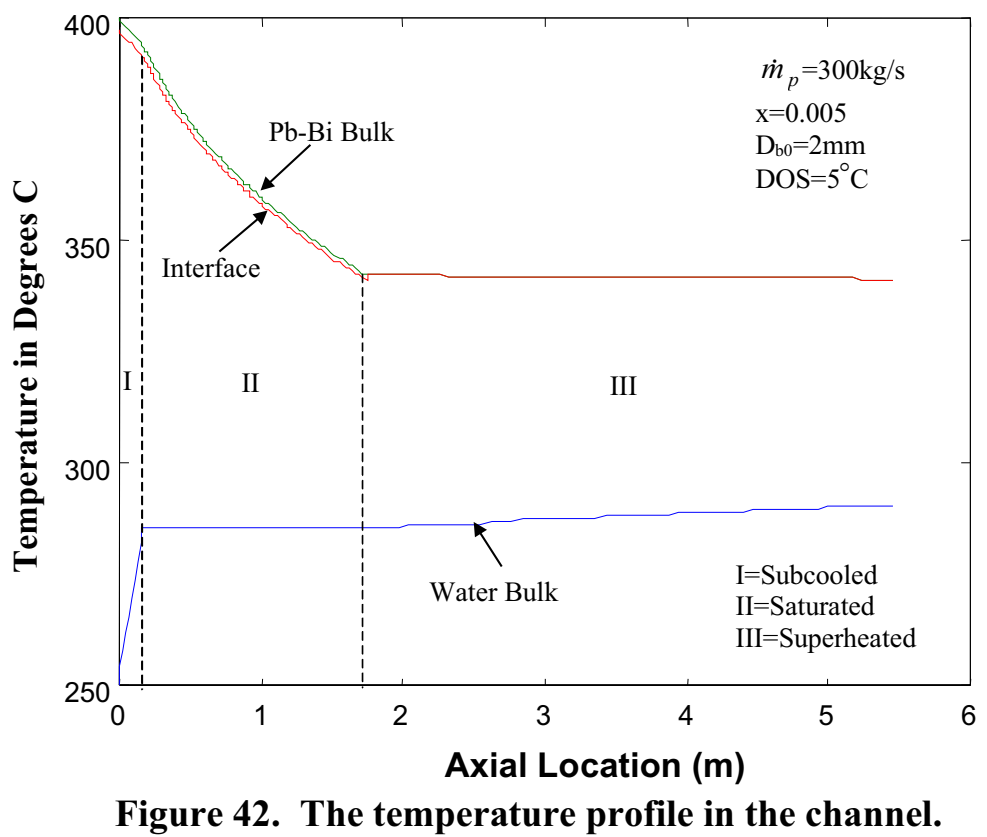

temperature indicating that the thermal resistance in the liquid metal is negligible compared with the thermal resistance in the water droplets/bubbles. This is particularly true in the superheated region where the heat within the steam bubbles is transferred only by conduction. Also, the interface temperature in the sub-cooled region is significantly above the homogeneous temperature of water at the lead-bismuth/water direct-contact reactor operating pressure, $330^{\circ} \mathrm{C}$. 
Thus, the assumption of a vapor film blanketing the water droplet in the sub-cooled region is correct. As expected, the length of the superheated region is considerably larger than that of the sub-cooled and saturated regions even for a modest value of the steam superheat (about $5^{\circ} \mathrm{C}$ ). This reflects the abrupt change in the dominant heat transfer mode (from liquid water evaporation to steam conduction) at the boundary of the saturated and superheated regions (see Figure 45). Finally, the lead-bismuth temperature change in the saturated region is largest because most energy exchange in the channel is associated with the vaporization of the liquid water in this region.

In Figure 43 the void fraction variation along the channel is illustrated for the same inlet conditions of Figure 42. The void fraction rapidly increases at the inlet of the saturated region as massive water evaporation begins. However, as the bubbles swell and their mutual distance decreases, coalescence phenomena become important and larger bubbles form that raise at higher velocity hence causing the water/lead-bismuth slip to increase. Therefore, the void fraction in this region, is the result of two competing effects: (i) the increasing water volumetric flow due to water vaporization and (ii) bubble coalescence. With regards to Equation 10, effect (i) results in an increase of $\beta$, which tends to increase the void fraction. Effect (ii) results in an increase of $u_{w j}$, which tends to decrease the void fraction. The net result is a slower increase of the void fraction until the superheated region is reached, where effect (i) becomes negligible and effects (ii) dominates, causing a slow reduction of the void fraction in this region. It should be noted that as the flow progresses in the channel, the velocity and void profiles become fully-developed, the bubbles tend to drift towards the center of the channel and the distribution coefficient $\mathrm{C}_{0}$ increases, which further contributes to the void fraction reduction (again see Equation 10). Moreover, since the model assumes that the transition from bubbly to intermittent flow is completed by $\alpha=0.3$, it can be concluded that part of the saturated region and the entire superheated region are in intermittent flow.

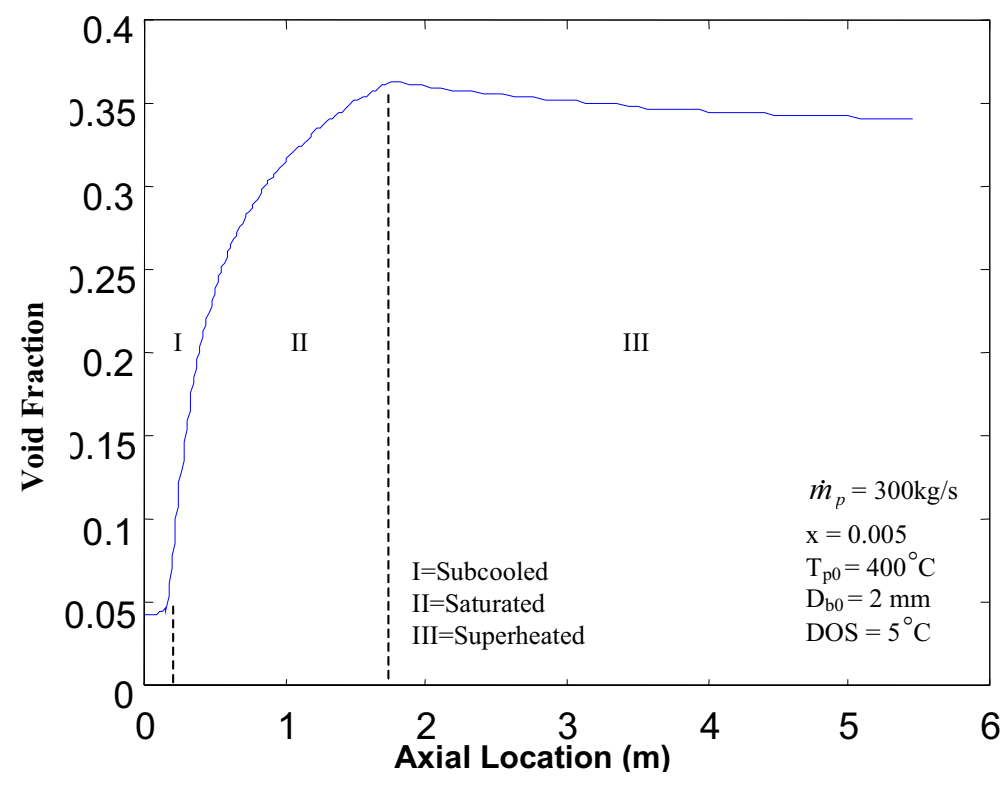

Figure 43. The void fraction profile in the channel. 
To illustrate the effect of bubble coalescence, the variation of the interfacial area concentration in the saturated region, $\mathrm{a}_{\mathrm{i}}$, is plotted in Figure $\mathbf{4 4}$ for three different droplet inlet diameters. In the first part of the saturated region coalescence is not important and the bubbles grow undisturbed (i.e. bubbly flow). This means that the value of $n_{b}$ (the number of bubbles per unit flow volume), does not change appreciably with the axial location. When $n_{b}$ is constant, the interfacial area concentration increases with the bubble diameter and thus with the axial location. This can be proven by eliminating the void fraction $\alpha$ from Equations 12 and 13.

As the void fraction increases, coalescence becomes important, larger bubbles form and the transition from bubbly to intermittent flow begins. As the transition proceeds, the interfacial area drops to an approximate constant value given by Equation 16 corresponding to fully-developed intermittent flow.

Note that in bubbly flow (i.e. before the $\mathrm{a}_{\mathrm{i}}$ maximum), the interfacial area depends on the mode of injection. This is expected because, for a given value of the void fraction (which does not depend on the bubble diameter), the interfacial area concentration is inversely proportional to the bubble diameter (see Equation 13), which, in turn, is directly proportional to the droplet inlet diameter (see Equation 11). As a result, in bubbly flow the interfacial area concentration is a decreasing function of the droplet inlet diameter $\mathrm{D}_{\mathrm{b} 0}$. On the other hand, bubble interaction (i.e. coalescence) destroys the effect of the injection mode and when the transition to intermittent flow is complete, the value of $a_{i}$ is practically independent on the droplet inlet diameter.

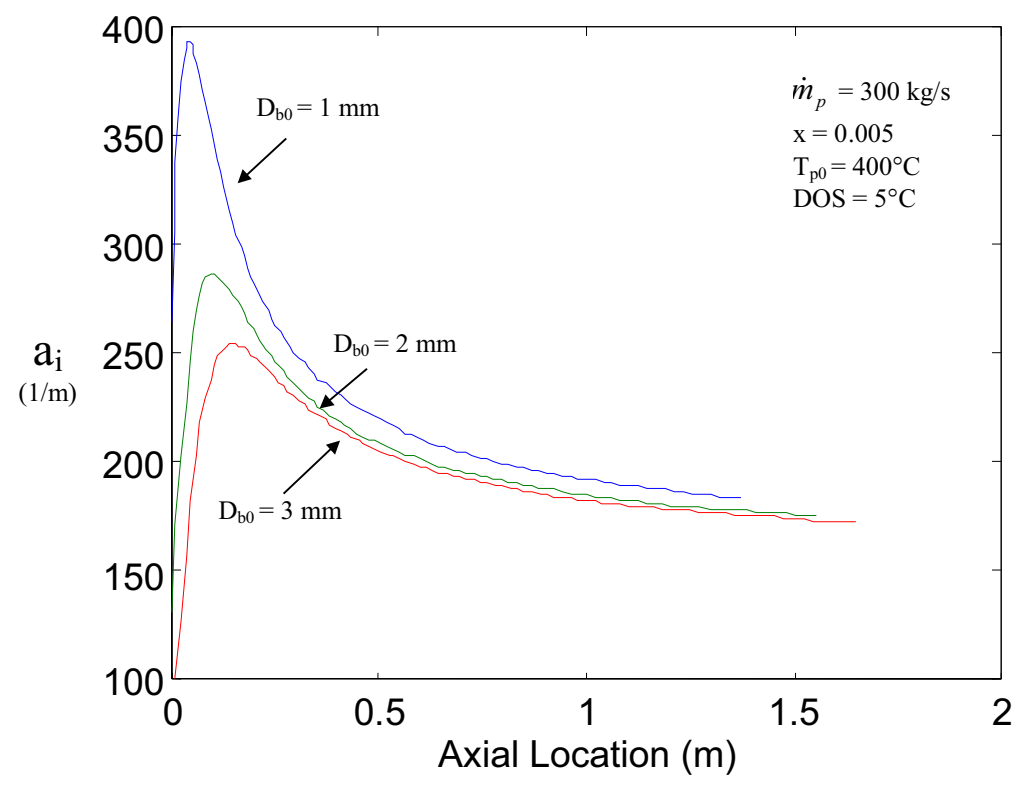

Figure 44. The interfacial area concentration in the saturated region.

In Figure 45 the value of the vhtc is plotted as a function of the axial location in the channel. The vhtc in the saturated region follows the same behavior of the interfacial area concentration (see Figure 44). It should be noted that a similar variation of the vhtc in the saturated region was observed in Sideman and Gat (1966). Sideman (1966) and Blair (1976) also report similar absolute values of the vhtc, although for different fluid pairs (water/pentane and water/freon, respectively vs. lead-bismuth/water in our case). This is not too surprising given that the 
dominant thermal resistance in the saturated region is film boiling whose heat transfer coefficient is relatively insensitive to the thermo-physical properties of the fluids. Finally, note that, as expected, a marked reduction of the vhtc occurs when the liquid water dries out in the bubbles and the superheated region begins.

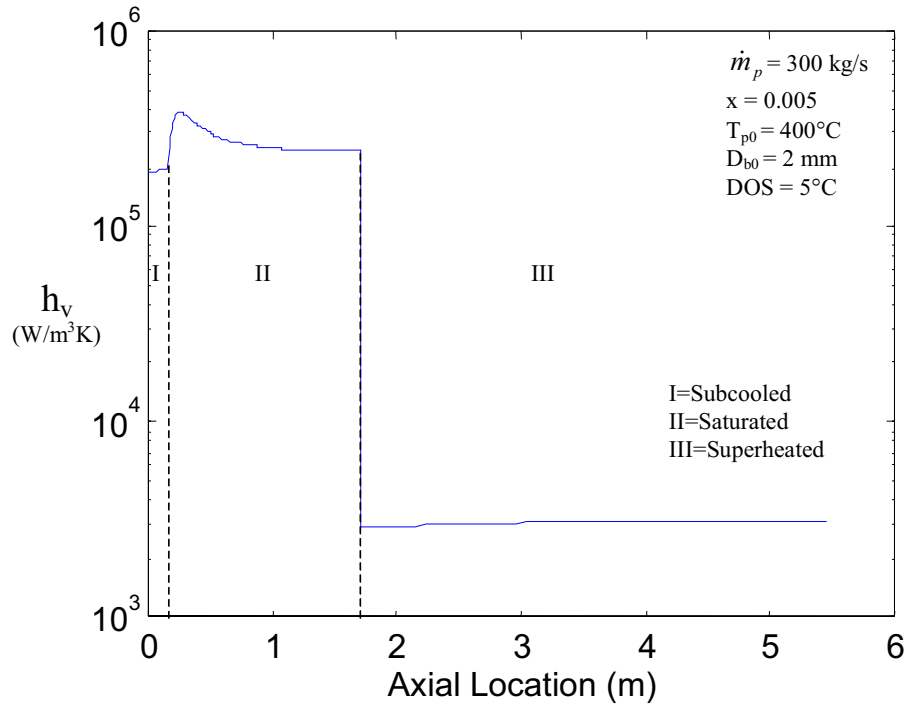

Figure 45. The volumetric heat transfer coefficient in the channel.

It was reported in Kinoshita et al. (2000) and Smith et al. (1982) that the length required to completely vaporize the water, $L_{\text {sat }}$, is a decreasing function of the temperature difference $T_{\text {psat }}{ }^{-}$ $\mathrm{T}_{\text {sat }}$ (where $\mathrm{T}_{\text {psat }}$ is the lead-bismuth temperature at the inlet of the saturation region). Therefore, the product $\mathrm{L}_{\mathrm{sat}} \cdot\left(\mathrm{T}_{\mathrm{psat}}-\mathrm{T}_{\mathrm{sat}}\right)$ is approximately independent of $\mathrm{T}_{\mathrm{psat}}-\mathrm{T}_{\mathrm{sat}}$. Figure 46 shows that our model is capable of reproduceing this trend, particularly at low mixture qualities (i.e. low water mass flow rates). However, a significant deviation is observed at larger values of $\mathrm{x}$. To explain this deviation let us refer to Equations 7 and 8. Assuming that the vhtc is approximately constant, this equations can be readily integrated to yield an expression for the saturation region length:

$$
L_{s a t}=-\frac{\dot{m}_{p} c_{p}}{h_{v} A} \log \left(1-\frac{\dot{m}_{w} h_{f g}}{\dot{m}_{p} c_{p}\left(T_{p s a t}-T_{\text {sat }}\right)}\right)
$$

For low values of the $\frac{\dot{m}_{w}}{\dot{m}_{p}}$ ratio (i.e low values of $\mathrm{x}$ ) a Taylor expansion of the logarithm provides a simplified expression for $\mathrm{L}_{\mathrm{sat}}$ :

$$
L_{\text {sat }}=-\frac{\dot{m}_{w} h_{f g}}{h_{v} A\left(T_{p s a t}-T_{\text {sat }}\right)}
$$

which indicates that, for a given vhtc, the product $\mathrm{L}_{\mathrm{sat}}\left(\mathrm{T}_{\mathrm{psat}}-\mathrm{T}_{\mathrm{sat}}\right)$ does not depend on $\mathrm{T}_{\mathrm{psat}}-\mathrm{T}_{\text {sat }}$. However, at high values of $\mathrm{x}$, Equation 18 should be used instead which explains the deviation of Figure 46. The logarithmic term in Equation 18 is due to the lead-bismuth temperature change in the saturated region. This change is large at high values of $\mathrm{x}$, but relatively small at low $\mathrm{x}$. Note that the experiments of Kinoshita et al. (2000) were conducted at low values of the mixture quality so that the lead-bismuth could be considered isothermal and Equation 19 is appropriate. 
To obtain an isothermal continuum phase (necessary to test their direct contact model), Smith et al (1982) conducted their experiments in the form of short transients in a stagnant pool.

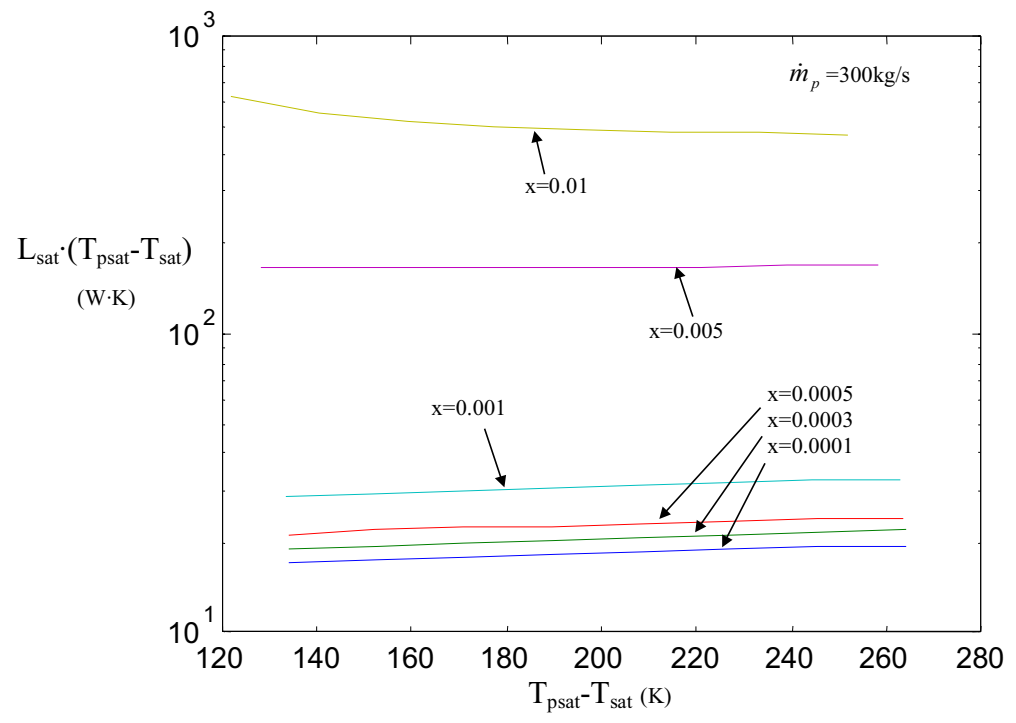

Figure 46. The $\mathbf{L}_{\text {sat }} /\left(\mathbf{T}_{\text {psat }}-\mathbf{T}_{\text {sat }}\right)$ relation.

The product $L_{\text {sat }}\left(T_{\text {psat }}-T_{\text {sat }}\right)$ slightly increases with $T_{\text {psat }}-T_{\text {sat }}$ at values of $x$ below 0.01 , indicating that the vhtc is a decreasing function of $\mathrm{T}_{\text {psat }} \mathrm{T}_{\text {sat }}$. This is a result of the dominant film boiling thermal resistance in the saturated region, whose heat transfer coefficient is inversely proportioned to the $1 / 4^{\text {th }}$ power of the temperature difference between the continuum and dispersed phase. Sideman and Gat (1966) also observed this trend.

Finally, the product $\mathrm{L}_{\text {sat }} \cdot\left(\mathrm{T}_{\text {psat }}-\mathrm{T}_{\text {sat }}\right)$ is substantially independent of $\mathrm{x}$ (i.e. independent of $\left.\dot{m}_{w}\right)$ at low values of $\mathrm{x}$. Therefore, Equation 19 indicates that the vhtc must be proportional to $\dot{m}_{w}$ in this region. Note that at low $\mathrm{x}$ the flow regime is likely to be bubbly, for which the bubble density $\mathrm{n}_{\mathrm{b}}$ (and thus the interfacial area concentration and the vhtc) is directly proportional to $\mathrm{x}$. This trend was observed by Kinoshita et al. (1997), Sideman and Gat (1966) and Smith et al. (1982). On the other hand, at higher values of $\mathrm{x}$, the flow regime is intermittent and the vhtc actually decreases with $\mathrm{x}$, because the interfacial area concentration is a decreasing function of the void fraction via $\mathrm{f}_{\mathrm{c}}$ (see Equation 16).

It is also interesting to evaluate the variation of the product $\mathrm{L}_{\mathrm{sat}} \cdot\left(\mathrm{T}_{\mathrm{psat}}-\mathrm{T}_{\text {sat }}\right)$ with the system pressure. Kinoshita et al. (2000) observed that $\mathrm{L}_{\mathrm{sat}} \cdot\left(\mathrm{T}_{\mathrm{psat}}-\mathrm{T}_{\mathrm{sat}}\right)$ increased with pressure in his experiments. However, the sign of this variation can be in general positive or negative being the result of the two effects listed below:

a) A higher pressure corresponds to a larger density of the dispersed phase. This results in a smaller dispersed phase volumetric flux and smaller void fraction, which has two opposite consequences depending on the flow regime:

- in bubbly flow (i.e. low values of $\mathrm{x}$ ), it lowers the interfacial area concentration and thus the vhtc, 
- in intermittent flow (i.e. higher values of $\mathrm{x}$ ), it lowers $\mathrm{f}_{\mathrm{c}}$ and thus increases the interfacial area concentration and the vhtc.

b) A higher pressure corresponds to a smaller heat of vaporization. Thus, for a given $x$, the energy required to vaporize the dispersed phase is smaller and so is the length of the saturated region (see Equation 19).

In Figure 47 the variation of the $\mathrm{L}_{\mathrm{sat}} \cdot\left(\mathrm{T}_{\mathrm{psat}}-\mathrm{T}_{\mathrm{sat}}\right)$ product with the system pressure is shown for three different values of $\mathrm{x}$ and for a small value of $\dot{m}_{p}$ (typical of Kinoshita's experiments). It can be seen that the trend observed by Kinoshita at low $\mathrm{x}$ and low pressure is correctly reproduced. However, at higher pressures, effect (b) becomes dominant and $\mathrm{L}_{\mathrm{sat}} \cdot\left(\mathrm{T}_{\mathrm{psat}}-\mathrm{T}_{\text {sat }}\right)$ decreases with pressure. The situation at low pressure strongly depends on the value of $\mathrm{x}$ (as explained in a)). At low $x$, the flow regime is bubbly and the pressure effect is to increase $\mathrm{L}_{\mathrm{sat}} \cdot\left(\mathrm{T}_{\mathrm{psat}}-\mathrm{T}_{\text {sat }}\right)$. At high $\mathrm{x}$, the flow is intermittent and $\mathrm{L}_{\mathrm{sat}} \cdot\left(\mathrm{T}_{\mathrm{psat}}-\mathrm{T}_{\mathrm{sat}}\right)$ decreases with pressure. At intermediate values of $\mathrm{x}$, as the pressure increases, a change of flow regime occurs (from intermittent to bubbly), that results in a local minimum of $\mathrm{L}_{\mathrm{sat}}\left(\mathrm{T}_{\mathrm{psat}}-\mathrm{T}_{\mathrm{sat}}\right)$.

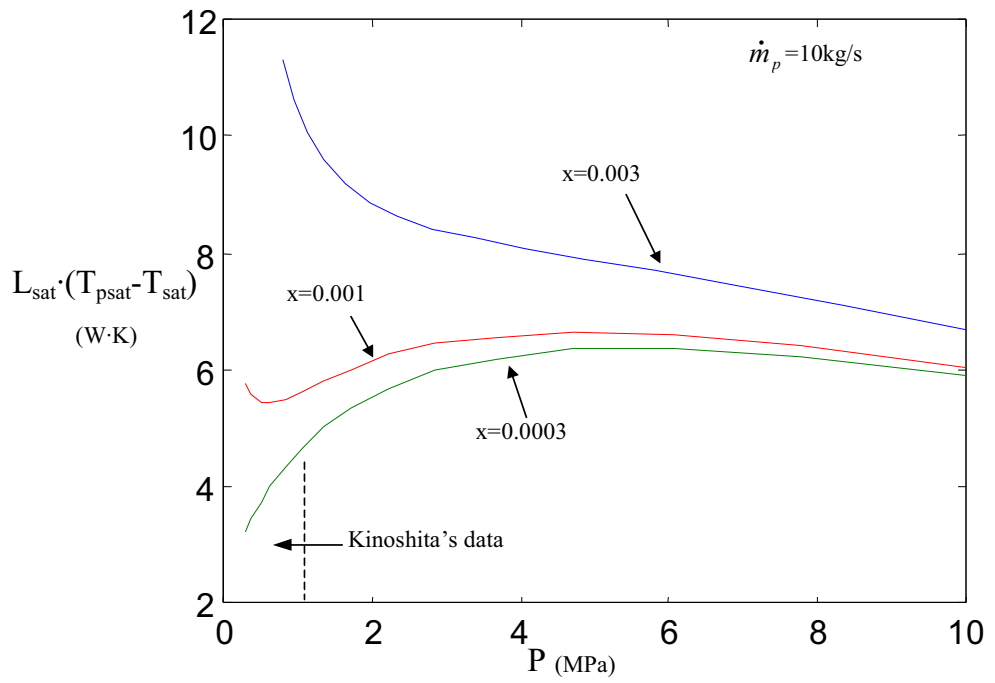

Figure 47. The effect of pressure on the $L_{\text {sat }} \cdot\left(T_{\text {psat }}-T_{\text {sat }}\right)$ product.

Figure 48 illustrates the effect of the degree of steam superheat on the total length of the channel, $\mathrm{L}_{\text {tot }}$, for given lead-bismuth mass flow rate and mixture quality, but for different lead-bismuth inlet temperatures. As expected, $\mathrm{L}_{\text {tot }}$ is a strong function of the specified degree of steam superheat reflecting the dominant importance of the superheated region in the channel. This suggests that it is not desirable to significantly superheat the steam, if the reactor pool height is to be maintained within reasonable limits. However, the channel length required to achieve a given degree of steam superheat can be considerably shortened if the lead-bismuth inlet temperature (and thus the mean lead-bismuth/water temperature difference) is increased. 


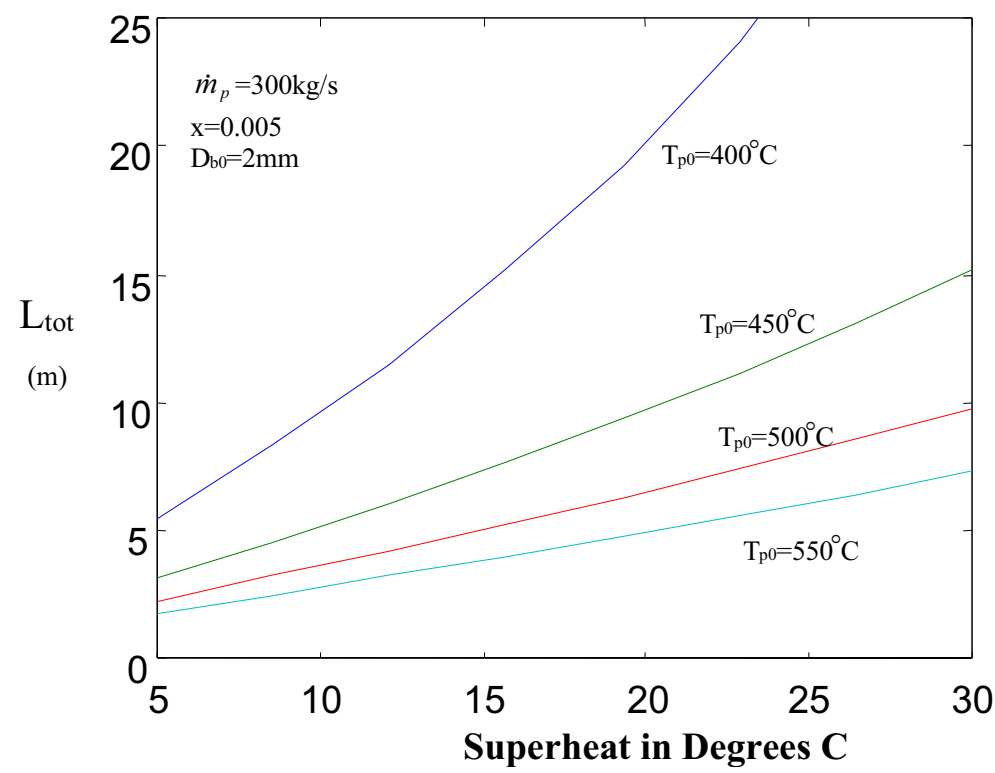

Figure 48. The effect of the steam superheat on the length of the channel.

\subsubsection{Aerosol Production}

\subsection{The Mechanisms of Lead-Bismuth Aerosols}

Two mechanisms of heavy metal release into steam are identified that take place in the upper region of the reactor pool and operate in parallel:

1) Lead-bismuth droplet entrainment in steam

2) Evaporation of lead-bismuth.

Because of the extremely low vapor pressure of the lead-bismuth coolant, mechanism (2) is not very important. It was estimated that only few grams of lead-bismuth are transported out of the reactor pool due to this mechanism over 40 years of operations. In the next section, it is demonstrated that the magnitude of heavy metal release associated with mechanism (1) is much more significant.

\subsection{Lead-Bismuth Entrainment and Steam Separation}

The simplest way to separate the two phases (i.e. steam and liquid lead-bismuth) at the top of the chimney is to rely on gravity for natural separation: the lighter volatile steam leaves the liquid free surface of the pool while the heavy lead-bismuth flows back into the down-comer. This configuration is extremely simple, the flow path is not complex and the pressure drops are typically less than only one kinetic head (Griffith 1997). In our case, gravity separation is clearly favored by the large density ratio of lead-bismuth to steam, which enables achievement of rather good separation efficiency. However, steam separation is not perfect because a certain amount of liquid entrainment always occurs and the use of a steam dryer (to further remove the liquid metal from the steam stream) is mandatory (see Figure 49). The entrainment mechanism is explained in terms of liquid droplet shear-off by steam jets running through the free surface (Kataoka and Ishii 1984). The height reached by these droplets depends on their size and initial velocity. The 
steam drag force acting on the droplets determines whether the droplet entrainment is stable or not. Large droplets can only reach a certain height ${ }^{17}$ and eventually fall back into the pool. On the other hand, smaller droplets are dragged away from the pool regardless of their initial velocity. Therefore, it is desirable to provide for a certain elevation above the pool free surface, so that the large droplets can precipitate back into the pool and a compact steam dryer can be employed to remove the smaller droplets only.

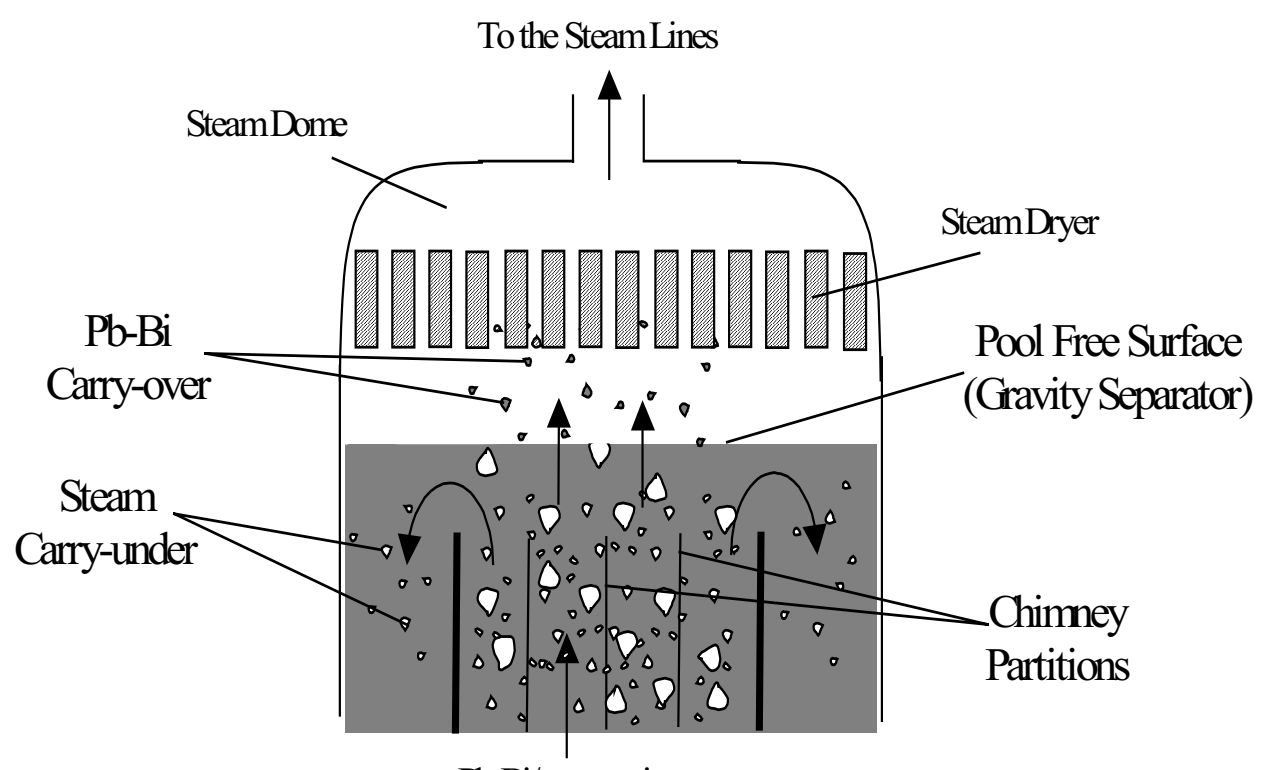

$\mathrm{Pb}-\mathrm{Bi} /$ steammixture

Figure 49. The reactor pool.

The relevant thermal-hydraulic characteristics of the pool free surface region are summarized in Table 25 for the 1800MWth reference conditions. The rate of liquid lead-bismuth entrainment at the free surface of the reactor chimney was evaluated by means of the model of Kataoka and Ishii (1984). Their semi-empirical mode $1^{18}$ was successfully benchmarked against numerous databases from steam-water and air-water systems at high and low pressure ${ }^{19}$ (i.e. from 0.1 to $18.7 \mathrm{MPa}$ ). For the conditions of interest, the model indicates that the maximum height achieved by the large droplets is about $0.4 \mathrm{~m}$, which is a relatively short distance from the pool free surface allowing for a compact design of the reactor pool upper region. The entrainment of the smaller droplets is illustrated in Figure 50, where 1-x is the liquid mass fraction in the flow above the pool ${ }^{20}$ and is plotted versus the steam superficial velocity, $\rho_{\mathrm{g}}$. Also, the maximum diameter of the entrained droplets is drawn as a function of $\mathrm{j}_{\mathrm{g}}$. At $\mathrm{j}_{\mathrm{g}} \sim 2 \mathrm{~m} / \mathrm{s}$ (corresponding to full power), the liquid entrainment is $\sim 0.4 \%$ only (or $4 \mathrm{~kg} / \mathrm{s}$ ). As expected, entrainment increases with the steam velocity.

\footnotetext{
${ }^{17}$ The height is directly proportional to the initial velocity of the droplets.

${ }^{18}$ Also recommended by Griffith (1997).

${ }^{19}$ At $0.3 \mathrm{MPa}$ an air-water system displays the same density ratio of steam/lead-bismuth in the leadbismuth/water direct contact reactor.

${ }^{20}$ The mass flow rate of lead-bismuth over the total mass flow rate (i.e. steam + lead-bismuth).
} 
Table 25. Conditions at the pool free surface.

\begin{tabular}{|l|l|l|}
\hline Parameter & Description & Value \\
\hline $\mathrm{T}$ & Steam temperature & $290^{\circ} \mathrm{C}$ \\
\hline $\mathrm{P}$ & Steam pressure & $7.45 \mathrm{MPa}$ \\
\hline $\mathrm{D}_{\mathrm{c}}$ & Chimney (or core barrel) diameter & $4 \mathrm{~m}$ \\
\hline $\mathrm{A}_{\mathrm{c}}$ & Chimney flow area $\left(=\frac{\pi}{4} D_{c}^{2}\right)$ & $12.6 \mathrm{~m}^{2}$ \\
\hline $\mathrm{D}_{\mathrm{H}}$ & Chimney hydraulic diameter ${ }^{21}$ & $0.26 \mathrm{~m}$ \\
\hline$\dot{M}_{g}$ & Steam mass flow rate (at full power) & $1,000 \mathrm{~kg} / \mathrm{s}$ \\
\hline $\mathrm{j}_{\mathrm{g}}$ & Steam superficial velocity (at full power) & $\sim 2 \mathrm{~m} / \mathrm{s}$ \\
\hline $\mathrm{V}_{\mathrm{g}}$ & $\begin{array}{l}\text { Steam velocity above the free surface } \\
\text { power) }\end{array}$ & $\sim 2 \mathrm{~m} / \mathrm{s}$ \\
\hline
\end{tabular}

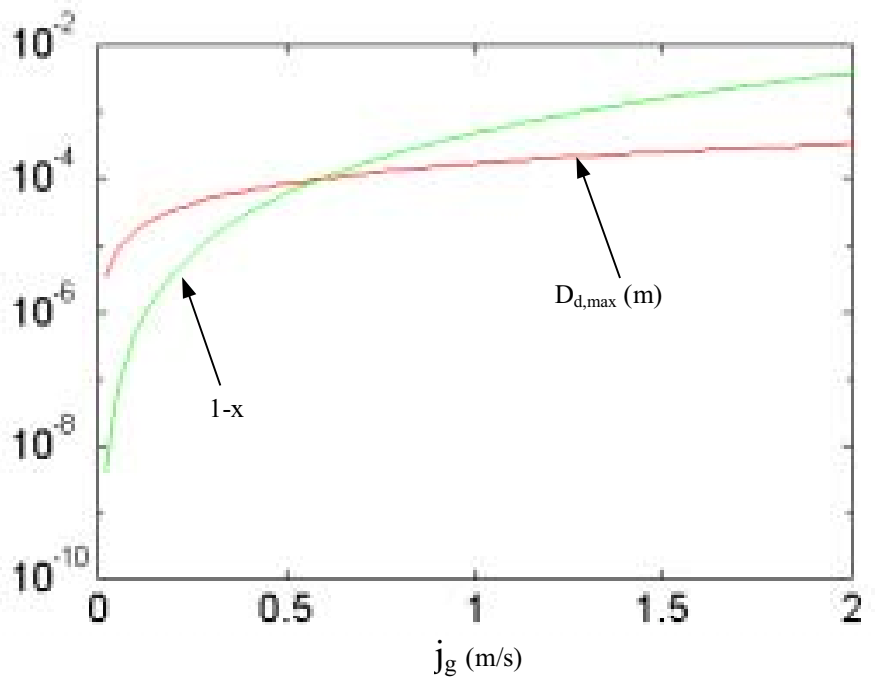

Figure 50. Lead-bismuth entrainment from the pool free surface.

To appreciate the performance of gravity separation in the lead-bismuth/water direct contact reactor, the liquid rate of entrainment from the lead-bismuth pool free surface was compared to that of liquid water from the free surface of a pool at BWR conditions. For consistence, the Katoaka-Ishii model was used for the BWR conditions. The maximum height reached by the large droplets is about $1 \mathrm{~m}$ and $1-\mathrm{x}$ is $13 \%$, which clearly indicates that gravity separation would not be very effective in water systems. Therefore, in BWRs the entire two-phase flow coming from the core is forced through a cyclone steam separator that removes the bulk of the liquid from the steam stream ${ }^{23}$. Subsequently the steam passes through a dryer and is then sent to the turbine. However, in our case the use of a cyclone steam separator is not necessary because gravity separation is very effective and the magnitude of entrainment from the pool surface is small ${ }^{24}$.

${ }^{21}$ The chimney is partitioned into square channels of side $0.26 \mathrm{~m}$.

${ }^{22}$ Note that steam absolute and superficial velocities are almost equal in the highly dispersed two-phase flow above the free surface.

${ }^{23}$ As a result the steam flow quality at the outlet of a cyclone steam separator is typically below $10 \%$.

${ }^{24}$ Note that the mass quality and the volumetric flow ratio in the lead-bismuth/water direct contact reactor are 1 and 2 orders of magnitude smaller than in the BWR, respectively. 
The size distribution of the droplets entrained at the free surface of the liquid pool was also estimated in order to design the steam dryer. Unfortunately, no droplet size distribution data for large pool situations in intermittent flow could be found in the literature. On the other hand, there is a considerable amount of data on droplet distribution in annular two-phase channels (Azzoppardi and Hewitt 1997, Kataoka et al. 1983, Kocamustafaogullari et al. 1994). The entrainment mechanism in annular flow is shear-off of roll-wave at the liquid film/steam core interface (Kataoka et al. 1983), which somewhat resembles that of pool entrainment in intermittent flow. On this basis, the annular flow channel distribution data were used for our intermittent flow pool system. Most available data fit an upper-limit log normal distribution, first proposed by Mugele and Evans (1951), whose features are its exclusive dependence on the maximum droplet diameter and its zero value above the maximum droplet diameter. The results are shown in Figure 51, where dv is the fraction of liquid volume carried by droplets of diameter $D_{d}$ between $D_{d}$ and $D_{d}+d D_{d}$. It can be seen that most liquid is in the form of droplets of diameter between 50 and $200 \mu \mathrm{m}$.

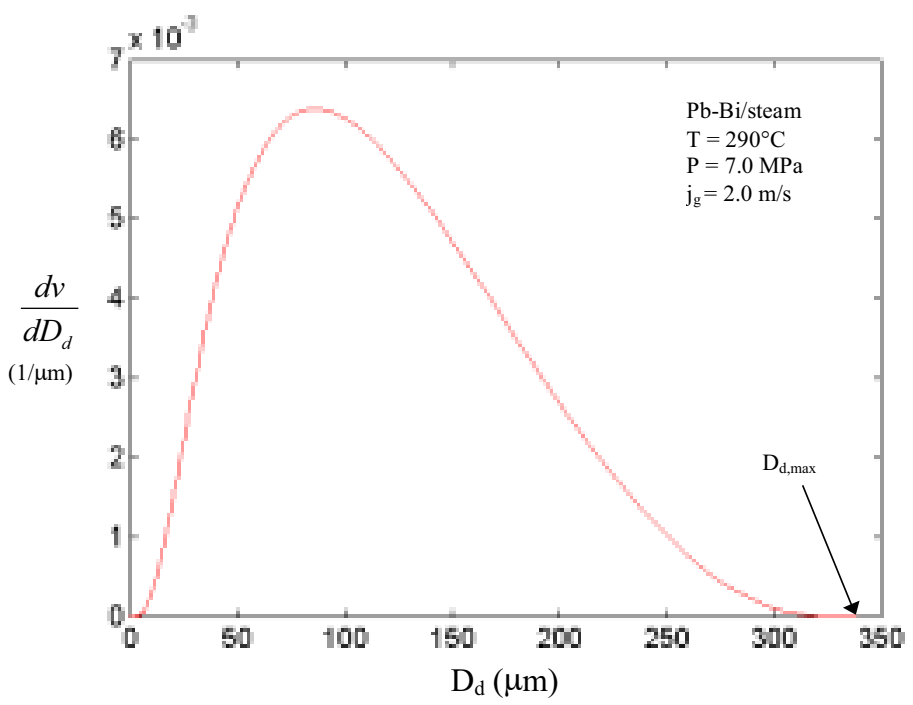

Figure 51. The droplet mass distribution at the steam dryer inlet.

The most commonly used types of steam dryers are the "chevron" separators. They belong to the family of the inertia separators because the heavier droplets impact the separator surface due to their inability to follow the steam flow path. The chevron separator is made of a bank of corrugated plates (or vanes) inducing a zigzag flow path, which causes the droplets to impact the plate surface and deposit (see Figure 52). A liquid film forms on the plate surface and then flows by gravity down to the drain pan at the bottom of the separator (see Figure 53). To prevent axial drag of the liquid film and facilitate wetness removal from the plate walls, the plates are equipped with drainage scoops. In chevron separators, higher droplet removal efficiency can be achieved by making the zigzag flow path more involved (e.g. reducing the chevron wavelength). This comes at the expense of the pressure drop. 


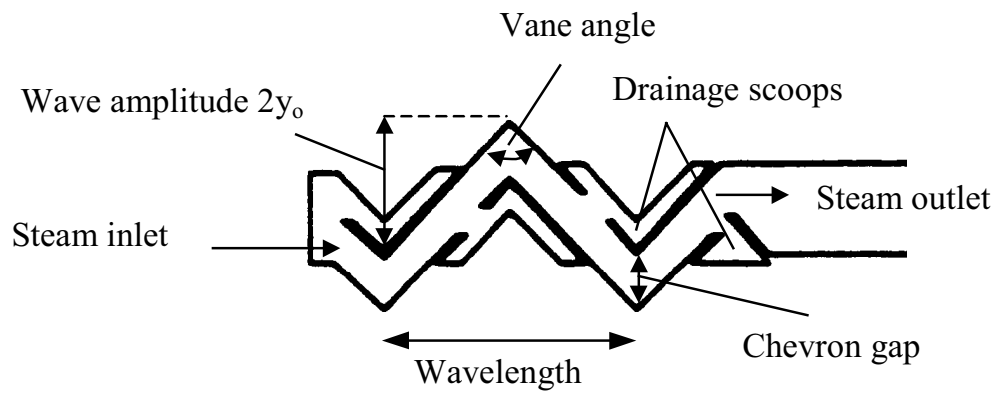

Figure 52. Cross-section of a chevron steam dryer vane (Nagase 1996).

In chevron separators particular care must be given to the selection of the steam velocity. A low steam velocity (and hence a low droplet velocity) generally means lower efficiency. However, if the steam velocity exceeds a critical value (the so-called breakthrough velocity), re-entrainment from the liquid film may occur (Griffith 1997, Moore and Sieverding 1976, Keshava et al. 1997), which results in failure of the separator function.

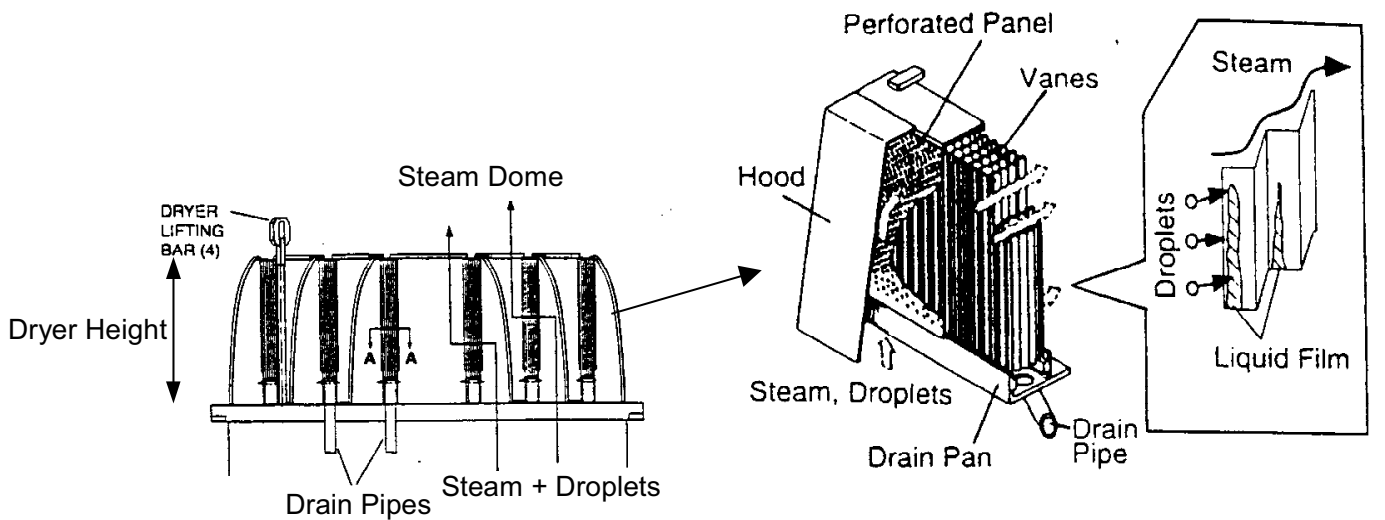

Figure 53. Chevron steam dryer (Nakao et al. 1999 and General Electric 1999).

Numerous different chevron separator designs have been proposed in the past for LWR applications. A good review of the their technical characteristics and performance can be found in Carson and Williams (1980) and Griffith (1997). Most modern chevrons are 4 wavelengths long with a $120^{\circ}$ vane angle, but they mainly differ in the shape, size and location of the drainage scoops. Because it was recently noted that most droplets are removed within the first two wavelengths of the dryer (Saito et al. 1995), advanced chevron separators have been proposed that feature only two wavelengths (to reduce the pressure drop) and a smaller vane angle (to increase the efficiency). Several values of the vane angle were explored and it was established that, under prototypical BWR conditions, the optimum pressure drop vs. efficiency performance is achieved with a $90^{\circ}$ angle- 2 wavelength chevron (Nagase et al. 1996, Nakao et al. 1999). As a result, it is now possible to design steam dryers with lower pressure drops and higher efficiency than in the past. The development and/or optimization of a new chevron separator for the steam dryer of the lead-bismuth/water direct-contact reactor is beyond the scope of this study. Therefore the advanced chevron design proposed in (Nakao et al. 1999) for BWR applications 
was adopted and its performance was assessed. This $90^{\circ}$ vane angle, 2 wavelength, chevron separator is shown in Figure 52 above. The chevron gap is $10 \mathrm{~mm}$, the wavelength is $50 \mathrm{~mm}$, and the wave amplitude $\left(2 \mathrm{y}_{\mathrm{o}}\right)$ is $25 \mathrm{~mm}$. The dryer height is $1.2 \mathrm{~m}$. The steam operating velocity, $\mathrm{U}$, is $2 \mathrm{~m} / \mathrm{s}$. At this velocity this chevron was found (Nagase et al. 1996) to display approximately the same pressure drop as a BWR traditional $120^{\circ}$ vane angle- 4 wavelength chevron. It was verified by means of two different correlations (Wilson et al. 1965, Panasenko and Koslov 1962) that the operating velocity of this separator is below the breakthrough velocity.

To evaluate the droplet removal efficiency of the lead-bismuth/water direct-contact reactor chevron separator, a simple theoretical model developed by Moore and Sieverding (1976) was utilized, which assumes no re-entrainment, Stokes flow of the droplet, and neglects the effect of the drainage scoops. Figure 54 illustrates the droplet removal efficiency of this chevron separator, $\eta$, as a function of the droplet diameter for the selected $2 \mathrm{~m} / \mathrm{s}$ steam operating velocity. The chevron efficiency for liquid water droplets is also plotted for reference. As expected, for a given droplet diameter, the removal efficiency of the lead-bismuth droplets is larger than that of the water droplets due to the larger liquid density. Moreover, practically every lead-bismuth droplet above $10 \mu \mathrm{m}$ is removed from the steam stream and practically every droplet below $0.1 \mu \mathrm{m}$ is not removed. If it is conservatively assumed that the removal efficiency for droplets of diameter below and above $10 \mu \mathrm{m}$ is zero and unity, respectively, the overall efficiency of the steam dryer ${ }^{25}$ was calculated to be $99.923 \%$, which results in a residual lead-bismuth mass flow rate of $0.003 \mathrm{~kg} / \mathrm{s}$ at the inlet of the steam lines.

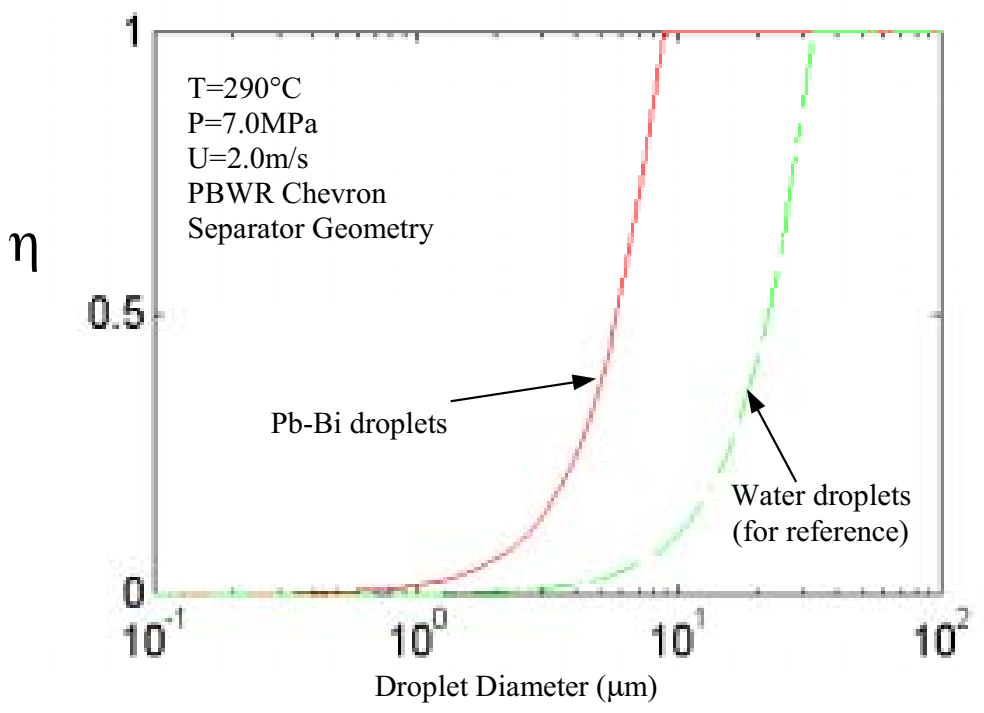

Figure 54. The chevron droplet removal efficiency. ${ }^{26}$

\footnotetext{
${ }^{25}$ defined as the ratio of the liquid removal rate to the liquid flow rate at the dryer inlet

${ }^{26}$ It is anticipated that there will be no liquid water droplets in the steam dryer. Therefore, the removal efficiency curve for the liquid water droplets is plotted in this figure for comparison purposes, only.
} 


\subsection{Transport of the Lead-Bismuth Droplets in the Steam Lines}

The dynamics of the lead-bismuth droplets passing through the steam lines was studied to evaluate the fraction of the lead-bismuth mass flow rate that actually reaches the turbine and the fraction that deposits on the walls of the steam lines. The relevant geometric and thermalhydraulic characteristics of the steam lines are reported in Table 26. The geometry is taken from the BWR and deemed applicable to the lead-bismuth/water direct contact reactor.

Table 26. The steam lines.

\begin{tabular}{|l|l|l|}
\hline Parameter & Description & Value \\
\hline $\mathrm{N}_{\mathrm{sl}}$ & \# of steam lines & 4 \\
\hline $\mathrm{D}$ & steam line diameter & $1 \mathrm{~m}$ \\
\hline $\mathrm{A}_{\mathrm{sl}}$ & steam line flow area & $0.785 \mathrm{~m}^{2}$ \\
\hline $\mathrm{L}$ & steam line length & $50 \mathrm{~m}$ \\
\hline$\dot{M}_{g}$ & total steam mass flow rate & $1,000 \mathrm{~kg} / \mathrm{s}$ \\
\hline$\dot{m}_{g}$ & steam mass flow rate per steam line & $250 \mathrm{~kg} / \mathrm{s}$ \\
\hline $\mathrm{V}_{\mathrm{g}}$ & steam average velocity & $8 \mathrm{~m} / \mathrm{s}$ \\
\hline $\mathbf{X}^{\dot{M}_{f}}$ & steam quality & $99.993 \%$ \\
\hline$\dot{m}_{f}$ & total lead-bismuth mass flow rate & $0.003 \mathrm{~kg} / \mathrm{s}$ \\
\hline $\mathrm{T}$ & lead-bismuth mass flow rate per line & $0.00075 \mathrm{~kg} / \mathrm{s}$ \\
\hline $\mathrm{P}$ & Steam Temperature & $290^{\circ} \mathrm{C}$ \\
\hline
\end{tabular}

Two different deposition mechanisms were considered whose relative importance depends on the droplet size.

a. Turbulent diffusion. The motion of small lead-bismuth droplets in the radial direction is dominated by turbulence. A droplet in the turbulent core is accelerated radially and its inertia (particularly if the droplet flows near the wall) may be large enough to penetrate the viscous layer and deposit on the wall. As a result the steam in the proximity of the wall is depleted of droplets. This creates a radial concentration gradient in the channel, which drives the diffusion of more droplets from the central region of the channel (i.e. the turbulent core) to the wall where a liquid film is formed.

b. Gravity deposition. Because the steam lines are horizontal, all the droplets acquire an average drift velocity (analogous to the drift velocity of the electrons of an ohmic conductor immersed in an electric field) that tends to deposit them on the bottom of the channel. At small diameters the effect of turbulence is dominant and the drift velocity is negligible. To a first approximation it can be assumed that the droplets are kept in suspension by the turbulent fluctuations and, therefore, do not precipitate ${ }^{27}$. On the other hand, droplets of large diameter do not feel the effect of turbulence and gravity can make them effectively precipitate.

The rate of droplet deposition by turbulent diffusion was calculated by means of the McCoy \& Hanratty (1977) correlation for annular two-phase flow in a round tube, which yields a rate of

\footnotetext{
${ }^{27}$ However, they can deposit by turbulent diffusion.
} 
droplet deposition of at most $5 \%$ of the total lead-bismuth mass flow rate over a $50 \mathrm{~m}$ long steam line. This clearly indicates that in our system, turbulent diffusion is not an effective mechanism of droplet deposition. It should be emphasized that re-entrainment of lead-bismuth from the liquid film on the steam line wall to the steam core was neglected in this analysis because the Reynolds number of the film was found to be smaller than the critical value given by the Govan et al. (1988) correlation for the onset of entrainment.

As for gravity deposition, the equation of motion of the lead-bismuth droplets was solved with the goal of estimating the droplet precipitation velocity in the steam lines. In Figure $\mathbf{5 5}$ this velocity is plotted against the droplet diameter $\mathrm{D}_{\mathrm{d}}$. Recalling that the steam line diameter (D) is about $1 \mathrm{~m}$ and that the droplet passage time in the steam line is $\mathrm{t}_{\mathrm{pass}}=\mathrm{L} / \mathrm{V}_{\mathrm{g}} \sim 6.3 \mathrm{~s}$, it can be readily concluded that only the droplets whose precipitation velocity is greater than $(\mathrm{D} / 2) / \mathrm{t}_{\text {pass }} \sim 0.08 \mathrm{~m} / \mathrm{s}$ will deposit by gravity on the bottom of the steam lines. Figure 55 indicates that all the droplets of diameter greater than $30 \mu \mathrm{m}$ fulfill this requirement. Because the maximum diameter of the droplets that escape the steam dryer is about $10 \mu \mathrm{m}$, it can be concluded that, in the leadbismuth/water direct-contact reactor steam lines, gravity precipitation is not an important deposition mechanism, either.

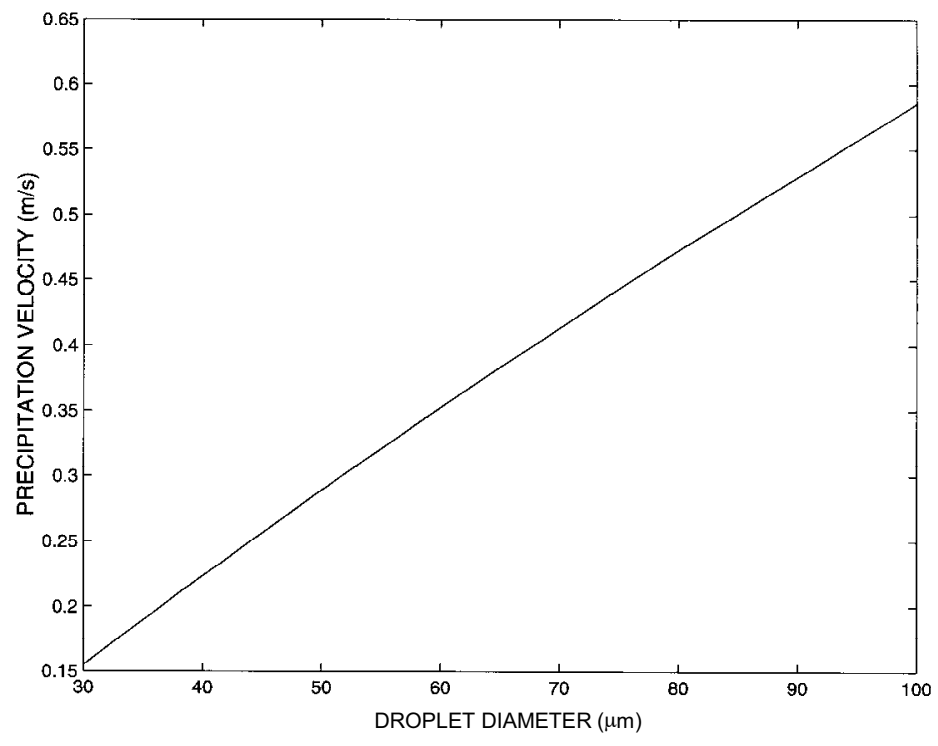

Figure 55. Vertical velocity of the droplets in the steam lines.

Note that in the previous analysis, the interaction of contiguous droplets was neglected. This assumption is justified in the discussion that follows. The liquid dragged out of the steam dryer is in the form of finely dispersed droplets. For a given lead-bismuth mass flow rate, the smaller the droplet size the larger the droplet concentration (number of droplets per unit volume). Coagulation phenomena (i.e. coalescence of droplets) may become important at high concentration. A droplet may collide with another droplet and form a bigger one. As the number of droplets decreases, so does the probability of collision until the average distance between two droplets is so large that the probability of collision becomes zero. If the time scale of these collision phenomena is small compared with the passage time of a droplet through the steam lines, coagulation dominates the size evolution of the small droplet population. The formation of bigger droplets by coagulation might change the rate of turbulent and gravity precipitation. 
Depending on the droplet size and degree of flow turbulence, the dominant coagulation mechanism can be either Brownian (thermal) collisions or turbulent eddy induced collisions. The application of a simple criterion proposed by Fuchs (1964) showed that Brownian coagulation is the dominant mechanism in the lead-bismuth/water direct-contact reactor steam lines. To assess the time evolution of a droplet population under the action of Brownian coagulation, Smoluchowski's theory (Fuchs 1964) was used, which assumes that:

1) all droplets are spherical and remain spherical after coalescence with another droplet, and

2) every collision is effective (i.e. it produces coalescence).

Then the evolution of the droplet size (due to Brownian coagulation) along the steam lines was studied assuming that all lead-bismuth droplets have the same diameter at the inlet of the steam lines.

Figure 56 illustrates the axial variation of the droplet size in the steam line for four different initial droplet diameters. It can be seen that, regardless of the initial diameter, the droplet size converges to a single curve within the first few meters of the steam lines. This behavior is expected because, as the diameter increases, the droplet concentration decreases and the collision probability becomes smaller and smaller. As a result, the average length traveled by the droplets between two consecutive interactions is increasingly large and the droplet previous history (which took place in the first few meters of the channel) becomes negligible. Figure 56 also indicates that after $10 \mathrm{~m}$ the droplet diameter must be at least $0.1 \mu \mathrm{m}$, which is much smaller than the minimum droplet diameter required for precipitation (see Figure 55). Therefore, coagulation induced distortion of the droplet size distribution can be neglected.

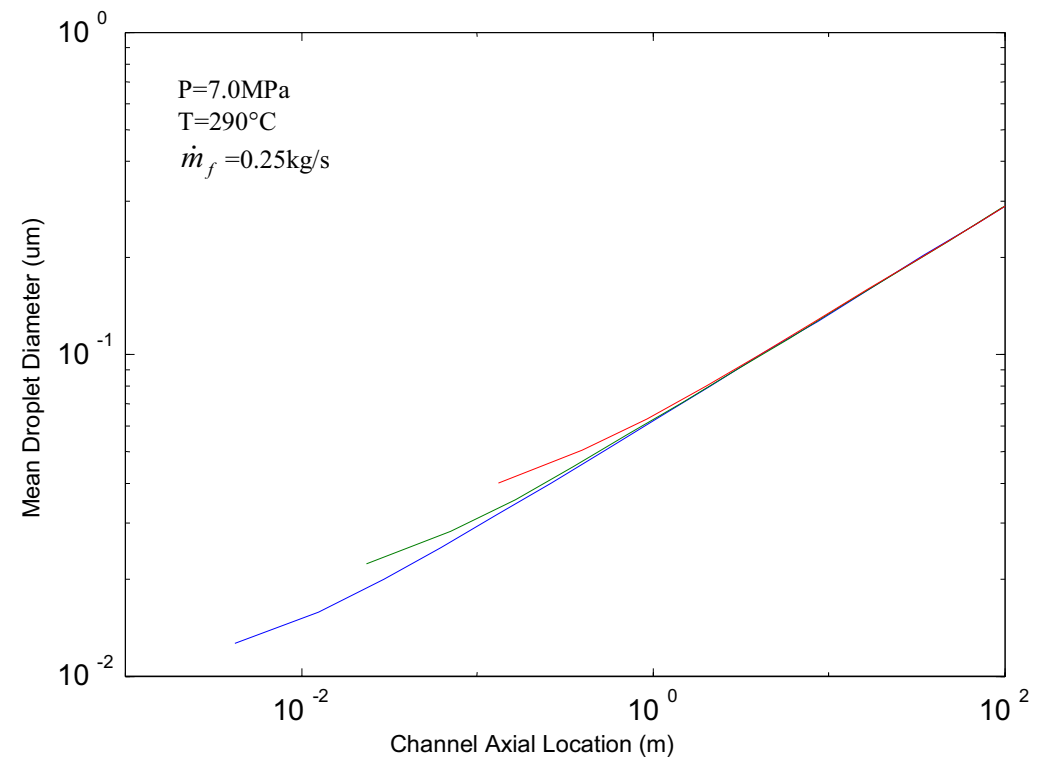

Figure 56. Coagulation phenomena in the steam lines.

\subsection{Lead-Bismuth Droplets in the Turbine}

The presence of heavy liquid metal droplets at the first stages of the turbine raises three basic concerns: 
1) Liquid metal embrittlement of the turbine blades and other stressed components

2) Erosion of the turbine surfaces exposed to the steam flow

3) Accumulation of lead-bismuth and consequential contamination of the turbine surfaces by radioactive polonium.

Liquid Metal Embrittlement. Liquid metal embrittlement is the brittle fracture, or loss of ductility, of a normally ductile metal (stressed in tension) upon contact with a liquid metal (Kamdar 1986), which can lead to catastrophic failure. Three characteristics of liquid metal embrittlement should be emphasized:

1) A mandatory prerequisite is that the liquid metal be in intimate contact with the solid surface. Even a thin oxide film (several angstroms thick) is enough to prevent liquid metal embrittlement.

2) Liquid metal embrittlement does not take place in ceramic materials, but in metallic solids, only.

3) Liquid metal embrittlement occurs in presence of tensile stresses, only.

The lead-bismuth droplets coming from the reactor enter the turbine and mostly impact the fixed or moving surfaces of the high-pressure section. The droplets that manage to escape the highpressure section are collected in the moisture separator/re-heater before they reach the lowpressure turbine. Therefore, in our reactor the liquid metal embrittlement analysis must focus primarily on the high-pressure turbine. Liquid metal contamination of the low-pressure turbine is effectively prevented by the presence of the moisture separator/re-heater and the high-pressure turbine itself. The most obvious way to eliminate liquid metal embrittlement would be to select an alternative structural material that is not prone to embrittlement upon contact with lead or bismuth. A list of materials immune to either lead or bismuth liquid metal embrittlement is reported in Table 27.

Table 27. Materials immune to lead or bismuth liquid metal embrittlement (Kamdar 1986).

\begin{tabular}{|c|c|c|}
\hline Material & $\begin{array}{c}\text { Immune to bismuth liquid } \\
\text { metal embrittlement }\end{array}$ & $\begin{array}{c}\text { Immune to lead liquid metal } \\
\text { embrittlement }\end{array}$ \\
\hline $\mathrm{Sn}$ & Yes & Yes \\
\hline $\mathrm{Bi}$ & Yes & Yes \\
\hline $\mathrm{Cd}$ & Yes & No \\
\hline $\mathrm{Zn}$ & Yes & Yes \\
\hline $\mathrm{Mg}$ & Yes & Yes \\
\hline $\mathrm{Ag}$ & Yes & No \\
\hline $\mathrm{Ni}$ & Yes & Yes \\
\hline $\mathrm{Fe}$ & Yes & Yes \\
\hline $\mathrm{Pd}$ & Yes & \\
\hline $\mathrm{Ti}$ & Yes & \\
\hline
\end{tabular}


Pure commercial titanium used in low-pressure turbine blades is not suitable to high temperature applications. However, titanium-aluminum alloys are successfully employed in a variety of applications in gas turbines and compressors at temperatures up to $540^{\circ} \mathrm{C}$ (Seagle 1990 , Bania 1988) due to their high strength-to-density ratio. Typical TiAl alloys are Ti-6242 and Ti-1100 whose composition is Ti-6Al-2Sn-4Zr-2Mo-0.1Si (\%wt) and Ti-6Al-2.75Sn-4Zr-0.4Mo-0.45Si$0.07 \mathrm{O}_{2}-0.02 \mathrm{Fe}(\% \mathrm{wt})$. Aluminum is susceptible to severe lead and bismuth liquid metal embrittlement (Kamdar 1986). However, the continuous phase of Ti-6242 is titanium ${ }^{28}$ and thus it is conceivable that liquid metal embrittlement would not occur in this alloy. Naturally, an experimental verification of this conclusion would be necessary, should this material be considered for the lead-bismuth/water direct-contact reactor turbine blades. Also, aluminum solubility in bismuth is relatively high (Weeks and Ramano 1969) and it must be ensured that leaching (i.e. selective attack of aluminum by bismuth) does not take place ${ }^{29}$.

The other materials in this list that are immune to both lead and bismuth embrittlement cannot practically be used in a turbine because they are either too expensive (e.g. silver, palladium) or mechanically inadequate at the temperatures of interest (e.g. tin, magnesium, cadmium, bismuth) or both. Moreover, the use of any of these materials in a steam turbine would require the development of a new technology and thus call for additional extensive investigations and considerable research costs.

A more viable option to reduce the concerns associated with liquid metal embrittlement is coating the surfaces of the high-pressure turbine critical components (which could then be made of stainless steel). The presence of a barrier to liquid metal/solid contact is known to completely prevent liquid metal embrittlement (see point 1.). To ensure the integrity of this barrier, the coating material should be ceramic (see point 2.). Blade coating of high temperature gas turbines is a mature and successful technology (Nakamura et al. 1990, Burgel 1986) aiming at the reduction of blade corrosion in the presence of chemically aggressive combustion gases typical of these turbines. However, it mostly makes use of metallic coating materials (e.g. CoCrAlY, NiCrAlY, AlPt) that could not be used in our case because of their potential susceptibility to liquid metal embrittlement. On the other hand, coating of high-pressure steam turbines is a less established technology, which does not make use of metallic coating materials. However, this technology has already been adopted in the United States by several utilities to mitigate the effects of solid particle erosion (Diaz-Tous et al. 1994). Several ceramic materials were explored for this purpose such as chromium carbide ${ }^{30}\left(\mathrm{Cr}_{2} \mathrm{C}_{3}\right)$, titanium nitride (TiN) and tungsten carbide (WC). To add compactness and strength to the coating, the ceramic base is normally blended with alloying metallic particles (up to $20 \% \mathrm{wt}$ of the final coating mixture) to form a material that is not perfectly ceramic, but ceramic-metallic (a so-called cermet). Nickel, chromium, indium, iron, aluminum and cobalt are the typical metals of choice for this purpose (Walsh et al. 1994). Because some of these metals are susceptible to liquid metal embrittlement (see Table 27), if the coating strategy is adopted, it will be necessary to test the liquid metal embrittlement susceptibility of the cermets. Also, the solubility of nickel in lead and bismuth is high (Weeks 1997, Alden 1957) and it must be ensured that this element is not prone to selective lead-bismuth attack when embedded in a cermet. However, it should be noted that, nickel (along with iron and

\footnotetext{
${ }^{28}$ Due to the relatively small weight fraction of Al, Sn, Zr, Mo, Si and Fe.

${ }^{29}$ On the other hand, Ti solubility in lead-bismuth is not high (Weeks and Ramano 1969) and dissolution of the Ti matrix is not expected.

${ }^{30}$ Chromium carbide based coatings were reported to increase the resistance of 422 stainless steel to solid particle erosion up to 20 times at $550^{\circ} \mathrm{C}$ (Walsh et al. 1994).
} 
chromium) is among the basic constituents of austenitic stainless steels, which are known to be corrosion compatible with lead-bismuth at temperatures up to $450^{\circ} \mathrm{C}^{31}$ (Tsirlin et al. 1999, Orlov et al. 1998) due to the formation of an oxide film acting as a kinetic barrier to nickel solution.

The cermet coating material is deposited by a technique known as "detonation gun deposition". The coating blend is initially in the form of a powder. The powder is laid on the substrate by the detonation of a gas which heats the powder particles above their melting point and accelerates them to about $1,000 \mathrm{~m} / \mathrm{s}$. The molten powder impacts the substrate and forms a compact, uniform layer with high adhesive and cohesive strength. Typical characteristics of a detonation gun deposited coating are reported in Table 28.

Table 28. A detonation gun cermet coating.

\begin{tabular}{|l|l|}
\hline Designation & $\mathrm{UCAR}^{\mathrm{TM}} \mathrm{LC}-1 \mathrm{H}$ \\
\hline Composition (\%wt) & $80 \mathrm{Cr}_{2} \mathrm{C}_{3}-16 \mathrm{Ni}-4 \mathrm{Cr}$ \\
\hline Density & $6,300 \mathrm{~kg} / \mathrm{m}^{3}$ \\
\hline Thickness & $\sim 150 \mu \mathrm{m}$ \\
\hline Tensile bond strength & $>70 \mathrm{MPa}$ \\
\hline Hardness (Vickers / Rockwell A) & $1000 / 88$ (Brady 1991) \\
\hline
\end{tabular}

Detonation-gun chromium-carbide/nickel-chrome coatings are not new to the nuclear industry. They were extensively investigated and tested as erosion resistant coatings for core components of sodium-cooled fast reactors (Johnson 1984). They were found to be superior to plasma and diffusion coatings in terms of irradiation damage, thermal cracking and corrosion when irradiated for 7 years (i.e. fast neutron fluence up to $6 \times 10^{22} \mathrm{n} / \mathrm{cm}^{2}$ ) in $625^{\circ} \mathrm{C}$ sodium at the Fast Flux Test Facility (FFTF). As a result, they are now successfully in use on the 316 stainless steel FFTF core components.

An alternative method to cope with the liquid metal embrittlement issue is to change the chemical state of the liquid lead-bismuth droplets from metallic to oxide before they reach the turbine. Ceramic materials like oxides or carbides do not induce liquid metal embrittlement (see point 2.). If a substantial amount of molecular oxygen is introduced in the steam flow, it is possible to entirely oxidize the metallic lead-bismuth hence eliminating its embrittlement potential. The oxygen can be injected in the steam flow at the beginning of the steam lines, which enables a thorough and complete oxidation before the lead-bismuth reaches the turbine.

The rate of oxidation of the droplets is dominated by the oxygen diffusion from the steam bulk to the droplet surface. The mass diffusion equation was solved for a spherical lead-bismuth droplet of given diameter to assess the time to complete oxidation $\tau_{\mathrm{ox}}$, under the assumption that chemical equilibrium exists at the droplet surface. The variation of $\tau_{\mathrm{ox}}$ with the droplet diameter and rate of oxygen injection $\left(\dot{m}_{O_{2}}\right)$ is illustrated in Figure 57 for the reference case of $\dot{m}_{\text {steam }}=1,000 \mathrm{~kg} / \mathrm{s}$. The droplet residence time in the steam lines is about $6 \mathrm{~s}$ and is indicated by the horizontal shaded line. It can be seen that the finer droplets are readily oxidized within the steam lines even at low

\footnotetext{
${ }^{31}$ The operating temperature of the high-pressure turbine blades in the lead-bismuth/water direct-contact
} reactor is below $300^{\circ} \mathrm{C}$. 
rates of oxygen injections. However, at $\dot{m}_{O 2}=1 \mathrm{~kg} / \mathrm{s}$, even the coarser droplets $\left(\mathrm{D}_{\mathrm{d}} \sim 10 \mu \mathrm{m}\right)$ rapidly oxidize in about $0.2 \mathrm{~s}$.

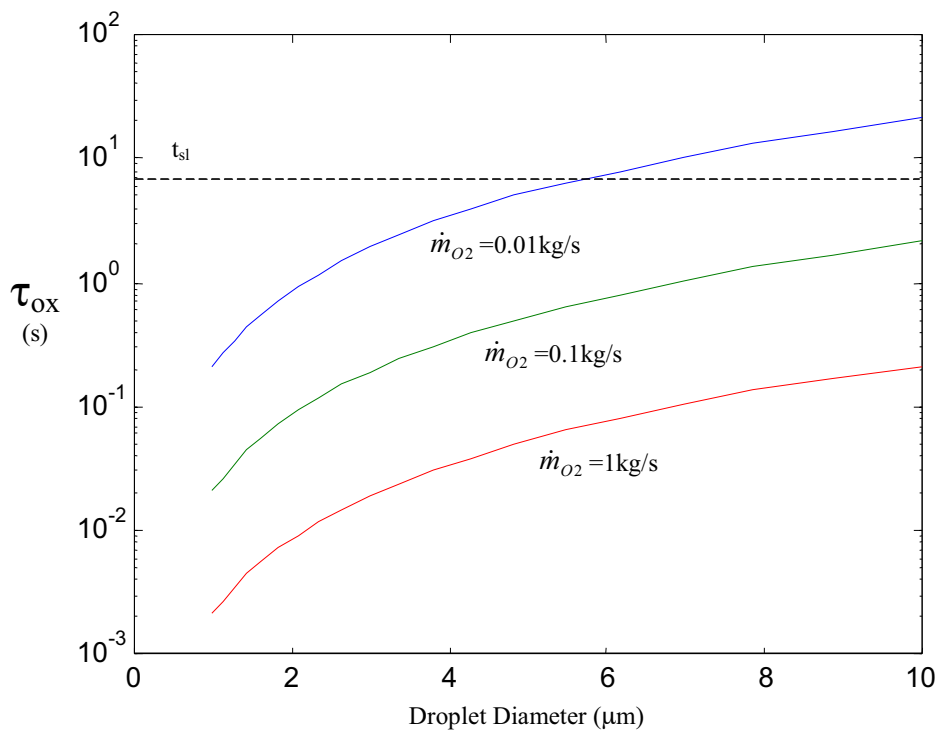

Figure 57. Oxidation time of the lead-bismuth droplets in the steam lines.

However, note that the proposed 1000ppm oxygen level is rather high compared with that of current BWR steam lines and turbines whose operating oxygen concentration ranges up to about 20ppm (ABB 1988). The evaluation of the consequences of this high oxygen level on the corrosion rate of the turbine materials is work in progress. Also an assessment of the use an electrostatic precipitator in the steam lines to remove the liquid metal droplets or, if combined with the oxidizer, the lead and bismuth oxides is in progress.

Note that downstream of the turbine, the lead and bismuth oxides can deposit on the condenser tubes, hence reducing the condenser heat transfer efficiency. Or they can form a slag in suspension that might clog the condenser outlets and (if transported throughout the whole secondary system) the pumps, the feed-water heaters and eventually even the water injector in the reactor pool, which can impair the coolability of the core. Evidently great care must be given to effectively filter the oxides out of the system as early in the secondary loop as possible. This can be done in the moisture separator/re-heater between the high- and low-pressure turbines. It is anticipated that the oxide particles will either stick to the liquid water droplets (generated by homogeneous condensation in the steam bulk upon expansion in the turbine) or will impact the turbine surfaces and be washed away by the liquid water rivulets present on those surfaces. Either way, it is expected that at the inlet of the moisture separator/re-heater the oxide particles will be entrained in the liquid water. The purpose of the moisture separator/re-heater is to remove liquid water from the steam stream and send it to the feed-water re-heaters. The water mass flow rate at the outlet of a typical LWR high-pressure turbine is a relatively small fraction of the total steam flow, approximately 13\% (Tsubouchi et al. 1990). Therefore, it should be feasible to 
install a full flow filter on the water line between the moisture separator/re-heater and the feedwater re-heaters, in order to completely remove the oxide slag from the system ${ }^{32}$.

\section{Erosion}

It was assessed whether the presence of lead-bismuth droplets in the lead-bismuth/water directcontact reactor high-pressure turbine introduces a new serious concern or can be handled within the framework of traditional erosion technology. For this purpose the lead-bismuth droplet erosion rate of the high-pressure turbine blades was compared to that induced by water droplets in a 3600rpm low-pressure turbine. It should be noted that in a traditional steam turbine the lowpressure moving blades is where most erosion takes place due to the large local speed and wetness. The relevant characteristics of the lead-bismuth/water direct-contact reactor highpressure turbines are reported in Table 29. Two different predictive tools were utilized to make the comparison: the Pouchot (1971) model and the Hitachi correlation (Tsubouchi 1990).

Table 29. Turbine parameters.

\begin{tabular}{|c|l|l|c|c|}
\hline Parameter & Description & \multicolumn{1}{|c|}{ Units } & \multicolumn{2}{|c|}{ Value } \\
\cline { 4 - 5 } & & & $\begin{array}{c}\text { Lead-bismuth/water } \\
\text { direct contact } \\
\text { reactor HP turbine } \\
\text { (1) }\end{array}$ & $\begin{array}{c}\text { Traditional low- } \\
\text { pressure } \\
\text { turbine } \\
\text { (2) }\end{array}$ \\
\hline $\mathrm{P}$ & Pressure Range & $\mathrm{Kpa}$ & $1000-7000$ & $7-1000$ \\
\hline $\mathrm{V}$ & Blade Velocity & $\mathrm{m} / \mathrm{s}$ & 170 & 680 \\
\hline$\omega$ & Angular Velocity & $\mathrm{rpm}$ & 1800 & 3600 \\
\hline $\mathrm{S}$ & Blade Hardness & Vickers Scale & 1000 & 430 \\
\hline$\rho_{\mathrm{g}}$ & Steam Density & $\mathrm{kg} / \mathrm{m}^{3}$ & 40 & 0.05 \\
\hline$\sigma$ & Liquid Surface Tension & $\mathrm{N} / \mathrm{m}$ & 0.4 & 0.07 \\
\hline $\mathrm{C}$ & Liquid Speed of Sound & $\mathrm{m} / \mathrm{s}$ & $1000(\mathrm{estimated})$ & 1500 \\
\hline$M_{\ell}$ & Liquid Mass Flow Rate & $\mathrm{kg} / \mathrm{s}$ & $<1$ & 50 \\
\hline $\mathrm{L}_{\mathrm{b}}$ & Blade Length & $\mathrm{mm}$ & 50 & 900 \\
\hline $\mathrm{A}$ & Impact Surface Area & $\mathrm{m}$ & 0.14 & 7.63 \\
\hline
\end{tabular}

The Pouchot model assumes that the liquid droplets impinge normally on the surface of the eroded material ${ }^{33}$ with velocity equal to that of the moving blades ${ }^{34}$. On the basis of the experimental evidence in (Pearson 1964), Pouchot also assumes that there exists a threshold velocity below which no erosion occurs.

\footnotetext{
${ }^{32}$ At nominal lead-bismuth/water direct contact reactor conditions the filter capacity should be $0.13 \times 1000=130 \mathrm{~kg} / \mathrm{s}$.

${ }^{33}$ It was reported in (Quets 1994, Walsh et al. 1994, Pearson 1964) that erosion increases with the impact angle (measured from the eroded surface). Therefore, Pouchot's assumption is conservative.

34 This is equivalent to assuming zero droplet absolute velocity.
} 
The Hitachi correlation considers water systems only, which makes its application to heavy liquid metal droplet erosion somewhat arbitrary. The qualitative trend with impact velocity, material hardness and impinging droplet mass flow rate is substantially similar to that of Pouchot model. However, the Hitachi investigation has revealed a strong dependence of erosion on the droplet diameter, which is missing in the Pouchot model.

With the values of the parameters of Table 29, the Pouchot model and the Hitachi correlation predict that (lead-bismuth droplet induced) erosion of high-pressure turbine blades is about three to five orders of magnitude smaller than (water droplet induced) erosion of traditional 3600rpm low-pressure blades. Therefore, it can be concluded that the presence of lead-bismuth droplets in the lead-bismuth/water direct-contact reactor high-pressure turbine does not seem to present a serious concern in terms of erosion.

\subsection{Lead-Bismuth Accumulation in the Turbine}

Accumulation of lead-bismuth in the turbine is to be prevented for several reasons:

1) it increases the chances of liquid metal embrittlement of the turbine components,

2) it represents a significant source of contamination due to its high concentration of radioactive polonium,

3) it can clog the water extraction lines,

4) it can favor re-entrainment of large lead-bismuth droplets into steam and consequently increase the magnitude of erosion and radionuclide carry-over to the condenser.

It is clear that ways to efficiently remove the heavy liquid metal should be identified if reliable operation of the turbine is to be achieved.

Because the steam produced by LWRs is generally saturated (or slightly superheated in Babcock \& Wilcox PWRs), significant water condensation occurs in the high-pressure section of the turbine. To prevent massive erosion of the blades and internals, high-pressure turbines are equipped with several devices (from hollow blades with suction slits to peripheral drainage slots) that remove the liquid water from the steam flow. However, these devices are not sufficient to remove all the liquid and thus the whole steam flow is extracted and forced through an external moisture separator/re-heater where it is dried and superheated ${ }^{35}$ before entering the low-pressure turbine (see Figure 58). Typical high-pressure turbine extraction temperatures can range between 176 and $192^{\circ} \mathrm{C}$ (Moore and Sieverding 1976, Yarden et al. 1997) (corresponding to a pressure between 1.0 and $1.2 \mathrm{MPa}$ ) depending on the reactor model and power. Because the melting point of lead-bismuth is $125^{\circ} \mathrm{C}$, it can be safely assumed that throughout the whole highpressure turbine the lead-bismuth remains liquid, which greatly simplifies its removal ${ }^{36}$.

\footnotetext{
${ }^{35}$ At the expense of high temperature steam extracted from the reactor steam line

${ }^{36}$ For example, the possibility of clogging of the water drainage channels is considerably reduced.
} 


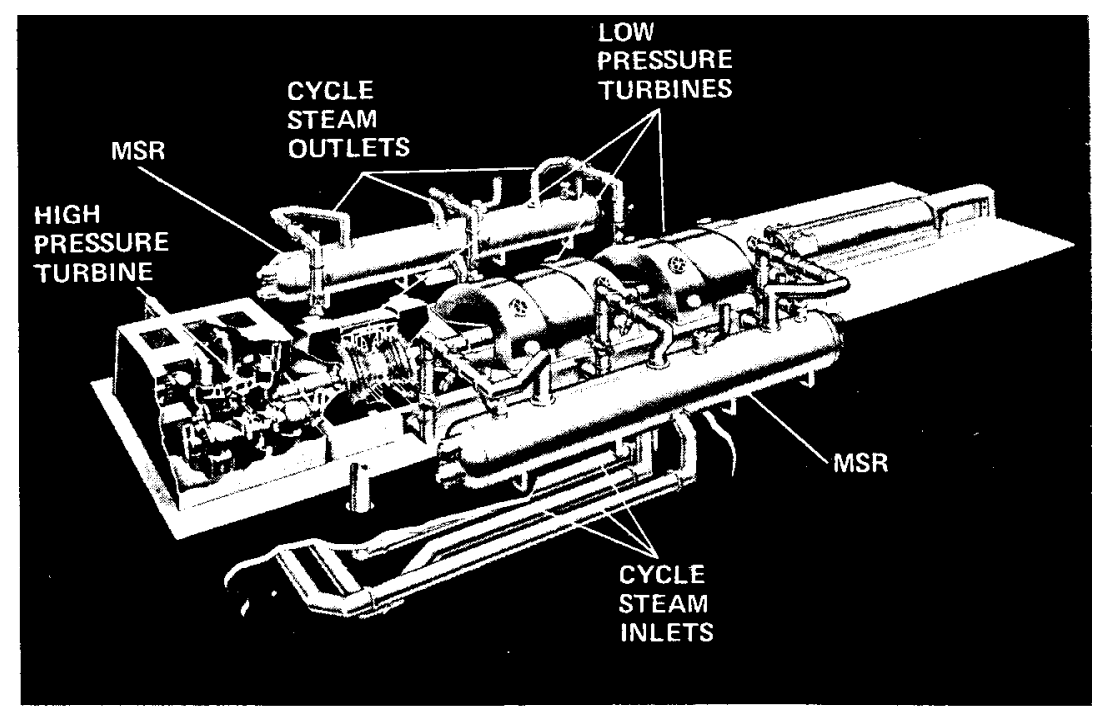

Figure 58. An LWR turbine with moisture separator/re-heater (Moore and Sieverding 1976).

It is anticipated that most lead-bismuth entering the high-pressure turbine in the form of fine droplets will impact the turbine blade and internal surfaces and will then be removed (along with liquid water) through the drainage slots located on the turbine casing and on the hollow fixed blades. The drained lead-bismuth will have to be filtered out of the water and returned to the reactor. However, some lead-bismuth is likely to reach the high-pressure outlet and be conveyed to the moisture separator/re-heater. Moisture separator/re-heaters are large pressure vessels where two distinct components are accommodated in series: the moisture separator and the steam re-heater. The moisture separator is typically equipped with steam separators of the chevron or wire-mesh type ${ }^{37}$ (Hayes et al. 1991, Cerezo and Yarden 1998) featuring a reported efficiency of up to $96 \%$ for water liquid droplets down to $13 \mu \mathrm{m}$ (Keshava et al. 1997). During operation of the first moisture separator/re-heaters it was observed that the major portion of the moisture leaving the high-pressure turbine is not entrained in the steam flow but instead flows along the walls of the connection line between the high-pressure turbine and the moisture separator/re-heaters ${ }^{38}$. This has prompted a redesign of the moisture separator/re-heaters, which now employ a preseparator stage removing the liquid film on the wall hence raising the overall moisture separator/re-heater separating efficiency to a remarkable 99.7\% (Von Boeckh et al. 1984). Due to the larger density of lead-bismuth with respect to water, it is reasonable to assume that these moisture separator/re-heaters are suitable to efficiently remove the lead-bismuth droplets and drain them from the system, as well. Again special care should be given to the drained leadbismuth/water mixture, so that the lead-bismuth is filtered out and returned to the reactor.

In conclusion, liquid extraction, drainage and separation systems in the high-pressure turbine and moisture separator/re-heaters are expected to drastically minimize the magnitude of lead-bismuth carry-over to the low-pressure turbine and condenser.

\footnotetext{
${ }^{37}$ Both are so-called inertia steam separators because they rely on the relatively large inertia of the liquid droplets as the separating mechanism.

${ }^{38}$ Probably due to liquid centrifuging at the last stage of the turbine.
} 


\subsubsection{Indirect Steam Power Conversion Cycle - Steady State Power Determination}

\subsubsection{Primary Coolant Natural Circulation}

The indirect cycle that has been studied uses a once-through, counter-flow steam generator coupled to a primary coolant system in which natural circulation drives the lead-bismuth. The core, vessel and steam generator parameters that comprise the base case are presented in Table 30. The core parameters are those of the actinide burner reactor described in Section 4.1.1. The vessel parameters are based on a static structural study presented by Buongiorno et al. (1999a). The secondary system parameters are based on analyses reported by Kim et al. (2000) and confirmed for key parameters by tradeoff studies summarized in the remainder of this section. These studies have been made in part with a simple Matlab code developed at MIT for steady state analysis and in part with ATHENA, a modification of RELAP5 developed at INEEL for steady state and transient analysis (Davis and Shieh 2000). The Matlab code has been benchmarked against ATHENA.

Table 30. System design parameters.

\begin{tabular}{|c|c|}
\hline Parameter & Value/Type \\
\hline \multicolumn{2}{|l|}{ Core: } \\
\hline Fuel Composition (wt \%) & $26 \% \mathrm{Pu}+\mathrm{MA}$ and $74 \% \mathrm{Zr}$ \\
\hline Fuel pin outside diameter (mm) & 10.3 \\
\hline Gap thickness (at BOL, mm) & 0.2 \\
\hline Cladding thickness (mm): & 0.63 \\
\hline Cladding material & Stainless Steel EP-823 $^{1}$ \\
\hline Bond material (wt $\%)$ & 33lead-33Sn-33bismuth ${ }^{2}$ \\
\hline pitch to diameter ratio in core & 1.2 \\
\hline Number of fuel assemblies & 157 \\
\hline Number of pins per assembly & 240 \\
\hline Active core length $(\mathrm{m})$ & 1.3 \\
\hline Gas plenum length $(\mathrm{m})$ & 1 \\
\hline Core barrel inner diameter $(\mathrm{m})$ & 4 \\
\hline \multicolumn{2}{|l|}{ Vessel: } \\
\hline Chimney height $(\mathrm{m})$ & 10 \\
\hline Vessel inner diameter $(\mathrm{m})$ & 6 \\
\hline \multicolumn{2}{|l|}{ Steam generator: } \\
\hline Height $(\mathrm{m})$ & 4 \\
\hline Coolant arrangement & Lead-bismuth in tube/Water in shell \\
\hline Tube lattice & Triangular \\
\hline Tube inside, outside diameter (mm) & 10,12 \\
\hline pitch to diameter ratio & 1.4 \\
\hline Pressure (bar) & 70 \\
\hline Water inlet temperature $\left({ }^{\circ} \mathrm{C}\right)$ & 200 \\
\hline Steam superheat $\left({ }^{\circ} \mathrm{C}\right)$ & 30 \\
\hline Recirculation & No \\
\hline
\end{tabular}

1. Due to unavailability of thermal physical properties, those of stainless steel 304 are used in this analysis.

2. Due to unavailability of thermal physical properties, those of lead-bismuth are used in this analysis.

In all tradeoff studies, maintaining the cladding temperature below $650^{\circ} \mathrm{C}$ has been the design goal. Tradeoff studies for the following parameters have been performed: 
- Lead-bismuth in the shell side of the steam generator vs. lead-bismuth in the tube side

- Triangular vs. square tube lattice

- Amount of steam superheat

- Pressure in the secondary system

- Re-circulation vs. no re-circulation in a system that produces saturated steam

- Steam generator coolant inlet temperature

- Core chimney height.

The results of the tradeoff studies are as follows.

1. Lower cladding temperatures result when the lead-bismuth flows on the shell side of the steam generator rather than through the tubes.

2. The steam generator triangular lattice yields lower cladding temperatures.

3. A steam generator that produces saturated steam yields lower cladding temperatures than one that produces superheated steam. Furthermore, the maximum allowable electric power is relatively insensitive to the amount of superheat.

4. The maximum allowable electric power is attained for a pressure of 70 bar in the secondary system.

5. A steam generator without re-circulation yields lower cladding temperatures than one with recirculation.

6. The cladding temperature increases as the secondary coolant inlet temperature increases.

7. The allowable core power increases with chimney height.

Based on an evaluation of the tradeoff studies and additional considerations, the following parameters are selected for the reference design:

1. Lead-bismuth is placed in the tube side of the steam generator. Slightly lower primary coolant temperatures (about $15^{\circ} \mathrm{C}$ ) are obtained when the lead-bismuth flows on the shell side of the steam generator. There is also an advantage relative to structural considerations in placing the higher-pressure coolant (water) inside the tubes. However, placing the leadbismuth inside the tubes has several advantages as discussed below.

- There is a safety benefit from a larger inventory of secondary coolant when the water is placed on the shell side of the steam generator

- There is an economic benefit from commonality with the existing steam generator design in current Babcock \& Wilcox power plants

- There is a benefit from reducing potential problems with materials (Buongiorno et al., 1999a)

- The design of the steam generator upper and lower heads is simplified

Based on the above reasons, the design with the lead-bismuth inside the tubes was selected.

2. Triangular tube lattice in steam generator. The triangular lattice was selected because it results in lower cladding temperatures.

3. No re-circulation in the steam generator. The tradeoff studies showed that lower cladding temperatures were obtained without re-circulation. 
4. Superheat in the steam generator. Based on the fact that the net electric output and capital cost are insensitive to whether the steam generator produces superheated or saturated steam, we conclude that the steam generator should produce superheated steam for the following reasons:

- Erosion of the turbine blades is greatly reduced if most of the steam expansion takes place in the superheated region.

- The design is simplified because separators and/or dryers are not required if superheated steam is produced.

- Operating a steam generator that produces saturated steam without re-circulation and without mechanical steam separation might result in entrainment of liquid into the steam lines during transients. If, on the other hand, re-circulation is adopted, the size of the steam generator increases because a down-comer and steam separator and/or dryer are needed, which makes it more difficult to fit the steam generator into the gap between the core barrel and the reactor vessel.

- A steam generator that produces superheated steam yields a slightly smaller thermal power because the thermal efficiency is higher, which is beneficial when it comes to removing decay heat during transients. However the water inventory is less, so the transient response is somewhat more challenging.

As for the degree of superheat, $30^{\circ} \mathrm{C}$ was chosen based on the Babcock \& Wilcox experience.

5. Steam generator pressure. A secondary pressure of 70 bar was selected based on the Babcock \& Wilcox experience and because the tradeoff studies showed that the maximum allowable electric power decreases as the pressure increases.

6. Steam generator coolant inlet temperature. A steam generator inlet temperature of $200^{\circ} \mathrm{C}$ was selected. This value yields reasonable cladding temperatures and is well above the freezing point of lead-bismuth.

7. Chimney height. A chimney height of $10 \mathrm{~m}$ was selected.

An evaluation of the selected design was performed to determine the limiting core power during normal operation. The evaluation showed that the limiting core power is approximately 1300 MW. Any further increases in power would cause the cladding temperature to exceed the $650^{\circ} \mathrm{C}$ steady-state design limit.

\subsubsection{Primary Coolant Forced Circulation}

The analysis of a steam or helium power conversion cycle coupled to a forced circulation primary system has not been completed yet. Currently, the benchmark of the Matlab code for parametric calculations is being undertaken against ATHENA. Therefore, in this progress report we will limit the discussion to some qualitative considerations.

The use of a pump adds considerable flexibility to the plant design because it enables selection of the primary coolant mass flow rate almost independently from the other variables (e.g. core geometry, chimney height). 
For a given cladding temperature limit and core power, the lead-bismuth flow can be increased to reduce the temperature rise across the core. The result would be a larger average temperature difference between the primary and secondary side in the steam generator (or heat exchanger if helium is the working fluid), which can then be designed to be more compact. Alternatively, the size of the steam generator or heat exchanger can be retained and the steam or helium outlet temperature increased, which results in a larger thermal efficiency of the plant. However, an increase of the lead-bismuth flow comes at the expense of higher erosion assisted corrosion in the core where the coolant velocity is largest and larger pump size and power requirements. Therefore, an economic analysis will be needed to quantitatively establish the tradeoff between increased thermal efficiency and/or reduced heat exchanger size, higher pump capital and operating costs, and higher core materials requirements.

\subsubsection{Plant Capital Cost Estimation Model}

The basic cost data for the primary and secondary coolant systems of the actnide-burner reactor are based on the Advanced Liquid Metal Reactor (ALMR) cost estimation report (Hutchins et al., 1991) and system description report (Stimmell, 1991). While the S-PRISM design (Boardman et al., 2000) is an upgraded version of this earlier 1991 ALMR, insufficient cost data are presently available to us to adopt it as our reference plant for the cost assessment presented in this report. It is planned that our final cost estimates will be based on the S-PRISM design.

The actnide-burner reactor primary system, with its liquid metal coolant and pool-type arrangement, is similar to the ALMR. However there are many component differences between the ALMR and the actnide-burner reactor. For instance, the ALMR has an intermediate heat transport system but the actinide-burner reactor does not. Therefore the first step in using the ALMR cost data in this work has been identifying the system differences between the two reactor types. The base assumption for the actinide-burner reactor primary system cost estimate is that the ALMR cost can be used for the system (or components) except for those major differences described in Table 31.

The cost models are as follows:

Capital cost model. The capital cost estimating method developed by ORNL is used (Delene and Hudson 1993).

Interest During Construction. Once money is raised and the construction payment is made, a return must be paid on it. This return on borrowed money is sometimes referred to as the "allowance for funds used during construction" or, more simply, the "interest during construction". The financial parameters given in Table 32 are used in determining the interest during construction costs.

Production Capacity Scaling. When making cost estimates for constructing a new facility, cost estimates will usually already exist for a facility with the same basic functions as the one to be estimated, but with a larger or smaller production capacity. In those instances, a general rule of thumb exists for scaling the original estimate (or the known cost for known capacity) to reflect the different production capacity of the proposed new facility. That general rule of thumb for capacity scaling can be expressed by the following expression. 
$C_{n}=C_{0}\left(\frac{K_{n}}{K_{0}}\right)^{m}$

where

$C_{0}$ : known cost

$K_{0}$ : known facility capacity

$C_{n}$ : new cost to be estimated

$K_{n}:$ new specified facility capacity

$m$ : representative value of size scaling factor

Financial Parameters. The key financial parameters are taken from the DOE Nuclear Energy Cost Data Base (NECDB 1985). Table 32 shows the key financial parameters used in the capital cost estimation in this report. Note that the financial parameters in Table 32 are applicable to utility plant ownership.

Table 31. Summary of the characteristics of major systems (or components) that differ in the actinide-burner reactor and the ALMR.

\begin{tabular}{|c|c|c|}
\hline & \multicolumn{2}{|r|}{ Characteristics } \\
\hline $\begin{array}{c}\text { System } \\
\text { (component) }\end{array}$ & $\begin{array}{c}\text { Actinide-Burner } \\
\text { Reactor } \\
\text { (Reference design) }\end{array}$ & $\begin{array}{c}\text { ALMR } \\
\text { (Reference plant) }\end{array}$ \\
\hline $\begin{array}{l}\text { Intermediate Heat } \\
\text { Transport System }\end{array}$ & None & $\begin{array}{l}\text { Components: intermediate heat exchanger, } \\
\text { isolation valves, sodium pump, sodium water } \\
\text { reaction pressure relief subsystem, auxiliary } \\
\text { systems, piping }\end{array}$ \\
\hline $\begin{array}{l}\text { Auxiliary liquid } \\
\text { metal system }\end{array}$ & $\begin{array}{l}\text { Lead-bismuth coolant } \\
\text { system } \\
\text { - } \quad \text { Assumed to have } \\
\text { same subsystems } \\
\text { and cost as sodium } \\
\text { system in the } \\
\text { ALMR }\end{array}$ & \begin{tabular}{ll} 
& \multicolumn{1}{c}{ Sodium (Na) coolant system } \\
- & Na receiving \& transfer subsystem \\
- & Intermediate Na processing subsystem \\
- & Primary $\mathrm{Na}$ processing subsystem \\
- & Primary $\mathrm{Na}$ storage \\
- & Primary $\mathrm{Na}$ purification \& cover gas \\
- & Piping \\
- & Cesium trap
\end{tabular} \\
\hline Primary Coolant pump & None & - $\quad 4$ electromagnetic pumps in a reactor \\
\hline Reactor vessel & $\begin{array}{ll}- & \text { OD }: 6 \mathrm{~m} \\
- & \text { Height }: 13.9 \mathrm{~m} \\
- & \text { Assume same cost } \\
& \text { as ALMR vessel }\end{array}$ & $\begin{array}{ll}- & \text { OD : } 5.74 \mathrm{~m} \\
- & \text { Height } ; 18.7 \mathrm{~m}\end{array}$ \\
\hline
\end{tabular}

\subsubsection{Capital Cost and Sensitivity Analysis}

A more realistic thermal efficiency for the actinide-burner reactor is obtained through matching the ideal thermal efficiency to the typical saturated steam secondary system PWR value. The efficiency for an ideal saturated steam system is $38.09 \%$ and a typical PWR value is $33.5 \%$ (Todreas and Kazimi, 1990). Therefore a realistic thermal efficiency of $33.9 \%$ for $7 \mathrm{MPa}, 30^{\circ} \mathrm{C}$ superheat steam system is obtained as follows.

$$
\Delta \eta=38.09 \%-33.5 \%=4.59 \% \text { for saturated steam state }
$$


where:

$$
\eta_{\text {real }}=38.49 \%-4.59 \%=33.9 \% \text { for } 30^{\circ} \mathrm{C} \text { superheated steam state }
$$

$38.49 \%=$ ideal thermal efficiency for $30^{\circ} \mathrm{C}$ superheated steam state

Table 32. Key financial parameters (Delene and Hudson 1993).

\begin{tabular}{|l|c|c|}
\hline \multicolumn{1}{|c|}{ Parameters } & Symbol & Value (Utility owned) \\
\hline \hline Capitalization (\%) & & \\
Debt & $b$ & 50 \\
Preferred stock & $p$ & 10 \\
Common equity & $c$ & 40 \\
\hline Interest rate (\%/yr) & $i_{b}$ & \\
Debt & $i_{p}$ & 9.7 \\
Preferred stock & $i_{c}$ & 9.0 \\
Common equity & & 14.0 \\
\hline Average cost of money (\%/yr) & & 11.35 \\
\hline Ratio of cost of debt/average cost of money & $i$ & 0.427 \\
\hline Inflation rate (\%/yr) & & 5.0 \\
\hline Combined state and federal tax rate (\%) & $X_{0}$ & 36.64 \\
\hline Real (inflation adjusted) average cost of money (\%/yr) & $d$ & 6.05 \\
\hline Effective (tax adjusted) cost of money (\%/yr) & $d_{0}$ & 9.57 \\
\hline Real (tax and inflation adjusted) cost of money (\%/yr) & & 4.35 \\
\hline
\end{tabular}

Table 33 summarizes the assumptions used in this capital cost estimation. The financial parameters can be found in Section 4.4.3 and the design parameters for the primary and secondary coolant systems are defined in Section 4.4.2. The preliminary estimated capital cost for the actinide-burner reactor with optimal design parameters, a steam power conversion cycle, and natural circulation of the primary coolant is 40 to $45 \mathrm{mills} / \mathrm{kW}-\mathrm{hr}$ based on 1999 dollars (Kim et al. 2000). This estimate is based on cost information from the ALMR.

Table 33. Assumptions in capital cost estimation for the actnide burner reactor.

\begin{tabular}{|c|c|}
\hline Parameter & Value \\
\hline \hline Power (MWth) & 1300 \\
\hline Capacity factor (\%) & 80 \\
\hline Thermal efficiency (\%) & 33.9 \\
\hline System life time (yr) & 60 \\
\hline Plant type & First commercial \\
\hline
\end{tabular}

The sensitivity of the actinide-burner reactor cost to variations in three key parameters has been determined. Degree of superheat, secondary system pressure and height of chimney are examined in this sensitivity analysis since the requisite data are available. Cost sensitivity analysis has not been performed on other parameters due to lack of available cost data. It should be noted that the following results apply for the configuration with lead-bismuth inside the steam generator tubes, which is currently the preferred arrangement.

Capital cost as a function of degree of superheat has been calculated as shown in Figure 59. The capital cost does not vary significantly with superheat, which is consistent with the variation in electrical power output with superheat. 


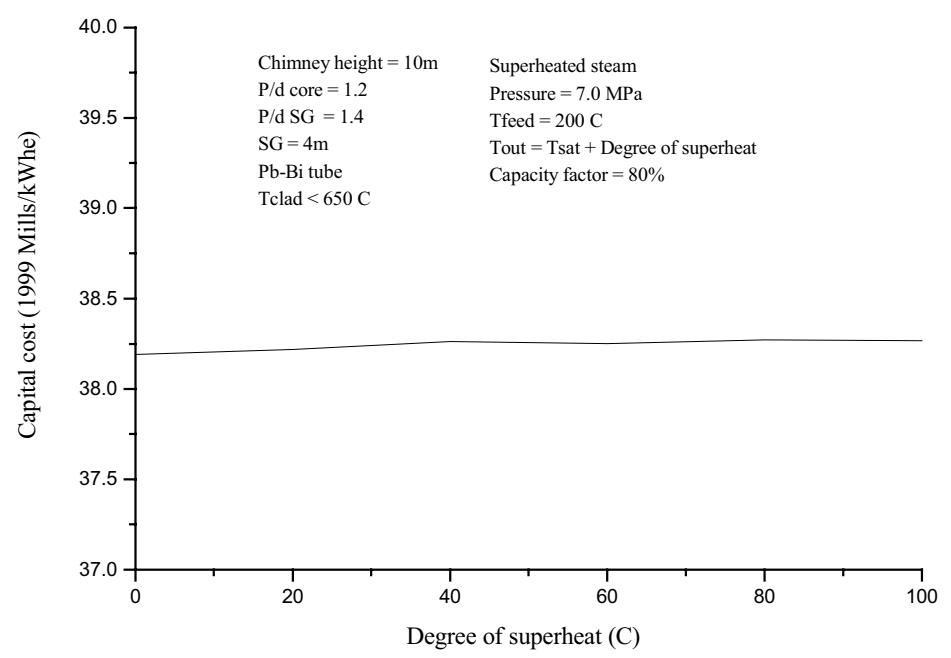

Figure 59. Capital cost variation due to steam superheat.

The effect of secondary coolant pressure on system cost has been evaluated from WASH 1088 (1969). This report gives the cost for pressure adjustment in 1969. The cost for a similar pressure adjustment in 1991 is presented in Table 34.

Table 34. Pressure adjustment cost amount (WASH 1088 1969).

\begin{tabular}{|c|c|c|c|}
\hline $\begin{array}{c}\text { Low } \\
\text { pressure }\end{array}$ & $\begin{array}{c}\text { Intermediate } \\
\text { pressure }\end{array}$ & $\begin{array}{c}\text { Pressure adjustment cost } \\
\text { amount (1969) }\end{array}$ & $\begin{array}{c}\text { Pressure adjustment } \\
\text { cost amount (1991) }\end{array}$ \\
\hline $\begin{array}{c}1250 \mathrm{psi} \\
(87.31 \mathrm{bar})\end{array}$ & $\begin{array}{c}2680 \mathrm{psi} \\
(184.78 \mathrm{bar})\end{array}$ & $810,000 \$$ & $2,369,461 \$$ \\
\hline
\end{tabular}

It should be noted that the cost in Table 34 is only for turbine and electrical generator items, so this amount should be adjusted to the total turbine and plant equipment account. The turbine and generator occupy $1 / 1.26$ of the total turbine and plant equipment account (WASH 1088, 1969). Therefore, it is assumed that the pressure adjustment cost has the following linear relation with secondary pressure.

$$
P C=\frac{(P-70)}{97.47} \times 1.26 \times 2,369,461
$$

where

$P C$ : pressure adjustment cost amount

$P$ : secondary pressure in bar

70 : secondary pressure in bar at reference

97.47 : pressure difference between two pressures in bar (WASH 1088, 1969)

1.26 : scale factor to total turbine plant equipment account

2,369,461 : pressure adjusted cost amount (1991\$) 
With this pressure adjustment and power capacity scaling method, the capital cost as a function of secondary system pressure has been calculated as shown in Figure 60. Capital cost increases with secondary system pressure. This result is consistent with the effect of secondary system pressure on electrical power output.

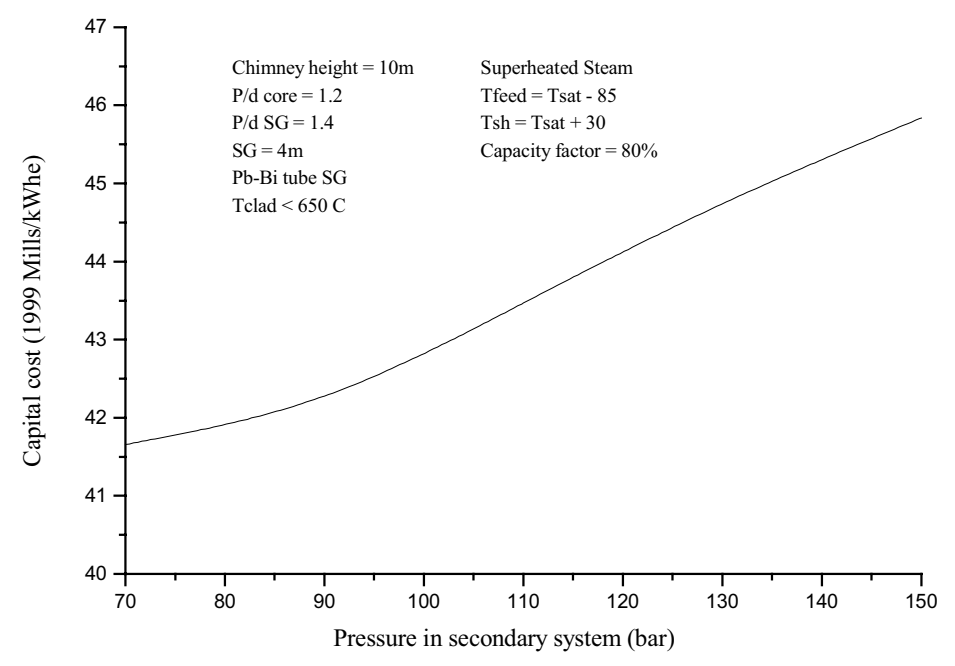

Figure 60. Capital cost variation with secondary system pressure.

The variation of capital cost with chimney height has also been performed. Capacity scaling for the chimney height change is performed using Equation 24.

$$
C_{n}=C_{0}\left(\frac{K_{n}}{K_{0}}\right)^{m}
$$

where

$C_{0}:$ known cost

$K_{0}:$ known length

$C_{n}$ : new cost to be estimated

$K_{n}:$ new specified length

$m$ : representative value of size scaling factor $=0.6$

With this chimney height cost adjustment, the capital cost as a function of chimney height has been obtained. The result is given in Figure 61. As expected, capital costs decrease with increased chimney height and this result is consistent with the increase of electrical power output. 


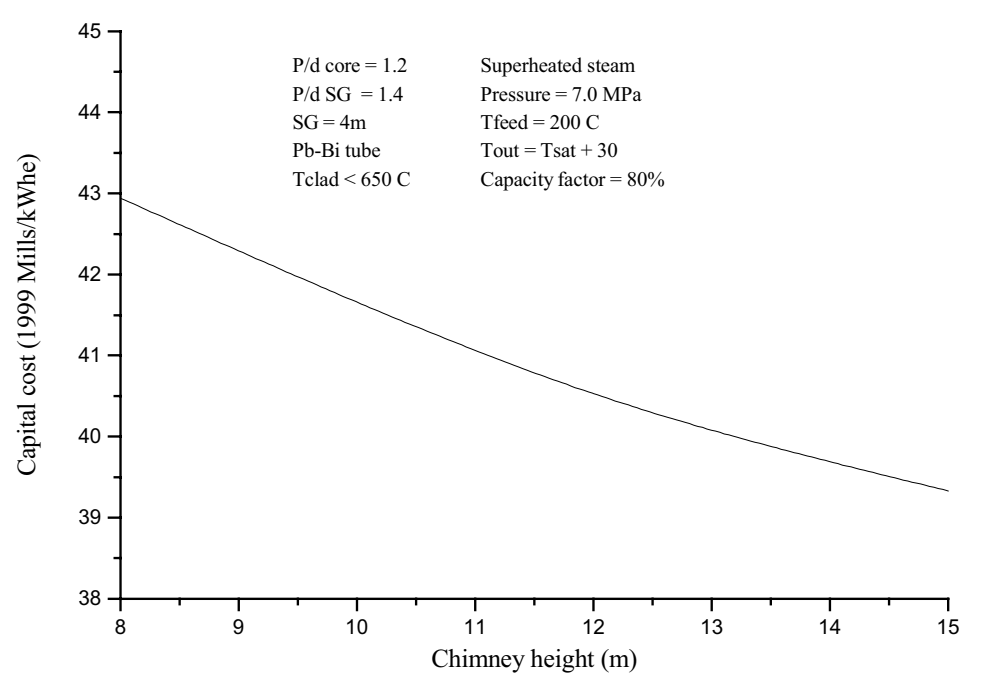

Figure 61. Capital cost with chimney height.

\subsubsection{Indirect Power Conversion Cycle - Transient State Power Determination}

This section describes an evaluation of the actinide-burner reactor during a loss-of-feed-water transient (Davis 2000). The evaluation was performed for an indirect power cycle using water as the secondary coolant and with natural circulation of the primary coolant. However, the evaluation results are also applicable to an indirect cycle using helium as the secondary coolant because the heat exchangers do not remove significant amounts of heat during a loss-of-feedwater transient. The results are also applicable for a forced circulation system provided that the motive force for convection is lost during the transient.

A passive decay-heat removal system was designed for the actinide-burner reactor based on the PRISM RVACS (General Electric 1986). The RVACS consists of the reactor vessel, a containment vessel, a collector cylinder, and inlet and outlet piping to draw in and subsequently heat atmospheric air. The RVACS is designed to remove core decay heat during accident conditions and is illustrated in Figure 62. 


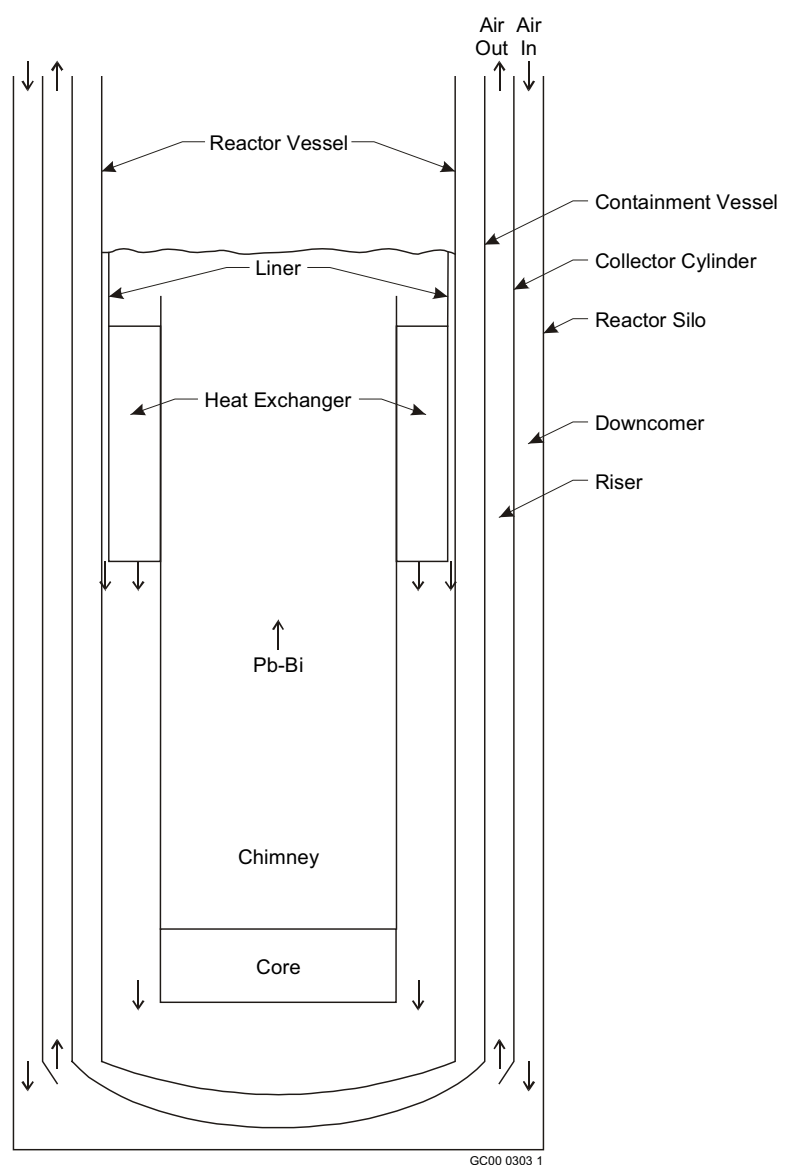

Figure 62. Schematic of the actidide-burner reactor RVACS.

The RVACS operates by transferring decay heat from the core fuel rods to the lead-bismuth coolant and then to the reactor vessel wall using natural convection heat transfer. The decay heat is then transferred by conduction through the reactor vessel wall. The decay heat is transferred from the outer surface of the reactor vessel wall to the inner surface of the containment vessel, principally based on radiation heat transfer. Fluid convection and conduction transfer some heat between the reactor and containment vessels because the gap between vessels is filled with an inert gas. The decay heat is then transferred through the containment vessel wall via conduction. The decay heat is finally transferred to air flowing upwards through an annular riser that is located between the containment vessel and collector cylinder. The air flows due to natural circulation caused by density differences between the hot air in the riser and the cold air in the down-comer, which is the annular region between the collector vessel and the reactor silo. The natural circulation process draws atmospheric air down the down-comer. After it reaches the bottom of the collector cylinder, the air turns and flows up through the riser, where it is heated by the containment vessel and collector cylinder. The outer surface of the collector cylinder is thermally insulated to protect the concrete reactor silo from excessive temperatures.

A liner is placed inside the reactor vessel wall above the bottom of the heat exchangers. During normal operation, there is no net flow through the annulus between the liner and the reactor vessel. The lead-bismuth located in the annulus is relatively cold because it is cooled by the RVACS while receiving some heat from the secondary coolant. Following a loss-of-feed-water transient, the primary coolant expands, increasing the level in the pool until it reaches holes 
located in the vessel liner. These holes allow hot lead-bismuth to flow into the annular gap between the liner and reactor vessel, increasing the heat removed by the RVACS.

An ATHENA model was developed to evaluate the performance of a PRISM RVACS on the actinide-burner reactor during a loss-of-feed-water transient. The model represents the actinideburner core with streaming tube assemblies described by Hejzlar et al. (2000). The RVACS was based on the PRISM design. Specifically, the thickness of the vessel liner, the containment vessel, and collector cylinder were all based on PRISM values. Similarly, the thickness of the various gaps between the reactor vessel liner and the reactor silo were initially set to the values used in PRISM. Important parameters assumed in subsequent analyses are listed in Table 35.

\section{Table 35. Key parameters for the ATHENA actinide-burner reactor model.}

\begin{tabular}{|l|c|}
\hline \multicolumn{1}{|c|}{ Parameter } & Value \\
\hline Core: & 1.2 \\
\hline Fuel rod pitch-to-diameter ratio & 1.3 \\
\hline Heated length, $\mathrm{m}$ & 1.0 \\
\hline Gas plenum length, $\mathrm{m}$ & 157 \\
\hline Number of fuel assemblies & Triangular \\
\hline Steam Generator: & 64,262 \\
\hline Lattice & 1.4 \\
\hline Number of tubes & 0.010 \\
\hline Tube pitch-to-diameter ratio & 0.001 \\
\hline Tube inner diameter, $\mathrm{m}$ & \\
\hline Tube thickness, $\mathrm{m}$ & 10.0 \\
\hline Miscellaneous: & 14.8 \\
\hline Chimney length, $\mathrm{m}$ & 4.00 \\
\hline Active vessel length, $\mathrm{m}$ & 0.02 \\
\hline Core barrel inner diameter, $\mathrm{m}$ & \\
\hline Core barrel thickness, $\mathrm{m}$ & 6.03 \\
\hline RVACS: & 0.0254 \\
\hline Vessel liner inner diameter, $\mathrm{m}$ & 0.0381 \\
\hline Vessel liner thickness, $\mathrm{m}$ & 0.05 \\
\hline Gap between liner and reactor vessel, $\mathrm{m}$ & 0.127 \\
\hline Reactor vessel thickness, $\mathrm{m}$ & 0.0254 \\
\hline Gap between reactor and containment vessels, $\mathrm{m}$ & 0.1778 \\
\hline Containment vessel thickness, $\mathrm{m}$ & 0.0254 \\
\hline Riser gap thickness, $\mathrm{m}$ & 0.0508 \\
\hline Collector cylinder thickness, $\mathrm{m}$ & 0.5842 \\
\hline Collector cylinder insulation thickness, $\mathrm{m}$ & \\
\hline Down-comer gap thickness, $\mathrm{m}$ & \\
\hline & \\
\hline & \\
\hline & \\
\hline & \\
\hline & \\
\hline & \\
\hline & \\
\hline
\end{tabular}

The ATHENA actinide-burner reactor model is illustrated in Figure 63. The model represents the primary coolant system, the secondary coolant system, and the RVACS. The primary coolant system is represented by components 500 through 595. The reactor core is represented by two parallel flow channels, one (component 516) representing eight high-powered fuel assemblies and the other (component 510) representing 149 fuel assemblies. The peaking factor of the eight high-powered bundles is 1.24. The axial power shape represents end-of-life conditions and has a maximum peaking factor of 1.12 (Hejzlar et al., 2000). Each control volume is approximately 1 $\mathrm{m}$ long except in the active core and steam generator, where smaller control volumes are used. For convenience, the cover gas above the normal liquid level is not explicitly modeled. Instead, a time-dependent volume (component 595) is used to set the pressure of the system and to receive 
or supply fluid as the primary coolant heats or cools. A valve (component 582) is used to represent the holes in the vessel liner. Opening the valve initiates the flow that occurs as the liquid level reaches the holes in the liner and spills over into the annular region (component 585) between the liner and reactor vessel. The opening time of the valve is treated parametrically. The average-powered and high-powered fuel rods, core barrel, and steam generator tubes are represented with heat structures.

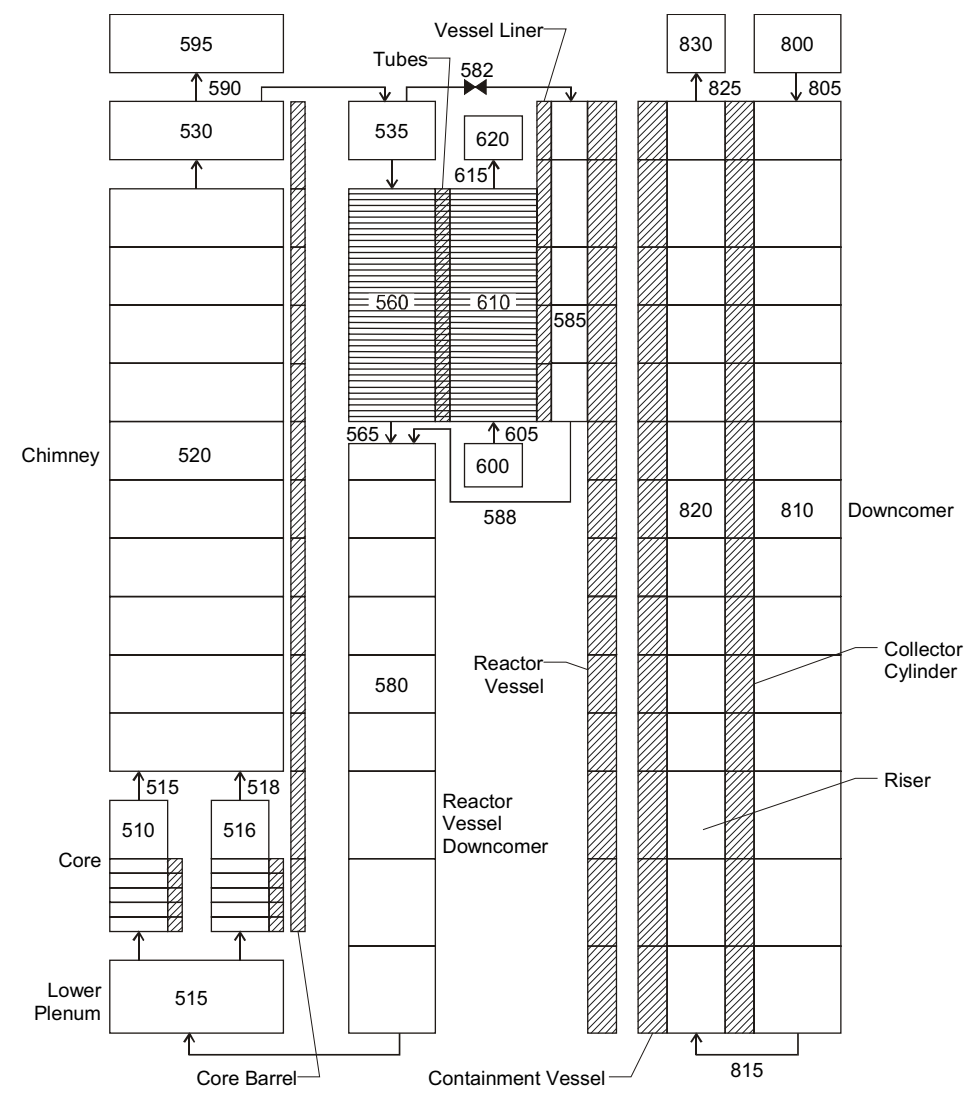

Figure 63. ATHENA model of the actnide-burner reactor.

The secondary coolant system is represented by components 600 through 620 . Feed-water is supplied with a time-dependent junction (component 605). The pressure in the steam generator is set with a time-dependent volume (component 620) that represents the steam line.

The RVACS is represented by components 800 through 830 . The air supply and exhaust are represented with two time-dependent volumes (components 800 and 830), which are set at atmospheric pressure. In the PRISM design, the hot and cold air columns are significantly longer than the length of the vessel. However, details of the inlet and outlet air ducts, including the inlet air screens, are not provided in the PRISM description (General Electric 1986). To simplify the model, the lengths of the down-comer and riser are set to that of the vessel $(14.8 \mathrm{~m})$ and the inlet and outlet air ducts are neglected. The form loss coefficient at the bottom of the down-comer (junction 815) was adjusted to obtain the same air mass flow rate during emergency operation of the RVACS as in PRISM. The resulting value of the form loss coefficient was 0.33 .

The model represents all the major heat structures associated with the RVACS, including the vessel liner, the reactor and containment vessels, and the collector cylinder. Radiation enclosure 
models are used to represent the radiation heat transfer between the reactor and containment vessels and between the containment vessel and the collector cylinder. The emissivity of these surfaces was set to 0.75 , which is representative of the average measured value during the PRISM test program (Hunsbedt and Magee 1988). The convection and conduction of the inert gas in the gap between the reactor and containment vessels was neglected. Insulation was applied to the outside surface of the collector cylinder.

The ATHENA model was benchmarked against calculations performed by General Electric (1986) for PRISM to check the performance of the RVACS. This benchmark was possible because the overall dimensions of the actinide-burner reactor and PRISM are similar. For example, the total reactor vessel heat transfer surface areas are nearly identical in the two designs. Benchmark comparisons were performed for two cases. The first case represented emergency RVACS operating conditions with the core generating decay heat, the steam generators unavailable for removing heat, and the liquid level above the elevation of the holes in the vessel liner. The second case represented normal, full-power operation with the steam generators removing heat. The RVACS was operating at a relatively low power in this case because the primary coolant temperature was relatively low and the vessel liquid level was below the elevation of the holes in the vessel liner. Both ATHENA calculations were performed with sodium coolant, rather than lead-bismuth, to facilitate the comparison with PRISM.

Results of the benchmark calculations are shown in Table 36. The comparisons for emergency conditions were generally in excellent agreement, which was expected because the form loss coefficient at the bottom of the down-comer was adjusted to obtain the desired air flow rate. However, the calculated fluid temperatures in the chimney were also in reasonable agreement. The chimney temperature calculated by ATHENA was $23^{\circ} \mathrm{C}$ lower than that reported for PRISM, corresponding to only a $4 \%$ difference in the temperature drop from the chimney to the ambient air.

Table 36. Benchmark comparisons for RVACS operation with sodium coolant.

\begin{tabular}{|l|c|c|}
\hline \multicolumn{1}{|c|}{ Parameter } & PRISM & ATHENA \\
\hline Emergency operation: & & 37.8 \\
\hline Air inlet temperature, ${ }^{\circ} \mathrm{C}$ & 37.8 & 149 \\
\hline Air outlet temperature, ${ }^{\circ} \mathrm{C}$ & 152 & 22.2 \\
\hline Air flow rate, $\mathrm{kg} / \mathrm{s}$ & 22.2 & 2.50 \\
\hline Heat removed, $\mathrm{MW}$ & 2.5 & 589 \\
\hline Chimney temperature, ${ }^{\circ} \mathrm{C}$ & 612 & \\
\hline Normal operation: & & 37.8 \\
\hline Air inlet temperature, ${ }^{\circ} \mathrm{C}$ & 37.8 & 74.0 \\
\hline Air outlet temperature, ${ }^{\circ} \mathrm{C}$ & 81.1 & 14.1 \\
\hline Air flow rate, $\mathrm{kg} / \mathrm{s}$ & 15.0 & 0.52 \\
\hline Heat removed, $\mathrm{MW}$ & 0.65 & 442 \\
\hline Chimney temperature, ${ }^{\circ} \mathrm{C}$ & Not meaningful $^{1}$ & 432 \\
\hline Core power, $\mathrm{MW}$ & 432 & \\
\hline
\end{tabular}

1. Not meaningful for comparison because of design differences between PRISM and the actnide-burner reactor.

The ATHENA and PRISM calculations for normal operation agreed reasonably well. This benchmark comparison was not expected to be perfect because of design differences between plants, which affect the results during normal operation. For example, PRISM uses electromagnetic pumps whereas the actinide-burner reactor relies on natural convection. PRISM 
also uses an intermediate heat transport system whereas the actinide-burner reactor removes core power directly using steam generators.

After the ATHENA RVACS model was successfully benchmarked using the PRISM calculations, a series of steady-state calculations were performed to determine the maximum cladding temperature as a function of core power. These calculations assumed that the primary coolant was lead-bismuth, the coolant level exceeded the elevation of the holes in the vessel liner, and the steam generators were not available to remove heat. Figure 64 compares the results of the calculations with the proposed transient cladding temperature limit of $750^{\circ} \mathrm{C}$ identified in Section 3. These steady-state calculations show that the RVACS can maintain the maximum cladding temperature below $750^{\circ} \mathrm{C}$ if the core decay power is less than $3.77 \mathrm{MW}$.

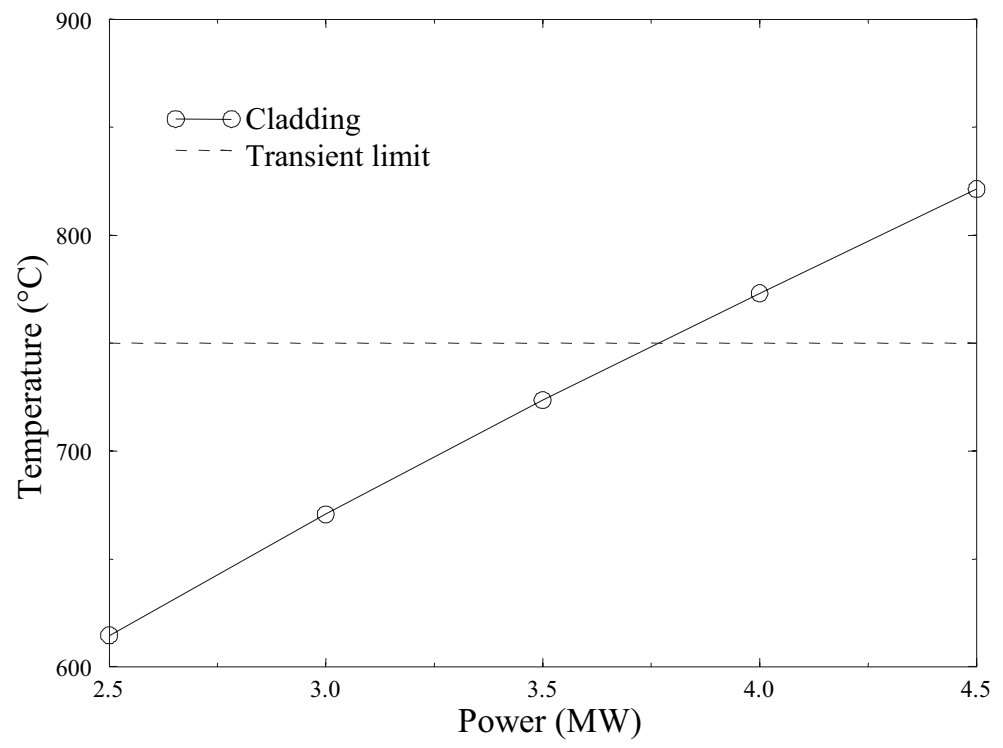

Figure 64. Maximum cladding temperature as a function of core power.

The temperature differences across various RVACS components were compared to determine the dominant thermal resistances. This comparison showed that the largest temperature differences were due to: (1) convection from the outer surface of the containment vessel to the riser air $(56 \%$ of the total), (2) radiation between the reactor and containment vessels (24\%), and (3) convection from the lead-bismuth to the reactor vessel wall $(14 \%)$. The temperature differences due to conduction across the reactor and containment vessels comprised the remaining $6 \%$ of the total. The calculations also showed that both convection and radiation were important at the outer surface of the containment vessel. About $54 \%$ of the energy flowed directly from the outer surface of the containment vessel to the air via convection, while the remainder was transferred by radiation to the inner surface of the collector cylinder. About $85 \%$ of the energy reaching the collector cylinder was then transferred to the air in the riser via convection. The remaining $15 \%$ of the energy reaching the collector cylinder, corresponding to $7 \%$ of the total energy, was transferred across the collector cylinder and heated the air in the down-comer. This energy flow path was relatively insignificant because the outside surface of the collector cylinder was insulated.

A total loss-of-feed-water transient was simulated to determine the thermal-hydraulic response of the system and to determine an appropriate power limit so that the peak cladding temperature 
would remain below the transient limit of $750^{\circ} \mathrm{C}$. The initial conditions for this calculation are summarized in Table 37. The decay power was based on an actinide-burning core with 200,000 MW-days/metric ton of burnup (Buongiorno et al. 1999b).

Table 37. Initial conditions for the loss-of-feed-water transient.

\begin{tabular}{|l|c|}
\hline \multicolumn{1}{|c|}{ Parameter } & Value \\
\hline Primary coolant system: & 650 \\
\hline Core power, MW & 17,409 \\
\hline Mass flow rate, $\mathrm{kg} / \mathrm{s}$ & 267 \\
\hline Core inlet temperature, ${ }^{\circ} \mathrm{C}$ & 518 \\
\hline Core outlet temperature, ${ }^{\circ} \mathrm{C}$ & 603 \\
\hline Maximum cladding temperature, ${ }^{\circ} \mathrm{C}$ & \\
\hline Secondary coolant system: & 7.0 \\
\hline Pressure, MPa & 317 \\
\hline Feed-water flow rate, $\mathrm{kg} / \mathrm{s}$ & 200 \\
\hline Feed-water temperature, ${ }^{\circ} \mathrm{C}$ & 30 \\
\hline Steam superheat, ${ }^{\circ} \mathrm{C}$ & \\
\hline RVACS: & 0.56 \\
\hline Power removed, $\mathrm{MW}$ & 14.4 \\
\hline Air flow rate, $\mathrm{kg} / \mathrm{s}$ & 38 \\
\hline Air inlet temperature, ${ }^{\circ} \mathrm{C}$ & 76 \\
\hline Air exit temperature, ${ }^{\circ} \mathrm{C}$ & \\
\hline
\end{tabular}

The transient was initiated by reducing the feed-water flow to zero and scram of the reactor at 0 seconds. The steam generators dried out 5 minutes after the loss of feed-water. The RVACS was the only system subsequently available for removing core decay power. The primary coolant was assumed to expand to the elevation of the holes in the vessel liner between the liner and the reactor vessel 7 hours into the transient based on the timing in PRISM (Hunsbedt and Magee 1988). Hand calculations indicate that the lead-bismuth would expand to the elevation of the holes in 7 hours if the holes were about $0.2 \mathrm{~m}$ above the normal operating level.

Figure 65 compares the power removed by the RVACS with the core decay power during the loss-of-feed-water transient. The core decay power decreased monotonically throughout the transient. The power removed by the RVACS increased gradually due to the heating of the primary coolant until 7 hours into the event, when the primary coolant spilled over into the gap between the vessel liner and the reactor vessel. The power removed by the RVACS then increased sharply due to two effects. First, the effective area for heat transfer from the reactor vessel increased substantially. Before 7 hours, heat transfer from the reactor vessel at the elevation of the steam generators was relatively poor because the lead-bismuth in the gap was stagnant and only heated through the liner by the steam on the secondary side of the steam generator. After spillover occurred, nearly half of the total lead-bismuth flow passed through the gap, resulting in an effective region of heat transfer. Second, the heat transfer coefficient from the lead-bismuth to the reactor vessel was significantly higher in the gap than in the reactor vessel down-comer because the fluid velocity in the gap was much higher due to its smaller flow area. After spillover, the power removed by the RVACS continued to increase until it equaled the core decay power near 47 hours at a value of $3.76 \mathrm{MW}$. The power removed by the RVACS exceeded the core decay power after 47 hours, causing the primary coolant system to cool. 


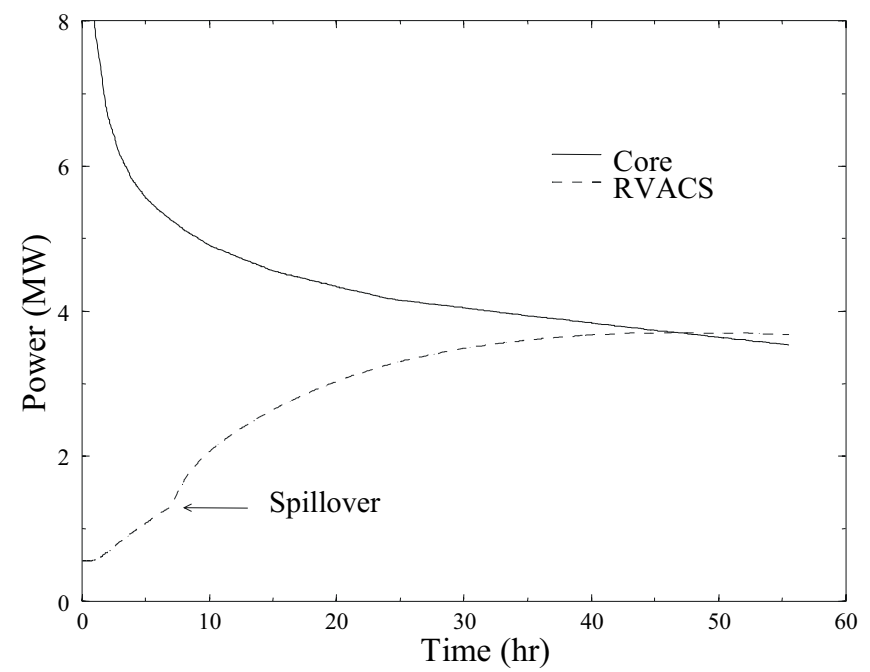

Figure 65. RVACS and core decay power during a loss-of-feed-water transient.

The maximum fuel rod cladding temperature during the loss-of-feed-water transient is shown in Figure 66. The cladding temperature experienced some perturbations during the first hour of the transient due to the effect of the reactor scram on the natural circulation flow rate. The cladding temperature then began to increase reflecting the increase in average primary coolant temperature that occurred because the core decay heat exceeded the heat removed by the RVACS as shown in Figure 65. The rate of temperature increase slowed significantly following the spillover of primary coolant through the holes in the vessel liner at 7 hours. The temperature then increased gradually until reaching a peak value of $744^{\circ} \mathrm{C}$ near 47 hours. The peak cladding temperature remained slightly below the transient temperature limit of $750^{\circ} \mathrm{C}$. Hand calculations, based on the steady-state results shown in Figure 64 and a normalized power at 47 hours (0.0057), showed that the initial core power could be raised from 650 to $660 \mathrm{MW}$ and the peak cladding temperature during the transient would still remain just below the $750^{\circ} \mathrm{C}$ limit.

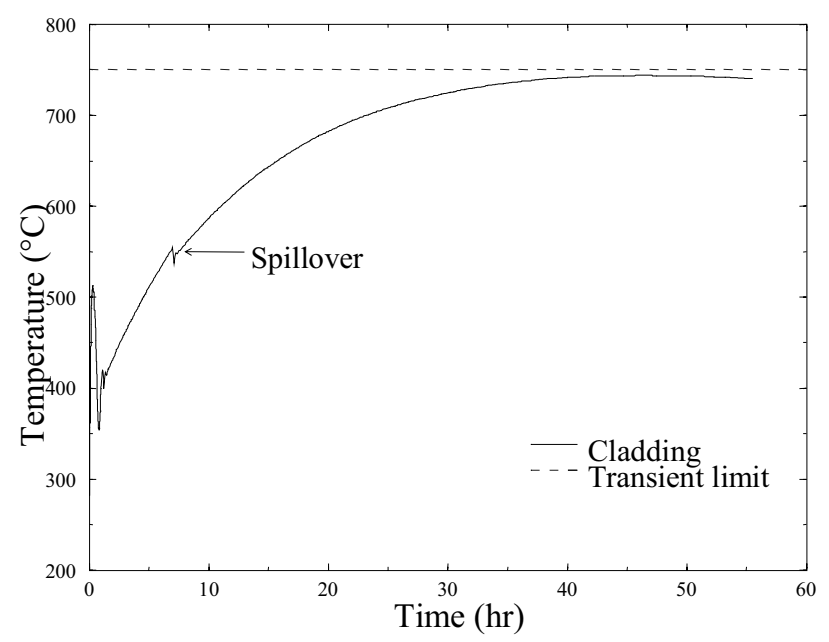

Figure 66. Maximum cladding temperature during a loss-of-feed-water transient.

The initial core power of 650 MW shown in Table 37 was selected so that the peak cladding temperature during the loss-of-feed-water transient would be slightly below the limit of $750^{\circ} \mathrm{C}$. Thus, one might expect that the power removed by the RVACS at the time of the peak cladding 
temperature during the transient would be consistent with the limiting power identified during the steady-state analysis illustrated in Figure 64. In fact, the decay and RVACS powers were equal at 3.76 MW during the transient, which was nearly identical to the limiting value of $3.77 \mathrm{MW}$ identified during the steady-state analysis. These results indicate that, at a given temperature, the RVACS will remove nearly the same power during a loss-of-feed-water transient as at steady state. Thus, the loss-of-feed-water transient is nearly quasi-steady, which is expected because the transient is very slow.

Three design changes to the RVACS were evaluated in an attempt to increase the power that could be removed during a loss-of-feed-water transient. The purpose of the evaluation was to support an increase in the initial core power to improve the economic efficiency of the plant. The first case was identical to the reference case described previously except that the vessel length was increased by $10 \%$. This was accomplished by increasing the length of the wetted portion of the reactor vessel and the RVACS by $1.48 \mathrm{~m}$. The $10 \%$ increase was approximately the maximum that could be accommodated while still meeting the transportation limit of $18.9 \mathrm{~m}$ for overall vessel length established for PRISM (Spencer et al. 2000) and accounting for the space required for the cover gas and the upper head. The second case was identical to the reference case except that the gap between the reactor and containment vessels was filled with lead-bismuth and the gap width reduced from 0.127 to $0.05 \mathrm{~m}$. The rationale for this design change was that the heat transfer between the reactor and containment vessels could be improved by replacing the relatively inefficient radiation with conduction and convection. For simplicity, only conduction was accounted for in the model so the calculated limiting power is expected to be somewhat conservative. (Hand calculations indicate that the limiting power would have increased by about $5 \%$ if convection in the gap had been accounted for.) The third case was the same as the second case, but also simulated fins on the outside of the containment vessel. The rationale for this change was to increase the surface area for heat transfer to the air. The fins were simulated by doubling the heat transfer coefficient on the outer surface of the containment vessel, thus essentially doubling the surface area.

The results of the design changes are compared with the reference design in Figure 67, which shows maximum cladding temperature as a function of steady-state power. The evaluation

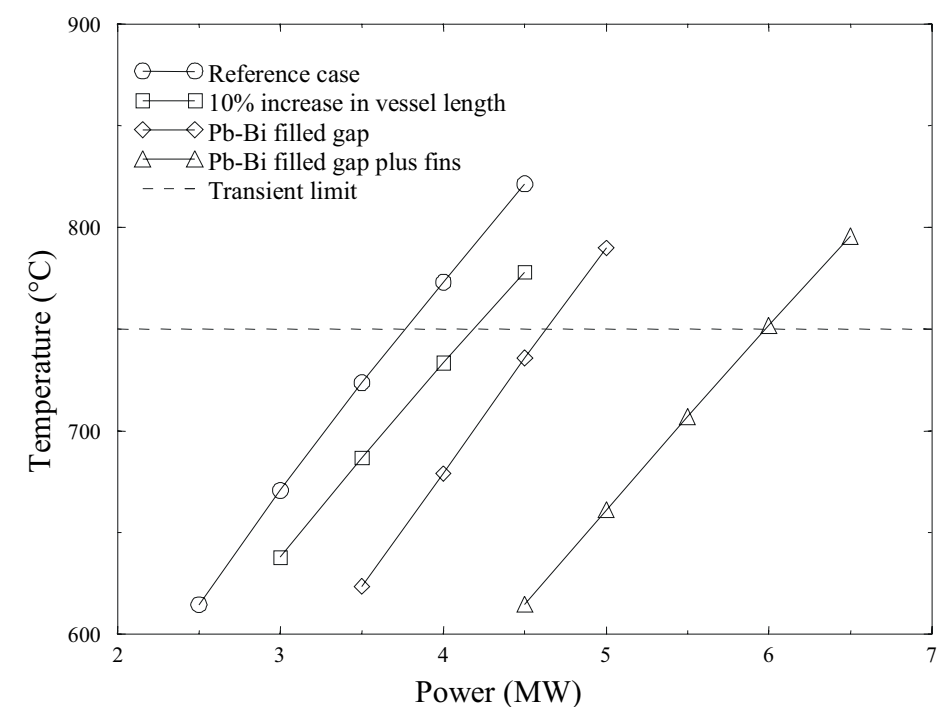

Figure 67. The effect of the RVACS design changes on maximum cladding temperature 
showed that the $10 \%$ increase in vessel length increased the limiting power, which yields a maximum cladding temperature of $750^{\circ} \mathrm{C}$ at a power of $4.19 \mathrm{MW}$, an $11 \%$ improvement compared to the reference design. Thus, the limiting power is a nearly linear function of vessel length. The evaluation also showed that filling the gap between the reactor and containment vessels with lead-bismuth increased the limiting power to $4.63 \mathrm{MW}$, a $23 \%$ improvement from the reference design. The results also showed that the further addition of fins on the containment vessel raised the limiting power to $5.98 \mathrm{MW}$, a $59 \%$ increase from the reference design.

A transient analysis was then performed to determine the effect of the design changes on the limiting initial power that would yield a peak cladding temperature of $750^{\circ} \mathrm{C}$. The design changes considered included narrowing the gap between the reactor and containment vessels and filling it with lead-bismuth and adding fins on the exterior of the containment vessel. Results of a loss-offeed-water transient initiated from $950 \mathrm{MW}$ core power are shown in Figures 68 and 69. The peak cladding temperature for this case was $747^{\circ} \mathrm{C}$. The core decay power and power removed by RVACS crossed 29 hours after the start of the transient, at a value of $5.95 \mathrm{MW}$. Hand calculations indicate that an initial core power of 955 MW would result in a peak cladding temperature of $750^{\circ} \mathrm{C}$ during the transient. The limiting core power for this case was $45 \%$ greater than in the reference design, which was somewhat less than that estimated from the steady-state analysis because the crossover point occurred 18 hours earlier than in the reference case. However, the transient power removed by the RVACS at the time of the temperature peak was consistent with the steady-state analysis.

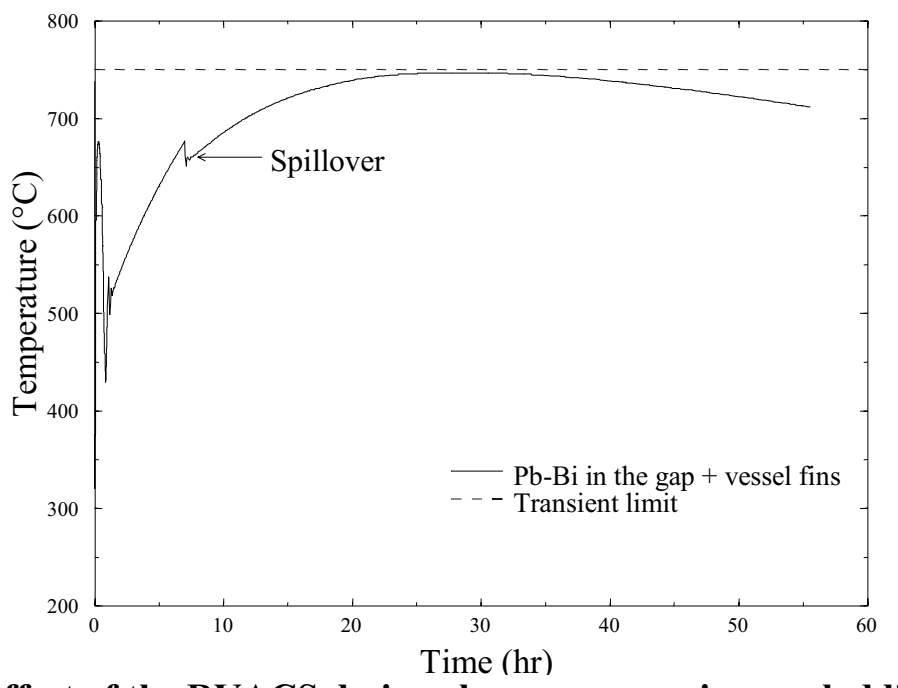

Figure 68. The effect of the RVACS design changes on maximum cladding temperature during a loss-of-feed-water transient.

The transient analyses showed that the limiting initial core power varies from $660 \mathrm{MW}$ for the reference design to $955 \mathrm{MW}$ if the gap between the reactor and containment vessels is filled with lead-bismuth and fins are added to the exterior of the containment vessel. If the vessel length is increased to the maximum value consistent with the transportation limits, the maximum core power can be increased by about $11 \%$ to $1060 \mathrm{MW}$. It is instructive to compare these transient power limits with the steady-state limit of $1300 \mathrm{MW}$ derived in Section 4.4.2.1. The steady-state limit was computed assuming a uniform core power shape. To ensure that the maximum cladding temperature of the high-powered bundles also remains below the steady-state temperature limit of $650 \mathrm{C}$, the steady-state power limit should be reduced to $1300 / 1.24=1048 \mathrm{MW}$. For the 
reference design, the transient power limit of $660 \mathrm{MW}$ is considerably more restrictive than the steady-state limit of $1048 \mathrm{MW}$. However, the analyses showed that design changes to the RVACS could increase the transient power limit to slightly above the steady-state value. Nevertheless, the maximum power limit for an air-cooled RVACS appears to be around 1060 MW. If further increases in core power are desired, additional modifications to the RVACS, such as using water to cool the exterior of the containment vessel (Buongiorno et al. 1999b), are required.

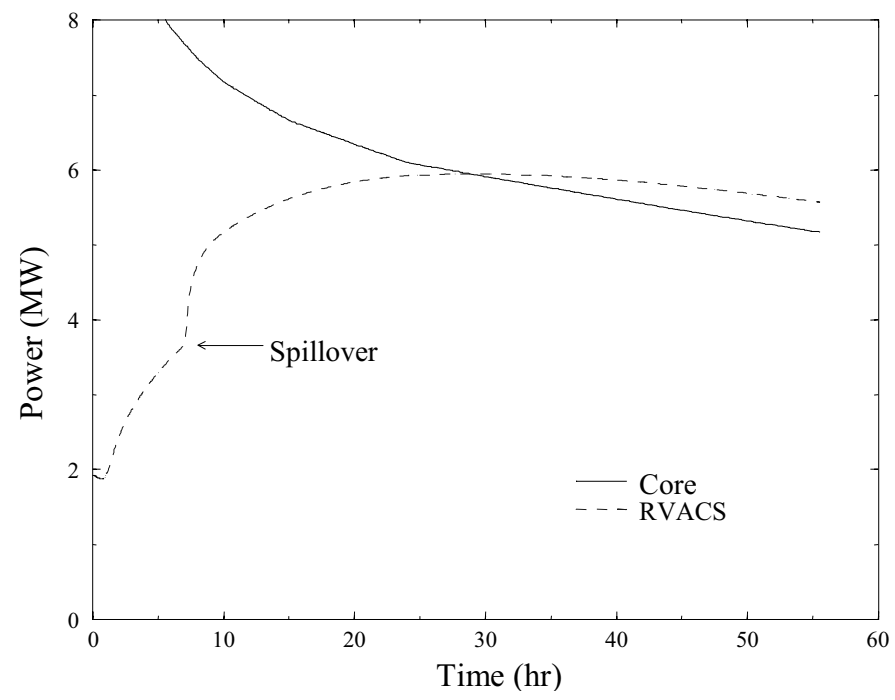

Figure 69. The effect of the RVACS design changes on maximum power removed during a loss-of-feed-water transient.

\subsubsection{Gas Lift Pump Evaluation for the Indirect Cycle Design}

A gas lift pump is being considered in both the direct and indirect cycle designs, but the application is considerably different. In the direct cycle design, liquid water will be injected into the chimney above the core. The liquid will quickly boil to steam resulting in a mixture of leadbismuth and steam. Because of the presence of the steam, the density of the fluid in the chimney is less than that of the lead-bismuth in the reactor vessel down-comer. The difference in density provides a driving force for flow. The pressure of the primary coolant will be about 7.0 MPa to produce high-pressure steam that can be used in the power conversion system. In contrast, the pressure will be relatively low in the indirect cycle because the cover gas above the primary coolant will be near atmospheric pressure. Furthermore, helium gas, rather than liquid water, will be injected into the chimney.

Section 4.4.1 presents an evaluation of several correlations that could potentially be used to calculate gas lift pump performance for the direct contact cycle. The remainder of this section discusses a method that could be used to calculate the performance of a gas lift pump in the indirect cycle (Davis and Shieh 2000).

The RELAP5 code (The RELAP5 Development Team 1999), upon which ATHENA is based, has been extensively used and assessed for the thermal-hydraulic analysis of light water reactors. However, neither code has been assessed as thoroughly for non-aqueous fluids, and in particular for two-phase mixtures involving lead-bismuth. Consequently, the capability of the ATHENA 
code to predict the void fraction of a mixture of lead-bismuth and steam for vertical up-flow was assessed using the El-Boher et al. (1988) void correlation.

The El-Boher and Lesin void correlation was developed for co-current up-flow of different mixtures, including water and air, mercury and steam, and lead-bismuth and steam. The leadbismuth/steam data were taken in the ETGAR-3 facility, which is illustrated in Figure 70. The ETGAR-3 facility contained two vertical pipes, called a riser and down-comer, that were connected at the bottom with a crossover pipe and at the top with a separator. Tests were conducted by mixing steam with lead-bismuth near the bottom of the riser. The mixture of leadbismuth and steam then flowed upwards through the riser and into the separator, which returned liquid lead-bismuth to the down-comer. Natural circulation flow was induced by the difference in density between the riser and down-comer pipes. The pipes were $0.203 \mathrm{~m}$ in diameter and $7.5 \mathrm{~m}$ long.

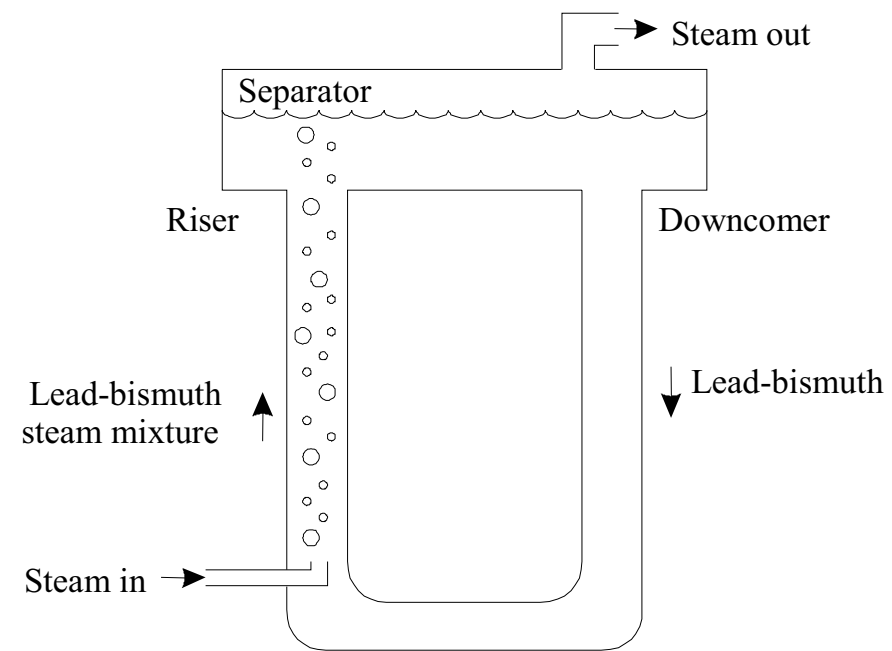

Figure 70. Schematic of the ETGAR-3 facility.

Tests were conducted at a nominal pressure of $3.5 \times 10^{5} \mathrm{~Pa}$ and a nominal temperature of $170^{\circ} \mathrm{C}$. The liquid superficial velocity varied from 0.6 to $1.6 \mathrm{~m} / \mathrm{s}$. The ratio of gas superficial velocity to liquid superficial velocity varied from about 0.35 to 5.8. The average flow quality was about $1 \times 10^{-4}$. The pressure in the riser was measured at over twenty locations. The void fraction distribution in the riser was calculated from the measured axial pressure distribution.

The El-Boher and Lesin correlation is:

$$
\alpha=1 /\left[1+0.27\left(\mathrm{Q}_{\mathrm{R}}\right)^{-0.69}(\mathrm{Fr})^{-0.177}\left(\mu_{\mathrm{f}} / \mu_{\mathrm{g}}\right)^{0.378}(\mathrm{Re} / \mathrm{We})^{0.067}\right]
$$

where $\alpha$ is the gas volume fraction, $\mathrm{Q}_{\mathrm{R}}$ is the volumetric flow ratio, Fr is the Froude number, $\mu_{\mathrm{f}} / \mu_{\mathrm{g}}$ is the dynamic viscosity ratio, Re is the Reynolds number, We is the Weber number, and the subscripts $f$ and $g$ refer to the liquid and gas, respectively. The non-dimensional numbers are calculated as:

$$
\begin{aligned}
& \mathrm{Q}_{\mathrm{R}}=\mathrm{x} \rho_{\mathrm{f}} /\left[(1-\mathrm{x}) \rho_{\mathrm{g}}\right]=\mathrm{j}_{\mathrm{g}} / \mathrm{j}_{\mathrm{f}} \\
& \mathrm{Fr}=\mathrm{j}_{\mathrm{f}}^{2} /(\mathrm{gD}) \\
& \mathrm{Re}=\rho_{\mathrm{f}} \mathrm{j}_{\mathrm{f}} \mathrm{D} / \mu_{\mathrm{f}}
\end{aligned}
$$




$$
\mathrm{We}=\mathrm{j}_{\mathrm{f}}^{2} \rho_{\mathrm{f}} \mathrm{D} / \sigma
$$

where

$\begin{array}{lll}\mathrm{x} & = & \text { flow quality } \\ \rho & = & \text { density } \\ \mathrm{j} & = & \text { superficial velocity } \\ \mathrm{D} & = & \text { pipe diameter } \\ \mathrm{g} & = & \text { acceleration due to gravity } \\ \sigma & = & \text { surface tension }\end{array}$

Equation 25 predicted the lead-bismuth/steam data with a root-mean-square error of $10.87 \%$. ElBoher et al. (1988) also reported that Equation 25 was tested against different data sets using air/water, steam/mercury, freon/mercury, and nitrogen/mercury mixtures. The root-mean-square error for all the data was $11.97 \%$. The overall range of the correlation was reported to be between 0.08 and 0.83 for void fraction, 0.016 and $0.203 \mathrm{~m}$ for diameter, and 0.09 to $2.58 \mathrm{~m} / \mathrm{s}$ for liquid superficial velocity. The temperature varied from ambient to $170^{\circ} \mathrm{C}$.

Although Equation 25 was based on over 3400 lead-bismuth/steam data points, El-Boher et al. (1988) presented only limited data. For the purposes of the present discussion, Equation 25 will be used as a substitute for the underlying data.

The ATHENA input model of the ETGAR-3 facility is illustrated in Figure 71. The model represented only the $7.5-\mathrm{m}$ long riser pipe, which was all that was necessary to assess the code's prediction of void fraction. Liquid lead-bismuth and gas were introduced into the bottom of the riser with time-dependent junctions, component 505 for the liquid and component 515 for the gas. The pressure at the top of the riser was specified with a time-dependent volume (component 535). The riser was divided into 17 control volumes using a pipe (component 520) and a branch (component 530). The lower $7.0 \mathrm{~m}$ of the riser was modeled with 14 control volumes that were each $0.5 \mathrm{~m}$ long. The upper $0.5 \mathrm{~m}$ of the riser was divided into three smaller control volumes so that the pressure in these control volumes nearly equaled that of component 535, which was set at the nominal ETGAR-3 pressure. The void fraction from the uppermost volume of component 520 was used in the comparisons with the El-Boher and Lesin correlation that are shown later.

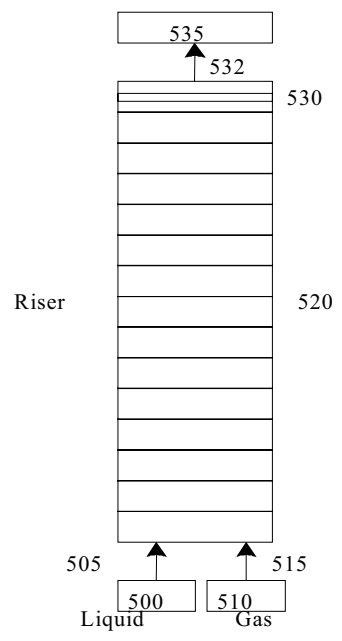

Figure 71. ATHENA model of the ETGAR-3 facility. 
The steam injection in the ETGAR-3 facility was simulated using a mixture of ideal, noncondensable gases. The mass fractions of these non-condensable gases were set so that the density of the mixture equaled that of steam at nominal ETGAR-3 conditions. The steam injection could not be simulated using the normal water property tables available in ATHENA because the code allows the use of only one working fluid, which in this case was lead-bismuth, in a hydrodynamic system. The use of non-condensable gases to simulate steam is acceptable because steam would not condense at the operating pressure and temperature of the ETGAR-3 facility.

ATHENA calculations were performed by holding the liquid flow rate constant and varying the gas flow in steps over the range tested in the ETGAR-3 facility. The steps were long enough to allow steady state conditions to be reached. The calculations were performed at nominal conditions for ETGAR-3. Specifically, the liquid superficial velocity was set to $1.1 \mathrm{~m} / \mathrm{s}$, the pressure at the top of the riser pipe was set to $3.5 \times 10^{5} \mathrm{~Pa}$, and the liquid and gas inlet temperatures were set to $170^{\circ} \mathrm{C}$.

Figure 72 compares calculated results from ATHENA with the El-Boher and Lesin correlation. The trends calculated by ATHENA were in reasonable agreement with Equation 25. However, the calculated void fractions exceeded the values from the correlation by up to $30 \%$.

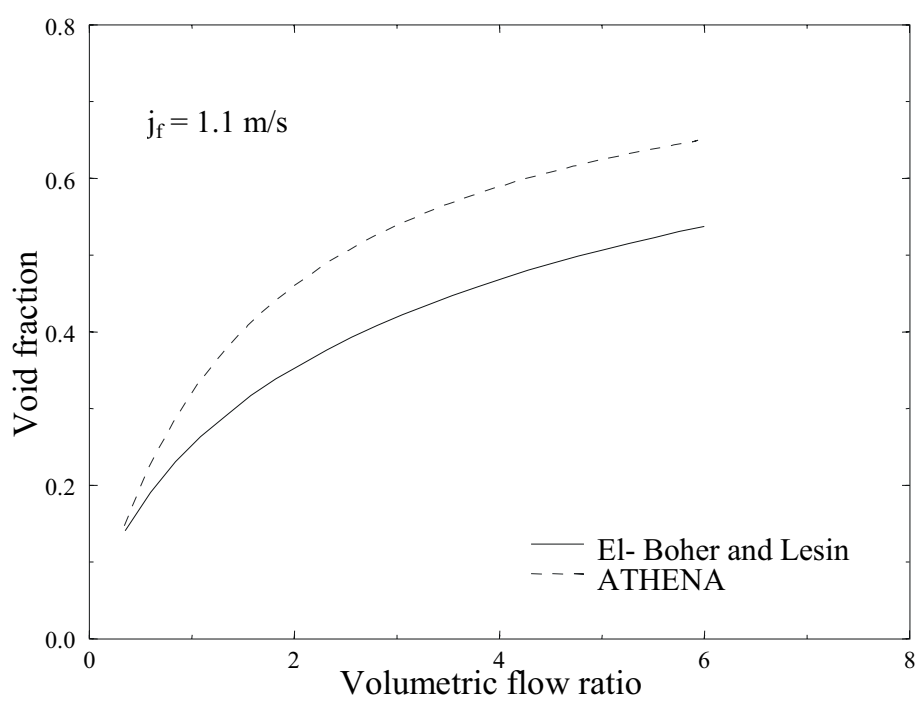

Figure 72. A comparison of the El-Boher and Lesin void correlation with ATHENA.

The calculation of void fraction depends heavily on the calculation of phase slip, which ATHENA calculates using inter-phase drag coefficients. The code uses a drift-flux approach for the bubbly and slug flow regimes in vertical components and converts the essential results from a drift-flux correlation to an equivalent inter-phase drag coefficient. ATHENA used the Kataoka and Ishii (1987) drift-flux correlation to calculate the results shown in Fig. 27. Slightly worse results were obtained using the other drift-flux correlations that are available in the code.

Based on the results shown in Figure 72, the El-Boher and Lesin correlation was implemented into a modified version of ATHENA. One method to implement the correlation might be to try to use it directly within the code. However, the code obtains the void fraction through a 
simultaneous solution of a system of six differential equations based on the continuity, momentum, and energy equations for the gas and liquid phases. The code's solution for the void fraction cannot be replaced with an explicit void correlation without fundamentally altering the code's solution scheme. Thus, a direct implementation of the El-Boher and Lesin correlation is not feasible given the structure of the code.

Another way to implement the El-Boher and Lesin correlation would be to convert it to a driftflux formulation. The gas velocity, $v_{\mathrm{g}}$, can be written (Zuber and Findlay 1965) as

$$
\begin{aligned}
& \mathrm{v}_{\mathrm{g}}=\mathrm{j}_{\mathrm{g}} / \alpha=\mathrm{C}_{0} \mathrm{j}+\mathrm{v}_{\mathrm{gj}} \\
& \mathrm{j}=\mathrm{j}_{\mathrm{g}}+\mathrm{j}_{\mathrm{f}}=\alpha \mathrm{v}_{\mathrm{g}}+(1-\alpha) \mathrm{v}_{\mathrm{f}}
\end{aligned}
$$

where $\mathrm{C}_{0}$ is the distribution parameter, $\mathrm{v}_{\mathrm{gj}}$ is the (constant) drift velocity, $\mathrm{j}$ is the total superficial velocity, and $\mathrm{v}_{\mathrm{f}}$ is the liquid velocity.

The gas velocity predicted by the El-Boher and Lesin correlation is shown as a function of total superficial velocity in Figure 73. The figure also shows the results of a linear regression fit that determined optimal values of the coefficients $\mathrm{C}_{0}(1.48)$ and $\mathrm{v}_{\mathrm{gj}}(1.17 \mathrm{~m} / \mathrm{s})$. According to Equation 30 , the gas velocity should be a linear function of total superficial velocity if $C_{0}$ and $v_{\mathrm{gj}}$ are constant. Since the gas velocity obtained from the El-Boher and Lesin correlation was nearly linear, correlations for $\mathrm{C}_{0}$ and $\mathrm{v}_{\mathrm{gj}}$ could be developed that would allow the drift-flux model to match the El-Boher and Lesin correlation reasonably well. However, Equation 30 with the optimal coefficients predicts gas velocities that are too large, and hence void fractions that are too small, compared to the correlation at low and high values of superficial velocity. Thus, even though the comparison between the El-Boher and Lesin correlation and Equation 30 with constant coefficients is reasonable in the region shown, the two curves would diverge as the superficial velocity is extrapolated. Furthermore, it could be relatively complicated to develop correlations for $\mathrm{C}_{0}$ and $\mathrm{v}_{\mathrm{gj}}$ based on the El-Boher and Lesin correlation.

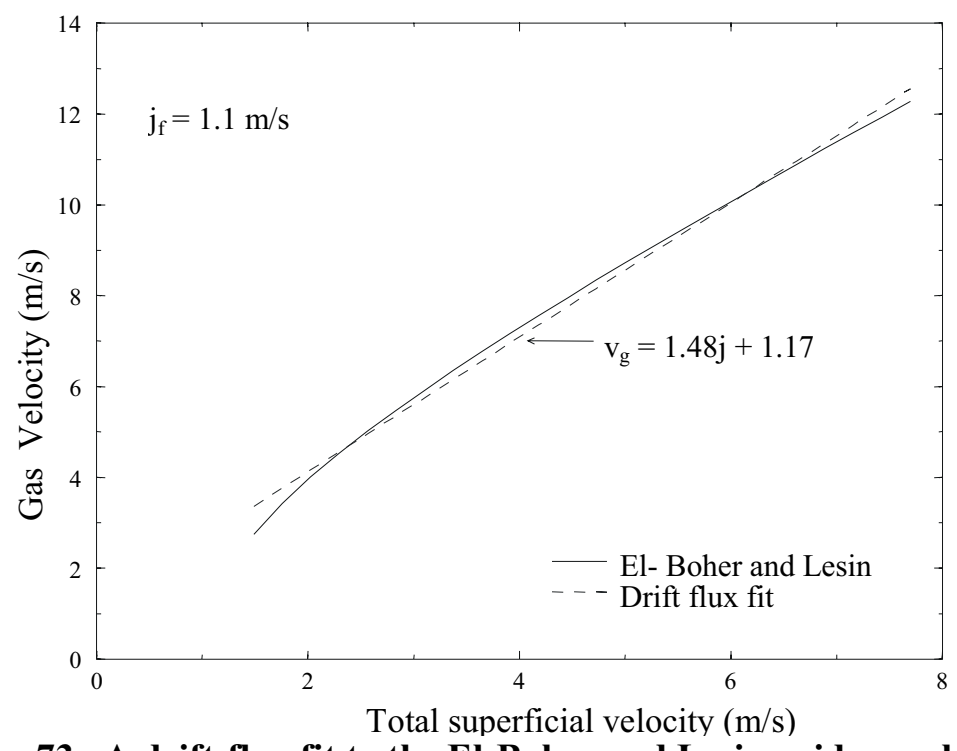

Figure 73. A drift-flux fit to the El-Boher and Lesin void correlation. 
Rather than convert Equation 25 to a drift-flux correlation, the El-Boher and Lesin correlation was implemented in a modified version of ATHENA by making a minor change to the way that the code applies the drift-flux model. Specifically, solving Equation 30 for $\mathrm{C}_{0}$ yields:

$$
\mathrm{C}_{0}=\left(\mathrm{j}_{\mathrm{g}} / \alpha-\mathrm{v}_{\mathrm{gg}}\right) / \mathrm{j}
$$

Since $\mathrm{j}_{\mathrm{g}}$ and $\mathrm{j}$ can be computed at each junction and $\alpha$ can be obtained from Equation $25, \mathrm{C}_{0}$ can be determined if $\mathrm{v}_{\mathrm{gj}}$ is known. Of the correlations available in the code, the Kataoka-Ishii correlation's prediction of drift velocity was in the best agreement with the $1.17 \mathrm{~m} / \mathrm{s}$ value obtained from the fit to the El-Boher and Lesin correlation. Consequently, the Kataoka-Ishii correlation was used to calculate $\mathrm{v}_{\mathrm{gg}}$. Figure $\mathbf{7 4}$ shows the solution to Equation 32 for nominal ETGAR-3 conditions. Note that the values of $\mathrm{C}_{0}$ shown depend on the assumed drift velocity and would differ if a different drift velocity correlation had been used. However, the actual values of $\mathrm{C}_{0}$ are not as important to the prediction of void fraction as the combined values of $\mathrm{C}_{0}$ and $\mathrm{v}_{\mathrm{gj}}$.

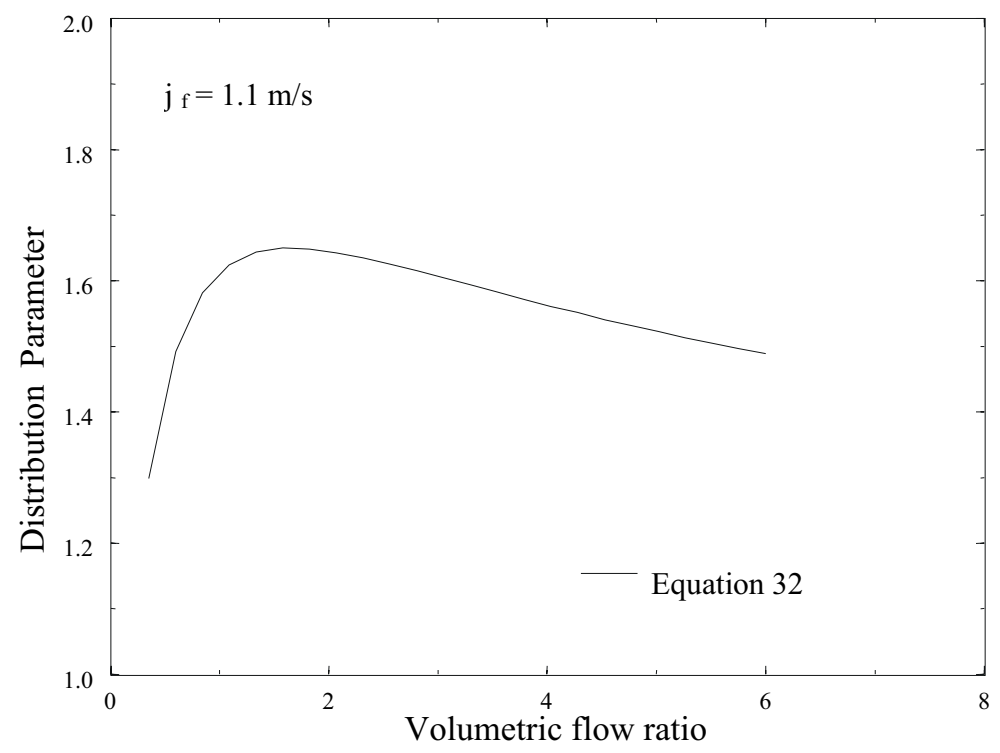

Figure 74. The distribution parameter as a function of volumetric flow ratio.

The calculation of $\mathrm{C}_{0}$ from Equation 32 is a departure from the current implementation of driftflux models in ATHENA. Currently, $\mathrm{C}_{0}$ depends only on fluid properties and, in some correlations, on mass flux. Because the gas flow generally does not significantly affect the mass flux, $\mathrm{C}_{0}$ is currently independent, or nearly independent, of the gas flow. However, the solution to Equation 32 depends directly on the gas superficial velocity, as well as the total superficial velocity.

A modified version of ATHENA was created that implemented the solution to Equation 32 using the El-Boher and Lesin and Kataoka-Ishii correlations. Figure $\mathbf{7 5}$ shows predictions from the modified code and the El-Boher and Lesin correlation for the range of liquid flows tested in the ETGAR-3 facility. The results from the modified code are in excellent agreement with the ElBoher and Lesin correlation. The figure shows that the correlation was implemented correctly into ATHENA. 


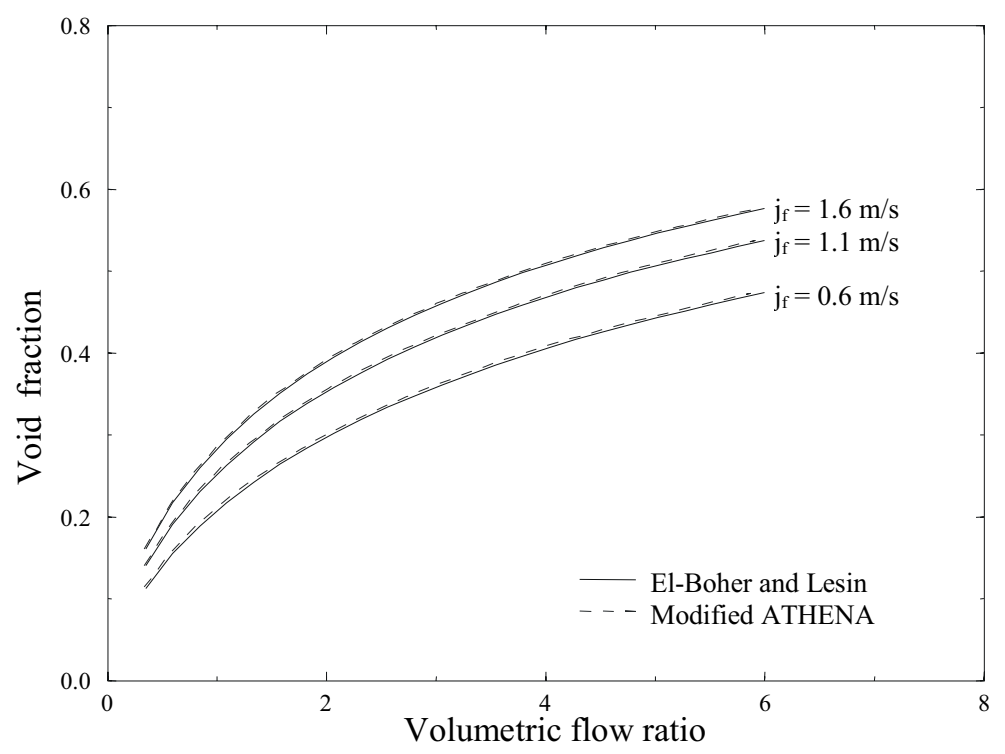

Figure 75. A comparison of the El-Boher and Lesin correlation with the modified ATHENA code.

The modified version of ATHENA applies the El-Boher and Lesin correlation only for systems containing lead-bismuth, and for control volumes in the bubbly and slug flow regimes in vertical up flow. The range of the El-Boher and Lesin correlation, which was given previously, limits the code's range of applicability for those calculations using the correlation. Of course, care should be taken when extrapolating any correlation outside of the range of its database. Particular care should be taken when extrapolating an empirical correlation, such as the El-Boher and Lesin correlation.

The failure of the drift-flux correlations presently available in ATHENA to accurately predict the void fraction data generated in the ETGAR-3 facility is not surprising since the correlations were primarily developed for two-phase mixtures of air and water or steam and water. Properties of the steam/lead-bismuth mixture are significantly different than those of air/water and steam/water. For example, the gas-to-liquid density ratio for the lead-bismuth/steam mixture in the ETGAR-3 facility is about 7 times smaller than for air/water at atmospheric pressure and about 300 times smaller than for steam/water at $7 \mathrm{MPa}$. The gas-to-liquid viscosity ratio for the lead-bismuth/steam mixture is about 4 times smaller than for air/water and about 40 times smaller than for steam/water. Thus, the steam/lead-bismuth fluid properties represent a substantial extrapolation from those for which the water-based correlations were developed.

The operating conditions for the actinide-burner reactor also require a substantial extrapolation from those tested in ETGAR-3. For example, Table 37 shows that the core outlet temperature in the actinide-burner reactor is $518^{\circ} \mathrm{C}$, which far exceeds the $170^{\circ} \mathrm{C}$ value tested in ETGAR-3. Furthermore, the injected gas will be helium rather than steam. Ultimately, experimental data will be required to demonstrate the applicability of the El-Boher and Lesin void correlation at typical actinide-burner reactor operating conditions. 


\section{Major Technical Accomplishments}

\subsection{NEUTRONIC CORE DESIGN}

\subsubsection{Concept Optimized for Actinide Burning}

An innovative core for actinide burning with streaming fuel assemblies that exhibits excellent reactivity performance upon coolant voiding, even for voids in the core center, has been proposed and evaluated. It has been shown that a refueling interval of $1.5 y e a r s$ can be achieved in a 2batch cycle and the feasibility of compensation of a large reactivity swing through a system of $\mathrm{B}_{4} \mathrm{C}$ control rods was also confirmed. The TRU destruction rate per MWt per full power year is $660 \mathrm{~kg} / \mathrm{FPY}$. This amount corresponds very closely with other studies of sodium-cooled fast reactor designs for actinide burning, but is slightly less than the actinide destruction rate claimed for ATW, provided that the availability factor of both systems is the same. Considering the availability data for current accelerators and the fact that the ATW needs for its function both a reactor and an accelerator and may thus have an appreciably smaller capacity factor than the proposed critical burner, the destruction rates per calendar year of both systems may be said to be comparable.

The effective delayed neutron fraction is about $25 \%$ less than that of typical oxide-fueled fast reactors or that of a conventional IFR core with metallic fuel, making the requirements on reactor control more demanding. The Doppler coefficient of the metallic fuel is negative $(-0.04 \phi / \mathrm{K})$, but significantly smaller than the Doppler effect of plutonium oxide-fueled, sodium-cooled reactors. On the other hand, the magnitude of $-0.04 \phi / \mathrm{K}$ is comparable to U-235-fueled metal fuel reactors, such as the Enrico Fermi Reactor or EBR-I and EBR-II. Because the design with streaming fuel assemblies exhibits a negative coolant void coefficient, even in scenarios with partial core voiding, and because of the negative fuel thermal expansion coefficient, which is also prompt and relatively large (about the same magnitude as the Doppler coefficient) the Doppler coefficient of $0.04 \varnothing / \mathrm{K}$ is deemed acceptable.

The large reactivity compensation by control rods brings a challenge of large reactivity changes due to control-rod drive-line expansion. This issue has been resolved by introducing the doubleentry control-rod drive system, which minimizes reactivity variation from drive-line dilatation. The top-entry control-rod drives are inserted into the core upon temperature increase while the bottom-entry rods expand out of the core, canceling out the reactivity reduction from the topentry control-rod drives. Another important benefit of double-entry control rods is significant flattening of axial power shape. As is customary for fast breeder reactors of United States design, the reactor needs to be equipped with two diverse shutdown systems.

It has been shown that the design was capable of incinerating about $2.6 \%$ ( $4.5 \%$ per pass) of the initial Tc-99 inventory per FPY, which is comparable with other studies on critical sodium-cooled burners, but less than the ATW Tc-99 incineration efficiency.

Qualitative first hand assessment of various accident sequences associated with reactivity changes indicate that the proposed core with streaming fuel assemblies is less prone to core compaction scenarios than traditional sodium-cooled, oxide-fueled fast breeder reactors. The streaming tubes 
prevent assembly-to-assembly damage propagation and slumping of adjacent fuel assemblies together. Should the damaged fuel assemblies get unlocked from their design position, they would not slump but float upward toward the gas plenum region where leakage is enhanced leading to a reactivity reduction. In case of hypothetical total core melting, the fuel, which is lighter than coolant would rise and spread into a layer above the coolant pool. MCNP calculations show that should a such state be achieved, it would be deeply sub-critical due to excessive leakage into the upper space.

Finally, a fuel cycle cost analysis has been performed and the fuel cost in the actinide-burner reactor was found to be considerably higher than the 6 mills $/ \mathrm{kW}$-hr characteristic of current LWR nuclear power plants.

\subsubsection{Concept Optimized for Economic Electricity Production}

The path of the design of an economic electricity production system has been pursued through long life cores and a once-through fuel cycle that does not require expensive fuel reprocessing. In addition, minimization of waste inventory and toxicity, and proliferation resistance figures of merit of the discharged fuel have been investigated for various fuel chemical forms and compositions of fertile and fissile materials. The results are qualitatively summarized in Table 38, where the longer bars stand for higher values and vice versa.

Table 38. Reactivity, waste and proliferation aspects of various fuel forms and fissile/fertile combinations

\begin{tabular}{|c|c|c|c|c|c|}
\hline Fuel form & $\begin{array}{l}\text { Conversion } \\
\text { ratio }\end{array}$ & TRU inventory & $\begin{array}{l}\text { Curie } \\
\text { inventory }\end{array}$ & $\begin{array}{l}\text { Ingestion } \\
\text { hazard }\end{array}$ & $\begin{array}{l}\text { Proliferation } \\
\text { threat }\end{array}$ \\
\hline \multicolumn{6}{|l|}{ Oxide } \\
\hline \multicolumn{6}{|l|}{ Nitride } \\
\hline \multicolumn{6}{|l|}{ Carbide } \\
\hline \multicolumn{6}{|l|}{ Metallic (Zr) } \\
\hline \multicolumn{6}{|l|}{ Fissile/Fertile } \\
\hline \multicolumn{6}{|l|}{ U-235/U-238 } \\
\hline \multicolumn{6}{|l|}{$\mathrm{Pu} / \mathrm{U}-238$} \\
\hline \multicolumn{6}{|l|}{ U-235/Th-232* } \\
\hline $\mathrm{Pu} / \mathrm{Th}-232$ & & & & & \\
\hline
\end{tabular}

${ }^{*}$ Th-232 mixed with U-238 to denature bred-in U-233

${ }^{* *}$ Pure Th-232

Fuels driven by U-235 with U-238 fertile material were found to exhibit high conversion ratios and reactivity gain and the smallest ingestion hazard, waste inventory, decay heat, and radioactivity of discharged fuel. On the other hand they pose the worst proliferation threat since 
the bred-in plutonium has a high $\mathrm{Pu}-239$ content. The fuels that have plutonium fissile material exhibit a significantly higher ingestion hazard and curie inventory. Fuels with Th-232 fertile material produce less plutonium, nevertheless, their fuel toxicity is slightly higher than that of the U-238 fuels due to the activity of polonium, radon, and radium from the thorium decay chain. In terms of discharged waste mass inventory, the long-life core generates three times less waste than a typical PWR at $33 \mathrm{GWd} / \mathrm{t}$ if a burnup limit of $100 \mathrm{MWd} / \mathrm{kg}$ is employed, but doubling the burnup to $200 \mathrm{MWd} / \mathrm{kgHM}$, which is still feasible with metallic fuels, further increases this benefit.

\subsubsection{Approaches for both actinide burning and low cost electrical production}

The choice of fuel for a lead or lead-bismuth cooled fast reactor depends on the objective of the reactor. If the goal were to burn the greatest amount of actinides possible, then a non-fertile metallic fuel would be the best choice. If the goal is to produce low cost electricity, and limit the amount of actinides discharged while making the plutonium "dirty", then a fertile fueled core using uranium or thorium, or both, would be the most appropriate choice. The apparent long fuel life and, therefore, high capacity factors achievable with fertile fueled cores make them the fuel choice for electricity production. However, it also appears that a compromise can be found with actinide burning, keeping in mind that other factors such as excess reactivity, reactivity feed back, and reactor controllability must be taken into consideration.

The reactivity of each fuel type varied, with the $20 \mathrm{wt} \% \mathrm{Pu}+\mathrm{MA}$ uranium fuels having the highest excess reactivity at beginning-of-life and the longest fuel cycles, and the remaining uranium and thorium fuels having the lowest beginning-of-life excess reactivities with the next longest fuel cycles. The $\mathrm{Pu}+\mathrm{MA}(13.1 \mathrm{wt} \%) \mathrm{UZr}, \mathrm{Pu}+\mathrm{MA}(15.3 \mathrm{wt} \%) \mathrm{UN}$, and thorium fuels also have the smallest reactivity swing of all the fuel types that were studied; varying from $9 \%$ to $<1 \% \Delta \mathrm{k} / \mathrm{k}$. For the thorium-based fuels, the small reactivity swing of the nitride fuel can be attributed to the softening of the spectrum, which results in a larger capture cross section for the thorium and, therefore, an increased production of U-233. The end result is a growth in the fissile inventory and prolonged reactivity with burnup. For the uranium fuels, the long life is due to the fertile uranium available for conversion to fissile plutonium. However, the use of uranium in the fuel will reduce the actinide burning potential by $>50 \%$.

Since reprocessing is not currently an option, a "hands off" proliferation-resistant once through fuel cycle was exclusively considered. This leads to the conclusion that if long fuel cycles are desirable while maintaining the capability to burn actinides, the thorium based fuels would be the best choice. They may have an actual shorter life than the uranium fuels (particularly for the metallic fuel), but have a small beginning-of-life excess reactivity, a small reactivity swing, and produce the least amount of actinides (including plutonium) of all the cases studied.

Taking into account the plutonium and minor actinides $(\mathrm{Pu}+\mathrm{MA})$ in a once through cycle, the consumption rates were 5 to $110 \mathrm{~kg} / \mathrm{FPY}$ for the uranium cases, with the exception of the $\mathrm{Pu}+\mathrm{MA}(15.3 \mathrm{wt} \%) \mathrm{UN}$ case that generated $10 \mathrm{~kg} / \mathrm{FPY}$. However, the thorium cases consumed 230 to $239 \mathrm{~kg} / \mathrm{FPY}$.

The plutonium content of the fuel is depleted in all but two of the cases, where the plutonium content of the lower enriched uranium cases increases by $5 \%$ to $9 \%$. The plutonium isotopics of the thorium fuels are superior by way of proliferation resistance compared to the other fuel forms (based on the higher Pu-238, 240 and 242 fractions and a much lower Pu-239 fraction). The 
higher isotopic fraction of Pu-238, 240 and 242 in the fertile thorium fuels would make them undesirable as a source for weapons material due to the high decay heat rate and spontaneous neutron production.

Based on the calculations done, thorium based fuels:

- have a small beginning-of-life excess reactivity;

- have a long lifetime with a small reactivity swing;

- discharge less actinides than the uranium based fuels due to the smaller generation rate;

- are able to burn $35-38 \%$ of the initially loaded plutonium, and twice the amount of minor actinides than the uranium fuel; and

- have high isotopic fractions of Pu-238, 240 and 242 in the plutonium, making it unattractive as a source for weapons material.

Thus, for proliferation concerns, actinide consumption, and long fuel cycles (high capacity factors), the thorium-based fuels show the most promise in this type of reactor. However, although these fuels provide a plutonium vector with the highest proliferation resistance, proliferation aspects of bred-in U-233 need to be considered as well. This will require denaturing the U-233 with U-238 resulting in a higher plutonium production rate than in the case with pure Th-232 as the fertile isotope. Future calculations will be performed to identify the optimum composition of Th-232/U-238 mixture.

\subsection{MATERIALS COMBATIBILITY STUDIES}

During this reporting period the following significant accomplishments have been achieved:

1) The rotating electrode testing system has been designed and constructed at MIT.

2) Oxygen probes have been designed and constructed at both MIT and INEEL. Initial testing has been accomplished. Further work is necessary to identify the source of the DC offset in the output at MIT. However, the temperature dependence of the potential on measured oxygen concentration is correct.

3) The dynamic corrosion cell at the INEEL is operational and conducting experiments as listed in the testing matrix. Over 124 hours of molten lead experiments have been performed to date (Loewen et al. 2000).

4) Initial scanning electron microscope results from the INEEL runs show that Zircaloy and 410 stainless steel are fairly resistant to lead corrosion.

\subsection{COOLANT ACTIVATION}

The radiological hazard raised by the activation of the lead-bismuth coolant was evaluated with particular emphasis on a direct contact heat transfer reactor. In this system, the lack of a physical barrier between the primary and secondary coolant favors the release of the alpha-emitter Po- 210 (a product of neutron activation of bismuth) and its transport throughout the plant. Modeling undertaken on the basis of the scarce information available in the literature confirmed the importance of this issue, as well as the need for experimental work to reduce the uncertainties on the basic characteristics of volatile polonium chemical forms. Experiments are currently being conducted at MIT to validate the theoretical analysis. 


\subsection{PLANT ENGINEERING}

\subsubsection{Direct Power Conversion Cycle}

\subsubsection{Direct Contact Heat Transfer}

The essential characteristics of the direct contact phenomena occurring in a lead-bismuth/water mixture at high pressure and temperature, were modeled with the goal of predicting the thermalhydraulics of the lead-bismuth/water direct-contact reactor chimney. The flow map of the leadbismuth/water direct-contact reactor chimney two-phase flow was generated. Several void fraction correlations were analyzed in the quest for a suitable predictive tool. A methodology was developed to test the acceptability of a void fraction correlation when it is to be used beyond its database.

The most relevant parameter of direct contact heat transfer is the volumetric heat transfer coefficient, which can be calculated from the knowledge of the local surface-based heat transfer coefficient and the interfacial area concentration. Expressions for the local heat transfer coefficient and the interfacial area concentration were also derived on the basis of simple thermal and geometric considerations. Moreover, all the models were integrated in a computational algorithm that enables assessing the evolution of the temperature and void fraction profiles along the channel. Finally, it was demonstrated that the models reproduce all the theoretically expected and experimentally observed trends.

\subsubsection{Aerosol Transport in the Direct Cycle Reactor}

The issue of lead-bismuth carry-over in the direct contact heat transfer reactor was investigated. The rate of entrainment at the free surface of the reactor pool was calculated and found to be significantly smaller than in a water system due to the larger density difference between the phases in the lead-bismuth/water direct contact reactor. An efficient steam dryer was selected that reduces the amount of lead-bismuth entrainment by three orders of magnitude. The transport of lead-bismuth aerosols through the steam lines was also evaluated and it was found that the lead-bismuth droplets fly relatively undisturbed to the turbine. Liquid lead-bismuth can cause liquid metal embrittlement of the stressed components of the turbine, particularly of the stainless steel moving blades. It seems possible to prevent liquid metal embrittlement by selecting alternative blade materials that are not susceptible to liquid metal embrittlement. Also, blade coating with detonation gun cermet coats may be a viable option, although the liquid metal embrittlement immunity of the coating materials itself needs to be verified. Finally, it is thought that the accumulation of lead-bismuth in the turbine can be prevented by means of steam turbine traditional wetness drainage technology.

\subsubsection{Indirect Steam Power Conversion Cycle-Steady State Power Determination}

\subsubsection{Primary Coolant Natural Circulation}

Design parameters for the actinide-burner reactor using natural circulation to drive the primary coolant and an indirect steam power conversion cycle have been established. The actinide-burner core described in Section 4.1.1 was the starting point for the design. Design parameters for the remainder of the primary coolant system and the secondary coolant system were then established. 
Sensitivity calculations were performed to optimize a variety of design parameters. The parameter used to optimize the design was the cladding temperature during full-power, steady operation. A reference design was selected based on the results of the sensitivity calculations and further considerations. Parameters for the reference design are as follows. The core chimney height is $10 \mathrm{~m}$. The steam generator is a counter-flow, once-through, tube-in-shell heat exchanger with lead-bismuth inside the tubes and water outside. The steam generator tubes are arranged in a triangular lattice. The steam generator operates at $7.0 \mathrm{MPa}$ and produces $30^{\circ} \mathrm{C}$ of steam superheat with a feed-water temperature of $200^{\circ} \mathrm{C}$.

A core power limit was derived for the reference design such that the maximum cladding temperature during steady, full-power operation was less than or equal to the design limit of $650^{\circ} \mathrm{C}$. Assuming a uniform power distribution in the core, the limiting core power is $1300 \mathrm{MW}$ for the reference design.

\subsubsection{Primary Coolant Forced Circulation}

The numerical tool to perform the analysis of the plant configuration using forced circulation of the primary coolant has been completed, but the analysis has not been initiated. The analysis of this configuration will be performed next year.

\subsubsection{Plant Capital Cost Estimation Model}

The capital cost estimation model developed by ORNL was adapted for this economic study. The ALMR cost data were used as the reference for the primary coolant and steam secondary systems of the actnide-burner reactor.

\subsubsection{Capital Cost and Sensitivity Analysis}

The capital cost (mills/kW-hr) has been estimated for the actinide-burner reactor with leadbismuth natural circulation in the primary coolant system and a steam secondary system with the optimal design parameters described in Section 4.4.2. The final cost value is in the range of 4045 mills/kW-hr in constant 1999 dollars using the ORNL capital cost estimation model. This estimate needs to be refined by further work comparing the actinide-burner reactor cost estimate with published liquid metal system cost estimates (ALMR and S-PRISM).

A sensitivity analysis of the actinide-burner reactor capital cost to key parameter variations has been performed with the optimal design parameters. The degree of superheat, secondary-system pressure, and height of chimney were examined in this sensitivity analysis since the requisite data are available. A cost sensitivity analysis has not been performed on the other parameters due to lack of available cost data.

The capital cost does not vary significantly with superheat, which is consistent with the variation in electrical power output with superheat. The capital cost increases with secondary system pressure, which is consistent with the effect of pressure on electrical power. And, the capital cost decreases with increased chimney height, also consistent with the increase of electrical power with chimney height. 


\subsubsection{Indirect Power Conversion Cycle - Transient State Power Determination}

An evaluation was performed for the actinide-burner reactor during a loss-of-feed-water transient using the ATHENA computer code. The evaluation was performed for a design using an indirect power cycle with water as the secondary coolant and with natural circulation flow in the primary coolant system. A passive, air-cooled decay-heat removal system was designed for the actinideburner reactor based on the PRISM RVACS.

The ATHENA model represented the primary coolant system, the secondary coolant system, and the RVACS. The ATHENA model was benchmarked against PRISM calculations performed by General Electric (1986) to check the performance of the RVACS. Two benchmark comparisons were performed, one representing RVACS operation during emergency conditions and the other representing normal, full-power operation. Both benchmark comparisons were satisfactory.

The operation of the RVACS during a loss-of-feed-water transient was evaluated using a series of steady and transient calculations. The evaluation determined the limiting initial core power so that the peak cladding temperature would remain below $750^{\circ} \mathrm{C}$ during the transient. The evaluation showed that the limiting initial core power was $660 \mathrm{MW}$ using the reference RVACS design, which is considerably more restrictive than the steady-state limit of $1300 \mathrm{MW}$ described previously. The evaluation also showed that the transient was nearly quasi-steady. Thus, the RVACS performance during a loss-of-feed-water transient can be modeled reasonably well using either steady or transient methods.

Design modifications to the RVACS were evaluated in an attempt to increase the limiting core power. One evaluation showed that the limiting core power was nearly a linear function of reactor vessel length and could be increased by $11 \%$ by increasing the length of the vessel to the transportation limit of $18.9 \mathrm{~m}$ established for PRISM (Spencer et al. 2000). Another evaluation showed that the limiting core power could be increased to $955 \mathrm{MW}$ by narrowing the gap between the reactor and containment vessels, filling it with lead-bismuth, and adding fins to the outside surface of the containment vessel. Based on a combination of all the design changes, the maximum power limit for an air-cooled RVACS is about $1060 \mathrm{MW}$.

\subsubsection{Gas Lift Pump Evaluation for Direct and Indirect Cycle Designs}

A gas lift pump is being considered in both the direct and indirect cycle designs. The use of a gas lift pump will result in a two-phase, co-current vertical up flow in the chimney above the core. Consequently, the capability of the ATHENA code to predict the void fraction of a mixture of lead-bismuth and gas for vertical up flow was assessed using the El-Boher et al. (1988) void correlation. The El-Boher and Lesin void correlation was developed from lead-bismuth/steam data taken in the ETGAR-3 facility.

The void fractions predicted by the ATHENA code were in reasonable agreement with the ElBoher and Lesin correlation. However, the calculated void fractions exceeded the values predicted by the correlation by up to $30 \%$. Consequently, the El-Boher and Lesin correlation was implemented into a modified version of the code using a slight modification to the code's existing drift-flux formulation. The void predictions of the modified code were in excellent agreement with the El-Boher and Lesin correlation. Thus, the modified version of the code can be used to simulate situations in which the El-Boher and Lesin correlation is applicable. 


\section{Major Remaining Technical Challenges And Future Work}

\subsection{NeUtronic CORE DESIGN}

\subsubsection{Concept Optimized for Actinide Burning}

The feasibility of the actinide (minor actinides + plutonium) burner has been confirmed. Another attractive mission to explore is to return plutonium separated from LWR spent fuel back to LWRs as mixed oxide fuel (MOX) for burning, and then use special machines for burning the minor actinides and the residual MOX plutonium. Since the number of recycles of separated plutonium from MOX spent PWR fuel is limited by deteriorating safety characteristics, plutonium that cannot be recycled back to PWRs can be mixed with the minor actinides to provide fuel for a minor actinide burner. This mission of symbiotic PWR plutonium burners and minor actinide burners would require about a factor of 10 less capacity than a mission to burn plutonium and minor actinides in the same burner. Therefore, it may make sense to develop independent machines for the missions of:

1) minor actinide residual MOX burning, and

2) low cost electricity.

Our first unit cell results on minor actinide burning show that it is neutronically feasible to design a fertile-free, long-life core for preferable incineration of minor actinides with a small reactivity swing. Future work on this design will include the following activities:

- evaluate burnup performance of the fuel with minor actinides only;

- identify the optimum mixture of minor actinides and plutonium from spent MOX fuel to attain a small reactivity swing and long batch cycle;

- quantify important safety indices, in particular coolant void coefficient, Doppler coefficient, delayed neutron fraction; and,

- evaluate the potential of the resulting conceptual design to achieve the above missions.

\subsubsection{Concept Optimized for Economic Electricity Production}

The key challenge for the lead-bismuth-cooled long-life core appears to be the attainment of a discharged fuel composition that would be at least as proliferation resistant as current LWR spent fuel. In particular, metallic fuels with U-235 fissile yield a clean plutonium vector due to high $\sigma_{c}^{28} / \sigma_{a}^{29}$ (an order of magnitude higher than in PWR cores) and 3 times smaller $\sigma_{c}^{29} / \sigma_{a}^{29}$ than in a PWR. Thus, the hard-spectrum, high conversion, core produces $\mathrm{Pu}-239$ more effectively and transmutes it to higher plutonium isotopes at a smaller rate than PWRs. All fuels with U-235/U238 mixtures exhibit similar behavior. Replacing U-238 with Th-232 only shifts the problem to production of weapons-usable U-233.

Future efforts will be directed to overcoming this issue. The following strategies will be explored: 
- Increase burnup. The burnup limit of $100 \mathrm{MWd} / \mathrm{kg}$ used in the current study is a proven limit, which is conservative. The experimental data for metallic fuels show that much higher burnups can be achieved. Maximum burnups of $200 \mathrm{MWd} / \mathrm{kg}$ have already been confirmed by tests and even higher burnups may be feasible. Higher burnup leads to an increase of the content of Pu-240 and higher isotopes making the fuel more proliferation resistant. High burnups are also favorable for economics since they allow the increase of core power density.

- Spectrum softening. Increasing pitch to diameter ratio and introducing zirconium hydride or yttrium hydride rods, or adding moderating materials at the end of core life will be explored to soften the spectrum and enhance $\mathrm{Pu}-239$ transmutation into higher plutonium isotopes.

- Full core burnup of fuel with higher enrichment. The results obtained from the infinite unit cell model in this scoping study over-predict the proliferation threat because they are based on a slightly harder spectrum than in a real core and very low enrichment is required in the absence of leakage. In the full core model, the enrichment must be increased reducing the conversion ratio and leading to less plutonium production.

The second key challenge for the long-life cores is the attainment of a small reactivity swing (less than B) while keeping the coolant void worth negative. Although the streaming fuel assembly proposed for the actinide-burner design can also enhance the negative coolant-density coefficient trend for fertile fuels, the increased leakage of neutrons must be compensated with higher enrichment, penalizing conversion ratio and economics. UPuZr fuels provide more option space to optimize the core to attain both long life and negative coolant void worth at the same time. Future efforts will explore if both objectives can be attained concurrently. Finally, an economic analysis of the once-through U-235 fueled core will be performed to permit comparison to plutonium-driven cores employing recycle. In this regard all work on this type core design will be for a once-through fuel cycle.

\subsubsection{Design Approaches for both Actinide Burning and Low Cost Electrical Production}

The future work that is proposed for the combined actinide burning and low electrical production cost concept includes:

- the investigation of alternative fuel forms (oxide, carbide, etc.). that are similar to those studied in the optimized breed and burn concept;

- optimization of the fuel form;

- verification of the efficacy of using the current streaming assemblies to minimize the void coefficient; and

- performing an economic assessment of using this particular reactor (including an assessment of a multi-recycling fuel cycle).

In order to accomplish these tasks, it will be necessary to quantify the operating indices for the optimum fuel and core design. This includes quantifying the reactivity coefficients (void, Doppler, etc.) and the delayed neutron fraction from the beginning to end-of-life. It also involves quantifying the waste indices (e.g., discharge composition and radiotoxicity), and proliferation resistant indices (e.g., actinide composition). The challenges associated with these tasks are similar to those mentioned previously, i.e., maximizing the destruction of actinides while maintaining a low $\Delta \mathrm{k}$ from beginning to end-of-life will be difficult for the currently proposed thorium based fuel due to the amount of uranium needed to denature the U-233 that is produced. 


\subsection{MATERIALS COMPATIBILITY STUDIES}

\subsubsection{Corrosion Testing Activities}

Both teams are poised to rapidly complete the testing matrix presented in Tables 20 and 21 in Section 4.2.4. In the absence of unforeseen difficulties, no major technical challenges remain for full operation of both experimental facilities.

Both MIT and INEEL have started with 316 stainless steel in an effort to obtain overlap correlation data. This will allow us to compare results early in the program to make any adjustments before longer runs are completed. Also this will allow both participants to validate their testing protocol.

\subsubsection{Oxygen Potential Probe Construction}

The major technical challenge remaining for the development of the MIT oxygen probe is to resolve the origin of the DC offset in the potential vs. oxygen concentration. We are in contact with other laboratories (Los Alamos National Laboratory, LASL) at which similar development efforts are under way to see what experience they have had. MIT plans to visit LASL in the middle of July for this purpose.

Oxygen probes have been used extensively for measuring oxygen activities in gaseous environments. The performance in molten lead-bismuth needs to be verified. One question to be addressed is the chemical resistance of the probe to bismuth in the molten alloy. The response time for the probe to establish equilibrium oxygen vacancy concentrations at temperatures to be used for the lead-bismuth experiments also needs to be checked. We will do this by using a reference gas of known oxygen composition. The performance of the probe will initially be established. The probe will then be exposed to molten bismuth or molten lead-bismuth. The performance of the oxygen probe will then be rechecked against the reference gas. Once these probes are fully operational they will be used both experimental facilities.

\subsection{COOLANT ACTIVATION}

The experimental data collected at the MIT polonium facility will be utilized to estimate the release of polonium under accident conditions for indirect cycle plants and to improve the assessment of polonium transport under normal operating conditions for the direct cycle reactor. Also, means to reduce release of the polonium species will be explored that include rare earth addition to the lead-bismuth melt and online polonium extraction.

\subsection{PLANT ENGINEERING}

\subsubsection{Direct Power Conversion Cycle}

An economic analysis of the lead-bismuth/water direct-contact heat transfer reactor will be undertaken. The objective of the economic analysis will be to assess the tradeoff between its relatively simple primary system (i.e. elimination of the steam generators and pumps) and the additional systems required to control the polonium and lead-bismuth aerosol transport out of the 
reactor pool. This analysis will ultimately establish whether the direct cycle reactor concept is an attractive option worth further investigation in the future.

\subsubsection{Indirect Steam Power Conversion Cycle - Steady State Power Determination}

\subsubsection{Natural Circulation Primary Coolant}

An economic analysis approach to determine the cost of electricity production in the actinideburner reactor was developed during the past year. Preliminary cost estimates were made for an optimized actinide-burner reactor that utilized natural circulation of the primary coolant and an indirect steam power conversion cycle. The economic approach will be formulated into a model that will be applied to make final cost estimates for this design option based on comparison to the recent S-PRISM design during the next year of the project.

The thermal-hydraulic design of an actinide-burner reactor that utilizes natural circulation of the primary coolant and a helium power conversion system will be evaluated during the remainder of this fiscal year. If the results of this evaluation are positive, the design will be optimized during the next fiscal year. Steady-state power limits and cost estimates will also be determined for the optimized design. If the results of this evaluation are negative, and preliminary indications are that they may be, future activities will concentrate on the steam power conversion cycle.

\subsubsection{Forced Circulation Primary Coolant}

An optimized design that utilizes forced circulation of the primary coolant and a steam power conversion cycle will be developed during the next year of the project. Both mechanical and gas lift pumps will be considered. Steady-state power limits will be identified for each design option. Cost estimates will also be made. A design using a helium power conversion cycle will also be considered based on the results of the evaluation described in Section 6.4.2.1.

\subsubsection{Plant Capital Cost Estimation Model}

The economic parameters regarding finance, plant construction time, and cash flows during construction for the actinide-burner reactor capital cost estimation are adapted from the ORNL model in this work. These parameters will be reassessed to incorporate current relevant conditions as well as comparison with the values assumed for the recent S-PRISM cost estimate. Further the cost of engineering features in the S-PRISM will be compared to those of the ALMR, which were the basis for our actinide-burner reactor cost estimate. These steps will enable the final cost value of electricity (mills/kWh) to be estimated more reliably.

\subsubsection{Capital Cost and Sensitivity Analysis}

The cost estimation in this report includes only the capital cost of the actnide burner reactor. However the assessment of electricity cost should include the plant capital, operation and maintenance costs and the fuel cycle costs as well. Therefore, these will be addressed in future work. The cost sensitivity analysis will be performed on other design parameters except for the reported in this report. 


\subsubsection{Indirect Power Conversion Cycle - Transient State Power Determination}

Power limits for a loss-of-feed-water transient were determined for an actinide-burner reactor that utilized natural circulation of the primary coolant and an indirect steam power conversion cycle during the last year. Power limits will be determined next year for an actinide-burner reactor using forced circulation and a steam power conversion system. Transient power limits may also be generated for a helium power conversion system depending on the results of the evaluation described in Section 6.4.2.1.

Other transients will be analyzed next year using the ATHENA code to determine the effect of various design options on safety margins. Analysis of transients such as overcooling, loss-ofcoolant, and heat exchanger tube rupture will demonstrate safety margins during accidents. Plant startup and load change transients will also be analyzed to demonstrate the operability of the plant.

A sub-channel analysis of the core will be performed to evaluate the detailed thermal-hydraulic response of the core during steady, transient, and accident conditions to ensure that designated temperature limits are not violated. The results of the sub-channel and ATHENA codes will be compared to determine differences in temperatures between the hot sub-channel and the hot fuel element.

\subsubsection{Gas Lift Pump Evaluation for Direct and Indirect Cycle Designs}

The theoretical investigation of the thermal-hydraulics of heavy liquid metal/gas mixtures will be continued. The purpose of this task is to evaluate the feasibility of a design that utilizes gas lift pumps to enhance the flow rate and to predict the response of the reactor to ruptures of heat exchanger tubes. A plan for an experimental investigation of the thermal-hydraulics of heavy liquid metal/gas mixtures will be developed.

The capability of the ATHENA code to predict the void fraction of lead-bismuth/steam mixtures based on the El-Boher and Lesin correlation that was developed during the past year will be applied in the evaluation of designs using gas lift pumps. 


\section{REFERENCES}

ABB Atom AB, 1988. "Influence of Forward-Pumped Heater Drains and Magnetic Filtration on Water Chemistry and Radiation Buildup in BWRs," EPRI NP-5864, pp. 3-26, 3-27, Electric Power Research Institute, June.

Abdelrahman, M. S. and N, M. Abdurrahman, 1998. UTXS: The University of Texas Neutron Cross Section Library: Generation and Validation," ANS Transactions, Vol. 79, November.

Adamov, E., V. Orlov, A. Filin, V. Leonov, A. Sila-Novitski, V. Smirnov, and V. Tsikunov, 1997. "The Next Generation of Fast Reactors," Nuclear Engineering and Design, Vol. 173, pp. 143-150.

Alden, T. H., 1957. "The Solubility of Nickel and Chromium in Liquid Lead," M.S. Thesis MIT.

Amodeo, R. J. and N. M.Ghoniem, 1985. "Development of Design Equations for Ferritic Alloys in Fusion Reactors," Nuclear Engineering and Design/Fusion, Vol. 2, 97-110.

Asher, R. C., D. Davies and S. A. Beetham, 1977. "Some Observations on the Compatibility of Structural Materials with Molten Lead," Corrosion Science, 1, pp. 545-557.

Azzoppardi, B. J. and G. F. Hewitt, 1997. "Maximum Drop Sizes in Gas-Liquid Flows," Multiphase Science and Technology, Vol. 9, pp. 109-204.

Bailey, H. S., 1977. "Nuclear Performance of LMFBRs Designed to Preclude Energetic HCDAs," Trans. ANS, Vol. 26, June.

Bania, P. J., 1988. “Advanced Alloy For Elevated Temperatures," Journal of Metals, Vol. 40, No. 3, pp. 20-22, March.

Blair, C. K., R. F. Boehm, and H. R. Jacobs, 1976. "Heat Transfer Characteristics of a Direct Contact Volume Type Boiler," ASME paper 76-HT-23.

Boardman, C. E., et al., 2000. "A Description of the S-PRISM Plant," Proceeding of ICONE 8, Baltimore, MD, USA, April.

Brady, G. S. and H. R. Clauser, 1991. Materials Handbook, p. 183, $13^{\text {th }}$ Edition, McGraw-Hill, Inc.

Branover, H., 1992. "Liquid Metal MHD Research and Development in Israel," Proceedings of the 1992 Symposium on Engineering Applications of MHD, Baltimore, June-July.

Branover, H., 1989. "Promising Applications of the Liquid Metal MHD Energy Conversion Technology," Proc. $24^{\text {th }}$ Intersociety Energy Conversion Engineering Conf. (IECEC-89, Cat. No. 89CH2781-3), Vol. 2, pp. 1051-1058, August. 
Briesmeister, J. F., Ed., 1986. "MCNP - A General Monte Carlo Code for Neutron, Photon and Electron Transport, Version 3A/3B/4A/4B," Los Alamos National Laboratory Rep. LA-7396-M, Revised in 1988, 1991 and 1997.

Buongiorno, J., N. E. Todreas, and M. Kazimi, 1999a. "Thermal Design of Lead-Bismuth Cooled Reactor for Actinide Burning and Power Production,” MIT-ANP-TR-066, July.

Buongiorno, J., et al., 1999b. "Design of an Actinide Burning, Lead-Bismuth Cooled Reactor that Produces Low Cost Electricity," INEEL/EXT-99-00693, MIT-ANP-TR-065, July.

Buongiorno, J., N. Todreas, and M. Kazimi, 2000. "Void Fraction Prediction for the Pb-Bi/Water Direct Contact Nuclear Reactor," ICONE-8739, Proceedings of ICONE-8, $8^{\text {th }}$ International Conference on Nuclear Engineering, April 2-6, Baltimore, MD, USA.

Burgel, R., 1986. "Coating Service Experience with Industrial Gas Turbines," Materials Science and Technology, Vol. 2, No. 3, pp. 302-308, March.

Carlson, K. E., et al., 1986, ATHENA Code Manual Vol. I: Code Structure, System Models, and Solution Methods, EGG-RTH-7397, September.

Carson, W. R. and H. K. Williams, 1980. "Method Of Reducing Carry-Over and Reducing Pressure Drop Through Steam Separators,” EPRI NP-1607, pp. c-1,c-2, November.

Cerezo, L. M. and A. L. Yarden, 1998. "MSR Upgrade Adds Megawatts at Cofrentes," Nuclear Engineering International, Vol. 43, No. 530, pp. 38-40, September.

Chexal, B., G. Lellouche, J. Herowitz, and J. Healzer, 1992. “A Void Fraction Correlation For Generalized Applications,” Progress in Nuclear Energy, Vol. 27, No. 4, pp. 255-295.

Chexal, B., J. Herowitz, and G. Lellouche, 1991. “An Assessment of Eight Void Fraction Models,” Nuclear Engineering and Design, Vol. 126, pp. 71-88.

Corradini, M. and J. C. Casas, 1992. "Study Of Void Fraction And Mixing Of Immiscible Liquids in a Pool Configuration by an Upward Gas Flow," Nuclear Technology, Vol. 99. pp. 104119, July.

Croff, A. G., 1980. “A User's Manual for the ORIGEN2 Computer Code,” Oak Ridge National Laboratory Rep., ORNL/TM-7175.

De Schutter, F., J. A. Dekeyser, J. Luyten and H. Tas, 1991. "Electrochemical Sensors for Oxygen and Lithium Detection in Pb-17Li" Fusion Engineering and Design, 14, 241-248.

Delene, J. G. and C. R. Hudson II, 1993. "Cost Estimate Guidelines for Advanced Nuclear Power Technologies,” ORNL/TM-10071/R3, May.

Diaz-Tous, I. A., A. H. Khan, and T. H. McCloskey, 1994. "Solid Particle Erosion Technology Assessment," pp. 247-254, PWR-Vol. 26, Advances in Steam Turbine Technology for the Power Generation Industry, ASME. 
Dix, G. E., 1971. "Vapor Void Fractions For Forced Convection With Subcooled Boiling At Low Flow Rates," NEDO-10491, November.

El-Boher, A., S. Lesin, Y. Unger, and H. Branover, 1988. "Experimental Studies Of LiquidMetal Two-Phase Flows In Vertical Pipes," Proceedings of the $1^{\text {st }}$ World Conference on Experimental Heat Transfer, Fluid Mechanics and Thermodynamics, Dubrovnik (Yugoslavia), September.

EPA, 1988. "Limiting Values of Radionuclide Intake and Air Concentration and Dose Conversion Factors for Inhalation, Submersion And Ingestion," Federal Guidance Report No. 11. EPA 520/1-88-020, September.

Eriksson, M. and C. Piaszczyk, 1998. "Reliability Assessment of the LANSCE Accelerator System," NEA/OECD Workshop on Utilization and Reliability of High Power Accelerators in Mito, Japan, 13-15 Oct.

Feuerstein, H., J. Oschinski, and S. Horn, 1992. "Behavior of Po-210 in Molten Pb-17Li," Journal of Nuclear Materials 191-194, 288-291.

Forsberg, C. W., C. M. Hopper, and H. C. Vantine, 1999. "What is Non-weapons-Usable ${ }^{233}$ U?," ANS Transactions, Vol. 81, November.

Fu, X. Y., S. Kim, X. Wang, and M. Ishii, 1999. "Application of Four-Sensor Method for Slug and Churn-Turbulent Two-Phase Flow,” Trans. Am. Nuc. Soc. Vol. 81, p. 349. November.

Fu, X. Y., Y. Mi, and M. Ishii, 2000. "Interfacial Area Measurement in a Bubbly-Slug Transition Air-Water Flow," ICONE-8327, Proceedings of ICONE-8, Baltimore, MD, USA, April 2-6.

Fuchs, N. A., 1964. The Mechanics of Aerosols, pp. 80-83, 258-259, 288-290, Pergamon Press.

Furuya, M., I. Kinoshita, and Y. Nishi, 1996. "Vapor Explosions in the System of Water Droplet Impinging onto Melt Surface," Heat Transfer - Houston 1996, AICHE Symposium Series, Vol. 92, N. 310. pp. 310-316.

General Electric 1996. "Nuclides and Isotopes, Chart of Nuclides," Fifteenth Edition, GE Nuclear Energy, Lockheed Martin.

General Electric 1999. “The ABWR. Plant General Description,” GE Nuclear Energy, April.

General Electric 1986. Preliminary Safety Information Document, GEFR-00793, UC-87Ta, November.

Golfier, H., J. Bergeron, and R. Lenain, 1999. "Parametrical Analysis of ${ }^{99}$ Tc and ${ }^{129} \mathrm{I}$ Transmutations in Reactor," Proceedings of International Conference on Future Nuclear Systems, Global '99, Jackson Hole, WY, August.

Govan, A. H., G. F. Hewitt, D. G. Owen, and T. R. Bott, 1988. "An improved CHF modelling code," $2^{\text {nd }}$ UK National Conference on Heat Transfer, 1, 33-48, Institute of Mechanical Engineers, London, September. 
Grachev, N. S., P. L. Kirillov, and P. N. Martynov, 1999. "Steam Generators with Direct Contact Between Liquid Metal and Water," Proceedings of the $9^{\text {th }}$ International Topical Meeting on Nuclear Reactor Thermal Hydraulics (NURETH-9), San Francisco, October 3-8.

Greenspan, E., K. Aoki, E. Elias, W. E. Kastenberg, N. Stone, and N. W. Brown, 1998. "Compact Long Fuel-life Reactors for Developing Countries," Proceedings of the Ninth International Conference on Emerging Nuclear Energy Systems (ICENES'98), pp. 74-83, Herzliya, Israel, June.

Griffith, P., 1997. “Steam-Water Separation,” Multiphase Science and Technology, Vol. 9, pp. $381-437$.

Gromov, B. F., E. Yefimov, M. P. Leonchuk, A. A. Veremeev, V. V. Chekunov, Y. I. Orlov, D. Pankratov, V. S. Stepanov, and V. T. Gorshov, 1996. "Liquid-Metal Lead-Bismuth Target for High-Energy Protons as an Intense Source of Neutrons in Accelerator-Controlled Systems," Atomic Energy, Vol. 80, No. 5, pp. 378-384.

Gromov, B. F., V. M. Dekusar, E. Yefimov, A. G. Kalashnikov, M. P. Leonchuk, D. Pankratov, Y. G. Pashkin, V. N. Stepanov, V. V. Chekunov, V. S. Stepanov, M. L. Kulikov, and S. K. Leguenko, 1994. "Lead-Bismuth as a Perspective Coolant for Advanced Reactors and Accelerator-Based Plants," Proceedings of the International Topical Meeting on Advanced Reactors Safety. Pittsburgh, PA, USA, April.

Gromov, B. F., Y. S. Belomitcev, E. I. Yefimov, M. P. Leonchuk, P. N. Martinov, Y. I. Orlov, D. V. Pankratov, Y. G. Pashkin, G. I. Toshinsky, V. V. Chekunov, B. A. Shmatko, and V. S. Stepanov, 1997. "Use Of Lead-Bismuth Coolant in Nuclear Reactors and AcceleratorDriven Systems,” Nuclear Engineering and Design, 173, pp. 207-217.

Handwerk, C. S., M. J. Driscoll, N. E. Todreas, M. V. McMahon, 1998. "Economic Analysis of Extended Operating Cycles in Existing LWRs," MIT-NFC-TR-007, January

Hayes, J. K., S. A. Trovato, S. Misilo, and J. Burger, 1991. “An Investigation and Assessment of Methods to Improve Moisture Removal and Reheating of PWR Cycle Steam," Design, Repair and Refurbishment of Steam Turbines, PWR-Vol. 13, pp. 115-126, ASME.

Hejzlar, P., M. J. Driscoll and M. S. Kazimi, 2000. "Conceptual reactor Physics Design of a Lead-Bismuth-Cooled Critical Actinide Burner," Topical Report MIT-ANP-TR-069, Massachusetts Institute of Technology, Dept. of Nuclear Eng., January.

Hejzlar, P., M. J. Driscoll, and M. S. Kazimi, 1999a. "Void Reactivity Performance in LeadBismuth-Cooled Reactors for Actinide Transmutation," Topical Report MIT-ANP-TR-068, Massachusetts Institute of Technology, Dept. of Nuclear Eng., June.

Hejzlar, P., M. Driscoll, and M. Kazimi, 1999b. "Neutronic Design for a Pb-Bi-Cooled Actinide Burner Fast Reactor," Transactions of the American Nuclear Society, Vol. 81, pp. 271-273.

Henry, R. E. and L. M. McUmber, 1997. "Vapor explosion potential under LWR hypothetical accident conditions," Proc. Light Water React. Saf. Meet., CONF-770708, p. 414-425, Sun Valley, Idaho. 
Henry, R. E., 1978. "Test Plan: Large Scale Molten Salt-Water Vapor Explosion Studies to be Conducted at Ispra, Italy,” NUREG/CR-0728, ANL-79-20. Argonne National Laboratory.

Henry, R. E., J. D. Gabor, I. O. Winsch, D. J. Quinn, E. G. Erickson, J. J. Heiberger, and G. T. Goldfuss, 1974. "Large Scale Vapor Explosions," Proc. Fast Reactor Safety Meeting, Argonne IL, Conf. 740 401-P2, p. 922.

Henry, R. E.and H. K. Fauske, 1975. "Energetics of Vapor Explosions,” Am. Soc. Mech. Eng. Paper 75-HT-66.

Herring, J. S. and P. E. MacDonald, 1999. "Low Cost, Proliferation Resistant, Uranium-Thorium Dioxiide Fuels for Light Water Reactors," Trans. ANS, Vol. 80, June.

Hetrick, D. L., 1993. Dynamics of Nuclear Reactors, American Nuclear Society, LaGrange Park, Illinois.

Hill, R. N., D. C. Wade, J. R. Liaw, and E. K. Fujita, 1995. "Physics Studies of Weapons Plutonium Disposition in the Integral Fast Reactor Closed Fuel Cycle," Nucl. Sci. Eng. Vol., 121, pp. 17-31.

Hill, R. N., J. E. Cahalan, H. S. Khalil and D.C. Wade, 1999. "Development of Small, Fast Reactor Core Design Using Lead-Based Coolant," Proc. Global '99 Int. Conf. on Future Nuclear Systems, Jackson Hole, WY, August.

Hobdell, M. R. and C. A. Smith, 1982. "Electrochemical Techniques for Monitoring Dissolved Carbon, Hydrogen and Oxygen in Liquid Sodium," Journal of Nuclear Materials 110, 125-139.

Hofman, G. L., et al., 1985. “Metallic Fuels Handbook,” ANL-IFR-29. Argonne National Laboratory.

Hunsbedt, A. and P. M. Magee, 1988. "Design and Performance of the PRISM Natural Convection Decay Heat Removal System," Proceedings of the International Topical Meeting on Safety of Next Generation Power Reactors, Seattle, Washington, May1-5.

Hutchins, B., G. Pavlenco, and P. Babka, 1991. "1991 ALMR Power Plant Capital and Busbar Cost Estimates," GEFR-00900, UC-87Ta, September.

Jacobs, H. R., S. B. Plass, and A. C. Hansen, 1977. "Operational Limitations Of Direct Contact Boilers For Geothermal Applications," ASME Paper 77-HT-5.

Johnson, R. N., 1984. “Coatings For Fast Breeder Reactor Components,” Thin Solid Films, 118, pp. 31-47.

Kamdar, M. H., 1986. "Liquid Metal Embrittlement," Metals Handbook, $9^{\text {th }}$ Edition, Vol. 11, pp. 225-238, American Society for Metals. 
Kataoka, I. and M. Ishii, 1987. "Drift-Flux Model for Large Diameter Pipe and New Correlation for Pool Void Fraction," International Journal of Heat and Mass Transfer. Vol. 30, No. 9, pp.1927-1939.

Kataoka, I. and M. Ishii, 1984. "Mechanistic Modeling of Pool Entrainment Phenomenon," International Journal of Heat and Mass Transfer, Vol. 27, No. 11, pp. 1999-2014, November.

Kataoka, I., M. Ishii, and K. Mishima, 1983. "Generation and Size Distribution of Droplets in Annular Two-Phase Flow," Transactions of ASME, Vol. 105, June.

Kaushik, S. C., S. S. Verma, and A. Chandra, 1995. "Solar-Assisted Liquid Metal MHD Power Generation: A State Of The Art Study," Heat Recovery Systems \& CHP, Vol. 15, No. 7, pp.675689.

Kawanishi, K., Y. Hirao, and A. Tsuge, 1990. "An Experimental Study on Drift Flux Parameters for Two-Phase Flow in Vertical Round Tubes," Nuclear Engineering Design, Vol. 120, p. 447458.

Keshava Iyer, V., A. Dasgupta, and B.Venkat Rao, 1997. "Some Investigations on Flow Through Chevrons of Moisture Separator and Reheater Used in Nuclear Power Plants," Proceedings of the ASME Fluids Engineering Division, FED-Vol. 244. pp. 381-386, ASME.

Kim, D., M. S. Kazimi, and N. E. Todreas, M. J. Driscoll, 2000a. "Economic Analysis of the Fuel Cycle of Actinide Burning Systems," MIT-NFC-TR-019, MIT, Department of Nuclear Engineering, February.

Kim, D., N. E. Todreas, M. J. Driscoll, and M. S. Kazimi, 2000b, Plant Design and Cost Estimation of a Natural Circulation Lead-Bismuth Reactor with Steam Power Conversion Cycle, to be published.

Kim, H., M. Anderson, R. Bonazza, M. Corradini, and D. H. Cho, 2000. "Interfacial Transport Phenomena and Stability in Molten Metal-Water Systems," ICONE-8478, Proceedings of ICONE-8, Baltimore, MD, USA, April 2-6.

Kinoshita, I., Y. Nishi, and M. Furuya, 1997. "Fundamental Heat Transfer Characteristics of Direct Contact Heat Exchanger between Melting Alloy and Water," Experimental Heat Transfer, Fluid Mechanics and Thermodynamics 1997, M. Giot, F. Myinger, G. P. Celata (editors), Edizioni ETS, pp. 2071-2077.

Kinoshita, I., Y. Nishi, and M. Furuya, 2000. "On Applicability of Direct Contact Heat Transfer Steam Generators for LMFBRs," ICONE-8769, Proceedings of ICONE-8, Baltimore, MD, USA, April 2-6.

Kocamustafaogullari, G. and M. Ishii, 1995. "Foundation Of The Interfacial Area Transport Equation and its Closure Relation,” Int. J. Heat Mass Transfer. Vol. 38, pp. 481.

Kocamustafaogullari, G., S. R. Smits, and J. Razi, 1994. "Maximum and Mean Droplet Sizes in Annular Two-Phase Flow," Int. J. Heat Mass Transfer, Vol. 37, No. 6, pp. 955-965. 
LANL, 1999. "A Roadmap For Developing ATW Technology. Target-Blanket Technology," LA-UR-99-3022, Los Alamos National Laboratory, September.

Li N., E. Yefimov, and D. Pankratov, 1998. "Polonium Release from an ATW Burner System with Liquid Metal Lead-Bismuth Coolant," LA-UR-98-1995, Los Alamos National Laboratory, April.

Li, N., 1999a. "Active Control Of Oxygen In Molten Lead-Bismuth Eutectic Systems to Prevent Steel Corrosion and Coolant Contamination," LA-UR-99-4696. Los Alamos National Laboratory. Li, N., 1999b. Unpublished paper, LANL.

Lienhard, J. H., 1981. A Heat Transfer Handbook, pp. 410-412, Prentice Hall, Inc.

Loewen, E. P., C. B. Davis, and P. E. MacDonald, 2000. “A Technique for Dynamic Corrosion Testing in Liquid Lead Alloys," ICONE-8245, Proceedings of ICONE-8. Baltimore, MD, USA, April 2-6.

Manly, W. D. (ed.), 1954. Interim report on static liquid-metal corrosion, ORNL.

Manly, W. D., 1956. "Fundamentals of Liquid Metal Corrosion," Corrosion-NACE, 12, 46-52.

Matsumura, K. and H. Nariai, 1996. "The Occurrence of Spontaneous Vapor Explosions," Proc. $4^{\text {th }}$ ASME/JSME Joint Conference on Nuclear Engineering (ICONE-4), Vol. 1, Pt.A, pp. 325332.

McCoy, D. D. and T. J. Hanratty, 1977. "Rate of deposition of droplets in annular two phase flow," International Journal of Multiphase Flow, 3, pp. 319-331.

Moore, M. J. and C. H. Sieverding, 1976. Two-Phase Steam Flow in Turbines and Separators. pp. 11-19, 317-337, McGraw-Hill Inc.

Moore, R. L., B. G. Schnitzler, C. A. Wemple, R. S. Babcock, and D. E. Wessol, 1995. "MOCUP: MCNP-ORIGEN2 Coupled Utility Program," INEL-95/0523, Idaho National Engineering Laboratory, September.

Mugele, R. A. and H. D. Evans, 1951. "Droplet Size Distribution In Sprays,” Ind. Eng. Chem., Vol. 43, pp. 1317.

Nagase, M, Y. Saito, and T. Nakao, 1996. "Development of Reactor Internals for Next Generation BWR," ICONE-4, Vol. 2, pp. 511-515, ASME.

Nakamura, S., Y. Fukuy, Y. Kojima, M. Siga, and S. Yamaguchi, 1990. "Development of Materials and Coating Processes for High Temperature Heavy Duty Gas Turbines," ASME Paper, 90-GT-79.

Nakao, T., M. Nagase, G. Aoyama, and M. Murase, 1999. "Development of Simplified WaveType Vane in BWR Steam Dryer and Assessment of Vane Droplet Removal," Journal of Nuclear Science and Technology, Vol. 36, No. 5, pp. 424-432, May. 
NECDB, 1985, A Reference Data Base for Nuclear and Coal-fired Power Plant Power Generation Cost Analysis, DOE/NE-0044/3, June.

Nicholson, R. B., 1960. “The Doppler Effect in Fast Neutron Reactors,” APDA-139, (in Hetrick, 1993).

Nishi, Y., I. Kinoshita, M. Furuya, N. Takenaka, and M. Matsubayashi, 1998. "Visualization of direct contact heat transfer between molten alloy and water by neutron radiography," Proceedings of the $11^{\text {th }}$ International Heat Transfer Conference, Kyongju, South Korea.

Novikova, N. N., V. V. Chekunov, Y. G. Pashkin, and M. L. Kulikov, 1998. "Conceptual Projects of Self-Protected Lead-Bismuth Cooled Fast Reactors and Their Adaptation to Problem of Plutonium Utilization and Minor Actinides Transmutation," Proceedings of the Ninth International Conference on Emerging Nuclear Energy Systems (ECENES'98), pp. 74-83, Herzliya, Israel, June.

Orlov, V. V., P. N. Alekseev, N. I. Geraskin, V. V. Poliksha, V. V. Kikhanskij, A. E. Novikov, C. S. Smirnov, A. I. Lobojko, M. P. Leonchuk, G. A. Khacheresov, and A. P. Vasiliev, 1994. "Study of Ultimate Accidents for Lead-Cooled Fast Reactor," Proceedings of the ARS'94 Int. Topical Meeting on Advanced Reactor Safety, Pittsburgh, April 17-21, pp. 53-550.

Orlov, Y. I., 1998. "Stages Of Development of Lead-Bismuth as a Coolant for Nuclear Reactors in Russia," Notes of the ATW Workshop held at MIT, January.

Orlov, Y., E. Yefimov, J, Stbbins, M. Bjornberg, X. He, W. Gregory, and N. Li, 1998. "LANL/ IPPE/EDO-GP Collaboration Programs on Liquid Lead-Bismuth Technology," Notes of the MIT ATW Technical Review, January 15-16.

Panasenko, M. D. and Y. V. Koslov, Teploenergetika, 1962. No. 8, pp. 69.

Pankratov, D., B. F. Gromov, M. A. Solodjankin, E. I. Yefimov, V. N. Stepanov, G. I. Toshinsky, V. V. Kalchenko, V. V. Stekolnikov, V. S. Stepanov, L. N. Moskvin, O. G. Panov, and Y. A. Prokhorov, 1992. "The Experience In Handling Lead-Bismuth Coolant Contaminated By Polonium-210," Transactions of the ANS. Vol. 67, Supplement No. 1, p. 256, September.

Pearson, D., 1964. "A Summary Of The MEL Experiment Data On Erosion". Marchwood Engineering Laboratories, CEGB, RDD/M/MIB, Job No.30023. November.

Piaszczyk, C. M., 1998. "Understanding Accelerator Reliability,” XIX International Linear Accelerator Conference, Chicago, Illinois, USA, August 23 - 28.

Quets, J.M., P.N.Walsh, V.Srinivasan, R.C.Tucker, 1994. "High Temperature Erosion And Fatigue Resistance Of A Detonation Gun Chromium Carbide Coating For Steam Turbines". pp.255-260. PWR-Vol.26, Advances in Steam Turbine Technology for the Power Generation Industry. ASME.

Reid, R., 1983. "Rapid Phase Transitions from Liquid to Vapor," Advances in Chemical Engineering, Vol. 12, pp. 105-208, Academic Press. 
Rouault, J., J. C. Garnier, et. al., 1996. "Design of U Free Large Fast Reactor Cores, The CAPRA Program Trends," International Conference on the Physics of Reactors, MITO, Japan, Vol, 3, H11-H20.

Rouhani, S., 1969. “Modified Correlations For Void And Pressure Drop,” AB Atomenergi, Sweden, Internal Report AE-RTC 841, March.

Rouhani, S., 1992. "TRAC-BF1 Models and Correlations". NUREG/CR-4391, EGG-2680, INEEL. August.

Saito, Y., et al., 1995. “Two-Phase Flow Analyses In BWR Separators And Dryers,” Proc. $3^{\text {rd }}$ ASME/JSME Nucl. Eng. Joint Conference (ICONE-3), Vol. 1, pp. 155-160.

Salvatores, M., 1986. "Fast Reactor Calculations," in CRC Handbook of Reactors Calculations, CRC Press, Boca Raton.

Sawyer, C., 1999. GE Nuclear Energy, E-mail communication to J. Buongiorno, July 7.

Schipakhin, O. L., N. B. Borisov, and S. L. Churkin, 1992. "The Polonium-210 Problem in Thermonuclear Reactor," Transactions of the ANS, Vol. 67, Supplement No. 1. p. 405, September.

Seagle, S. R., 1990. “Titanium/Titanium Alloys,” Advanced Materials \& Processes, Vol. 137, No. 1, pp. 29, 90, January.

Sheir, L. L., R. A. Jarman and G. T. Burstein (ed.), 1993. "Corrosion, Vol. I Metal/Environment Reactions \& Vol. II Corrosion Control,” (Butterworth-Heinemann Ltd., Oxford).

Shimizu, Y. and Y. H. Mori, 1988. "Evaporation of Single Liquid Drops in an Immiscible Liquid at Elevated Pressures: Experimental Study with N-Pentane and R113 Drops in Water," Int. J. Heat Mass Transfer, Vol. 31, No. 9, pp. 1843-1851.

Shirakata, K., T. Sanda, and F. Nakashima, 1999. "Spatial Neutronic Decoupling of Large Fast Breeder Reactor Cores," Nuclear Science and Engineering, Vol. 131, pp. 187-198, February.

Sideman, S. and Y. Gat, 1966. "Direct Contact Heat Transfer with Change of Phase: SprayColumn Studies of a Three-Phase Heat Exchanger," AICHE Journal, Vol. 12, pp. 296-303.

Smith, R. C., W. M. Rohsenow, and M. S. Kazimi, 1982. "Volumetric Heat-Transfer Coefficients for Direct-Contact Evaporation," Journal of Heat Transfer, Vol. 104, pp. 264-270, May.

Spencer, B. W., R. N. Hill, D. C. Wade, D. J. Hill, J. J. Sienicki, H. S. Khalil, J. E. Cahalan, M. T. Farmer, V. A. Maroni, and L. Leibowitz, 2000. "An Advanced Modular HLMC Reactor Concept Featuring Economy, Safety And Proliferation Resistance," ICONE-8145, Proceedings of ICONE-8, Baltimore, MD, USA, April 2-6.

Stimmell, G. L., 1991. ALMR Summary Plant Design Description, GEFR-00893, UC-87Ta, September. 
Su'ud, Z. and H. Sekimoto, 1995. "Design Study of Lead - and Lead-Bismuth-Cooled Small Long-Life Nuclear Power Reactors Using Metallic and Nitride Fuel," Nuclear Technology, 109, March.

Subbarao, E. C. (ed.), 1980. "Solid Electolytes and Their Applications," Plenum Press, New York.

Taitel, Y., D. Bornea, and A. E. Dukler, 1980. "Modelling Flow Pattern Transitions for Steady Upward Gas-Liquid Flow in Vertical Tubes," AICHE Journal. Vol. 26, No. 3, pp. 345-354.

Takahashi, M., N. Sawada, H. Sekimoto, M. Kotaka, T. Yano, S. Uchida, T. Tkahashi, K. Hata, and T. Suzuki, 2000. "Design And Construction Of lead-bismuth Corrosion Test Loop And Test Plan,” ICONE-8507, Proceedings of ICONE-8, Baltimore, MD, USA, April 2-6.

The RELAP5-3D Development Team, 1999. RELAP5-3D Code Manual, Volume 1: Code Structure, System Models and Solution Methods, INEEL-EXT-98-00834, Revision 1.1b.

Todd, F., 2000. Hope Creek Nuclear Power Station, PSEG. E-mail communication to J. Buongiorno, March 18.

Todreas, N. E. and M. S. Kazimi, 1990. "Nuclear Systems I - Thermal Hydraulic Fundamentals," Hemisphere Publishing Corporation.

Tokiwai, M., S. Yoshie, R. Yuda, M. Kambe, M. Nakagawa, T. Nishimura, Y. Tsuboi, and M. Fujiwara, 1999. "Development of Thermal Expansion Controlled Materials for Enhancement of Inherent Safety of Metallic Fueled FBR Core," Proc. Global '99 Int. Conf. on Future Nuclear Systems, Jackson Hole, WY, August.

Tommasi, J. and S. Massara, 1999. "L.M.F.R. Dedicated Cores for Transmutation: Critical versus Subcritical Systems Comparison,” Proc. Global '99 Int. Conf. on Future Nuclear Systems, Jackson Hole, WY, August.

Tsirlin, M., S. Lesin, and H. Branover, 1999. "Some Aspects of Structural Materials Compatibility With Liquid Lead-Containing Coolants,” ANS Transactions, Vol. 80, pp. 196-197.

Tsubouchi, K., N. Yasugahira, S. Yoshida, R. Kaneko, and T. Sato, 1990. “An Evaluation of Water Droplet Erosion for Advanced Large Steam Turbine,” pp. 245-251, PWR-Vol. 10, Advances in Steam Turbine Technology for Power Generation, ASME.

Venneri, F., 1998. “ATW Overview,” Set of slides presented at MIT technical overview, January.

Von Boeckh, P., J. Hutton, and J. Patrick, 1984. "Moisture Separator and Cycle Efficiency Improvements by Installing Moisture Preseparators,” ASME Paper 84-JPGC-PWR-30.

Wakabayaski, T., S. N. Hunter, and K. Sugino, 1998. "Study on Plutonium Burning in a Fast Reactor," OECD Proceedings of the Workshop on the Physics and Fuel Performance of ReactorBased Plutonium Disposition, 28-29 September. 
Walsh, P. N., J. M. Quets, and R. C. Tucker, 1994. "The Effects of Erodent Particle Size and Composition on the Erosion of Chromium Carbide Based Coatings," pp. 261-265, PWR-Vol. 26, Advances in Steam Turbine Technology for the Power Generation Industry, ASME.

Waltar, A. E. and A. B. Reynolds, 1981. Fast Breeder Reactors, Pergamon Press, New York.

WASH 1088, 1969. "An Evaluation of Steam-Cooled Fast Breeder Reactors,” April.

Weeks, J. R, 1971. "Lead, Bismuth, Tin and Their Alloys as Nuclear Coolants," Nuclear Engineering and Design, 15, pp. 363-372.

Weeks, J. R. and A. J. Romano, 1969. "Liquidus Curves and Corrosion of Fe, Ti, Zr, and Cu in Liquid Bi-Pb Alloys," Corrosion, 25, pp. 131-136.

Weeks, J. R., 1998. "Compatibility of Structural Materials with Liquid Lead-Bismuth and Mercury," Materials for Spallation Neutron Sources, pp.77-81, edited by M. S. Wechsler, L. K. Mansur. C. L. Snead, and W. F. Sommer, The Minerals, Metals \& Materials Society.

Weeks, J. R., 1997. "Compatibility of Structural Materials with Liquid Lead-Bismuth and Mercury," Materials for Spallation Neutron Sources TMS Annual Meeting 1997, pp.77-81.

Wilkinson, W. D., E. W. Hoyt and H. V. Rhude, 1955. "Attack on Materials by Lead at $1000^{\circ}$ C," ANL-5449, Argon National Laboratory.

Wilson, J. F., R. J. Grenda, R. H. Klumb, W. E. Littleton, W. C. Meyer, and H. W. Yent, 1965. ACNP 65003.

Wright, R. F., J. S. Tulenko, G. J. Schoessow, R. G. Connel, M. A. Dubecky, Jr., and T. Adams, 1996. "Thermal Bonding of Light Water Reactor Fuel Using Nonalkaline Liquid Metal Alloy," Nuclear Technology, 115, pp. 281-292.

Yarden, A. L., T. W. Clement, and H. W. Kang, 1997. "Kori Gains 30 Mwe from MSR Reconstruction," Nuclear Engineering International, Vol. 42, No. 515, pp. 35-39, June.

Yefimov, E., D. Pankratov, and S. Ignatiev, 1998. "Removal And Containment of High-Level Radioactive Polonium From Liquid Lead-Bismuth Coolant," Materials Research Society Symposium Proceedings, Vol. 506, p. 679-686.

Zaki, S. and H. Sekimoto, 1995. "Safety Aspect Of Long-Life Small Safe Power Reactors," Progress in Nuclear Energy, Vol. 22, No. 11, pp. 711-722.

Zrodnikov, A. V., V. I. Chitaykin, B. F. Gromov, G. I. Toshinsky, U. G. Dragunov, and V. S. Stepanov, 1999. "Applications Of Reactors Cooled by Lead-Bismuth Alloy in Nuclear Power Energy," Proceedings of Global '99: International Conference on Future Nuclear Systems, Jackson Hole, WY, USA, August-September.

Zuber, N. and J. A. Findlay, 1965. "Average Volumetric Concentration in Two-Phase Flow Systems," Journal of Heat Transfer, Vol. 87. pp. 453-468. 


\section{Appendix A - Project Work Plans for January Through October 2000}

\section{A.1. NEUTRONICS CORE DESIGN WORK PLAN}

\section{A.1.1. Ultimate goals:}

Burn and Breed Design (MIT)

- Develop a large breed and burn core design that would achieve very long refueling cycle, would not need reprocessing and would generate a small amount of waste (most of the waste is burned while the fuel resides in the core) and would satisfy rigorous safety requirements.

Optimized economical design (INEEL + support from MIT as needed)

- Develop the most economical design that would burn TRUs and produce electricity at the lowest cost.

\section{A.1.2. Details of the Burn and Breed Work Plan(MIT)}

Objective of the work in this period: Map possible fuels, and lattice configurations from reactor physics viewpoint

1. Benchmark of MOCUP in hard spectrum reactor. Use international benchmark case. Choose optimum ORIGEN2.1 timestep and MCNP number of histories.

2. Study effect of fuel selection of reactivity versus burnup curve on a unit cell model. Use metallic, nitride, carbide and oxide fuels (UZr, UZrTh, UN, UThN, UC,UThC, UO2,UThO2, or possibly weapons grade plutonium in these fuels to explore the potential of weapons grade plutonium as the startup fissile). Take into consideration the key constraints (thermohydraulics, burnup limits, fluence limits, proliferation resistance limits) to make sure that the fuels stay within acceptable envelope. Identify the most promising database of fuels.

3. Study the effect of pitch to diameter, lattice arrangement, type of heavy metal coolant on reactivity versus burnup curve using unit cell model for the most promising fuel types and identify the most promising arrangements.

4. Quantify other important indices affecting the overall goal for all the considered fuels. These will involve primarily safety indices (coolant void coefficient, Doppler coefficient, delayed neutron fraction), waste indices (fuel composition at discharge, radiotoxicity at discharge, volume of waste per 1MWth), proliferation resistance-indices (actinide composition at discharge) and economic indices (primarily fuel cycle cost at this stage).

5. Identify the most promising fuel type based on the results from 2 through 4 and select it for further detailed studies.

6.

This is maximum plan. The more realizable plan will exclude Task 4 and Task 5. 


\section{A.1.3. Details of the Optimized Economical Design (INEEL + support from MIT as needed)}

Objective of the work in this period: Explore various fuels, and lattice configurations to identify the most promising design of actinide-burner and long-life core

Suggested plan:

1. Decrease burnup step and investigate MOCUP sensitivity to burnup steps size

2. Finish study of various fuels on reactivity versus burnup curve on a unit cell model. Use metallic, nitride and oxide fuels (PuMAUZr, PuMaUThZr, PuMaUN, PuMAUThN, PuMAUO2,PuMAThUO2). Take into consideration the key constraints (thermohydraulics, burnup limits, fluence limits, proliferation resistance limits) to make sure that the fuels stay within acceptable envelope (focus on proliferation resistance of Th based fuels, while limiting the U-233 to $<12 \mathrm{wt} \%$ of the uranium).

3. Study the effect of pitch to diameter, lattice arrangement, type of coolant on reactivity versus burnup curve using unit cell model for the most promising fuel types and identify the most promising arrangements for the purpose of actinide burning in long-life cores.

4. Quantify other important indices affecting the overall goal for the top performing fuels. These will involve primarily safety indices (coolant void coefficient, Doppler coefficient, delayed neutron fraction), waste indices (fuel composition at discharge, radiotoxicity at discharge, volume of waste per 1MWth), proliferation resistance-indices (actinide composition at discharge) and economic indices.

5. Identify the most promising fuel type for long-life actinide-burner based on the results from 2 through 4 .

The relationship between the various tasks is shown in Figure 76 below.

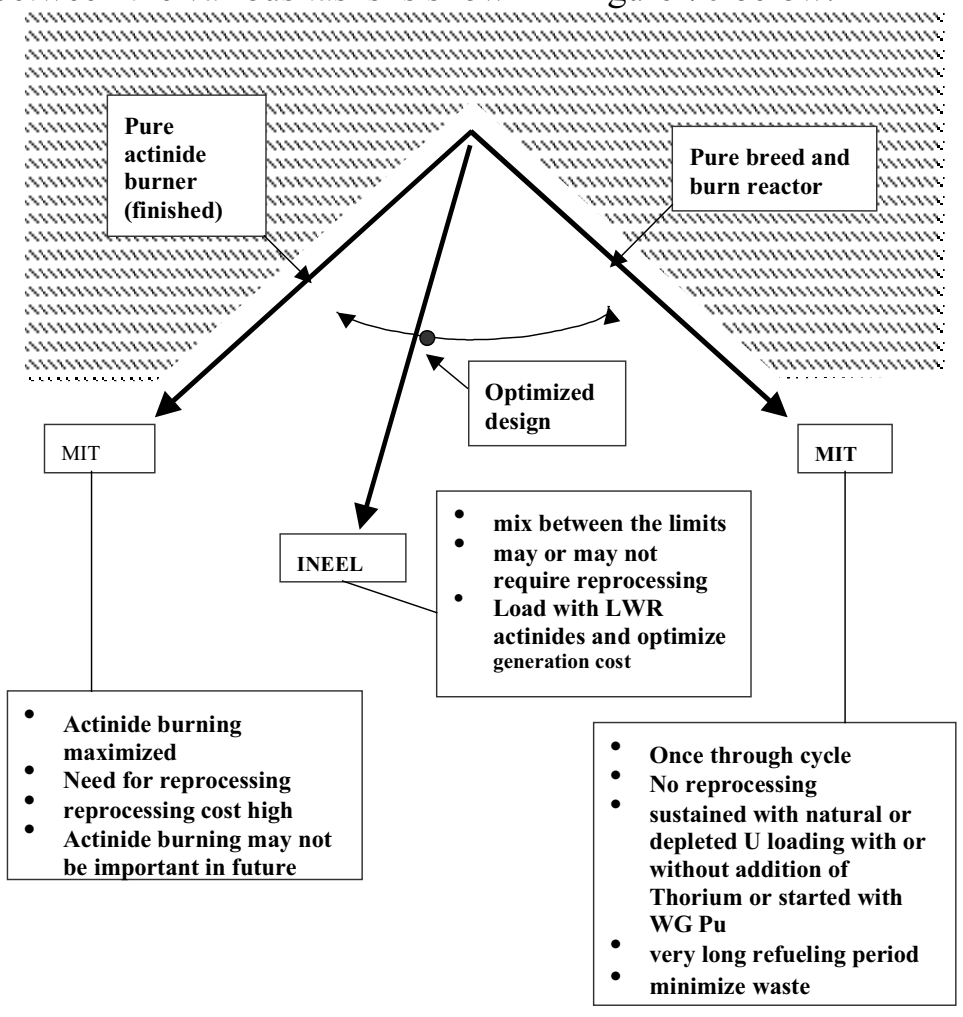

Figure 76. Spectrum of options for the design of a lead-based cooled reactor 


\section{A.2. MATERIALS COMPATIBILITY STUDIES}

\section{A.2.1. Project Goals:}

- Develop structural and cladding materials resistant to lead and lead-alloy corrosion.

- Test advanced materials for high temperature corrosion resistance.

- Better understand how lead-alloy corrosion mechanisms occur.

\section{A.2.2. Investigators:}

INEEL: Eric Loewen, Galen Smolik, Phil MacDonald, and Kathy McCarthy.

MIT: Jeongyoun Lim and Ron Ballinger.

\section{A.2.3. Project Equipment and Joint Objectives:}

- MIT: Spin Corrosion Tester that will allow for the testing of small unique materials and a fixed and known flow rate on the metal coupon. Expected corrosion data is corrosion rate as function of temperature and flow rate of small samples.

- INEEL: Dynamic Corrosion Cell Tester will allow for the testing of large metal samples with fixed temperature and lead flow with induced flow from inter gas injection. Expected corrosion data will be as function of material, oxygen fugacity, temperature, and lead flow rate. Also data will be gathered to corrosion in and around the weld effective zone.

- Deploy corrosion cells at both facilities.

- Develop $\mathrm{O}_{2}$ probes to measure dissolved oxygen in molten lead-alloys.

- Obtain corrosion data on candidate metals (see attached test matrix).

- Determine what measures have to be taken to ensure the formation of the protective oxide film.

\section{A.2.4. Work Elements:}

- Equipment and Sampling:

1. Deploy corrosion cells at MIT and INEEL to obtain experimental data and experience handling lead.

2. Development of $\mathrm{O} 2$ probes that will work in the molten lead environment. Once probes have been developed at both facilities exchange probes for validation.

3. MIT to provide Neutron Activation Analysis of lead samples obtained from INEEL experiments.

4. MIT to provide small samples of test metals for placement inside INEEL corrosion cell.

5. INEEL willing to support an MIT student (graduate or undergraduate) during the summer of 2000 .

- Experiments (see Tables 39 and 40):

In general the experiments will be performed in two different types of corrosion cells to allow a better understanding of the corrosion mechanisms. To provide tie points and help in 
validating INEEL flow calculations performed on the dynamic corrosion testing system some replicate testing will be performed across platforms as discussed in the appendix.

1. INEEL will obtain corrosion data on typical structural materials (e.g. stainless steels 316 and 410, carbon steel, and zirconium alloy). as a function of temperature and oxygen potential.

2. INEEL will develop an oxidation/reduction control system to provide a protective layer to structural materials.

3. MIT will assess the corrosion performance of advanced alloys based on materials featuring low solubility in lead-bismuth (which may include $\mathrm{Nb}, \mathrm{Ta}, \mathrm{V}, \mathrm{W}$ ).

4. See attached overlap of experimental materials and conditions.

Table 39. MIT test matrix

\begin{tabular}{|c|c|c|c|c|c|c|c|c|c|c|c|}
\hline \multirow{3}{*}{$\begin{array}{l}\text { Mat. } \\
\text { Mo }\end{array}$} & \multicolumn{5}{|c|}{ Temperature (C) } & \multicolumn{5}{|c|}{ Rotating Speed (rpm) } & \multirow{3}{*}{\begin{tabular}{|l}
$\begin{array}{l}\text { Time } \\
\text { (hrs) }\end{array}$ \\
25 \\
Total:5*5* \\
$25=625)$
\end{tabular}} \\
\hline & \multirow[t]{2}{*}{400} & \multirow[t]{2}{*}{500} & \multirow[t]{2}{*}{600} & \multirow[t]{2}{*}{700} & \multirow[t]{2}{*}{800} & \multicolumn{3}{|c|}{ Laminar } & \multicolumn{2}{|c|}{ Turbulent } & \\
\hline & & & & & & 10 & 50 & 100 & 300 & 500 & \\
\hline \multirow[t]{2}{*}{ W } & \multirow[t]{2}{*}{400} & \multirow[t]{2}{*}{500} & \multirow[t]{2}{*}{600} & \multirow[t]{2}{*}{700} & \multirow[t]{2}{*}{800} & \multicolumn{3}{|c|}{ Laminar } & \multicolumn{2}{|c|}{ Turbulent } & \\
\hline & & & & & & 10 & 50 & 100 & 300 & 500 & $\begin{array}{l}\text { Total: } 5 * 5 * \\
25=625)\end{array}$ \\
\hline \multirow[t]{2}{*}{$\mathrm{Ta}$} & \multirow[t]{2}{*}{400} & \multirow[t]{2}{*}{500} & \multirow[t]{2}{*}{600} & \multirow[t]{2}{*}{700} & \multirow[t]{2}{*}{800} & \multicolumn{3}{|c|}{ Laminar } & \multicolumn{2}{|c|}{ Turbulent } & \\
\hline & & & & & & 10 & 50 & 100 & 300 & 500 & $\begin{array}{l}\text { Total: } 5 * 5 * \\
25=625)\end{array}$ \\
\hline \multirow[t]{2}{*}{316} & & & 600 & & & \multicolumn{3}{|c|}{ Laminar } & \multicolumn{2}{|c|}{ Turbulent } & \\
\hline & & & & & & & 50 & & 300 & & $\begin{array}{l}\text { Total: } 1 * 5 * \\
25=125)\end{array}$ \\
\hline
\end{tabular}

Table 40. INEEL Test Matrix.

\begin{tabular}{|l|l|l|}
\hline Metal & Temperature $(\mathrm{C})$ & Time $(\mathrm{hr})$ \\
\hline 316 & 450 & 6 \\
\hline $\mathrm{Fe}$ & $550-650$ & 24 \\
\hline 316 Stainless & 650 & 24 \\
\hline $\mathrm{Fe}$ & 550 & 100 \\
\hline $\mathrm{Fe}$ & 650 & 100 \\
\hline 316 Stainless & 550 & 100 \\
\hline 316 Stainless & 650 & 100 \\
\hline Carbon Steel & 550 & 100 \\
\hline Carbon Steel & 650 & 100 \\
\hline 410 Stainless & 550 & 100 \\
\hline 410 Stainless & 650 & 100 \\
\hline $\mathrm{Zr} \mathrm{w} / 2 \% \mathrm{Nb}$ & 550 & 100 \\
\hline $\mathrm{Zr} \mathrm{w} / 2 \% \mathrm{Nb}$ & 650 & 100 \\
\hline
\end{tabular}

Note MIT samples will be placed in each corrosion cell.

\section{A.2.5. Deliverables (for July 2000 project review):}

1. Accomplishments:

- Obtain corrosion data on at least the different commercial available materials. 316 SS will be run in both corrosion cells so that comparison between the testing apparatus can be made. 
- Operational $\mathrm{O}_{2}$ probes in a molten lead environment.

- Analysis of the combined preliminary experimental corrosion data to establish a path forward.

2. Publications:

- Topical reports which will summarize several experimental runs.

- Joint ICONE -8 conference. Abstracts due in the fall.

- Joint paper in an ANS or other publication to compare and contrast the experimental apparatus being used and the data obtained. Submit paper January of 2001.

- Independent papers on the experimental efforts at both locations in Nuclear Technology and/or Corrosion literature.

- Joint paper on an oxidation/reduction control model as verified in both of the experimental apparatuses. Submit paper June of 2001.

\section{A.3. POLONIUM RESEARCH WORK PLAN}

\section{A.3.1. Objective:}

To evaluate the rate of polonium release from hot lead-bismuth to steam.

\section{A.3.2. Investigators:}

\section{MIT: Jacopo Buongiorno, Ken Czerwinski (MIT)}

\section{A.3.3. Work Elements:}

- Modeling

Existing data on polonium and lead-polonide at relatively high temperature $\left(>600^{\circ} \mathrm{C}\right)$ will be extrapolated to lower temperatures $\left(<500^{\circ} \mathrm{C}\right)$ to generate a first estimate of the radioactive contamination of steam under conditions typical of a direct contact nuclear system.

- Equipment

The radioactive polonium will be produced by irradiation of "nuclear grade" bismuth in the MIT research reactor. A high temperature-high-pressure reaction cell will be deployed at MIT accommodating a liquid lead-bismuth bath and the radioactive polonium. The cell will consist of two distinct autoclaves connected by a separation valve. Steam will be injected in the first autoclave (which hosts the molten lead-bismuth and Po) and then collected in the second autoclave (which is empty) where will be condensed and drained. The alpha-activity of the condensed steam will then be measured in a liquid scintillator. Both autoclaves will be equipped with several thermocouples, an independent temperature controller and a pressure gauge. In addition, the lead-bismuth autoclave will be equipped with an oxygen probe and a stirrer.

- Experiments

The experiments will generate data on:

- vapor pressure of lead-polonide at low temperature $\left(<500^{\circ} \mathrm{C}\right)$. 
- equilibrium concentration of polonium hydride in steam in the 300 to $500^{\circ} \mathrm{C}$ temperature range as a function of polonium activity and oxygen partial pressure in the molten leadbismuth.

- the effect of rare-earth additives (e.g. thulium) on the release of polonium.

- the rate of polonium hydride and lead-polonide deposition on stainless steel.

\section{A.3.4. Deliverables (for 2000 project review):}

Accomplishments:

- $\quad$ Measured the rate of release of polonium and its compounds over a wide range of eutectic temperature and oxygen potential.

- $\quad$ Estimated the thermodynamic properties of polonium hydride.

- $\quad$ Evaluated the interaction of polonium compounds with steel.

- $\quad$ Established a strategy to minimize the formation and/or release of volatile polonium compounds.

- $\quad$ Acquired experience in handling polonium-activated lead-bismuth.

\section{Publications:}

- $\quad$ Topical report which will describe the experimental apparatus in details, summarize the experimental runs and thoroughly discuss the data.

- $\quad$ Paper in Nuclear Technology, ANS proceedings and/or Chemistry literature to illustrate the major findings.

\section{A.3.5. Computational Tools to be used:}

- MATLAB codes to manage and rationalize the experimental data.

\section{A.4. PLANT ENGINEERING WORK PLAN}

\section{A.4.1. Ultimate Objective}

To select a plant configuration that minimizes the cost of electricity production ( $\varnothing / \mathrm{kWh})$.

\section{A.4.2. Investigators}

- Workers:

Dohyoung Kim (MIT), Jacopo Buongiorno (MIT)

Cliff Davis (INEEL)

- Supervisors:

Neil Todreas (MIT)

Phil MacDonald (INEEL) 


\section{A.4.3. Work Elements}

1. Design Issues:

- Natural vs. forced circulation in the primary system,

- Steam vs. helium power cycle,

- Superheated vs. saturated steam power cycle,

- Chimney height,

- Secondary coolant operating pressure,

- HX or SG type and geometry,

- Decay heat removal system.

2. Plant Transient Response

- Decay heat removal with loss of the normal heat sink (i.e. HX or SG),

- Reactor coolant pump trip (for forced convection option),

- Steam or helium line break, SG or HX tube rupture,

- Loss-of-coolant accident,

- Load change under normal operating conditions,

- Plant start-up.

3. Figure of Merit

- Capital and O\&M cost of the plant $(\varnothing / \mathrm{kWh})$.

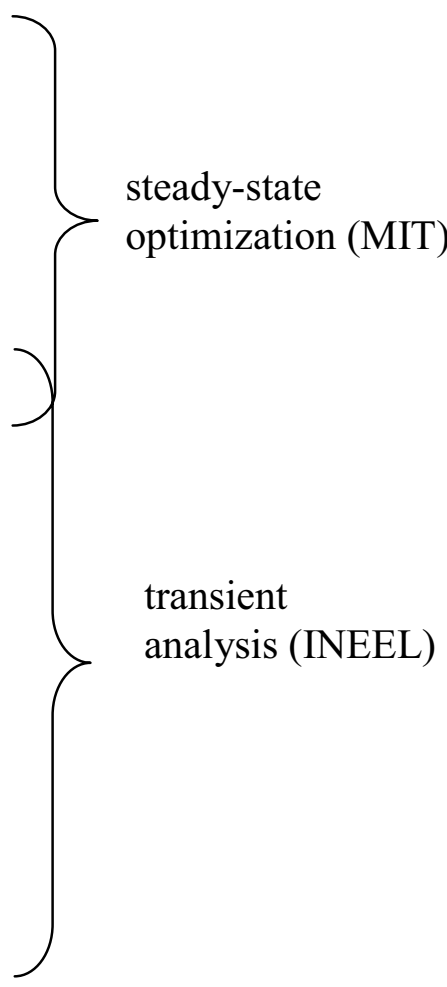

\section{Constraints}

a) Maximum cladding temperature:

- steady state $<650^{\circ} \mathrm{C}$

- $\quad$ transient $<750^{\circ} \mathrm{C}$

b) Maximum fuel temperature:

- steady state $<1200^{\circ} \mathrm{C}$

- transient $<1600^{\circ} \mathrm{C}$

c) The core geometry (i.e. fuel pin number, diameter, length and pitch) is fixed. The reference core is the neutron streaming core described in topical report MIT-ANPTR-67.

\section{A.4.4. Deliverables}

Technical

A detailed plant design that minimizes the plant component of the cost of electricity.

Publications

ANS paper summaries that will report on the major findings. 


\section{A.4.5. Tools}

For all transients and detailed steady-state computations: ATHENA/RELAP.

For trend and parametric studies: MIT generated Matlab codes.

\section{Flowchart}

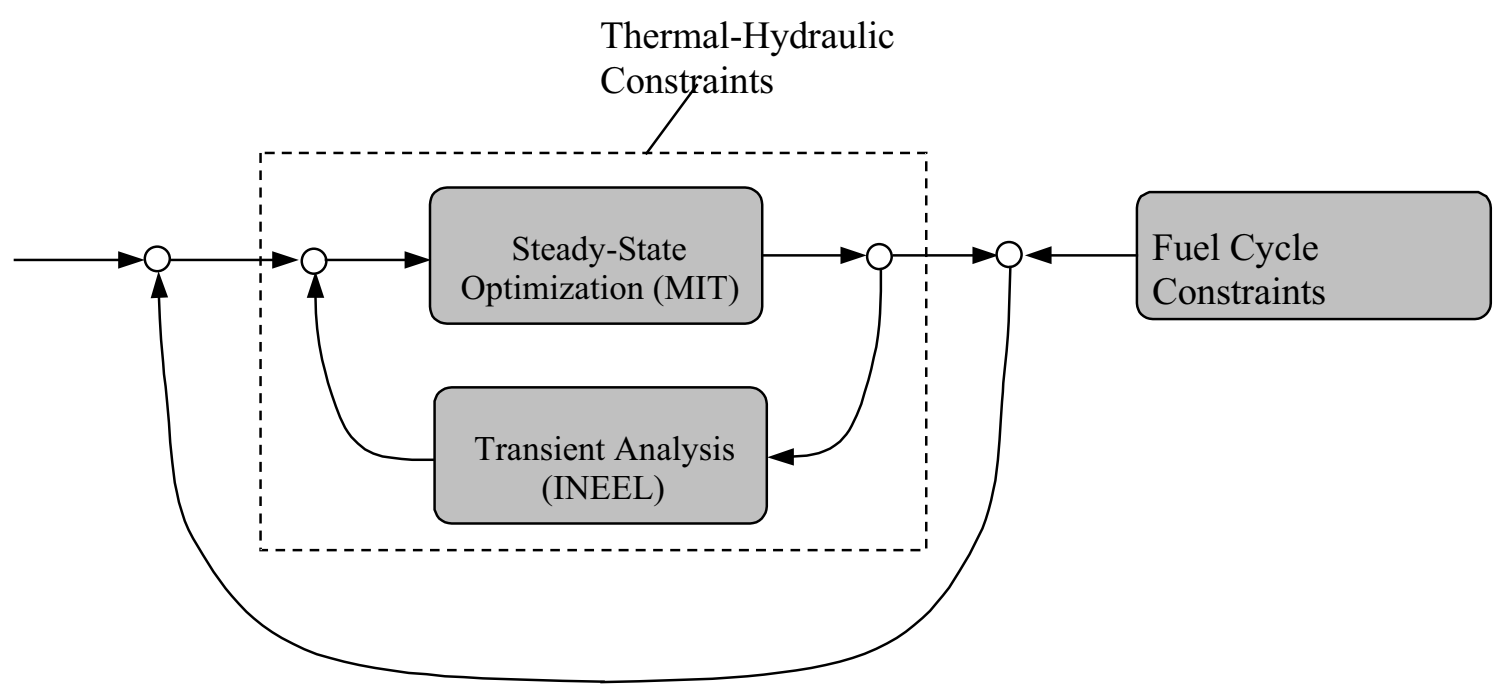




\title{
Appendix B Lead-Bismuth Project Papers and Reports
}

\author{
B.1 START - AUGUST 1999 \\ PAPERS:
}

P. Hejzlar, M.J. Driscoll and M.S. Kazimi, "Reactor Physics Design Challenges of a leadbismuth Cooled Actinide Burner Reactor," Transactions of the American Nuclear Society, Vol. 80, pp. 192-194 June 1999.

P. Hejzlar, M.J. Driscoll, and M.S. Kazimi, "Neutronic Design for a Pb-Bi-Cooled Actinide Burner Fast Reactor," Transactions of the American Nuclear Society, Vol. 81, pp. 271-273, 1999.

J. Buongiorno, M.S. Kazimi and N.E. Todreas, "Natural Circulation Potential of leadbismuth Cooled Reactors for Production and Actinide Burning," Transactions of the American Nuclear Society, Vol. 8, pp. 191-192, June 1999.

\section{REPORTS:}

J. Buongiorno, P. Hejzlar, N.E. Todreas, M.J. Driscoll and M.S. Kazimi, “Actinide Transmutation by Lead-Bismuth Cooled Reactors," MIT-ANP-TR-065, MIT Nuclear Engineering Dept., June 1999.

J. Buongiorno, N.E. Todreas and M.S. Kazimi, "Thermal Design of Lead-Bismuth Cooled Reactor for Actinide Burning and Power Production," MIT-ANP-TR-066, MIT Nuclear Engineering Dept., July 1999.

P. Hejzlar, M.J. Driscoll and M.S. Kazimi, "Void Reactivity Performance in Lead-Bismuth Cooled Reactor for Actinide Transmutation," MIT-ANP-TR-068, MIT Nuclear Engineering Dept., August 1999.

\section{B.2. SEPTEMBER 1999 TO PRESENT}

\section{PAPERS:}

J. Buongiorno, N.E. Todreas, M.S. Kazimi, M.J. Driscoll and P. Hejzlar, "Key Features of an Integrated Lead-Bismuth Cooled Reactor Based on Water/Liquid Metal Direct Heat Transfer," Transactions of the American Nuclear Society, Vol 81, pp. 360, Long Beach, CA, November 14-18, 1999.

J.Buongiorno, N.Todreas, M.Kazimi. "Void Fraction Prediction for the lead-bismuth/Water Direct Contact Nuclear Reactor". Proceedings of ICONE-8, $8^{\text {th }}$ International Conference on Nuclear Engineering, No. 8739, April 2-6, 2000, Baltimore, MD USA. 
C. B. Davis, "An Evaluation of a Passive Decay Heat Removal system During a Los-ofFeedwater Transient in a Reactor Cooled by Lead-Bismuth, To be published in the Journal of Nuclear Engineering and Design.

M.J. Driscoll and Dohyoung Kim, "The Need for Actinide Burner Reactor Fuel Cycle Cost Reduction," Transactions of the American Nuclear Society, Vol. 82, June 2000.

J. Buongiorno, N. Todreas, M. Kazimi, (Nuclear Engineering Department, Massachusetts Institute of Technology), "Thermal-Hydraulic Modeling of a Water/Liquid Metal Direct Contact Heat Transfer Reactor," submitted for presentation, ANS Winter Meeting, November, 2000, Washington, D.C.

C. B. Davis and A. S. Shieh, "Overview of the Use of ATHENA for Analysis of Lead-Bismuth Cooled Reactors", Proceedings of the $8^{\text {th }}$ International Conference on Nuclear Engineering (ICONE-8), April 2-6, 2000, Baltimore, MD.

P. Hejzlar, M.J. Driscoll, M.S. Kazimi, and NE Todreas, "Consequences of Fuel Choice for Spend Fuel Characteristics for Once-Through Heavy Metal Cooled Fast Reactors, submitted for presentation, ANS Winter Meeting, November, 2000, Washington, D.C.

E. P. Loewen, C. B. Davis, and P. E. MacDonald, "A Technique for Dynamic Corrosion Testing in Liquid Lead Alloys" Proceedings of the $8^{\text {th }}$ International Conference on Nuclear Engineering (ICONE-8), April 2-6, 2000, Baltimore, MD.

K. D. Weaver, J. S. Herring, and P. E. MacDonald, "Performance Modeling of Metallic and Nitride Fuels in Advanced Lead-Bismuth Cooled Fast Reactors," Proceedings of the $8^{\text {th }}$ International Conference on Nuclear Engineering (ICONE-8), April 2-6, 2000, Baltimore, MD.

K. D. Weaver, P. E. MacDonald, and J. S. Herring, "Reactivity and Isotopic Assessment of Fertile Fuels for Proliferation-Resistant, Actinide-Burning Lead or Lead-Bismuth Cooled Fast Reactors", To be published in the Journal of Nuclear Engineering and Design.

\section{REPORTS:}

P. Hejzlar, M.J. Driscoll and M.S. Kazimi, "Conceptual Reactor Physics Design of a LeadBismuth-Cooled Critical Actinide Burner," MIT-ANP-TR-069, MIT Nuclear Engineering Dept., January 2000.

D. Kim, M.S. Kazimi, N.E. Todreas and M.J. Driscoll, "Economic Analysis of the Fuel Cycle of Actinide Burning Systems," MIT-NFC-TR-019, MIT Nuclear Engineering Dept., February 2000.

D. Kim, M.J. Driscoll, M.S. Kazimi and N.E. Todreas, "Plant Design and Cost Estimation of a Natural Circulation Lead-Bismuth Reactor with Steam Power Conversion Cycle " MIT-ANP-TR074, July 2000 